\title{
Event-scale hydrologic response in urbanizing watersheds of the Canadian Great Lakes Basin and associations with fish richness
}

by

Mary Trudeau

A thesis submitted to the Faculty of Graduate and Postdoctoral Affairs in partial fulfillment of the requirements for the degree of

Doctor of Philosophy

in

The Geography of Environmental Change

Carleton University

Ottawa, Ontario

C) 2016, Mary Trudeau 


\section{Abstract}

The cumulative impacts of urban land use on stream flow regimes and lotic ecosystems are poorly understood. Moreover, flow assessments using daily or monthly flows cannot adequately characterize event-scale flow dynamics in urbanizing watersheds.

Accordingly, this empirical research examined high temporal resolution (15-minute) growing season hydrologic records in the Greater Toronto Region, Canada. Hydrologic records were matched with rainfall records to include precipitation in models. The first phase of research identified temporal trends in total runoff, rising limb event flows and rising limb accelerations in two watersheds. Results indicated dramatic changes: over a 42-year period, total seasonal discharge increased $45 \%$ in the Don and Humber Rivers during a period of stable rainfall patterns. Peak event flows and event flow variability also increased temporally. The second phase of research comprised a spatial analysis of twenty-seven watersheds ranging from $38 \mathrm{~km}^{2}$ to $806 \mathrm{~km}^{2}$ undertaken along an urban land use gradient from less than $0.1 \%$ to $88 \%$. Urban land use had a very strong influence on total runoff and event scale runoff. Changes in runoff characteristics began at urban cover under $4 \%$. Event flow acceleration increased, causing maximum runoff to be reached sooner as urban cover increased. The total runoff model had an interaction between watershed size and urban land use. The third phase of research identified associations of fish species richness with event-scale hydrologic characteristics in eight watersheds using fish data spanning approximately five decades. Maximum event flow acceleration and skew in instantaneous runoff explained a higher proportion of variation than urban percent in empirical models. Historic fish data are difficult to obtain and pose analytical challenges. By using high temporal resolution flow data, the research provides 
a new understanding of changes in event-scale flow regime dynamics associated with urbanization and, in turn, associations of event-scale hydrology with fish richness.

Compromised hydrologic stationarity is attributable to urbanization, with implications for stormwater infrastructure design, hydrologic event risk assessments and biodiversity protection. 


\section{Acknowledgements}

I would like to thank my thesis co-supervisors, Dr. Murray Richardson and Dr. Doug King for their guidance, funding assistance and, most of all, for their openness to supporting this research idea. As my co-author on two core chapters, Dr. Richardson spent many hours reviewing and advising on details of the analysis. A special thank you also to Dr. Antoine Morin, University of Ottawa, for agreeing to be an Advisor on my Thesis Committee; his biology expertise and statistical prowess were very important for the progress and successful completion of this research. Thank you to DGES Administration, Natalie Pressburger and Erin Johnston, for their support and assistance, to Carleton University Library staff and to Cindy Rodrigue, the Word whisperer.

The many individuals and organizations who contributed data and GIS skills are too numerous to mention here but are gratefully acknowledged in Chapter 3. Naming a few misses so many, but Dr. Gord Wichert's willingness to provide his fish research database and paper-based maps was truly a pivotal breakthrough in acquisition of the historical fish record (even though the database was in Lotus 123 format!). Similarly, Peter Thompson's generosity in providing some raw data files saved hours of effort. Scott Page's careful work and supervision of the GIS digitization team gave me confidence in the urbanization estimates and Rachel Plewes' skills rounded out the database. TRCA and CVCA staff were fantastic in answering questions, providing access to fish data and resources for urban estimates. Similarly, Environment Canada and NRCan staff were very helpful. I would be remiss in not acknowledging Les Stanfield's vision for FWIS and his commitment to data sharing that had a ripple effect on this research. 
A Carleton University scholarship and Environment Canada research assistant funding are gratefully acknowledged. Thanks also to the anonymous reviewers of the peer reviewed work.

I have numerous friends and family members to thank for their support, interest, entertainment and encouragement during my sojourn back to academe. I really cannot begin to name individuals because so many have been so important over these past several years. However, I must thank my fellow students for the laughs (and commiseration as needed) and my siblings and their families for moral support. One can never really adequately thank one's parents or express sufficient gratitude for the gifts children bring; instead of making an attempt, I will dedicate this thesis to my parents and my sons.

To

L. Patrick Trudeau, Margaret Trudeau, Eric Willmets and Ian Willmets with love.

I would love to live

Like a river flows, Carried by the surprise

Of its own unfolding.

John O’Donohue 


\section{Table of Contents}

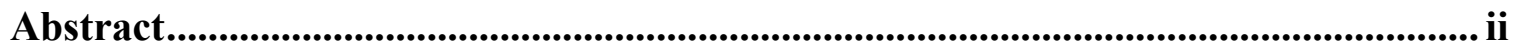

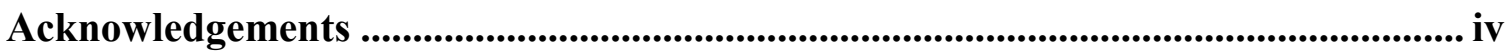

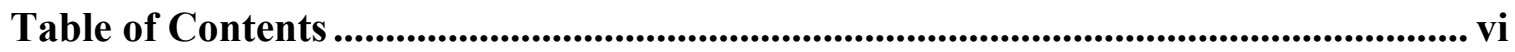

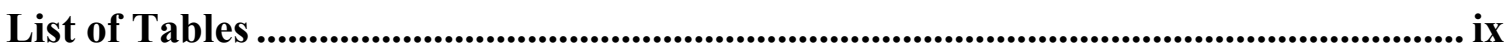

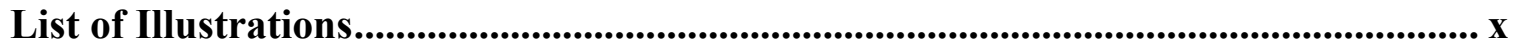

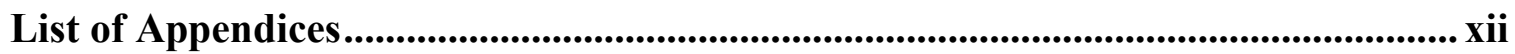

List of Abbreviations and Symbols ................................................................. xiii

Preface: Integrated Manuscripts and Related Research Output ................................ xv

1 Chapter: Introduction, Research Questions and Thesis Overview ...................................... 1

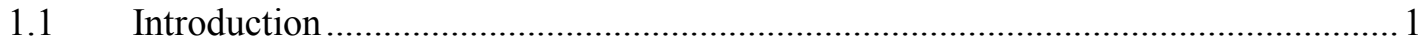

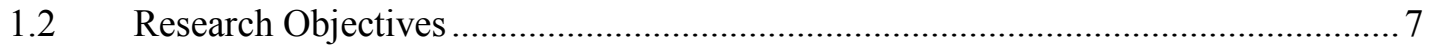

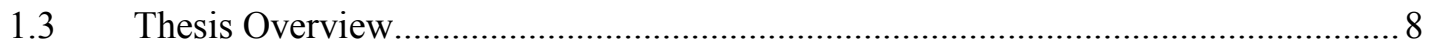

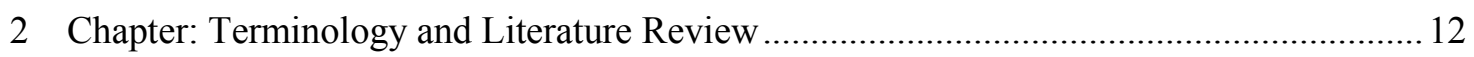

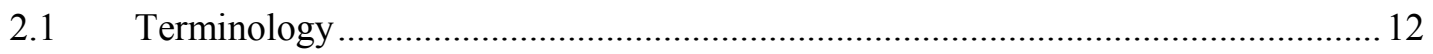

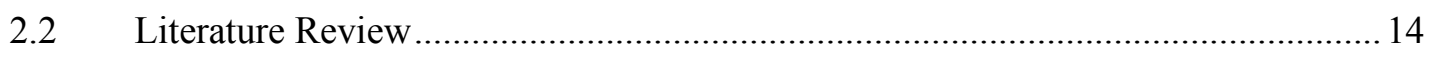

3 Chapter: Study Location, Design Rationale and Data Sources ....................................... 30

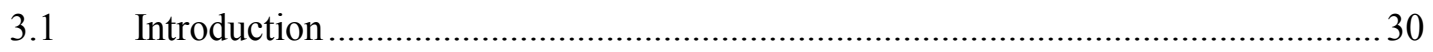

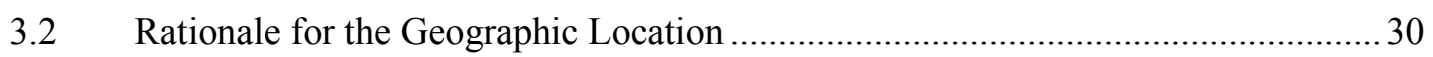

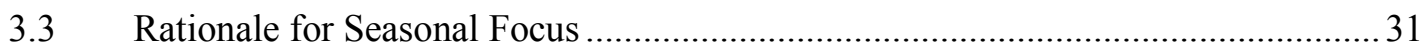

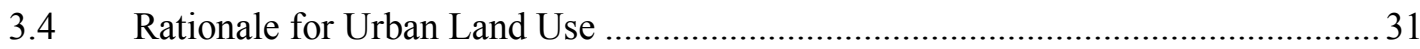

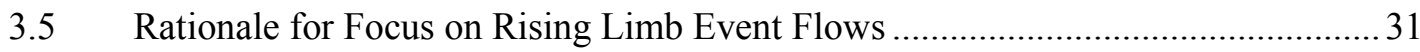

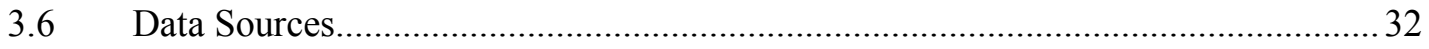

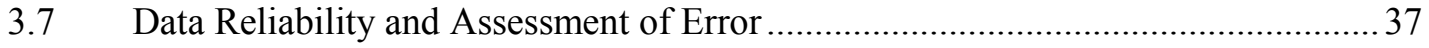

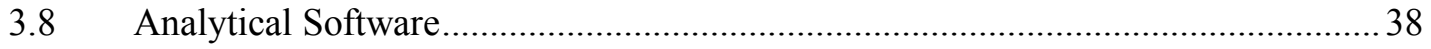


4 Chapter: Change in Event-Scale Hydrologic Response in Two Urbanizing Watersheds of

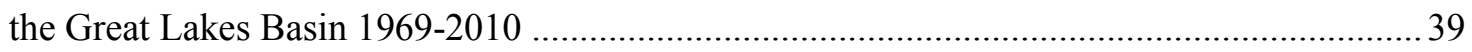

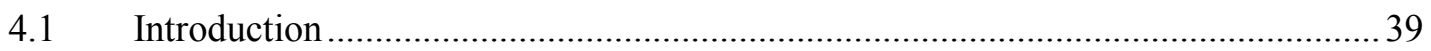

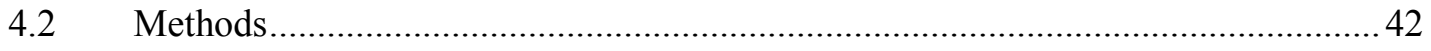

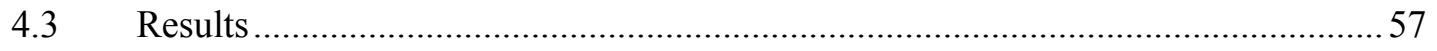

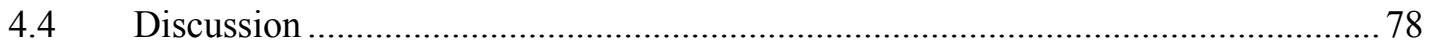

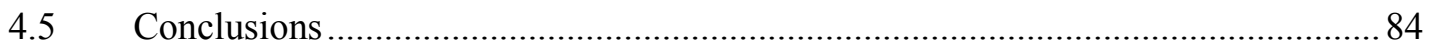

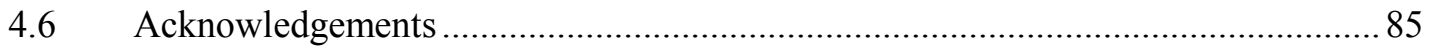

5 Chapter: Empirical Assessment of Watershed Scale Effects of Urbanization on Event Flow Hydrology in Watersheds of Canada's Great Lakes-St Lawrence Basin ................................. 86

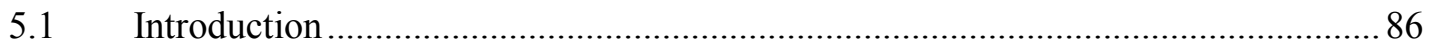

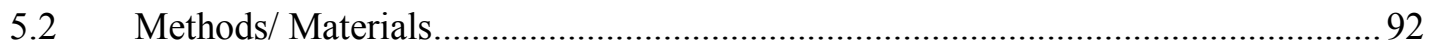

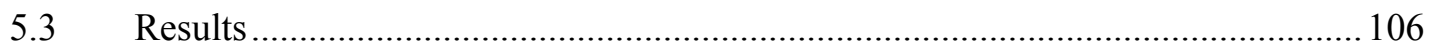

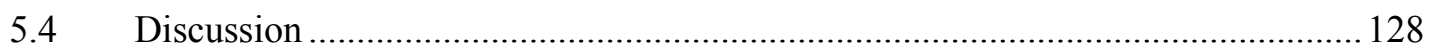

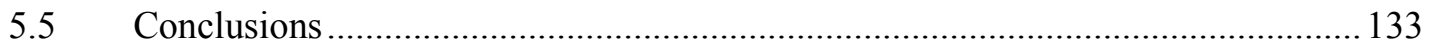

6 Chapter: Associations of Hydrological Characteristics with Fish Richness...................... 135

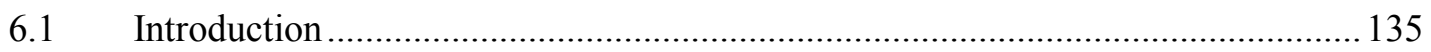

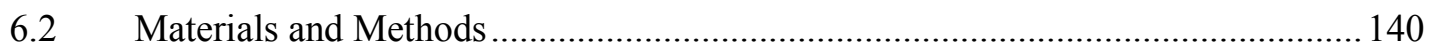

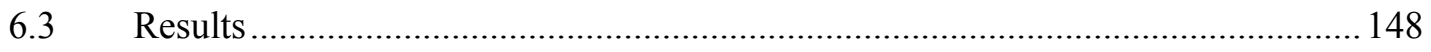

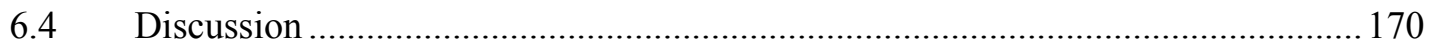

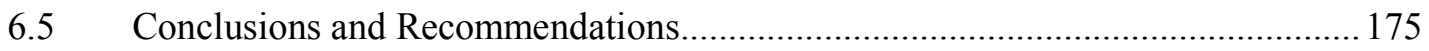

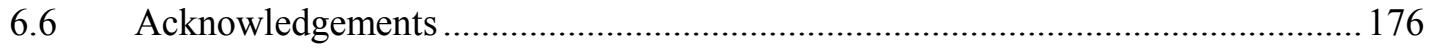

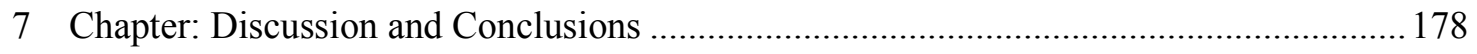

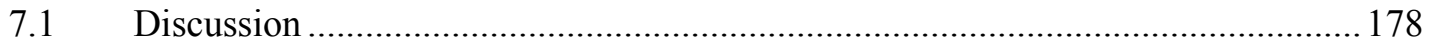

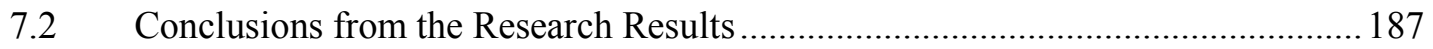

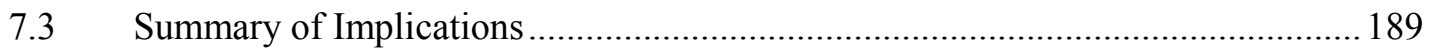


7.4 Approach for Protection of Lotic Biodiversity Arising from the Research

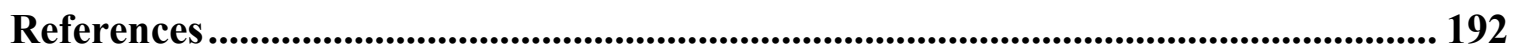

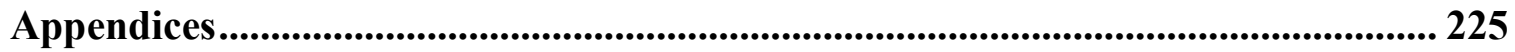




\section{List of Tables}

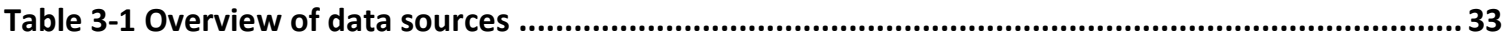

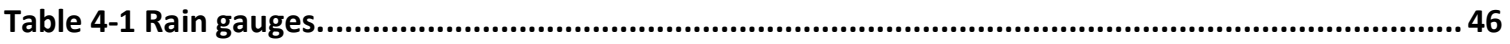

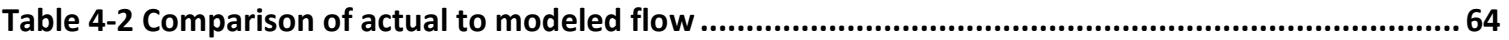

Table 4-3 Results for analyses of moments of rising limb distribution.............................................6.6.

Table 4-4 Results for analyses of moments of rising limb acceleration........................................ 75

Table 5-1 River systems, watersheds, gauges and urban land use sources. ......................................94

Table 5-2 Dependent and independent variables used in statistical models. .................................... 103

Table 5-3 Results for trends with time in rainfall characteristics. .............................................. 108

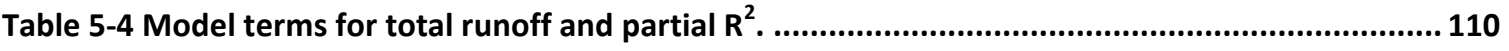

Table 5-5 GAM Model results for 80RLER (log transformed). .................................................... 118

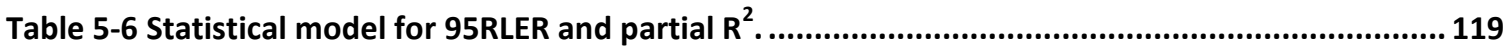

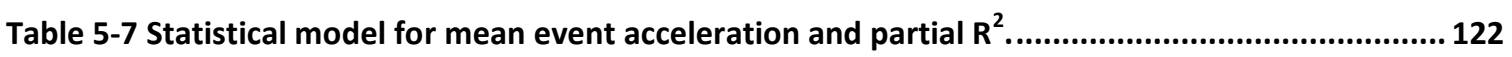

Table 5-8 GAM Model results for mean event acceleration with 80RLER as an independent variable.. 126

Table 6-1 Variables included in statistical analyses.

Table 6-2 GLMM model comparisons for watershed and fish site characteristics for the long-term record database. 155

Table 6-3 GLMM model comparisons for two independent variables for the long-term database. ...... 156

Table 6-4 Fish richness four variable model comparisons for the long-term database. 158

Table 6-5 LR Chi square of independent variables for three linear models for the long term database.161

Table 6-6 GLMM model comparisons for two independent variables for the database with all fish records 163

Table 6-7 Fish richness results for one four- variable model for the database with all fish records. ..... 165 Table 6-8 GLMM model comparisons for the recent database. 169 


\section{List of Illustrations}

Illustration 2-1 Conceptual sketch of three key relationships in the literature

Illustration 4-5 Don watershed event flow probability density distributions for four pairs of early and late period years with similar total rainfall.

Illustration 4-6 Humber watershed event flow probability density distributions for four pairs of early and late period years with similar total rainfall.

Illustration 4-9 Don River rising limb event flow acceleration probability density distributions for 4 pairs of early and late period years with similar total rainfall, for accelerations greater than zero....... 73 Illustration 4-10 Humber River rising limb event flow acceleration probability density distributions for 4 pairs of early and late period years with similar total rainfall, for accelerations greater than zero.

Illustration 4-11 Decadal time series for rising limb event flows and event flow acceleration for the Don and Humber watersheds. 
Illustration 5-6 Fitted 80RLER and UP for GAM model......................................................... 117

Illustration 5-7 Fitted model and illustration of the effect of increasing UP on 95RLER. ....................120

Illustration 5-8 Fitted model for rising limb event flow acceleration. ............................................ 123

Illustration 5-9 Illustration of the effect of UP on the relationship of mean acceleration with 80RLER. 127

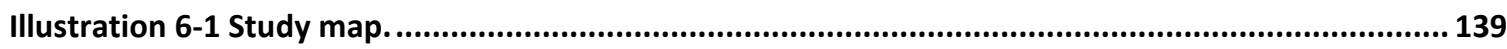

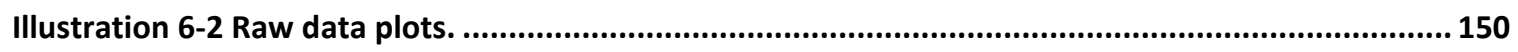

Illustration 6-3 Raw data plot of fish richness with year, urban percent and maximum acceleration $\left(\mathrm{m}^{3} \mathrm{~s}^{-}\right.$

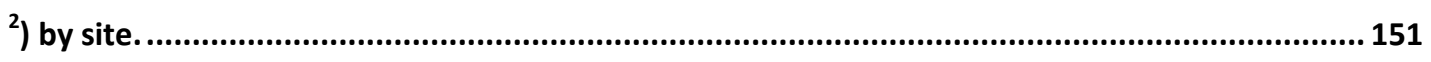

Illustration 6-4 Principal Component Analysis plot for Long term database. .....................................153

Illustration 6-5 Principal Component Analyses plot for the recent database. ....................................168 


\section{List of Appendices}

Appendix A Number of flow-rainfall record pairs 1969 to 1979

Appendix B Summary of event records removed in data cleaning

Appendix C Illustration of urban area delineation by watershed and year

Appendix D Protocols for geo-referencing and digitization of urban areas

Appendix E Rain gauge metadata

Appendix F Watershed baseflow index, channel and slope estimates

Appendix G Urban land use database summary

Appendix H Relationship of nested watersheds within river systems

Appendix I Data points by river system in the maximized data set

Appendix J Correlations of hydrologic variables

Appendix K Runoff coefficient analyses

Appendix L A theoretical basis for greater effects of urban land use on smaller watersheds

Appendix M Fish species in long-term and recent databases

Appendix N Principal Component Analyses results

Appendix O Fish richness independent variable correlations

Appendix P Negative binomial model

Appendix Q Comparison of independent variable ranges in the long-term and recent databases

Appendix R Potential confounding factors contributing to fish richness decline in urban areas 


\section{List of Abbreviations and Symbols}

\begin{tabular}{ll} 
AICc & Akaike's Information Criterion with correction for finite sample sizes \\
ANOVA & Analysis of variance \\
BCa & Bias-corrected and accelerated (bootstrap) \\
BFI & Baseflow index \\
CI & Confidence interval \\
CU & Carleton University \\
CVCA & Credit Valley Conservation Authority \\
df & Degrees of freedom \\
DEM & Digital elevation model \\
DGES & Department of Geography and Environmental Studies \\
EC & Environment Canada \\
FWIS & Flowing Waters Information System \\
GAM & Generalized additive model \\
GCP & Ground control points \\
GIS & Geographic Information System \\
GLMM & Generalized linear mixed model \\
GLSL & Great Lakes Saint Lawrence \\
HLY & MSC daily record of hourly rainfall data \\
HYSEP & Hydrograph Separation Program \\
LID & Low impact development \\
LME & Linear mixed effects \\
LR & Likelihood ratio \\
\hline
\end{tabular}




\begin{tabular}{ll} 
MEA & Millennium Ecosystem Assessment \\
MK & Mann Kendall \\
MSC & Meteorological Service of Canada \\
n.d. & no date \\
ND & Null deviance \\
NRCan & Natural Resources Canada \\
ODPD & Ontario Department of Planning and Development \\
OMNR & Ontario Ministry of Natural Resources \\
OSAP & Ontario Stream Assessment Protocol \\
PAGSE & Partnership Group for Science and Engineering \\
RD & Residual deviance \\
RMSE & Root mean square error \\
ROM & Royal Ontario Museum \\
SE & Standard error \\
TRCA & Toronto and Region Conservation Authority \\
UP & Urban percent land use on a watershed basis \\
USGS & United States Geological Survey \\
WSC & Water Survey of Canada \\
\hline
\end{tabular}

80RLE Eightieth percentile rising limb event flows 80RLER Eightieth percentile rising limb event runoff 95RLE Ninety-fifth percentile rising limb event flows 95RLER Ninety-fifth percentile rising limb event runoff 


\section{Preface: Integrated Manuscripts and Related Research Output}

Chapter 4 is adapted from (excluding the Abstract; Appendices and References are provided in consolidated sections) a Published Journal Article from Elsevier's Journal of Hydrology. Material from Chapter 4 should be cited as:

Trudeau, M.P., Richardson, M. Change in event-scale hydrologic response in two urbanizing watersheds of the Great Lakes St Lawrence Basin 1969-2010. J. Hydrol. (2015), http://dx.doi.org/10.1016/j.jhydrol.2015.04.031 doi:10.1016/j.jhydrol.2015.05.011

Chapter 5 reproduces in whole (excluding the Abstract; Appendices and References are provided in a consolidated sections) an article under review by Elsevier's Journal of Hydrology. In the event that article is published in the Journal, it should be cited with the appropriate doi and noting any changes in the final published paper.

Trudeau, M.P., Richardson, M. Empirical assessment of watershed scale effects of urbanization on event flow hydrology in watersheds of Canada's Great Lakes-St Lawrence Basin.

In addition to the two articles, the following research contributions related to the thesis have been presented (presenter in bold):

Trudeau, M.P. and M. Richardson, Change in event-scale hydrologic response 19692010 in urbanizing watersheds of the Great Lakes St. Lawrence Basin. Presented at the First Joint Scientific Congress of the Canadian Meteorological and Oceanographic 
Society (CMOS), Canadian Geophysical Union (CGU) and Canadian Water Resources Association (CWRA), May $26^{\text {th }}$ to $30^{\text {th }}, 2013$, Saskatoon, Saskatchewan.

Trudeau, M.P., M. Richardson, Long Term Trends in Hydrologic Response within Urban Watersheds, Presented at the Canadian Association of Geographers Annual Meeting, August $11^{\text {th }}$ to $15^{\text {th }}, 2013$, St John's, Newfoundland.

Trudeau, M.P., M. Richardson, Empirical Trends in Hydrologic Response to Rain Events in Urbanizing Watersheds in the Toronto Region of the Great Lakes Basin, Canada, Presented at the World Water Congress XV, May $25^{\text {th }}$ to $29^{\text {th }}, 2015$, Edinburgh, Scotland.

Trudeau, M.P. Hydrologic Trends in Urbanizing Watersheds and Climate Change Implications, Presented at the Latornell Conservation Conference, November $17^{\text {th }}$ to $19^{\text {th }}$, 2015, Alliston, Ontario.

Permission to reproduce published articles

The Elsevier Journal of Hydrology policy states (URL:

http://www.elsevier.com/about/company-information/policies/sharing):

"Theses and dissertations which contain embedded Published Journal Articles as part of the formal submission can be posted publicly by the awarding institution with DOI links back to the formal publications on ScienceDirect." 
In correspondence with the Journal of Hydrology, the Journal confirmed to M. Trudeau that “...no written permission is necessary" (e-mail correspondence 2015-07-10).

\section{Student Statement Regarding Co-Authored Material}

I was the principal researcher involved in setting up and conducting the research, obtaining data and analyzing results, as well as preparing and writing the material presented in the co-authored articles integrated within this thesis. I relied on my coauthor, Dr. Murray Richardson, for event flow separation script, advice on hydrologic analyses and for review and editing of drafts of the papers.

\section{Co-Supervisor Statement}

As thesis co-supervisor, I, Doug King, provided funding for the research and to Mary Trudeau, advised on design and analytical aspects of the research, and reviewed final journal and conference paper drafts, making only a few very minor editorial suggestions. I was not involved in the data analysis or paper preparation to a degree that warranted coauthorship.

A signed Statement of Co-Authorship and Permission by Dr. Murray Richardson is provided as a separate document. The text of the statement is reproduced following.

\section{Statements of Co-Authorship and Permission}

As co-author of 'Change in event-scale hydrologic response in two urbanizing watersheds of the Great Lakes St Lawrence Basin 1969-2010', published in the peerreviewed Journal of Hydrology, and of 'Empirical assessment of watershed scale effects of urbanization on event flow hydrology in watersheds of Canada's Great Lakes-St Lawrence Basin' submitted for peer review by the Journal of Hydrology, I, Murray Richardson, acknowledge Mary Trudeau as the manuscripts' lead contributing author. 
Mary designed the studies, performed the analyses and wrote and revised the manuscripts.

I, Murray Richardson, have contributed to the published papers and the paper submitted for publication in the thesis as co-supervisor of Mary Trudeau's $\mathrm{PhD}$ program. This role has entailed discussion, criticism, advice and editorial contribution to the design, analyses and writing of the thesis. These activities have been entirely consistent with the role of thesis co-supervisor.

These manuscripts represent significant contributions to the understanding of trends in event-scale flows with urbanization, both temporally and spatially. I fully support the inclusion of these articles as components in Mary's doctoral thesis.

Dr. Murray Richardson 


\section{Chapter: Introduction, Research Questions and Thesis Overview}

\subsection{Introduction}

Biodiversity comprises life and the life support systems of the Earth. It is difficult to characterize because it is omnipresent, complex and diverse, but it includes the Earth's genes, species, ecosystems and land/seascapes (Carpenter et al., 2009; PAGSE, 2010), as well as the range of services that underpin human health, security, economy (PAGSE, 2010), cultures and quality of life. Biodiversity safeguards our survival (Steffen et al., 2004) in a solar system that is otherwise uninhabitable to humans.

Biodiversity is in precipitous decline globally, with the current extinction rate up to 1000 times higher than the fossil record (MEA, 2005). Freshwater biodiversity is of particular concern (MEA, 2005); the highest proportion of threatened species by taxonomic group relies on freshwater habitats (MEA, 2005). Estimated rates of extinction for North American freshwater fauna are five times higher than for terrestrial fauna (Ricciardi and Rasmussen, 1999). Despite some increased efforts to protect it, there has been no significant reduction in the rate of biodiversity decline (Butchart et al., 2010). Although it is a signatory to the International Convention on Biological Diversity, Canada has not taken sufficient measures to reverse negative trends in aquatic biodiversity (PAGSE, 2010). Future global decline is projected to be ten times higher than the current rate (MEA, 2005) because pressures on biodiversity continue to rise (Butchart et al., 2010; Carpenter et al., 2009). Climate change will introduce additional changes to freshwater systems (Carpenter et al., 1992) making predictions of future trends unreliable 
(Malmqvist and Rundle, 2002).

Biodiversity and human social systems are interconnected through complex direct and indirect processes and responses (Carpenter et al., 2009). The interactions among Earth's multi-scalar processes maintain the diversity and resilience of ecological systems, operating across local to global scales within timeframes from instantaneous to geologic (Gunderson and Holling, 2002). The interactions in this complex system are non-linear and produce alternating stable states encompassing both biotic and abiotic factors (Gunderson and Holling, 2002). Levin (1992) describes the challenge of trying to understand patterns observed at one level of detail in terms of mechanisms that are operating on other scales as familiar and one of 'surpassing importance' for understanding the response of ecosystems over long temporal scales to anthropogenic forces.

Addressing declining biodiversity is challenged by the tension between acquiring specialized knowledge and skills to undertake reductionist scientific investigations and the need to understand the holistic and multi-faceted nature of human and natural systems. Gunderson and Holling (2002) assert that ecologists do not adequately consider human behaviour and institutional arrangements, with the consequence that actions they propose are not effective over time. They have similar critiques of economists and social institutions (Gunderson and Holling, 2002). Castree (2005) argues societal understandings of nature, including biodiversity, are shaped by the agendas and perceptions of investigators and thus understanding of nature also requires examination 
of the motives underlying inquiry into its aspects. Nevertheless, biodiversity loss increases risk to human social systems by reducing the resilience of ecosystem services and limiting future management options (Carpenter et al., 2009).

Given its dynamic properties, humans should not expect to fully explain or predict biodiversity or the ecosystems within which biodiversity resides. Further, reductionist scientific approaches may preclude detection or prediction of emergent phenomena in complex systems until they are well underway. Although all the solutions are not necessarily going to be found in scientific advancements, science has an important role in identifying threats to biodiversity and informing decision-making responses by private and public entities.

Understanding baseline conditions from which to assess the magnitude of biodiversity change in Canada is inherently difficult because changes preceded scientific data collection and anthropogenic disturbances are on-going. A lack of scientific baseline measurements and/or pristine reference landscapes can result in 'shifting baseline syndrome' (Pauly, 1995). This syndrome causes current diversity patterns to be accepted as baseline conditions, and the basis for protection or conservation goals, even though they do not represent the ecological potential or past conditions.

There are numerous contributing factors to biodiversity loss. The current epoch has been called the Anthropocene in recognition the scale of human influence on the biosphere (Steffen et al., 2004). Ecosystems have changed more within the past five decades than at 
any other time in human existence (Carpenter et al., 2009). Watercourses worldwide have been — and continue to be — significantly manipulated and modified (Vörösmarty et al., 2010). Vörösmarty et al. (2010) estimated that " $65 \%$ of global river discharge, and the aquatic habitat supported by this water, is under moderate to high threat" (p. 559). While water security increases with affluence, biodiversity threats also increase with affluence (Vörösmarty et al., 2010; Palmer, 2010; Dinda, 2004), in part due to the measures taken to improve water security (Vörösmarty et al., 2010). Urban water security measures (Cook and Bakker, 2012) such as flood prevention, drainage, sanitation (Chocat et al, 2007) and supply-side infrastructure (Kevinsen et al., 2014) contribute to the myriad incremental alterations to aquatic ecosystems.

Overall, broad stressors to biodiversity have been identified but causal factors and the role of spatial and temporal scales are poorly understood. One such stressor for aquatic biodiversity is land use change (Klein, 1979; Löfvenhaft et al., 2004; Paul and Meyer, 2001; Schueler, 1994; Stanfield et al., 2006; Stanfield and Kilgour, 2006). Urban land use brings with it so many concurrent environmental changes (e.g. Dudgeon et al., 2006; Brabec et al., 2002; Costa et al., 2003; Adamowski and Prokoph, 2013; Boers et al., 1986; Morin and Benyamini, 1977) that the term "urban stream syndrome" (Walsh et al., 2005) has been coined to capture the degraded condition of urban watercourses.

With $81 \%$ of Canada's population now living in urban centres (Statistics Canada, 2011), there is an urgency to understanding the cumulative effects of expanding urban land-use on functional and structural properties of lotic systems. The concept of 'extinction debt' 
resulting from habitat alteration has been documented for terrestrial habitats; species extinctions exhibit a lagged response to habitat loss (Hanski and Ovaskainen, 2002). Lagged effects of several decades have also been identified in wetland and other aquatic ecosystems in response to stressors associated with increased road density and other land use changes (Findlay and Bourdages, 2000; Löfvenhaft et al., 2004; Harding et al., 1998). Lagged biotic responses hamper correlation studies because long timeframes are needed to statistically detect signals. Similarly, systemic inertia may make it difficult to identify effective best management practices to protect biota because signals from past impacts may dampen or out-weigh positive improvements.

Urbanization and increased impervious land cover have long been associated with changes in flow regime (e.g. Hammer, 1972; Dunne and Leopold, 1978; Klein, 1979; Löfvenhaft et al., 2004; Paul and Meyer, 2001; Schueler, 1994; Stanfield et al., 2006; Stanfield and Kilgour, 2006). In turn, flow regime changes have been associated with aquatic biodiversity loss (Burcher et al., 2007; Hutchens et al., 2009). However, hydrologic analyses to date have been undertaken on coarse temporal scales (daily, weekly or monthly) (e.g. Monk et al., 2012; Clausen and Biggs, 1997). Event scale hydrologic changes cannot be assessed at daily or monthly temporal scales. Thus, hydrologic changes on a scale commensurate with the instantaneous experience of biota in the water column, or by habitat features affected by high energy water and sediment impulses during rain events, are poorly understood.

This transdisciplinary empirical study was designed to examine hydrologic event-scale 
changes with urban land use and associations with changes in aquatic biodiversity. The study was organized into three research phases, each designed to build the foundation for subsequent research phases.

This research is novel in both its temporal and spatial aspects. The difficulties encountered in building the database for the study, including acquiring urban land use data on a watershed basis, are also indicative of a novel approach for the study region. The Greater Toronto Area was selected because of its intensive urbanization over several decades. In recognition of the potential for both incremental cumulative effects and lagged effects, long term datasets (spanning at least 4 decades) were compiled for hydrology, rainfall, urban land use and fish richness. Hydrologic data were in 15-minute increments to capture rising limb event-scale responses for the post-freshet year (May $26^{\text {th }}$ to November $\left.15^{\text {th }}\right)$. Thus, hydrologic signals were analyzed using two very different temporal scales: event-scale change over a 42 year span. To the author's knowledge no previous studies of urban development effects on hydrology or biodiversity have utilized such a detailed data set over a long period of time. Such data and analyses are, however, needed in order to develop understanding of longer term impacts. Another novel aspect of the analyses is that hydrologic records were matched to rainfall so variation in precipitation could be accounted for in the empirical models. Sufficient historic urban land use information was not available on a watershed basis, so aerial photographs were used to address data gaps. Watersheds were selected for a range of percent urban land cover, from $0.06 \%$ to $87.6 \%$. Watershed characteristic data (e.g. slopes and other variables) were also researched or derived. To examine watershed scale effects, 
watershed sizes spanned an order of magnitude $\left(37 \mathrm{~km}^{2}\right.$ to $\left.806 \mathrm{~km}^{2}\right)$ in 11 river systems. Fish data were compiled for a 70 year timespan for 8 of those river systems. The cooperation of numerous agencies and researchers is gratefully acknowledged for assistance in building the database (see Chapter 3). Again, to the author's knowledge no previous studies have been undertaken on the effects of event-scale hydrology on fish richness in urbanizing watersheds utilizing such a detailed data set over the temporal and spatial scales in this research.

\subsection{Research Objectives}

This research was an observational study with the broad objective to examine empirical relationships of event-based flows and biotic community diversity in freshwater systems associated with cumulative increases in urban land cover.

The specific objectives of the research were to:

(1) Identify changes in event-scale flows through time (over four decades) of two watersheds to ascertain whether changes could be statistically detected (Chapter 4);

(2) Quantify the relationship(s) between changes in event-based flows and urban land use in watersheds across various spatial scales and urban extent (Chapter 5);

(3) Quantify the relationship(s) between event-based flows and aquatic biodiversity, specifically fish (Chapter 6).

The underlying hypotheses for these objectives were: 
1) Changes in urban land cover cause variance in hydrologic characteristics, including total runoff and event-scale runoff and flow acceleration.

2) Changes in the hydrologic regime cause variance in biotic response to land use change, if changes in the hydrologic regime are measured on an appropriate temporal scale and in the context of rainfall events.

\subsection{Thesis Overview}

This research is based exclusively on empirical data and statistical modeling techniques and was undertaken in three research phases. Each phase is reported in a Chapter within this dissertation (Chapters 4 to 6). The sequence of the phases was designed to build on earlier phase results, with consideration for available information at the commencement of each phase. The first phase worked with two temporal scales: a longitudinal period of four decades; and, flow resolution at 15-minute time increments. The second phase decoupled spatial and temporal scales by holding flow temporal resolution at the eventscale (15-minute increments) for a range of watershed sizes; although urban cover information spanned four decades, there was no longitudinal temporal analysis. The third phase was similar to the second, analyzing fish data spanning five decades using independent variables pertaining to event-scale flows over a range of watershed sizes. Following are summaries of the contents of each Chapter in this thesis.

Chapter 1 introduces the issue of urban lotic biodiversity, the broader research context and gaps necessitating this research project. It also presents the broad research objective of examining empirical relationships of event-based flows and biotic community 
diversity in urbanizing watersheds, and three specific research objectives. Each subsequent chapter is organized to reflect the progress of the research, including literature review and each of three study phases.

Chapter 2 discusses key terms that are not well defined in the literature and their usage in this research. This chapter also provides a literature review that identifies the three relationships that are documented with respect to biota, flow and urban land use. It also identifies knowledge gaps and where this research was designed to meet current research needs.

Chapter 3 provides the rationale for selection of the study location and other study design decisions. A summary of data sources is provided along with names and organizations of those who assisted in building the study database. Building the study database required years of effort and forging of multiple formal and informal agreements for data sharing. Each contributor is gratefully acknowledged in Chapter 3. Methodologies are reported in each of the core chapters.

Chapter 4 reports the methods and results for Phase 1 of the research. This first phase responds to the first specific objective by examining whether event scale hydrologic changes were statistically evident in long-term records of two watersheds undergoing intensive urbanization. The Chapter comprises a published article: Change in event-scale hydrologic response in two urbanizing watersheds of the Great Lakes Basin 1969-2010, published in the Journal of Hydrology in 2015 (DOI:10.1016/j.jhydrol.2015.05.011). 
Chapter 5 reports the methods and results for Phase 2 of the research. This second phase responds to the second specific objective through a spatial analysis of changes in eventbased flows along a gradient of urban extent on a watershed basis for watersheds ranging in size from $40 \mathrm{~km}^{2}$ to $800 \mathrm{~km}^{2}$. The content of this chapter comprises an article under external peer review: Empirical assessment of watershed scale effects of urbanization on event flow hydrology in watersheds of Canada's Great Lakes-St Lawrence Basin, submitted for review to the Journal of Hydrology in 2015. Appendices to the article are incorporated into the Appendices to this thesis. An additional appendix, Appendix L, provides a theoretical basis to explain possible but non-statistically significant tendencies observed during Phase 2 of the research pertaining to watershed scale and urbanization.

Chapter 6 reports the methods and results for Phase 3 of the research. This third phase responds to the third specific research objective to identify the relationship(s) of eventbased flows. Data on fish richness were available for this analysis, so the title of the chapter is: Associations of Event Flow Hydrology with Fish Richness in Urbanizing Canadian Watersheds of Lake Ontario.

Chapter 7 includes a discussion of the research results in context of the study phases and progress, current literature and the research hypotheses. The discussion also identifies what results are new and their significance as well as study limitations and further research needs. This chapter provides a summary of the conclusions and implications of the research. It also discusses the broader context for application of the research findings. 
Appendices provide supplemental information to the chapters. Appendices of embedded journal articles are incorporated into this consolidated Appendix section.

References contain consolidated references for all Chapters. 


\section{Chapter: Terminology and Literature Review}

The literature review is prefaced by a discussion of five terms that are used in the literature but they are either not commonly used or are used with ambiguous meaning. Each section of the literature review identifies the phase of research and corresponding chapter to which the review is relevant.

\section{$2.1 \quad$ Terminology}

Potentially ambiguous terms used in this thesis are defined as follows:

1. Event-based flows (and event flows) mean the in-stream hydrological conditions arising as a result of periods of precipitation, in particular, rainfall. The temporal scale for rain events is hours (or fractions of an hour) to several days. Similarly, the resulting changes in hydrological flows from rainfall running off the land have similar temporal scales, that is, hours to days. Hydrologic analyses based on daily, monthly or annual flows do not capture the extreme volumes or velocities of individual rain events because the averages include periods of time with no precipitation. One unique aspect of this thesis is the long-term (i.e. over four decades) analyses of high temporal resolution flow records (i.e. 15 minute increments).

2. Land use indicates broad categories of land cover, such as urban, agricultural or forested. Land cover may change even though the land use category may stay the same. For instance, a change in planted crop may change the land cover but the land use remains agricultural. Urban land use was a key independent variable in this research and 
is associated with higher extents of impervious land cover than other land uses.

3. Due to the focus on hydrology, urban land use was defined to be lands drained by engineered urban drainage systems. As described in more detail in Chapter 4, land cover within the urban area that was not readily drained by urban drainage systems (such as park areas exceeding 1 hectare) was excluded from estimated urban areas. Urban land use area was estimated on a watershed basis.

4. The term watershed is used in a generic sense without implications for nested relationships among watersheds. See Chapter 5 for application of this definition.

5. Impervious cover is not used in this document except in the literature review. In the literature, this term is used interchangeably with urban cover, at times without definition. Brabec et al. (2002) report that some studies equate percent impervious with percent urban, while others include only impervious cover with detailed analyses differentiating between total impervious area and impervious area directly connected to watercourses (called effective impervious area). Methodologies to identify impervious cover vary among studies (Brabec et al., 2002). The assertion in the literature that aquatic biota experience negative effects at about 10\% impervious cover (e.g. Schueler et al., 2009; Stanfield and Kilgour, 2006; Chin, 2006; Walsh et al., 2001) is therefore subject of methodological uncertainty. Urban percent reported in this research can be assumed to cover a proportionately larger land surface than impervious area because the urban areas include pervious lands such as lawns, boulevards and small parks (see Chapter 5). 


\subsection{Literature Review}

\subsubsection{Key Relationships: Land Use, Hydrology and Biota}

Lotic systems have wide ranging natural spatial and temporal variability and scales. Rivers integrate the conditions of the lands they drain, reflecting and constrained by abiotic factors (e.g. climate, geology and soils, groundwater distribution and topography) (Poff et al., 1997; Poff, 1997). They are unique aquatic ecosystems because they flow in one direction and, being relatively narrow, are intricately and immediately connected to their land base (Hynes, 1975 in Malmqvist and Rundle, 2002). Riverine biota are necessarily well adapted to dynamic environments (Giller and Malmqvist, 1998). Landbased activities within watersheds have the potential to affect downstream conditions and smaller, nested watersheds have potential to affect their larger receiving watersheds. Spatially, watersheds range from ephemeral hillslope rivulets to continental basins.

Many factors contribute to freshwater biodiversity decline (Burcher et al., 2007; Dudgeon et al., 2006; Paul and Meyer, 2001; Preston and Bedford, 1988; Stanfield et al., 2006; Thuiller, 2007, Vörösmarty et al., 2010). Despite numerous influences and high natural variability, three key correlative relationships have been identified in the literature: 1) biotic response to land use change; 2) flow regime response to land use change; 3) biotic response to flow regime change. Illustration 2-1 provides a conceptual sketch of these relationships. 


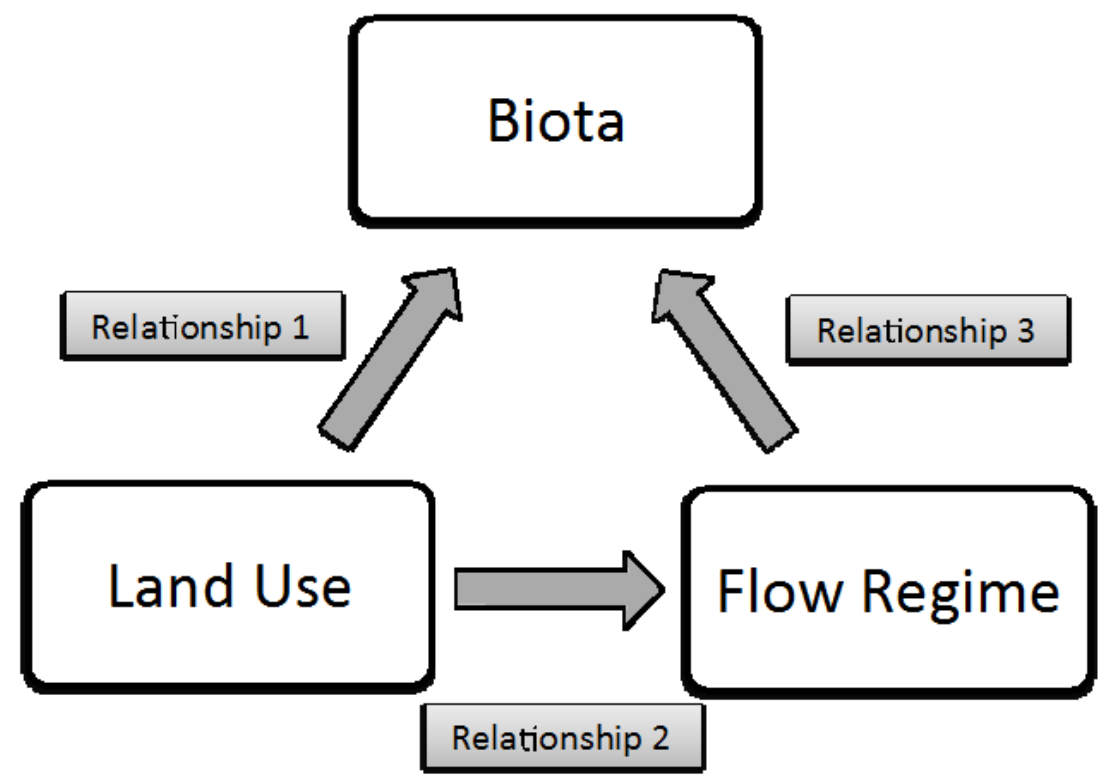

Illustration 2-1 Conceptual sketch of three key relationships in the literature

This simplified illustration indicates the direction of three relationships of interest for this study. 
Note that the relationships identified are one-way because these are the predominant directions of interest. Biota may influence land use (reverse Relationship 1) where human decision-makers allow biota to play a significant role in land development or protection, for example where endangered species legislation requires habitat protection. Flow regime may influence land use (reverse Relationship 2) where the flow regime is taken into consideration by human decision-makers, for example restricted development within floodplains or protection of recognized groundwater recharge areas. Biota may influence flow regime (reverse Relationship 3) where flow is altered by the activities of biota, for example beaver dams. These reverse relationships were not examined in the research.

The impact of land use on aquatic biodiversity must necessarily be mediated through mechanisms and processes that arise from and/or are altered by land use change. Land use change triggers flow regime changes that, in turn, result in altered conditions, mechanisms and/or processes that affect biodiversity (e.g. Burcher et al., 2007; Konrad and Booth, 2005; Lytle and Poff, 2004). In urban environments, the term urban stream syndrome has been applied to describe common urban conditions, including increased flow flashiness (i.e. frequent, rapid flow increases in response to rain events), increased pollutant loads, altered biotic communities and altered ecosystem function (Meyer et al., 2005). Numerous, simultaneous changes make it difficult to assess the relative importance of individual factors. Illustration 2-2 is a conceptual sketch of the potential role of flow regime, in contrast to the simplified relationships in Illustration 2-1. 


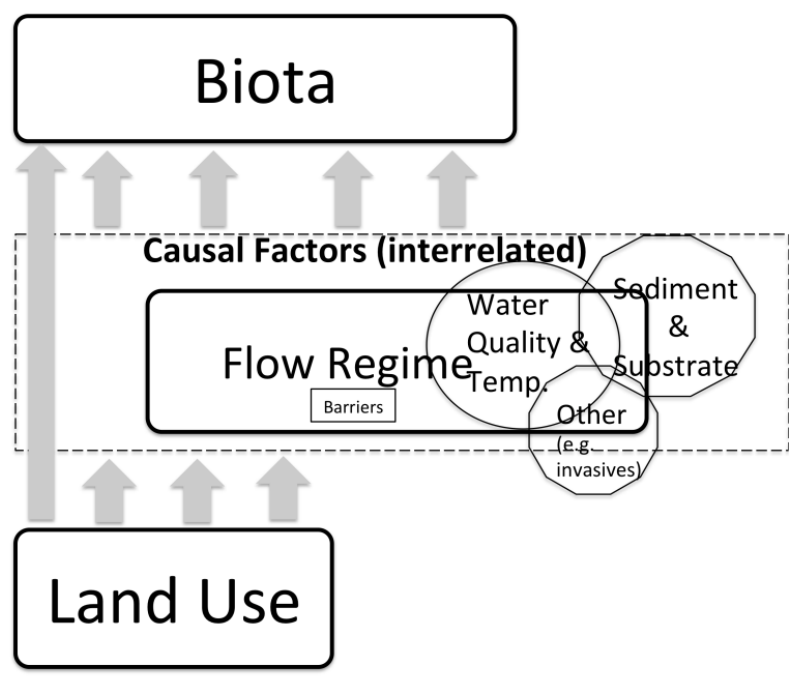

Illustration 2-2 Conceptual sketch of the role of flow regime (not to scale)

This simplified illustration focuses on flow regime factors only, not biological or other aspects that also entail more complexity than captured in Illustration 2-1. 
Each of the three relationships has numerous potential dependent variables because there is no single precise measure for aquatic biodiversity health, land use change, or hydrologic regime change. Aquatic biodiversity has been assessed using various types of organisms (e.g. fish, macroinvertebrate, algae, or other) (Moustakas and Karakassis, 2005) and numerous indices (Ghetti and Ravera, 1994). Similarly, flow regime may be assessed through flow characteristics on many temporal scales (e.g. event-based, daily, monthly, annual), or through associated conditions including bank stability, change in channel dimensions, suspended sediments and substrate characteristics (e.g. Burcher et al., 2007). Land use can also be defined using numerous categories on spatial scales ranging from fractions of a square meter to global and with broad categories of land use to very detailed (e.g. crop type within agricultural land use). The following three subsections summarize relevant research for the three key relationships identified in Illustration 2-1.

\subsubsection{Relationship 1: Biotic response to urban land use}

In a review of literature results from 65 studies, the range of impervious cover at which stream degradation could be first detected was 2-15\% (Schueler et al., 2009). Stream degradation was assessed in the studies using a variety of indicators, including habitat features, geomorphologic change, water quality and biotic indicators, among others. Watersheds with prior forest or natural vegetative cover exhibited lower threshold responses (i.e. more sensitive to the change) than watersheds with extensive cultivation or range management prior to the change (Schueler et al., 2009). Based on a range of indicators, the biotic community's condition in cultivated watersheds with impervious 
cover of $20-25 \%$ is consistently poor (Schueler et al., 2009). Urban catchments with $30 \%$ to $70 \%$ impervious cover are severely degraded with reduced benthic communities or the absence of fish life (Klein, 1979). Other land use changes are also associated with aquatic biodiversity change, including deforestation (e.g. Smith et al., 2009) and agriculture (e.g. Stevens et al., 2010; Stoate et al., 2009).

As outlined in Chapter 5, low levels of impervious land use (10\% or less) are associated with negative biotic response in diverse regions of the globe (Schueler et al., 2009, Stanfield and Kilgour, 2006, Chin, 2006, Walsh et al., 2001). Causal factors are not known but changes in biota likely arise from cumulative effects of disturbances, interactions and indirect changes through time and on numerous spatial scales (Preston and Bedford, 1988).

Inconsistent data collection methods (Roper et al., 2002) and sampling bias, such as a focus on vertebrates (Moustakas and Karakassis, 2005) or, more specifically, sports fish, further complicate efforts to understand trends in aquatic biota. In Ontario, fish and benthic assemblage data are typically collected in wadable streams, so fewer datasets are available for larger rivers (L. Stanfield, pers.comm, 2013). Also, due to the extensive and early land development in the study region, there is a lack of reference sites for unimpaired fish communities in Ontario (L.Stanfield, pers.comm., 2013).

The consistency in the literature of a biotic response at about $10 \%$ impervious cover supports the second hypothesis stated in Chapter 1. Specifically, it is possible that 
changes in the hydrologic regime produce mechanistic (and therefore consistent) changes in the structure and/or function of lotic systems which, in turn, cause a negative biotic signature. Phase 2 of this research examined flow responses across an urban spectrum. As indicated in Chapter 5, an investigation of the low urban cover range (i.e. $0.1 \%$ to $25 \%$ ) was undertaken to see whether runoff responses were quantifiably different at around $10 \%$ urban cover. It was hoped a direct examination of fish richness with urban land use and hydrologic characteristics could be undertaken but, as described in Chapter 6, the fish database had limitations and there were insufficient observations for detailed analysis of fish richness along gradients of flow variables and urban cover.

\subsubsection{Relationship 2: Flow regime response to land use change}

Relationship 2 includes both hydrological and geomorphological responses to land use change since flow regime change includes both water flow and channel dimension changes. Changes in physical stream properties with land use are associated with even lower impervious cover than identified for the biota-land use relationship discussed above. For instance, at about $4 \%$ impervious cover, channel dimension changes have been documented (in Stanfield and Kilgour, 2006) and severely altered flow patterns have been identified at 6-10\% impervious cover (Booth and Jackson, 1997). At around $10 \%$ impervious catchment area, the 2-year return period of post-alteration flows equaled the former 10-year return period of forested catchments and was correlated with channel instability (Booth and Reinelt, 1993). The distribution of imperviousness within urban areas (Jacobson, 2011) and landscape organization affecting the mean residence time of water in a catchment (i.e. catchment size) influence runoff production (McGlynn et al., 2003). Channels in urbanized areas typically become larger and straighter and have 
coarser bed materials due to armouring and loss of fines (Booth and Reinelt, 1993; Chin, 2006). They also tend to be incised and have fewer pools and riffles (Booth and Reinelt, 1993).

Stream power is the rate at which a stream can do work, determining sediment transport, bank erosion and thresholds in channel patterns (Kondolf et al., 2003). Stream power is empirically related to channel gradient, channel stability (Simon and Castro, 2003), channel sinuosity and channel width (Kondolf et al., 2003). It is proportional to the product of sediment discharge and mean sediment particle size (Lane, 1955 in Allan and Castillo, 2007). This proportionality is important because sediment transport and the mean sediment size have implications for habitat. Total stream power per unit length of stream can be expressed as (Gordon et al., 2004):

$$
\Omega=\rho g Q S \text { [per unit length of stream], }
$$

Where:

$$
\begin{aligned}
& \Omega \text { is stream power (Watts, or Joules } \mathrm{s}^{-1} \text { or } \mathrm{kg} \mathrm{m}^{2} \mathrm{~s}^{-3} \text { ) [per unit length of stream] } \\
& \rho \text { is the density of the liquid }\left(\mathrm{kg} \mathrm{m}^{-3}\right) \\
& \mathrm{Q} \text { is flow, } \mathrm{m}^{3} \mathrm{~s}^{-1} \\
& \mathrm{~g} \text { is acceleration due to gravity, } \mathrm{m} \mathrm{s}^{-2} \\
& \mathrm{~S} \text { is channel slope, used as an approximation of energy slope, dimensionless }
\end{aligned}
$$

Slope can change over time with erosion or aggradation of the streambed and with changes in channel sinuosity; channel adjustments of width or depth will change the relationship of flow per unit length of channel. Governing and feedback mechanisms in 
rivers, such as deposition and scour, work within two simultaneously incompatible requirements (uniform energy distribution and minimum total energy) to adjust stream dynamics from the headwaters to confluence and to perturbations over time (Langbein and Leopold, 1964).

Hammer (1972) identified basin slope to be the most critical determinant of stream channel enlargement with urbanization, consistent with Eq. 1 above. Post-flood adjustments, excess sediment loads and altered flow regimes are associated with the highest rates of channel dimension change (Fox, 1976). Channel enlargement effects are not as large where impervious developments are less than 4 years old or more than 30 years old (Hammer, 1972), indicating that width adjustments in response to increased flows are lagged but stabilize with time if stream power stabilizes. Other studies have identified channel re-stabilization after 5 to 30 years, but some channels had not stabilized after more than 40 years (Chin, 2006).

Documented flow regime changes due to urbanization, based on daily or annual flows, include increases in peak discharge and increased duration of sediment transporting events (Booth and Jackson, 1997). Three hydrologic characteristics change with urbanization: high-flow frequency; distribution of water between storm flow and base flow; and, daily flow variability (Konrad and Booth, 2005; Tetzlaff et al., 2005a). Based on daily or annual flow analyses, the magnitude of responses typically associated with urbanization include: 1) a 2-4 fold increase in peak discharge and runoff volumes; and, 2) reduced lag time to peak discharge of one-half to one-fifth the former times (Chin, 2006). 
Thus, streams in urban areas have been characterized as "flashier". Urbanization is also associated with increased duration of sediment transporting events (Booth and Jackson, 1997). Agricultural and urban land uses are associated with reduced channel stability (increased incision and bank height changes) and increased suspended solids and, ultimately, with changes in biotic community metrics (Burcher et al., 2007). Surface runoff potential also changes with conversion of land use from forest to agricultural pastures or grass (Chin, 2006).

In the literature, only one group of studies was identified that used high-resolution hydrologic data to assess hydrologic conditions in urban watercourses. Tetzlaff et al. (2005a) examined the relationship of urban land use with flow acceleration, using two sets of flow records ( 1 hour temporal resolution for 16 catchments; and 6 minute resolution for 3 catchments). Both modeled and empirical data were used in the analysis but results were inconclusive with respect to the relationship of urban cover with acceleration (Tetzlaff et al., 2005a) possibly because: data were analyzed as three separate databases; catchment characteristics (other than size) were not included; and, rainfall was not taken into consideration. The limitations of the Tetzlaff et al. (2005a) study were addressed in the research of this thesis. Tetzlaff et al. (2005b) assessed changes in flow dynamics in an urban watercourse; Tetzlaff et al. (2005c) developed discharge-mean velocity distributions for a cross section of their study stream and, with these curves, estimated the duration of exceedences of critical displacement velocities for Atlantic salmon. These studies raised the profile of flow acceleration as a potential determinant of fish diversity but were not able to make the direct linkages identified in 
this thesis.

Given the literature, no systematic research using fine resolution temporal data had been undertaken to build empirical models of changes in runoff or event scale hydrologic characteristics with increasing urban cover. Phases 1 and 2 of this research, described in Chapters 4 and 5 respectively, were designed to advance understanding of changes in total runoff, event flows and event flow accelerations in the rising limb through a 42 year period of urbanization in two watersheds and across a spectrum of urban land use for 27 watersheds spanning an order of magnitude in size. Using hydrologic data at 15-minute increments both temporally and spatially builds a strong understanding of hydrologic changes in the study area. Independent flow variables for stream power during events were used in the analyses of fish richness, described in Chapter 6.

\subsubsection{Relationship 3: Biotic response to flow regime change}

Flowing water is a defining feature of rivers (Konrad and Booth, 2005) and flow regime is a master variable in river and floodplain ecosystems (Bunn and Arthington, 2002; Mims and Olden, 2012). Aspects of flow regimes that are of potential ecological interest include the "magnitude, frequency, seasonal timing, predictability, duration and rate of change of flow conditions" (Lytle and Poff, 2004). Lotic system organisms have three broad forms of adaptation strategies that allow them to survive and thrive under variable flow regimes: life-history (e.g. timing of reproduction to avoid seasonal drought); behavioural (e.g. moving to sheltered areas when flow velocity increases); and, morphological (e.g. streamlined body shapes) (Lytle and Poff, 2004). Flow variability is 
necessary to sustain the health of freshwater ecosystems (Poff and Zimmerman, 2010) and, paradoxically, large natural fluctuations in flow are suspected of maintaining biodiversity by making it difficult for any one competitor within a biological community to dominate under all flow conditions (Power et al., 1995) and by discouraging invasions (Bunn and Arthington, 2002).

The ecological consequences of anthropogenic flow alterations are difficult to predict due to the wide range of natural flow regimes (Konrad and Booth, 2005) and potential adaptive strategies of organisms (e.g. Scott and Magoulick, 2008). Further, the full range of natural flow regimes that species can occupy is generally not known (Lytle and Poff, 2004), thus limiting scientists' ability to predict the adaptive capacity of organisms exposed to flow alterations. However, impacts of anthropogenic changes in flow regimes have been identified across various riverine plants, invertebrates and fish (Bunn and Arthington, 2002). Chronic disruptions of natural flow regimes are associated with simplified trophic structure, low taxonomic diversity, and dominance of a relatively low number of taxa (Blann et al., 2009; Konrad and Booth, 2005).

The degree of negative association of aquatic diversity with anthropogenic land use change may vary with the adaptive strategy of resident organisms (Lytle and Poff, 2004). The predictability of seasonal timing is likely important to organisms with life-history strategies that rely on flow signals (e.g. spawning times that coincide with optimum flow conditions), whereas organisms with behavioural adaptive strategies may rely on eventbased environmental signals to respond appropriately to impending conditions (e.g. to 
predict and evade large flows) (Lytle and Poff, 2004). Organisms with morphological adaptations have evolved to optimize species survival under prevailing conditions; thus, stability in the magnitude and frequency of flow events may be important variables for long-term community health (Lytle and Poff, 2004).

Research indicates some causal mechanisms impacting biota are direct and others occur indirectly through changes in resources available to organisms, such as habitat loss or gain (Auerbach and Poff, 2011). Direct causal mechanisms, for instance, include alteration of spawning behaviour signals and larval survival (Bunn and Arthington, 2002). Also, high flows that exceed the critical displacement velocities of fish threshold velocities above which fish cannot hold their station (Graham et al.,1996; Tetzlaff et al., 2005d) - interrupt foraging and affect fish growth rates (Tetzlaff et al., 2005d). In addition, population losses can occur when rapid flow changes prevent organisms from reaching refuge areas (Tetzlaff et al., 2005d). Indirect causal mechanisms can occur through alteration of habitat quality by scouring substrates and through changing energy and food availability by transporting nutrients, organic matter and organisms downstream (Konrad and Booth, 2005). In modeled results, Auerbach and Poff (2011) found organisms' mortality increased as the intensity of flow disturbance increased, implying that behavioural and physiological adaptations became less effective with more intense disturbances.

A frequency of high flow events greater than three times the median discharge was the most important flow parameter in predicting invertebrate community composition in a 
Scottish stream (Gibbins et al., 2001). The magnitude of flow fluctuation may be a more important signal for biota than the absolute magnitude of flow peak (Konrad and Booth, 2005).

No comprehensive spatial studies were identified in the literature review that used event scale hydrologic characteristics and a long term database of aquatic biodiversity variables. Chapter 6 describes Phase 3 of the research to empirically examine associations of fish richness with event-scale hydrologic characteristics, specifically pertaining to event flows, event accelerations and stream power.

\subsubsection{Temporal Scales in Hydrologic Research on Ecological Variables}

The hydrological variables used in studies to examine Relationship 3 have evolved over time. In the 1970's and 1980's, research predominantly examined annual average flows, daily mean flows and/or flood frequency (Olden and Poff, 2003). More recently, suites of hydrologic indices have been used to "explain a dominant proportion of statistical variation in the complete set of hydrologic indices" (Olden and Poff, 2003, p.101). A suite of over 170 indices was grouped into nine sub-categories organized around magnitude, frequency, duration, timing and rate of change (see Olden and Poff, 2003). The importance of different indices varies with stream type but such indices include: variations of daily and monthly flows; annual average and maximum flows at critical times of year; and, variability in annual high peak flows (Olden and Poff, 2003). One of the most consistently important indices was skewness in daily flow (Olden and Poff, 2003). No mention of event-based analyses was made in the survey of hydrologic indices 
and, more specifically, there was no mention of event-based peak flow analysis or recurrence or frequency of event-based peak flows.

In a 2010 literature review of 165 papers reporting on aquatic or riparian responses to flow regime change, a sub-set of 55 papers examined flow magnitude alteration, primarily as a result of dams and impoundments (Poff and Zimmerman, 2010). Of these studies, a small number reported on flow magnitude change within a temporal scale of hours or less than one day (Poff and Zimmerman, 2010), but these flow changes were primarily a result of dam operations not precipitation events (Poff and Zimmerman, Supplementary materials, 2010). As part of a recommended framework for developing regional environmental flows, daily stream flow was identified as the "appropriate temporal resolution for understanding most ecological responses to flow alteration." (Poff et al., 2010, p.153). Again, these more recent papers did not address temporal scales for precipitation event-based flow regimes.

In a study to predict fish assemblages from hydrologic regimes, Mims and Olden (2012) applied six hydrologic indicators:

1) Annual coefficient of variation, a function of standard deviation of daily flows and mean annual flow;

2) High pulse count, the number of high pulses in a water year;

3) Base flow index, derived from the 7 day minimum flow and mean flow in the year;

4) Flow predictability, a function of temporal invariance and periodicity; 
5) The ratio of temporal invariance (called constancy) to flow predictability; and,

6) High pulse duration, the median duration of high pulses.

The indices pertaining to pulse count were consistent with event-scale analysis, although they were not presented within an event-based context. Specifically, the number of high pulses per year were estimated using daily flow data (Mims and Olden, 2012).

Studies of ecologically relevant hydrologic variables for Canada included estimates for various flow averages, maxima, minima, timing, duration, etc. (Monk et al., 2011, Appendix A). An assessment of relevant hydrological variables in a north-western Canadian watershed identified 13 ecologically relevant hydrograph indices (Monk et al., 2012). These indices included 1-day and 90-day minima and maxima, timing of 1-day minimum and maximum and number of hydrograph reversals. No studies to identify ecologically relevant hydrologic variables using high-temporal resolution event-based data were identified for Canada. As indicated in 2.2.3 above, Tetzlaff et al. (2005a) reported on flow acceleration with inconclusive results. 


\section{Chapter: Study Location, Design Rationale and Data Sources}

\subsection{Introduction}

This chapter provides information on the approach to the research and data sources.

Detailed methodologies for each phase of research are provided in each relevant chapter.

\subsection{Rationale for the Geographic Location}

The Toronto Region of the Great Lakes St Lawrence (GLSL) Basin was selected as the geographic research location for several reasons:

1. The region has undergone dramatic urbanization over several decades.

2. High-resolution hydrologic data and rainfall data were available from Environment Canada (EC) for numerous watersheds within the region.

3. It was anticipated that records of historic urban land use would be available.

4. It was also anticipated that historic records of aquatic biota would be available.

5. The region lies within the GLSL, which contains watersheds on scales from ephemeral headwaters to a continental scale river with an ocean confluence.

River systems within the Greater Toronto Region analyzed include (west to east): Credit, Etobicoke, Mimico, Humber, Highland, Don, Rouge, Duffins. Also included due to available urban extent estimates (Thompson, 2013) were: Laurel Creek (near Waterloo, Ontario); Red Hill (Hamilton, Ontario); and, Harmony Creek (east of Oshawa, under jurisdiction of the Central Lake Ontario Conservation Authority). 


\subsection{Rationale for Seasonal Focus}

Statistical models for flow characteristics were developed for the period May $26^{\text {th }}$ to November $15^{\text {th }}$. This period was selected because:

1. Data for snowmelt were not available and snow pack and snowfall data were not as readily available as rainfall data so reliable estimates of snowmelt runoff were not possible

2. Flow indicators associated with biotic community health pertain to flow characteristics during rainfall seasons rather than winter or spring freshet

3. This season excludes freshet and its associated flow variability. Reduced statistical variation in flows would make detection of trends associated with urbanization easier to detect.

\subsection{Rationale for Urban Land Use}

Impervious cover and urban percent are used interchangeably in the literature. Urban extent was selected as a land use measure instead of percent impervious because: 1) it could be consistently applied across photo records at varying scales and by different research assistants; and 2) other relevant data sources (specifically Thompson, 2013; Thompson pers. comm., 2013; and, Credit Valley Conservation Authority pers. comm., 2013) had urban extent information that would supplement data developed under this project.

\subsection{Rationale for Focus on Rising Limb Event Flows}

Hydrologic analyses included total flow (normalized for watershed area, called total runoff), runoff coefficient and event flows. Event flow analyses focused on the rising 
limb of rain events because it is during this interval that aquatic biota need to shelter (Tetzlaff et al., 2005c), adjust or otherwise sustain themselves as the effects of a storm move through a watershed. The rising limb, until peak event flow, is also the period of highest energy impulse resulting from rain events and thus relevant to understanding both direct and indirect alterations to habitat features of the physical stream channel (substrate stability, for example). Additional information on hydrologic data analyses is provided in Chapters 4, 5 and 6.

\subsection{Data Sources}

Historic data records provided the foundation for this research. Numerous individuals and organizations contributed to identification and development of data sources and the database (Table 3-1).

The most complete long-term hydrological datasets were available from EC (working in collaboration with the provincial governments) (J. Duncan ${ }^{1}$, pers. comm., 2011). Highresolution hydrologic data, called 'instantaneous' by EC, were obtained for years 1969 to 2010 inclusive. Precipitation data, including rainfall in hourly time increments, were acquired from EC's Meteorological Service Canada (MSC). Precipitation and hydrologic data were acquired with the assistance of the Carleton University Library and research funding from Dr. Murray Richardson. Raw data files are deposited with Carleton University's library. The number of years available varied among hydrologic stations and rain gauges between 1969 and 2010.

\footnotetext{
${ }^{1}$ Water Resources Data Management Analyst, TRCA
} 
Table 3-1 Overview of data sources

\begin{tabular}{|c|c|c|}
\hline Data & Source(s) & Acknowledgments \\
\hline Rainfall & $\begin{array}{l}\text { Meteorological Service of Canada } \\
\text { (MSC), EC }\end{array}$ & $\begin{array}{l}\text { Climate Services Staff (EC) } \\
\text { Joel Rivard, (Carleton } \\
\text { University (CU) Library) }\end{array}$ \\
\hline $\begin{array}{l}\text { Hydrologic } \\
\text { data }\end{array}$ & Water Survey Division, MSC, EC & $\begin{array}{l}\text { Tom Arsenault (EC) } \\
\text { Joel Rivard (CU Library) }\end{array}$ \\
\hline $\begin{array}{l}\text { Event flow } \\
\text { separation }\end{array}$ & Hysep program in $\mathrm{R}$ code & Murray Richardson (CU) \\
\hline \multirow[t]{6}{*}{$\begin{array}{l}\text { Urban land } \\
\text { use }\end{array}$} & $\begin{array}{l}\text { CVCA ArcGIS shapefiles: Credit } \\
\text { watershed land use, } 1999,2003 / 2004 \text {, } \\
2005,2007,2009,2011\end{array}$ & $\begin{array}{l}\text { Adrienne Ockenden (Credit } \\
\text { Valley Conservation Authority } \\
\text { (CVCA)) }\end{array}$ \\
\hline & $\begin{array}{l}\text { 1) Peter Thompson ArcGIS shapefiles: } \\
\text { Don watershed }\end{array}$ & Peter Thompson \\
\hline & 2) Thompson, 2013, published data & \\
\hline & $\begin{array}{l}\text { Natural Resources Canada (NRCan) } \\
\text { aerial photos (see Chapter 5) }\end{array}$ & $\begin{array}{l}\text { Florin Savopol (NRCan) } \\
\text { Gord Argo (NRCan) }\end{array}$ \\
\hline & $\begin{array}{l}\text { Delineated urban areas through } \\
\text { digitization of NRCan photos, with } \\
\text { financial contribution agreement } \\
\text { between Toronto and Region } \\
\text { Conservation Authority (TRCA) and } \\
\text { Carleton University }\end{array}$ & $\begin{array}{l}\text { Dan Clayton (TRCA) } \\
\text { Doug King (CU) } \\
\text { Murray Richardson (CU) } \\
\text { Scott Page, GIS Specialist } \\
\text { Kent Jacobs, GIS Specialist } \\
\text { Junchi Li, GIS Specialist } \\
\text { Nahom Seyoum, Photo } \\
\text { Georeferencing }\end{array}$ \\
\hline & $\begin{array}{l}\text { Calculation of urban land use upstream } \\
\text { of each fish monitoring location }\end{array}$ & $\begin{array}{l}\text { Lindsay Faye Armstrong, GIS } \\
\text { Specialist }\end{array}$ \\
\hline \multirow{2}{*}{$\begin{array}{l}\text { Watershed } \\
\text { delineation }\end{array}$} & CVCA shapefiles & Adrienne Ockenden (CVCA) \\
\hline & $\begin{array}{l}\text { Delineated in ArcGIS with Ontario } \\
\text { Government Data (see Chapter 5, } \\
\text { methodology) }\end{array}$ & Rachel Plewes, GIS specialist \\
\hline $\begin{array}{l}\text { Basin and } \\
\text { channel slope } \\
\text { for watershed } \\
\text { basins } \\
\text { upstream of } \\
\text { hydrologic } \\
\text { stations and } \\
\text { fish sampling } \\
\text { sites }\end{array}$ & $\begin{array}{l}\text { Calculated in ArcGIS with Ontario } \\
\text { Government Data (See Chapter } 5 \text {, } \\
\text { methodology) }\end{array}$ & Rachel Plewes, GIS specialist \\
\hline $\begin{array}{l}\text { Stream length } \\
\text { by Strahler } \\
\text { stream order }\end{array}$ & $\begin{array}{l}\text { Calculated in ArcGIS with Ontario } \\
\text { Government Data upstream of each } \\
\text { fish monitoring location }\end{array}$ & Rachel Plewes, GIS specialist \\
\hline
\end{tabular}




\begin{tabular}{|c|c|c|}
\hline $\begin{array}{l}\text { Baseflow } \\
\text { Index }\end{array}$ & $\begin{array}{l}\text { 1) J. Buttle, pers. comm., } 2015 \\
\text { 2) USGS published data (G Model, } \\
\text { HYSEP1 Method, Neff et al., 2005) }\end{array}$ & Dr. James Buttle \\
\hline $\begin{array}{l}\text { River } \\
\text { regulation } \\
\text { type }\end{array}$ & $\begin{array}{l}\text { Water Survey Division website } \\
\text { (wateroffice.ec.gc.ca), MSC, EC }\end{array}$ & \\
\hline \multirow[t]{5}{*}{ Fish data } & $\begin{array}{l}\text { Database compiled by Dr. Gordon } \\
\text { Wichert for his } \mathrm{PhD} \text { research (Lotus } \\
123 \text { format) }\end{array}$ & Dr. Gord Wichert \\
\hline & $\begin{array}{l}\text { Ontario's Flowing Water Information } \\
\text { System (FWIS), through agreement } \\
\text { with TRCA and CVCA }\end{array}$ & $\begin{array}{l}\text { J. Duncan, TRCA } \\
\text { Jon Clayton, CVCA } \\
\text { Les Stanfield, Ontario } \\
\text { Ministry of Natural Resources } \\
\text { (OMNR) }\end{array}$ \\
\hline & $\begin{array}{l}\text { Royal Ontario Museum (ROM) Fish } \\
\text { database }\end{array}$ & Dr. Earling Holm, ROM \\
\hline & $\begin{array}{l}\text { Published sources including Martin- } \\
\text { Downs (1988), Steedman (1987), } \\
\text { Wichert (1995) }\end{array}$ & $\begin{array}{l}\text { Deborah Martin-Downs } \\
\text { (CVCA) }\end{array}$ \\
\hline & $\begin{array}{l}\text { Government of Ontario Reports } \\
\text { including Wainio and Hester (1973), } \\
\text { Johnson and Owen (1966), Wainio } \\
\text { (1959), Ontario Department of } \\
\text { Planning and Development (OPDP) } \\
\text { (1956) }\end{array}$ & Library staff, OMNR \\
\hline $\begin{array}{l}\text { Ontario Fish } \\
\text { Attributes }\end{array}$ & $\begin{array}{l}\text { Database of fish tolerances, habitats, } \\
\text { food sources, etc.; database compiled } \\
\text { by R.Eakins provided as a flat file } \\
\text { (R.Eakins, pers.comm., 2013) }\end{array}$ & $\begin{array}{l}\text { Rob Eakins, } \\
\text { Ontario Freshwater Fishes Life } \\
\text { History Database }\end{array}$ \\
\hline
\end{tabular}


Hydrologic stations selected had at least 5 consecutive years of data within watersheds with at least one urban extent estimate. A complete hydrologic-rainfall dataset by year comprised 16,708 records (May $26^{\text {th }}$ to November $15^{\text {th }}$ inclusive); Appendix A, Number of Flow-Rainfall Record Pairs, provides the actual number of records available by year and watershed. Event flows were separated using custom R script (M. Richardson) as described in Chapter 5; Appendix B, Summary of event records removed in data cleaning, provides a record of the number of events removed from the database due to event duration.

One of the most significant challenges for this research was acquisition of sufficient data for urban extent on a watershed basis in the study area. The CVCA, Peter Thompson and Peter Thompson's Master's Thesis (2013) provided about $40 \%$ of the urban extent estimates (Table 3-1). Credit watershed land use estimates were obtained through a data sharing agreement with the CVCA. In-house estimates for other watersheds were developed by digitizing urban areas of historic aerial photographs purchased from NRCan. Several potential sources for historical aerial photographs were explored, including municipal sources and university library archives. Municipal organizations' records did not provide watershed scale coverage and university archives did not provide sufficient consistent coverage. The NRCan photo library offered the best selection of historic aerial photos although even these generally provided very infrequent coverage on a watershed basis. Upon request, NRCan provided an Excel database of all available aerial photos dating between 1969 and approximately 1990 (when aerial photos were no longer collected) within the geographic study area. Photo corner coordinates were located 
spatially using ArcGIS software to identify years with adequate coverage on a watershed basis. Years for urban extent were selected on the basis of adequate spatial coverage of the full watershed. Photos were purchased through research funds provided by Dr. Richardson and Dr. King. Photos had not previously been scanned by NRCan, which increased cost of acquisition. Upon acquisition, the photos had no consistent spatial orientation, so geo-referencing was time consuming. Georeferencing and digitization of urban extent were undertaken by research assistants funded through agreement with the TRCA and Dr. Richardson's and Dr. King's NSERC research funds. Methodologies are described in Chapter 5. Appendix C, Illustrations of urban area delineation by watershed and year, provides images of the aerial photo coverage and urban extent by watershed and year developed by GIS analysts for this research. Urban extent datasets by watershed were delivered to TRCA. A second dataset is housed on a Carleton University Department of Geography and Environmental Studies (DGES) computer.

Biological data acquisition was also problematic in terms of both data consistency and availability. The original study design assumed benthic invertebrate data would be available. However, benthic data prior to about 1999 is stored on field sheets "in boxes" (R. Holm ${ }^{2}$ pers. comm., 2012). More recent benthic data housed in the Ontario Benthos Biomonitoring Network ${ }^{3}$ (OBBN) were available through agreement with TRCA and CVCA but had limited temporal scale (i.e. available subsequent to 2000).

As indicated by Wainio and Hester (1973), historic fish surveys in the Humber watershed

\footnotetext{
${ }^{2}$ Royal Ontario Museum

${ }^{3}$ A password protected system, with accessible main page at URL: http://desc.ca/programs/OBBN.
} 
varied in both their range and intensity of effort. This variability in fish surveys for watersheds throughout the region also extended to equipment and sampling protocols (D. Martin-Downs ${ }^{4}$, pers. comm., 2013), research objectives (H. Regier ${ }^{5}$, pers.comm., 2015), site numbering and location (L. Stanfield ${ }^{6}$, pers.comm., 2012) until 1999, with the adoption of the Ontario Stream Assessment Protocol (OSAP) (Stanfield, 2013) by Ontario and Conservation Authorities. OSAP focuses on wadable streams.

The primary source for historic fish data was a database compiled by Dr. Gordon Wichert in 1993 for his $\mathrm{PhD}$ research. This database digitized survey results from ODPD (1954/55), Steedman (1987), Wichert (1995) and others. Historic data were also obtained from the ROM. Data gaps were filled by accessing original reports. Recent fish data (post 1998) in the Ontario $\mathrm{FWIS}^{7}$ were accessed through data sharing agreements with TRCA and CVCA. Duplicate records, primarily resulting from ROM records, were identified and eliminated. Extensive data cleaning was required to reconcile site locations and to identify proximal sites for comparison through multiple years. Misleading data were eliminated, specifically ROM data pre-1940's which recorded only one or two species' presence (reflecting survey objectives to identify specific species, such as eels). Despite best efforts, the database is inherently biased, as described in Chapter 6. Also as indicated in that chapter, only fish species presence-absence could be analyzed.

\subsection{Data Reliability and Assessment of Error}

\footnotetext{
${ }^{4}$ Director, Ecology TRCA

${ }^{5}$ Formerly of the University of Toronto; ODPD survey team member in 1954 and 1955

${ }^{6}$ Ontario Ministry of Natural Resources, retired

${ }^{7}$ A password protected system, with accessible main page at URL: http://www.comap.ca/fwis/
} 
Sources of measurement error are discussed in respective chapters describing analyses, including:

- Precipitation and flow gauge operation and measurement accuracy (Chapter 4)

- Judgement required by Geographic Information System (GIS) technicians when delineating urban areas and catchments (Chapter 5)

- Use of temporal trends to assess feasibility of urban extent estimates (Chapter 5)

- Baseflow index (BFI) uncertainty (Chapter 5)

- Bias in the fish database (Chapter 6)

- Photo georeferencing in rural areas (Appendix D)

- Additional potential factors contributing to decline in fish richness within urban areas (Appendix R).

\subsection{Analytical Software}

Software tools used for the analyses included: the open source statistical package, R; the geographic information system (ArcGIS) ESRI software; and, the Microsoft suite of programs. Lotus 123 was used to access an historic fish data set.

Programming for hydrological statistical analysis was custom developed in R by the author, in some cases using referenced $\mathrm{R}$ packages for time series and hydrologic analyses. Custom HYSEP event separation R script was written by Dr. Murray Richardson. Off-the-shelf packages for hydrologic analyses were investigated but were found to be designed for coarser time intervals and/or were not open-source. 


\section{Chapter: Change in Event-Scale Hydrologic Response in Two Urbanizing Watersheds of the Great Lakes Basin 1969-2010}

Material from this chapter should be cited as:

Trudeau, M.P., Richardson, M. Change in event-scale hydrologic response in two urbanizing watersheds of the Great Lakes St Lawrence Basin 1969-2010. J.

Hydrol. (2015), http://dx.doi.org/10.1016/j.jhydrol.2015.04.031

doi:10.1016/j.jhydrol.2015.05.011

\section{Key Words}

Urban hydrology; event-scale flows; high temporal resolution; flow acceleration; flow regimes; hydrologic stationarity

\subsection{Introduction ${ }^{8}$}

Land use change, at multiple scales of watershed size, is associated with changes in hydrology (e.g. Costa et al., 2003; Siriwardena et al., 2006; Schueler et al., 2009; Muma et al., 2011). Typical flow regime changes due to urbanization include increases in peak discharge (Hundecha and Bárdossy, 2004), increased high-flow frequency, altered distribution of water between storm flow and base flow, increased daily flow variability (Konrad and Booth, 2005; Tetzlaff et al., 2005a) as well as increased duration of

\footnotetext{
${ }^{8}$ Abbreviations: Organizations: Meteorological Service of Canada (MSC); Water Survey of Canada (WSC); Toronto and Region Conservation Authority (TRCA). Analytical: 80\% of rising limb event (80RLE) flows. Statistical: Akaike's Information Criterion with correction for finite sample sizes (AICc); Confidence Interval (CI); degrees of freedom (df); likelihood ratio chi-square (LR chi-square); linear mixed effects (LME); Other: no date (n.d.).
} 
sediment transporting events (Booth and Jackson, 1997). The cumulative effects of land use change on increased risks of flood or other consequences to physical infrastructure are well recognized (e.g. Gilroy and McCuen, 2012; Suriya and Mudgal, 2012; Du et al., 2012). However, flow disturbance and natural flow fluctuations are also important variables in structuring biotic communities in aquatic ecosystems (Bunn and Arthington, 2002; Poff and Ward, 1989, Flecker and Feifarek, 1994). General associations of aquatic biodiversity decline with increased impervious cover have been identified for some time (Klein, 1979; Schueler, 1994; Paul and Meyer, 2001; Löfvenhaft et al., 2004; Stanfield et al., 2006; Stanfield and Kilgour, 2006; Schueler et al., 2009), but the causal mechanisms for the effect of flow regime change on biota are not well understood (Armanini et al., 2011). Studies of ecological flow regime indices, including magnitude, frequency, timing, duration and rate of change in flow conditions (e.g. Poff et al., 2006, Richter et al., 1996), are typically undertaken using daily and monthly flow records (e.g. Monk et al., 2012; Clausen and Biggs, 1997). At this temporal resolution, flow assessments cannot adequately characterize flow dynamics responding to rain events. The topic of trends in streamflow perturbations at fine timescale resolution (i.e. in response to rain events) has received relatively little attention due to the general lack of suitable long term flow records.

This descriptive, empirical study examines trends in total flow and rain event-scale hydrologic responses in two urbanizing watersheds in the Greater Toronto Region, Ontario, Canada, over a 42 year period, using Environment Canada's (EC) fifteen-minute interval flow records (Arsenault and Thompson, 2010). The rapid increase in flow 
resulting from rainfall events (called the rising limb of event flows) is examined because it is the interval during which aquatic biota need to shelter (Tetzlaff et al., 2005c), adjust or otherwise sustain themselves as the effects of a storm move through a watershed. The rising limb, until peak event flow, is also the period of highest energy impulse resulting from rain events and thus relevant to understanding both direct and indirect alterations to habitat features of the physical stream channel (substrate stability, for example).

We focus our analysis on the annual time period between May $26^{\text {th }}$ to November $15^{\text {th }}$ to exclude freshet variability and complications arising from lack of snowmelt records, and to include seasons with rainfall-dominated precipitation. Specifically, for the Don and Humber watersheds, we assess flow regime changes not attributable to changes in rainfall, including (1) total flow volume; (2) rain event rising limb flows; and (3) rain event rising limb flow accelerations (Tetzlaff et al., 2005b) of the mainstem rivers near their confluences with Lake Ontario. The study includes an analysis of rainfall records for the same period. We also discuss the observed flow regime changes in light of their potential for cumulative effects assessment in urbanizing watersheds.

Although hydrologic response varies considerably among watersheds (Jacobson, 2011), previously documented magnitude of responses associated with urbanization include a 24 fold increase in peak discharge and runoff volumes (Chin, 2006). This study provides a new understanding of the changes in magnitude of event rising limb flows, changes in the magnitude of acceleration of event flows and changes in variability of peak discharges over four decades of increased watershed urbanization. 


\subsection{Methods}

\subsubsection{Data Sources and Study site}

We used hydrometric records from EC's Water Survey of Canada (WSC) 15 minute stream flow data, called the "instantaneous hydrometric dataset" by EC. Rainfall data were supplied by EC's Meteorological Service of Canada (MSC) in the Daily Record of Hourly Data (HLY) format. ArcGIS shapefiles for the watersheds were developed using data sets from the Government of Ontario, Integrated Hydrology Data Part 2, including: enhanced flow direction grid; stream grid; and, enforced DEM from Ontario (Government of Ontario, 2013).

The Don and Humber watersheds in Toronto, Canada were selected for analysis because: (a) both flow and rainfall data were available over a continuous 40-plus year period; (b) they are both known to have experienced substantial increases in urbanization during the period of record; and, (c) both were anticipated to have additional ancillary datasets on historical land cover changes and species presence/absence data that can be used in subsequent research. Population in the Toronto Metropolitan Area has grown from 1,919,000 in 1961 to 3,893,000 in 1991 (Demographia, n.d.) to 5,583,064 in 2011 (Statistics Canada, 2014). The population density per square kilometer in 2011 was 945.4 (Statistics Canada, 2014).

Daily average air temperatures in Toronto range from $-3.7^{\circ} \mathrm{C}$ in January to $22.3^{\circ} \mathrm{C}$ in July (Government of Canada, 2014). Average precipitation is $831 \mathrm{~mm} / \mathrm{year}$, with rain 
occurring in all months and snowfall in winter months (November to April, inclusive) (Government of Canada, 2014). The average frost free period is 203 days, typically occurring from April 13 to November 3 (Government of Canada, 2014).

Selected hydrometric stations were those closest to the confluence with Lake Ontario so that flow changes reflect an integrated response of the watershed from headwaters to confluence over time. The Don River hydrological gauging station (WSC 02HC024) and the Humber River hydrological gauging station (WSC 02HC003) have continuous flow records from 1969 to 2010 . The Don watershed at hydrological station WSC $02 \mathrm{HC} 024$ is $311 \mathrm{~km}^{2}$, with an average channel slope of $0.004 \mathrm{~m} \mathrm{~m}^{-1}$ and overall average basin slope of $0.034 \mathrm{~m} \mathrm{~m}^{-1}$. The Humber watershed at hydrological station WSC $02 \mathrm{HC} 003$ is $806 \mathrm{~km}^{2}$, with an average channel slope of $0.003 \mathrm{~m} \mathrm{~m}^{-1}$ and overall average basin slope of $0.041 \mathrm{~m}$ $\mathrm{m}^{-1}$. Only one rain gauge in close proximity to the hydrologic gauging stations had a period of record matching the hydrologic years of record. Rain gauge MSC $6158350 / 6158355$ has rainfall records dating from the 1930's to 2012. The rain gauge equipment changed within the record, at which time a different site number was assigned to the gauge, but the station's location did not change. Illustration 4-1 indicates the locations of hydrological gauging stations and the rain station used in the empirical statistical flow models.

For the rainfall analyses, data from sixteen rain gauges, including MSC6158350/ 6158355, were analyzed. 


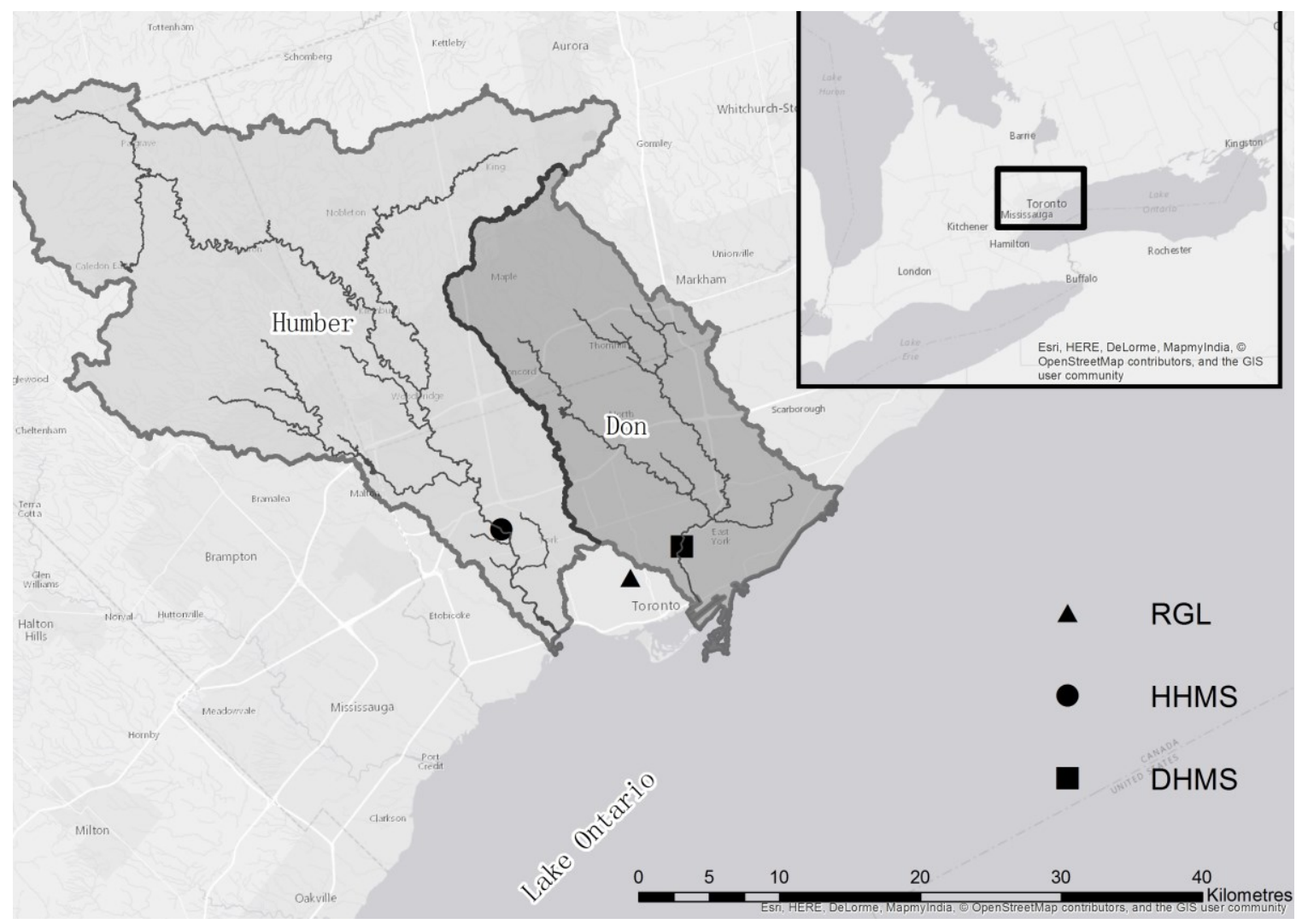

Illustration 4-1 Study area

The Don $\left(311 \mathrm{~km}^{2}\right)$ and Humber $\left(806 \mathrm{~km}^{2}\right)$ watersheds, with locations of the hydrometric stations and rain gauge (HHMS - Humber hydrologic metering station; DHMS - Don hydrologic metering station; RGL - Rain gauge location). The City of Toronto is among the largest cities in North America by population and is situated in a region experiencing dramatic increases in urban land cover over the past four decades. 
Table 4-1 identifies gauges with available data used in the rainfall analysis, and Illustration 4-2 identifies rain gauge locations relative to the Don and Humber catchments. The temporal coverage by rain gauges is very uneven, with only three gauges having records post-1995. All available records within either of the catchments terminate by 1988 . All gauges within 20 kilometers of the catchments and with more than 25 years of rainfall record are near the shore of Lake Ontario and located outside the catchments. Snowfall records for station MSC6158350/ 6158355 were examined for accumulated daily "Total Snowfall” and maximum daily "Snow on the Ground” (Daily Climatological Data, Elements 011 and 013, respectively, Government of Canada, 2013). Snowfall records were only available up to March 2009 for Element 011 and December 2006 for Element 013 for this station. 
Table 4-1 Rain gauges.

Summary of rain gauges within and proximal to the two urban catchments studied and number of years of rainfall data available from each gauge within the period of hydrologic record (1969-2010).

\begin{tabular}{|c|c|c|c|c|c|}
\hline $\begin{array}{l}\text { Rain } \\
\text { Gauge } \\
\text { MSC } \\
\text { Station } \\
\text { Number }\end{array}$ & $\begin{array}{l}\text { Latitude } \\
\text { (decimal } \\
\text { degrees N) }\end{array}$ & $\begin{array}{l}\text { Longitude } \\
\text { (decimal } \\
\text { degrees W) }\end{array}$ & $\begin{array}{l}\text { Time Span } \\
\text { of Available } \\
\text { Records }\end{array}$ & $\begin{array}{l}\text { Number of } \\
\text { years with } \\
\text { records } \\
\text { between } \\
\text { 1969-2010 }\end{array}$ & $\begin{array}{l}\text { Relative } \\
\text { Position in } \\
\text { Study Area }\end{array}$ \\
\hline \multicolumn{6}{|c|}{$\begin{array}{c}\text { Group 1: Stations outside the catchments, but within } 15 \mathrm{~km} \text { of the catchments, with more } \\
\text { than } 20 \text { years of record }\end{array}$} \\
\hline 6158350 & 43.6667 & -79.4000 & $1937-2012$ & 42 & Near Lake \\
\hline 6158733 & 43.67722 & -79.6306 & $1960-2007$ & 37 & Mid-region \\
\hline 6158520 & 43.7667 & -79.2667 & 1966-1995 & 25 & Near Lake \\
\hline 6158665 & 43.62861 & -79.395 & 1971-1994 & 24 & Near Lake \\
\hline 6158764 & 43.6500 & -79.4667 & 1966-1990 & 21 & Near Lake \\
\hline \multicolumn{6}{|c|}{ Group 2: All available stations within the Humber catchment } \\
\hline 6158740 & 43.800 & -79.5500 & $1965-1987$ & 18 & Mid-region \\
\hline 6150825 & 43.88333 & -79.7333 & 1978-1988 & 8 & Upper reaches \\
\hline 6150100 & 43.93333 & -79.8333 & $1960-1971$ & 2 & Upper reaches \\
\hline 6159510 & 43.9500 & -79.4333 & $1960-1970$ & 2 & Upper reaches \\
\hline \multicolumn{6}{|c|}{ Group 3: All available stations within the Don catchment } \\
\hline 6158718 & 43.76667 & -79.4833 & $1973-1986$ & 13 & Mid-region \\
\hline 6158385 & 43.71667 & -79.3167 & 1973-1984 & 11 & Near Lake \\
\hline 6154950 & 43.86667 & -79.4833 & 1960-1975 & 6 & Upper reaches \\
\hline 6158732 & 43.71667 & -79.3500 & $1985-1986$ & 2 & Near Lake \\
\hline \multicolumn{6}{|c|}{ Group 4: Other stations within $10 \mathrm{~km}$ of catchment that extend post 1987} \\
\hline 6158406 & 43.6500 & -79.3500 & 1980-1993 & 14 & Near Lake \\
\hline 6155790 & 43.91835 & -80.0864 & $1992-2007$ & 10 & Upper reaches \\
\hline 6157015 & 43.9000 & -79.4000 & 1989-1991 & 3 & Upper reaches \\
\hline
\end{tabular}




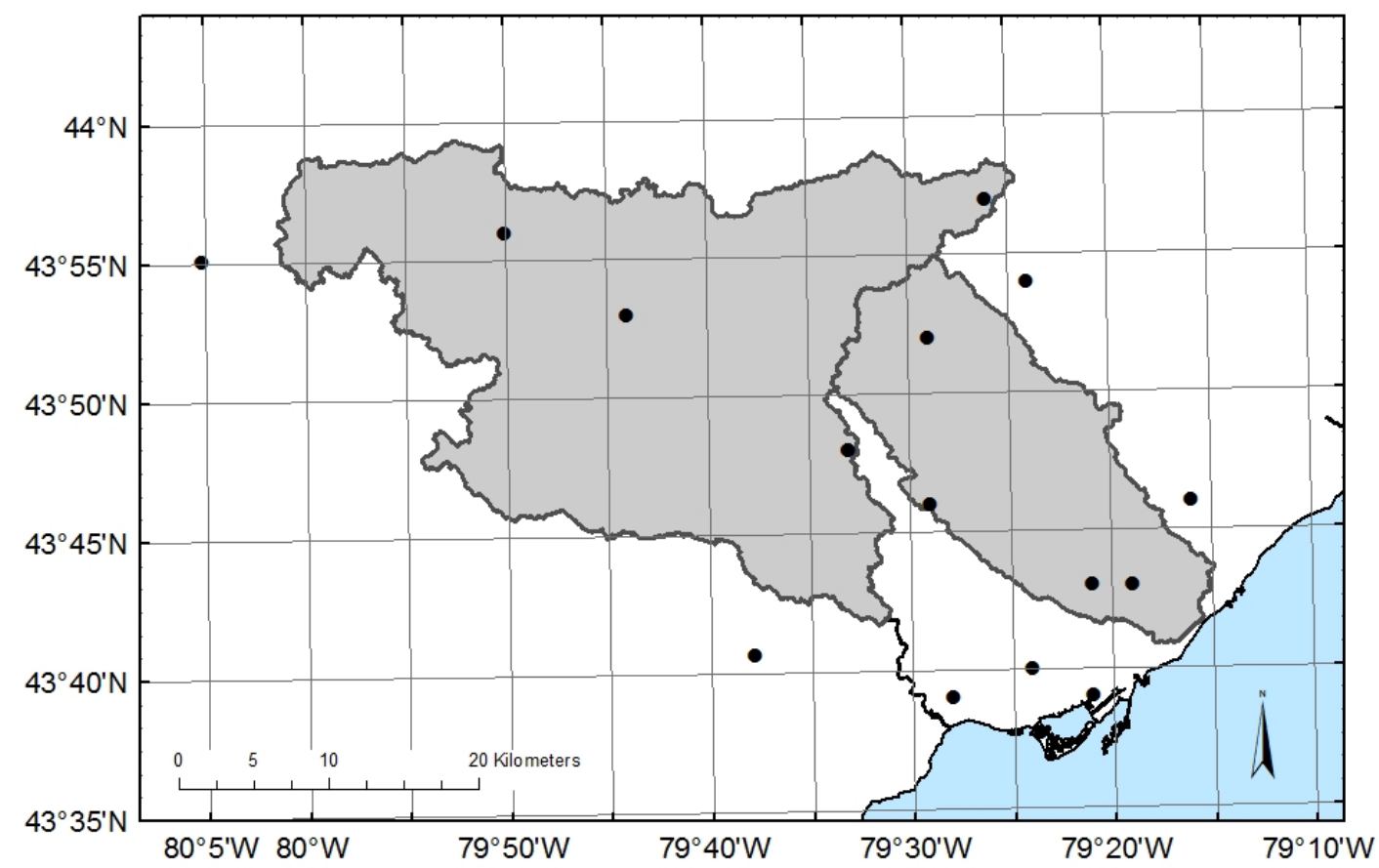

Illustration 4-2 Map of rain gauge locations

Locations of 16 rain gauges with available records within proximity of the two catchments studied.

Sixteen rain gauges were analyzed. Refer to Table 4.1 for information on the gauges. 
Several potential sources of historical urbanization within the study area were investigated. The method by Thompson (2013), who estimated urban extent for five years $(1955,1970,1978,1995,2005)$, was found to be the most detailed and comprehensive. Of these five years, four fall within the available high-resolution hydrologic record for the Don watershed.

The study scope is an analysis of hydrologic trends in two urbanizing watersheds in relation to time and urban extent. Stable watershed characteristics, such as soils and slope, are constants and were therefore not included as independent variables in this analysis.

\subsubsection{Data preparation}

R (R Core Team, 2012) was used both to read raw data files and fit statistical models. ArcGIS was used for: hydrologic station selection in closest proximity to confluence with the lake; estimation of rain gauge site proximity to selected hydrologic stations and rain gauge selection. Data were received from EC in raw text and .csv formats for hydrologic and rainfall stations.

Rainfall records from station MSC6158350/6158355 and hydrologic records for each watershed were matched on a time basis to create a merged rain-flow database for each watershed. Where rainfall or hydrologic records were missing, records for that 15-minute time interval were removed. 
In our original study design, it was anticipated that rainfall records could assist in identifying storm event flows. However, there are no long-term rainfall records within the catchments upstream of the hydrologic stations. Only one proximal rain gauge, in the vicinity of downtown Toronto, had a suitable continuous record to match the years of hydrologic data.

A subset of the data for each year was extracted for the period May $26^{\text {th }}$ to November $15^{\text {th }}$ inclusive. All flow analyses in this report were undertaken using this subset of data. Total rainfall used for flow analyses is the total rainfall calculated using this data subset. Event flows during the period of interest were isolated from baseflow using a customized R script based on the Hydrograph Separation Program (HYSEP) (USGS, 1996). For each discrete flow event, the rising limb was isolated from the falling limb and subsequently analyzed in further detail; the peak flow for each event was included as part of the rising limb flows. Event flow acceleration was calculated as the change in flow rate from one 15 minute interval to the next during rising limb event flows (in units of $\mathrm{m}^{3} \mathrm{~s}^{-2}$ ). Flows can fluctuate during rain events; acceleration analyses included only positive acceleration intervals in the rising limb. An instantaneous flow acceleration-to-peak was also calculated as the change in flow rate between each flow record during the rising limb and the event peak flow rate, divided by the intervening time (for units in $\mathrm{m}^{3} \mathrm{~s}^{-2}$ ); accelerationto-peak was not used in statistical analyses. All references to event flows and event flow accelerations in this report pertain to the rising limb only. 
Only available records with both rainfall and flow measurements were used in the database. Some years within this database are missing records. However, of 84 years (42 years each for the Don and Humber), 74 years have $80 \%$ to $100 \%$ of the full 16,708 potential precipitation-hydrology pairs of observations; the highest percentage of missing records is $48 \%$ (1973). Years with relatively higher rates of missing records were not used in flow comparisons of earlier with later years.

For coarser time scale analyses of trends, we grouped data into four decadal intervals: the 1970's (1969-1979), 1980's (1980-1989), 1990's (1990-1999) and 2000's (2000-2010). Thus, the 1970's and 2000's have one more year each than the 1980's and 1990's. These time increments were based on conventional decadal increments, except for the additional year at the two temporal extremes of the database.

To analyze long-term trends in rainfall, available records between May 26 and November 15 for years 1969 to 2010 from 16 rain gauge stations were compiled. Years with fewer than $35 \%$ of potential rainfall hours were not included in seasonal trend analyses although individual rainfall events during those years were retained for rain event trend analyses. No rain records outside the timeframe of the hydrologic record (i.e. 1969 to 2010) were analyzed. Rain events were defined as events with at least one period of an hour duration during which at least $5 \mathrm{~mm}$ of rain was recorded. Individual rain events comprise any consecutive rainfall records before and after the record exceeding $5 \mathrm{~mm}$ with no more than one hour break in rainfall. This rain event definition reflects the hourly resolution of the dataset and differs from daily or monthly definitions of rain events using 
coarser time intervals (e.g. Karl and Knight, 1998; Brunetti et al., 2000; Cannarozzo et al., 2006). The original EC rainfall data file for station MSC6158350/ 6158355 was used in the database, rather than the rainfall file matched to hydrologic records, so no rain event would be eliminated due to missing hydrologic records. Other database fields included total hours of record for each station by year (including periods with zero rainfall). To test for potential trends in annual snowpack accumulation that could indirectly influence hydrologic conditions in the study season, total daily accumulated snowfall (cm) from October to April was calculated for MSC6158350/ 6158355 for years 1968/69 to 2008/09 inclusive. Maximum daily snow on the ground was identified for each month from January to May for 1969 to 2006.

Percent urban area in the Don watershed was estimated for each year of record using the available data on urban extent. A conservative approach was used in which the estimated urban area from Thompson (2013) for each available year of record (4 in total) was applied to that year and all subsequent years until the next estimation (i.e. the last observation was carried forward). For example, the estimated urban extent in 1970 was assigned to 1970 through 1977; 1978 was assigned to 1978 through 1994. An exception was made for urban extent in 1969 , which was estimated to be equal to the urban area in 1970 rather than based on the urban area in 1955. Extrapolation of values was avoided because land development does not necessarily progress in a simple linear manner.

\subsubsection{Statistical analyses}

Statistical analyses were undertaken to assess trends with year in (1) rainfall; (2) total 
flow; (3) event flows; and (4) event flow accelerations. The best model fit to predict total flow with independent variables year and total rainfall was tested substituting urban cover for year in the Don watershed. Rainfall was used as an independent variable in statistical models to predict flow characteristics. However, it was important to assess the independence of rainfall with respect to time; thus, the first analysis was undertaken to assess temporal rainfall trends.

\subsubsection{Rainfall Analysis}

The purpose of the rainfall analyses was threefold: 1) to assess the suitability of rain station MSC 6158350/6158355 (the longest available rainfall record within the region) to represent rainfall in the catchments studied; 2) to assess trends in time of rainfall at all available proximal rain stations in the years with hydrologic records (1969-2010); 3) to assess trends in time of rainfall at rain station MSC 6158350/ 6158355. Mann Kendall tests were run using R Package rkt (Marchetto, 2013). Where appropriate, Regional Mann Kendall (Helsel and Frans, 2006) results were calculated using both median and average methods with multiple records in a year; median results are reported.

To assess the suitability of rain station MSC $6158350 / 6158355$ to represent rainfall in the catchments studied, the potential effect of Lake Ontario on rainfall was assessed. Thirteen stations were grouped into two groups: seven stations within 10 kilometers of the lake; and, six stations in the upper reaches of the watersheds, between approximately $35 \mathrm{~km}$ and $58 \mathrm{~km}$ from the lake. (Three mid-watershed stations were excluded for analyses for proximity to Lake Ontario.) When tests for assumptions of normally distributed 
populations were met, a two-sided t-test to compare means was performed; otherwise, the Wilcoxon rank sum test was applied. The effect of proximity to Lake Ontario was tested for: total rainfall ( $\mathrm{t}$-test); rain event frequency (number per year; covariate total hours of record) (Wilcoxon rank sum test); rain event maximum intensity in one hour $\left(\mathrm{mm}_{\max } /\right.$ hour for each event) (Wilcoxon rank sum test); total rain event depth per event (mm/event) (Wilcoxon rank sum test). Pooled data for the sixteen rain stations were also tested for trend in total rainfall by latitude (Mann Kendall). See Table 4-1 for relative position of rain gauges in the study area.

To assess temporal trends in rainfall at all available proximal rain stations (1969-2010), Regional Mann Kendall analyses were run for: total rainfall (mm; covariate total hours of record); rain event frequency (number per year; covariate total hours with records); rain event maximum intensity in one hour $\left(\mathrm{mm}_{\max } /\right.$ hour/ event); total hours with rain; rain event depth per event (mm/event); hours with rainfall in 6 different class intervals (Brunetti et al., 2000) with total hours of record as a covariate ( $>50 \mathrm{~mm} ; 50-40 \mathrm{~mm} ; 40$ - $30 \mathrm{~mm} ; 30-20 \mathrm{~mm} ; 20-10 \mathrm{~mm} ; 10-0 \mathrm{~mm} ; 0 \mathrm{~mm}$;); $99.999^{\text {th }}, 99.99^{\text {th }}, 99.9^{\text {th }}, 99^{\text {th }}, 95^{\text {th }}$ and $90^{\text {th }}$ percentile hourly rainfall (covariate total hours with records); and, proportion of total rainfall contributed by the $90^{\text {th }}$ percentile rain (Karl and Knight, 1998). To assess the proportion of total rainfall contributed by the $90^{\text {th }}$ percentile rain, the $90^{\text {th }}$ percentile value was calculated for each station and year using only records with rainfall greater than $0 \mathrm{~mm}$; all hourly rainfall records greater than or equal to the $90^{\text {th }}$ percentile were summed and divided by the total rain depth for the year. For other percentile calculations, the entire rainfall record (including periods of no rainfall) was used. At least four years of record are needed for the Mann Kendall test; four of the sixteen rain stations did not meet 
this minimum requirement so rainfall trends were assessed using the remaining 12 stations.

Trends with year at station MSC6158350/ 6158355 were assessed using the Mann Kendall test for the same rainfall variables listed above, except total rainfall (log transformed) was assessed with a linear model. Mann Kendall was also used to test trend on year for three snow variables: the total daily accumulated snowfall $(\mathrm{cm})$ from October to April; maximum daily snow on the ground by month individually (January to May); mean daily snow on the ground (January to April). Although detailed snow analyses was outside the study period, readily available snow records were assessed for potential contribution to confounding factors, such as trends in snow pack depth that could cause variation in Spring groundwater recharge.

For the period of study, 1969 to 2010 , in addition to the analysis of rainfall records reported herein, a literature review of available rainfall studies was undertaken with respect to statistical trends in rainfall patterns within the Toronto region.

\subsubsection{Analysis of total annual flows}

For an analysis of total flow by year (May $26^{\text {th }}$ to November $15^{\text {th }}$ ), as an initial diagnostic of detectable trends, the Mann Kendall trend test using a Yue-Pilon trend-free prewhitening (Yue et al., 2003; Yue et al. 2002) approach was applied to several flow variables, including: total; mean; highest; lowest; $1^{\text {st }}, 10^{\text {th }}, 20^{\text {th }}, 50^{\text {th }}, 70^{\text {th }}, 90^{\text {th }}, 99^{\text {th }}$ percentiles; and, the ratio of total flow to total rain (i.e. seasonal runoff coefficient). Flow 
duration curves were estimated using R's hydroTSM (Zambrano-Bigliarini, 2012) package.

For statistical modelling of total annual flows using two independent variables (total rainfall depth and year), we used linear mixed effect (LME) models. LME models were fit to the total flow data, with year and total rainfall as fixed effects; watershed was a random intercept effect; and, $\log _{10}$ total rainfall a random slope effect. Heteroscedasticity among watersheds was tested for model fit improvement. Total flow (May $26^{\text {th }}$ to November $\left.15^{\text {th }}\right)$ was expressed as runoff $(\mathrm{mm})$ by dividing the flow volume for each watershed by watershed area upstream of each hydrologic gauge.

\subsubsection{Analysis of event flows}

Event flow analyses (rising limb only as described in Section 4.2.2) included temporal trends in event flows, event flow accelerations, the ratio of event flow to median flow and the range of event flows.

For event flow and event acceleration, we estimated the slope with year for each of the first four moments of the distribution using Mann Kendall. The raw data for this analysis included all 15-minute records for event rising limbs, up to and including peak flows, of all event flows by year. Density plots (R's ggplot2, Wickham, 2009) were used to visually compare distributions of event flows and event accelerations of earlier years and later years with similar total rainfall depths (depths for each pair of years were within $3 \%$ of each other). The area under each density plot is one, and the comparisons by year 
indicate shifts in relative frequency of plotted flow rates. Density plots of flow attributes were also used to visually compare shifts in relative frequencies by decade.

For event flows, rising limb flow segments were pooled by year and trends over the period of record estimated independently for three different attributes of the distribution: the flow rate below which $80 \%$ of rising limb event (80RLE) flows occurred; the ratio of 80RLE to median flow; and, the range of flows. The $80 \%$ threshold was selected as the dependent variable based on the earliest years of record when event flows occurred within a narrow value range easily characterized by this threshold. The range of flows was calculated as the highest event flow minus the lowest flow by year.

For both watersheds, 80RLE, the ratio of 80RLE to median flow and acceleration were assessed by decade using ANOVA (Tukey method of multiple comparisons). Because the ANOVA assumption of normally distributed residuals was violated, a Kruskal-Wallis test was also run to assess consistency with ANOVA results; a Kruskal-Wallis test can only confirm that at least one pair of decades is significantly different. To estimate an annual rate of change in event flows, change in range of flows and event accelerations, Mann Kendall tests were used, with total rain as covariate.

\subsubsection{Substitution of urban extent for year}

For the Don watershed, total flow was estimated with the independent variables total rainfall and urban area (instead of year) using a simple linear regression. No comparable model was developed for the Humber because historic urban area estimates were not 
available for the Humber watershed.

\subsubsection{Model selection and data transformation}

LME model selection was based on an information theoretic approach using Akaike's Information Criterion with correction for finite sample sizes (AICc) (Mazerolle, 2013). In the case of simple linear models, fit was assessed on the basis of the coefficient of

determination $\left(\mathrm{R}^{2}\right)$. Interaction terms for independent variables were included among models tested. As a preliminary step in all analyses, histograms of dependent and independent variables were plotted to assess skew in the raw data. Scatter plots of variable pairs were also visually assessed for potential relationships.

The flow and rainfall data were right-skewed. Where variables were log transformed, a correction for the anti-log transformation bias was applied based on the mean of the antilog of the residuals for the model (Rothery, 1988; HERC, 2013).

\subsection{Results}

\subsubsection{Rainfall analysis}

Rainfall at seven stations in closest proximity to Lake Ontario demonstrated no significant differences from rainfall at six stations in the upper reaches of the Don and Humber watersheds for: total rainfall $(t=-0.76, d f=49.9, p=0.45)$; rain event frequency $(\mathrm{t}=-0.05 ; \mathrm{df}=50.9, \mathrm{p}=0.96) ;$ maximum event intensity $(\mathrm{W}=244977.5, \mathrm{p}=0.91) ;$ rain event depth $(\mathrm{W}=245840, \mathrm{p}=0.82)$. There was no trend in total rainfall with latitude 
among the 16 rain stations (Mann Kendall (MK) Score $=-8, \mathrm{p}=0.67$, median method).

Regional rainfall trends with year for 12 stations were not statistically significant for: total rainfall $($ MK Partial Score $=30, p=0.84)$; rain event frequency $($ MK Partial Score $=$ 211.5, $\mathrm{p}=0.13$ ); rain event maximum intensity (MK Score $=41, \mathrm{p}=0.79)$; total hours with rain $($ MK Score $=-63, p=0.67)$; rain event depth $($ MK Score $=-188, p=0.20)$; proportion of total rainfall contributed by the $90^{\text {th }}$ percentile rain $($ MK Score $=0, p=1)$; $99.999^{\text {th }}, 99.99^{\text {th }}, 99.9^{\text {th }}, 99^{\text {th }}, 95^{\text {th }}$ and $90^{\text {th }}$ percentile hourly records (MK Partial Score range from -245.3 to $165.8, \mathrm{p}$ range from 0.072 (for $95^{\text {th }}$ percentile) to 1 (for $90^{\text {th }}$ percentile)); hours with rainfall in class interval $>50 \mathrm{~mm}($ MK Partial Score $=117.8, \mathrm{p}=$ 0.40); class interval 50 - $40 \mathrm{~mm}(\mathrm{MK}$ Partial Score $=-56.1, \mathrm{p}=0.69$ ); class interval 30 $20 \mathrm{~mm}($ MK Partial Score $=44.0, \mathrm{p}=0.76)$; class interval $20-10 \mathrm{~mm}$ (MK Partial Score $=5.4, \mathrm{p}=0.98)$; class interval $10-0 \mathrm{~mm}(\mathrm{MK}$ Partial Score $=8.0, \mathrm{p}=0.96)$.

Statistically significant trends in the regional analyses were identified for three variables: total number of hourly records per year $(\mathrm{MK}$ Score $=-406, \mathrm{p}=0.005$, slope $=-2.79$ records/year); hours in the class interval with zero rainfall (MK Partial Score $=-131.1, p$ $=0.037$, slope $=-6.4$ hours year $\left.{ }^{-1}\right)$; hours in class interval $40-30 \mathrm{~mm}$ (MK Partial Score $=377.9, \mathrm{p}=0.008$, slope $=0.08$ hours year $\left.^{-1}\right)$.

No statistically significant rainfall trends with year were identified at station MSC 6158350/ 6158355, including: total rainfall $(\mathrm{t}=-0.028, \mathrm{df}=39, \mathrm{p}=0.98)$; rain event frequency (MK Partial Score $=101.1, \mathrm{p}=0.29)$; rain event maximum intensity (MK 
Score $=-44, p=0.64)($ Illustration $4-3) ;$ total hours with rain $($ MK Score $=-90, p=0.33)$; rain event depth $(\mathrm{MK}$ Score $=-149, \mathrm{p}=0.11)$; proportion of total rainfall contributed by the $90^{\text {th }}$ percentile rain (MK Score $\left.=-37, p=0.69\right) ; 99.999^{\text {th }}, 99.99^{\text {th }}, 99.9^{\text {th }}, 99^{\text {th }}, 95^{\text {th }}$ and $90^{\text {th }}$ percentile hourly records (MK Partial Score range from -155.5 to 33.4, $\mathrm{p}$ range from 0.07 (for $95^{\text {th }}$ percentile) to 1 (for $90^{\text {th }}$ percentile)); hours with rainfall in class interval $>50 \mathrm{~mm}($ MK Partial Score $=73.9, \mathrm{p}=0.40)$; class interval $50-40 \mathrm{~mm}($ MK Partial Score $=-41.7, \mathrm{p}=0.65)$; class interval $40-30 \mathrm{~mm}(\mathrm{MK}$ Partial Score $=72.8, \mathrm{p}=0.43)$; class interval $30-20 \mathrm{~mm}(\mathrm{MK}$ Partial Score $=-93.4, \mathrm{p}=0.31)$; class interval $20-10$ $\mathrm{mm}(\mathrm{MK}$ Partial Score $=6.2, \mathrm{p}=0.95) ;$ class interval $10-0 \mathrm{~mm}(\mathrm{MK}$ Partial Score $=$ $-76.4, p=0.41)$; class interval with 0 rainfall (MK Partial Score $=27.0, p=0.53$ ); total number of hours with records per year (MK Score $=-9, \mathrm{p}=0.93$ ). 


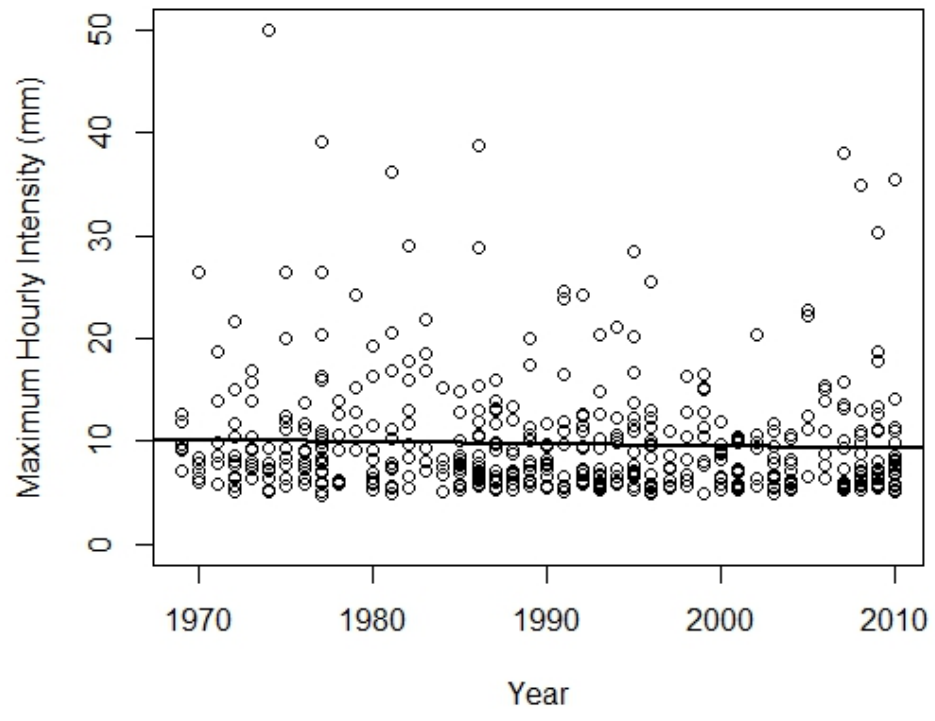

Illustration 4-3 Maximum hourly intensity of rainfall events.

Time series of maximum hourly intensity of rainfall events over $5 \mathbf{~ m m}$ with simple linear trend line indicated. 
No statistically significant trend with year in accumulated daily total snow (October to April) was identified between winters 1968/69 and 2008/09 inclusive (MK Score $=-143$, $p=0.11)$. No statistically significant trend with year in maximum depth of snow on the ground was identified between 1969 and 2006 inclusive for January (MK Score $=-91, p$

$=0.26)$, February (MK Score $=-8, p=0.93)$, March $($ MK Score $=34, p=0.68)$, or April $($ MK Score $=-56, p=0.45)$. No statistically significant trend with year in mean depth of snow on the ground was identified for January to April inclusive between 1969 and 2006 inclusive (MK Score $=-63, \mathrm{p}=0.44)$.

Our results indicating no relevant significant trends in rainfall are consistent with literature results for Southern Ontario. Palynchuk (2012), Hogg and Hogg,( n.d.), Zhang and Burns (2009), Adamowski and Bougadis (2003), and Hodgkins et al. (2007) also report similar results for Southern Ontario rainfall characteristics during contemporaneous timeframes.

\subsubsection{Total flow trend}

For both the Don and Humber mean flow, the highest $1 \%$ of flows (Illustration 4-4), $10^{\text {th }}$ percentile, $20^{\text {th }}$ percentile flows and the ratio of total flow to total rain each increased over the period of record $(\mathrm{p}<-0.05)$. The Don watershed data also indicate a statistically significant increase in $50^{\text {th }}$ percentile flows. The Humber indicates a statistically significant increase in highest flows and total flow. Trends in other characteristics assessed were not statistically significant at $\mathrm{p}=0.05$. 
Linear mixed modeling of $\log _{10}$ total flow $\left(\mathrm{mm}\right.$ year $\left.{ }^{-1}\right)$ shows a large positive effect of $\log _{10}$ total rainfall depth at gauge $(\mathrm{mm})\left(\beta_{1}=0.82+/-0.07, \mathrm{t}=12.0, \mathrm{df}=80, \mathrm{p}<0.0001\right)$ as well as year $\left(\beta_{2}=0.0039+/-0.00067, \mathrm{t}=5.8, \mathrm{df}=80, \mathrm{p}<0.0001\right)$ with substantial heterogeneity between watersheds $\left(\sigma_{0 D O N}^{2}=0.058 ; \sigma_{0 H U M B E R}^{2}=2.16 \sigma_{0 D O N}^{2}, \mathrm{LR}=21.2, \mathrm{p}<\right.$ 0.0001). Table 4-2 summarizes actual and modelled flow for pairs of years with similar total rainfall.

Based on the estimated effect of year, flow (standardized by watershed area) has increased annually by approximately $1 \mathrm{~mm}$ per season (May $26^{\text {th }}$ and November $15^{\text {th }}$ ) from 1969 to 2010, independent of total rainfall (increase estimated as the antilog ${ }_{10}$ of $0.0039)$. 


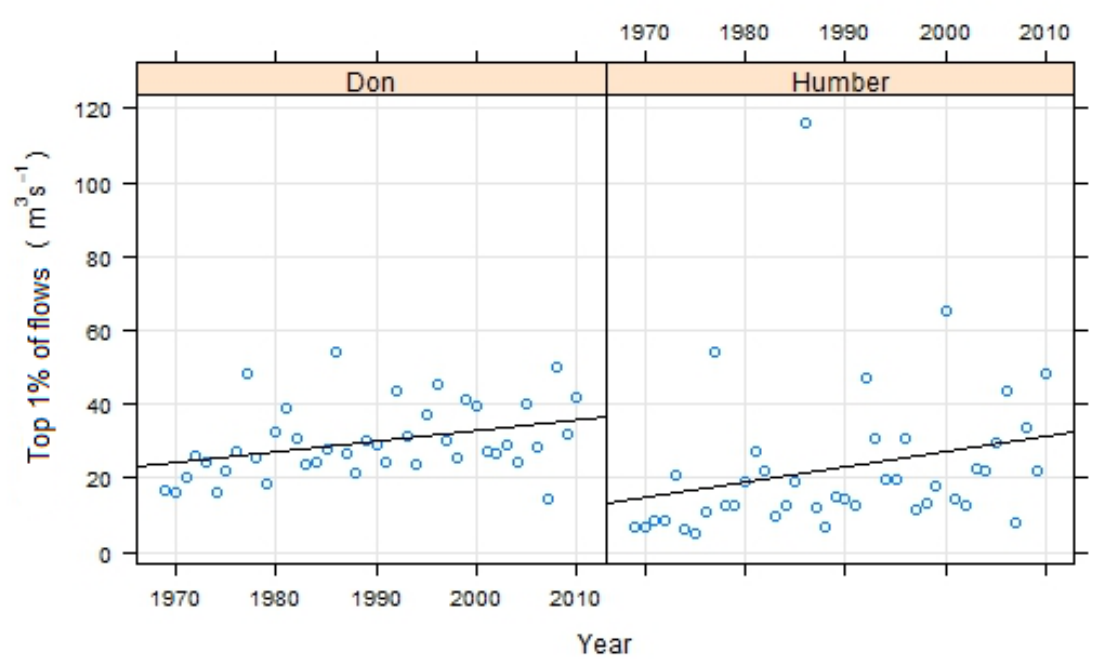

Illustration 4-4 Highest $1 \%$ of flows.

Time series of top one percent of flows, with simple linear trend line indicated. 
Table 4-2 Comparison of actual to modeled flow

Comparison of actual flow and modeled flow for pairs of years with similar rainfall spanning 27 to 36 years of the historical record.

\begin{tabular}{|c|c|c|c|c|c|c|c|c|c|c|}
\hline Watershed & Year 1 & $\begin{array}{l}\text { Year } 1 \\
\text { Rain } \\
(\mathrm{mm})\end{array}$ & $\begin{array}{c}\text { Actual } \\
\text { Year 1 } \\
\text { Flow (mm/ } \\
\text { season) }\end{array}$ & $\begin{array}{c}\text { Modeled } \\
\text { Year 1 } \\
\text { Flow (mm/ } \\
\text { season) }\end{array}$ & Year 2 & $\begin{array}{l}\text { Year } 2 \\
\text { Rain } \\
(\mathrm{mm})\end{array}$ & $\begin{array}{c}\text { Actual } \\
\text { Year } 2 \\
\text { Flow (mm/ } \\
\text { season) }\end{array}$ & $\begin{array}{c}\text { Modeled } \\
\text { Year } 2 \text { Flow } \\
(\mathrm{mm} / \\
\text { season) }\end{array}$ & $\begin{array}{c}\text { Actual \% } \\
\text { Increase in } \\
\text { Flow }\end{array}$ & $\begin{array}{c}\text { Modeled \% } \\
\text { Increase in } \\
\text { Flow }\end{array}$ \\
\hline Don & 1969 & 279 & 111 & 102 & 2005 & 272 & 156 & 138 & 40 & 35 \\
\hline Don & 1971 & 268 & 111 & 101 & 2006 & 270 & 117 & 138 & 5 & 38 \\
\hline Don & 1981 & 476 & 170 & 176 & 2008 & 474 & 243 & 223 & 43 & 27 \\
\hline Don & 1982 & 442 & 159 & 167 & 2009 & 445 & 189 & 214 & 19 & 28 \\
\hline Humber & 1969 & 279 & 38 & 38 & 2005 & 272 & 62 & 52 & 64 & 35 \\
\hline Humber & 1971 & 268 & 36 & 38 & 2006 & 270 & 52 & 52 & 43 & 38 \\
\hline Humber & 1981 & 484 & 64 & 67 & 2008 & 474 & 87 & 84 & 36 & 25 \\
\hline Humber & 1982 & 438 & 73 & 62 & 2009 & 445 & 98 & 81 & 33 & 29 \\
\hline
\end{tabular}




\subsubsection{Event (rising limb) flows}

Density plots of rising limb event flows in the Don and Humber (Illustration 4-5 and Illustration 4-6) indicate that earlier years (1969 and 1971) showed much more peaked distributions (greater maxima, smaller variance) compared to later years. Trends with year in moments of the distribution of event flows indicate increasing means and standard deviations in both watersheds (Table 4-3).

Over time, peak event flows increased in both watersheds. In the Don in the 1970's (1969 to 1979 ), $80 \%$ of event flows were equal to or less than $2.7 \mathrm{~m}^{3} \mathrm{~s}^{-1}$ (std. deviation 0.7 $\mathrm{m}^{3} \mathrm{~s}^{-1}$ ) on average; by the 2000's (2000 to 2010), the decadal average had increased to 4.8 $\mathrm{m}^{3} \mathrm{~s}^{-1}$ (std. deviation $1.6 \mathrm{~m}^{3} \mathrm{~s}^{-1}$ ), (ANOVA multiple $\mathrm{R}^{2}=0.23, \mathrm{p}=0.005$; Kruskal-Wallis test results consistent at $\mathrm{p}=0.004)$ (Illustration 4-7).

Similarly, in the Humber in the 1970 's, the $80 \mathrm{RLE}$ was equal to or less than $3.5 \mathrm{~m}^{3} \mathrm{~s}^{-1}$ (std. deviation $0.8 \mathrm{~m}^{3} \mathrm{~s}^{-1}$ ) on average; by the 2000's, it had increased to $6.5 \mathrm{~m}^{3} \mathrm{~s}^{-1}$ (std. deviation $3.7 \mathrm{~m}^{3} \mathrm{~s}^{-1}$ ). A Mann Kendall test on 80RLE by year, with total rain as a covariate, indicates an annual increase in the Don of $0.06 \mathrm{~m}^{3} \mathrm{~s}^{-1}(\mathrm{MK}$ Partial Score $=$ $316.7, \mathrm{p}=0.0001)$ and in the Humber, an annual increase of $0.07 \mathrm{~m}^{3} \mathrm{~s}^{-1}$ (MK Partial Score $=252.9, \mathrm{p}=0.002$ ), consistent with the magnitude of decadal changes identified in the ANOVA and increases in mean event flows. However, as indicated by the ANOVA and Illustration 4-7, the cumulative change in 80RLE was not uniform by year. 

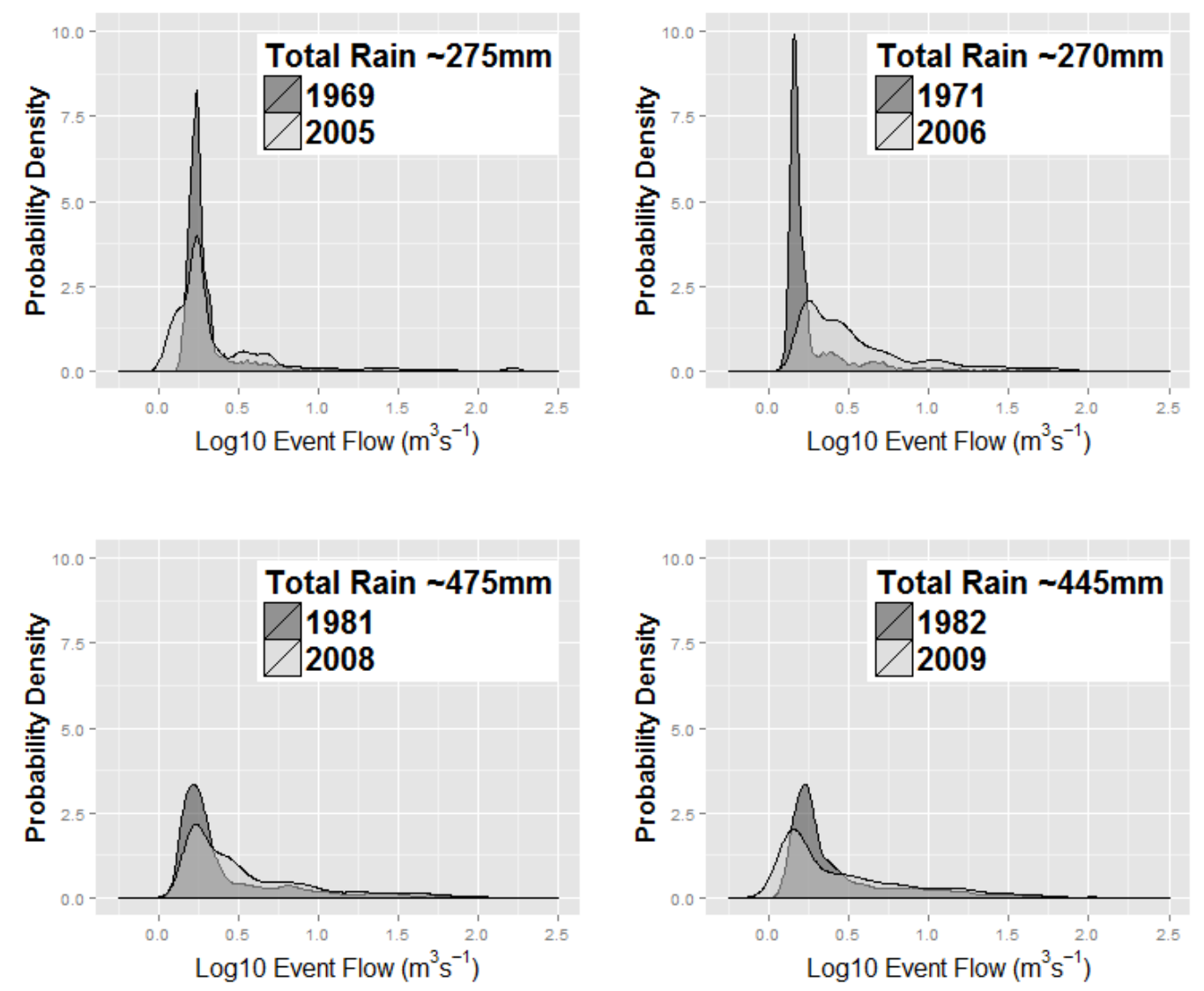

Illustration 4-5 Don watershed event flow probability density distributions for four pairs of early and late period years with similar total rainfall.

In 1969 and 1971, rising limb event flows were most likely to be between about $1.3 \mathrm{~m}^{3} \mathrm{~s}^{-1}$ and $2.4 \mathrm{~m}^{3} \mathrm{~s}^{-1}$ (converted from the $\log _{10}$ scale) with maximum flows of $51.6 \mathrm{~m}^{3} \mathrm{~s}^{-1}$ and $84.8 \mathrm{~m}^{3} \mathrm{~s}^{-1}$ respectively; by 1981 , event flows occur within a less predictable and broader range, with event flows occasionally exceeding $140 \mathrm{~m}^{3} \mathrm{~s}^{-1}$ (converted from the $\log _{10}$ scale) within a 15 minute interval. The figure plots pairs of years with similar total rainfall and low numbers of missing records. 

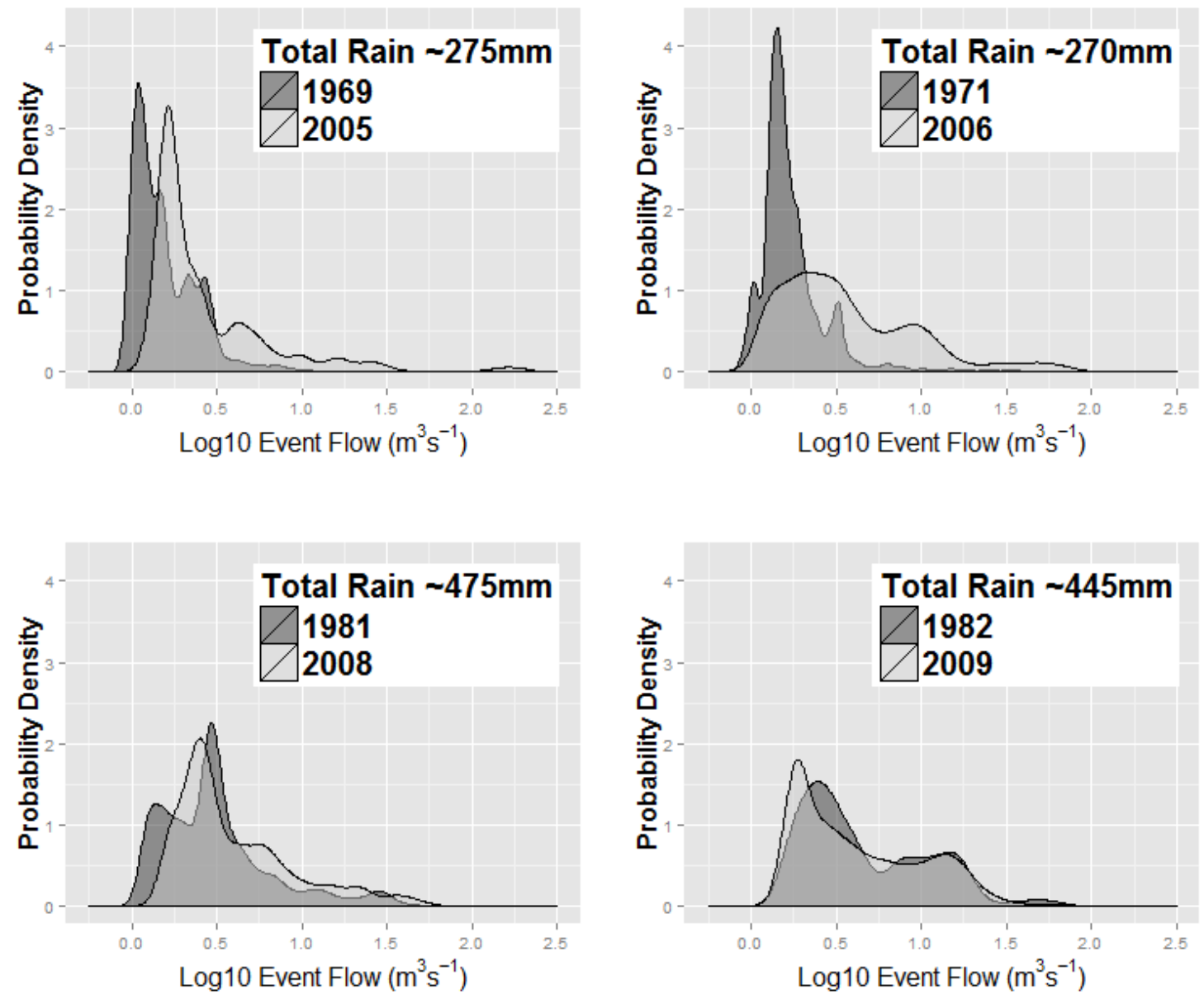

Illustration 4-6 Humber watershed event flow probability density distributions for four pairs of early and late period years with similar total rainfall.

In 1969 and 1971, most rising limb event flows were less than $2.5 \mathrm{~m}^{3} \mathrm{~s}^{-1}$ (converted from the $\log _{10}$ scale); in 1981 and later years, event flows occur over a higher and less predictable range. The maximum event flow in 1969 is $17.4 \mathrm{~m}^{3} \mathrm{~s}^{-1}$; in later years plotted (1981 to 2006), maximum flows are between $47.6 \mathrm{~m}^{3} \mathrm{~s}^{-1}$ and $204.9 \mathrm{~m}^{3} \mathrm{~s}^{-1}$. The figure plots pairs of years with similar total rainfall and low numbers of missing records. 
Table 4-3 Results for analyses of moments of rising limb distribution.

Results for Thiel-Sen estimate of slope, with confidence intervals, for moments of the distribution of rising limb event flows (in $\mathrm{m}^{3} \mathrm{~s}^{-1}$ ) at 15 minute intervals, on year.

\begin{tabular}{||c|c|c|c||}
\hline Watershed & Moment & $\begin{array}{c}\text { Slope } \\
\text { (Upper Confidence } \\
\text { Interval (CI), Lower CI) }\end{array}$ & Summary \\
\hline Don & Mean & $0.06(0.02,0.09)$ & Increasing \\
\hline & St.Dev. & $0.14(0.06,0.23)$ & Increasing \\
\hline & Skew & $-0.03(-0.07,0.01)$ & No Trend \\
\hline & Kurtosis & $-0.37(-1.01,0.19)$ & No Trend \\
\hline & Coefficient of Variation & $0.55(-0.26,1.36)$ & No Trend \\
\hline Humber & Mean & $0.06(0.02,0.11)$ & Increasing \\
\hline & St.Dev. & $0.12(0.06,0.21)$ & Increasing \\
\hline & Skew & $-0.04(-0.08,-0.01)$ & Decreasing \\
\hline & Kurtosis & $-0.48(-1.07,-0.14)$ & Decreasing \\
\hline & Coefficient of Variation & $1.31(0.38,2.33)$ & Increasing \\
\hline
\end{tabular}




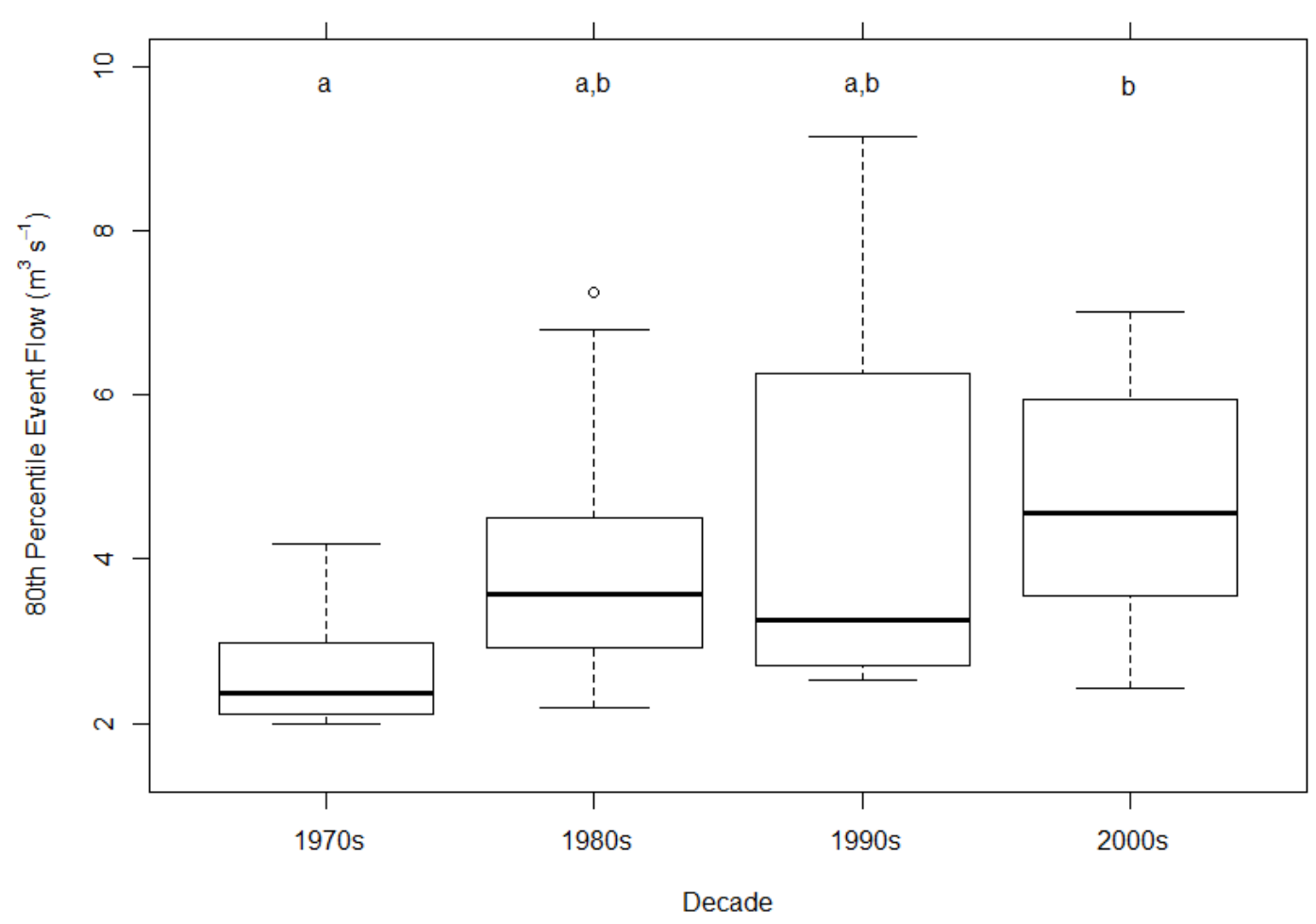

Illustration 4-7 Boxplots of Don watershed 80RLE by decade.

Boxplots with ' $a$ ' and 'b' indicating Tukey multiple comparison results. Heavy horizontal lines are means; boxes indicate $25^{\text {th }}$ and $75^{\text {th }}$ percentiles and whiskers extend to 1.5 times the interquartile range for the mean. 
In the Don, there is a statistically significant $(p=0.05)$ increase in the ratio of 80RLE to median flow between the 1970's and each of the other decades. In the 1970's, the rate below which $80 \%$ of event flows occurred was 1.5 times higher (std. deviation 0.3 ) than the median flow; in the 2000's, for example, this ratio was 2.3 times higher (std. deviation 0.6); (ANOVA $\mathrm{R}^{2}=0.28, \mathrm{p}=0.001$; Kruskal-Wallis test results consistent, $\mathrm{p}=$ 0.002). Similarly, in the Humber, the ratio of 80RLE to median flow was significantly different between the 1970's and each of the other decades. In the 1970's the ratio was 1.6 (std. deviation 0.4) and in the 2000's, it was 2.4 (std. deviation 0.9); $\left(\mathrm{ANOVA} \mathrm{R}^{2}=\right.$ $0.25, \mathrm{p}=0.003 ;$ Kruskal-Wallis test results consistent, $\mathrm{p}=0.002$ ).

An ANOVA comparison of other decades for both watersheds indicates no significant difference among decades for the ratio of 80RLE to median flows (Illustration 4-8), including the 1980's, 1990's and 2000's ( $\mathrm{p}>0.6$ for all comparisons in both watersheds). With the high variability of event flow responses, no definitive conclusions can be drawn about monotonic increases in decadal trends in ratio of peak event flows to median flows since the 1980 's.

A Mann Kendall analysis of flow range (maximum event flow minus minimum flow) with year, with total rain as a covariate, for the Don indicates an increase of $1.1 \mathrm{~m}^{3} \mathrm{~s}^{-1}$ per year $($ MK Partial Score $=197.3, \mathrm{p}=0.02)$ and for the Humber, an increase of $0.8 \mathrm{~m}^{3} \mathrm{~s}^{-1}$ per year in the flow range (MK Partial Score $=202.9, \mathrm{p}=0.02)$.

\subsubsection{Event flow acceleration}


Density plots of rising limb event flow acceleration in the Don and Humber (Illustration 4-9 and Illustration 4-10) indicate that earlier years (1969 and 1971) showed more peaked distributions compared to later years. Trends in the moments of distribution (Table 4-4) indicate increasing mean accelerations and increasing standard deviations of acceleration in both watersheds. An ANOVA of $\log _{10}$ mean acceleration by decade indicates significant differences between the 1970's and each of the two more recent decades (1990's and 2000's), with mean accelerations in the Don 2.0 times higher in 2000's ( $\mathrm{p}=$ 0.001 ) compared to the 1970 's $\left(4.4 \mathrm{e}-04 \mathrm{~m}^{3} \mathrm{~s}^{-2}\right.$ in the 1970 's to $8.8 \mathrm{e}-04 \mathrm{~m}^{3} \mathrm{~s}^{-2}$ in the 2000 's, ANOVA $\mathrm{p}=0.001)$ and in the Humber 2.3 times higher $\left(1.4 \mathrm{e}-04 \mathrm{~m}^{3} \mathrm{~s}^{-2}\right.$ in the 1970 's to $3.2 \mathrm{e}-04 \mathrm{~m}^{3} \mathrm{~s}^{-2}$ in the 2000 's, ANOVA $\mathrm{p}=0.003$ ). Kruskal-Wallis non-parametric tests confirm significant differences between at least two decades $($ Don $p=0.004$; Humber $p=$ $0.005)$. 


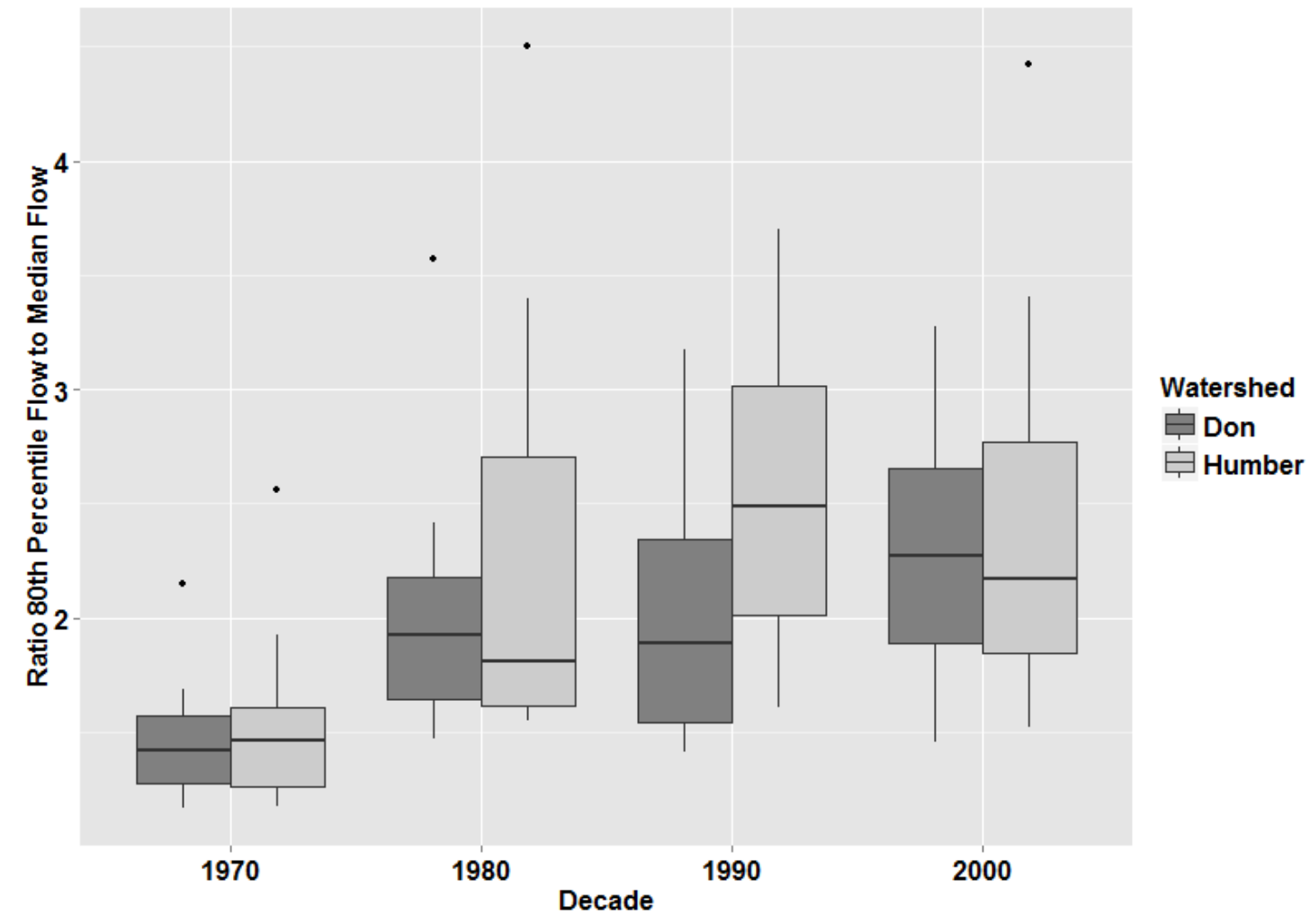

Illustration 4-8 Ratio of $80^{\text {th }}$ percentile flows to median flow for the two watersheds.

Heavy horizontal lines are medians; boxes indicate $25^{\text {th }}$ and $75^{\text {th }}$ percentiles and whiskers extend to 1.5 times the interquartile range for the median. 

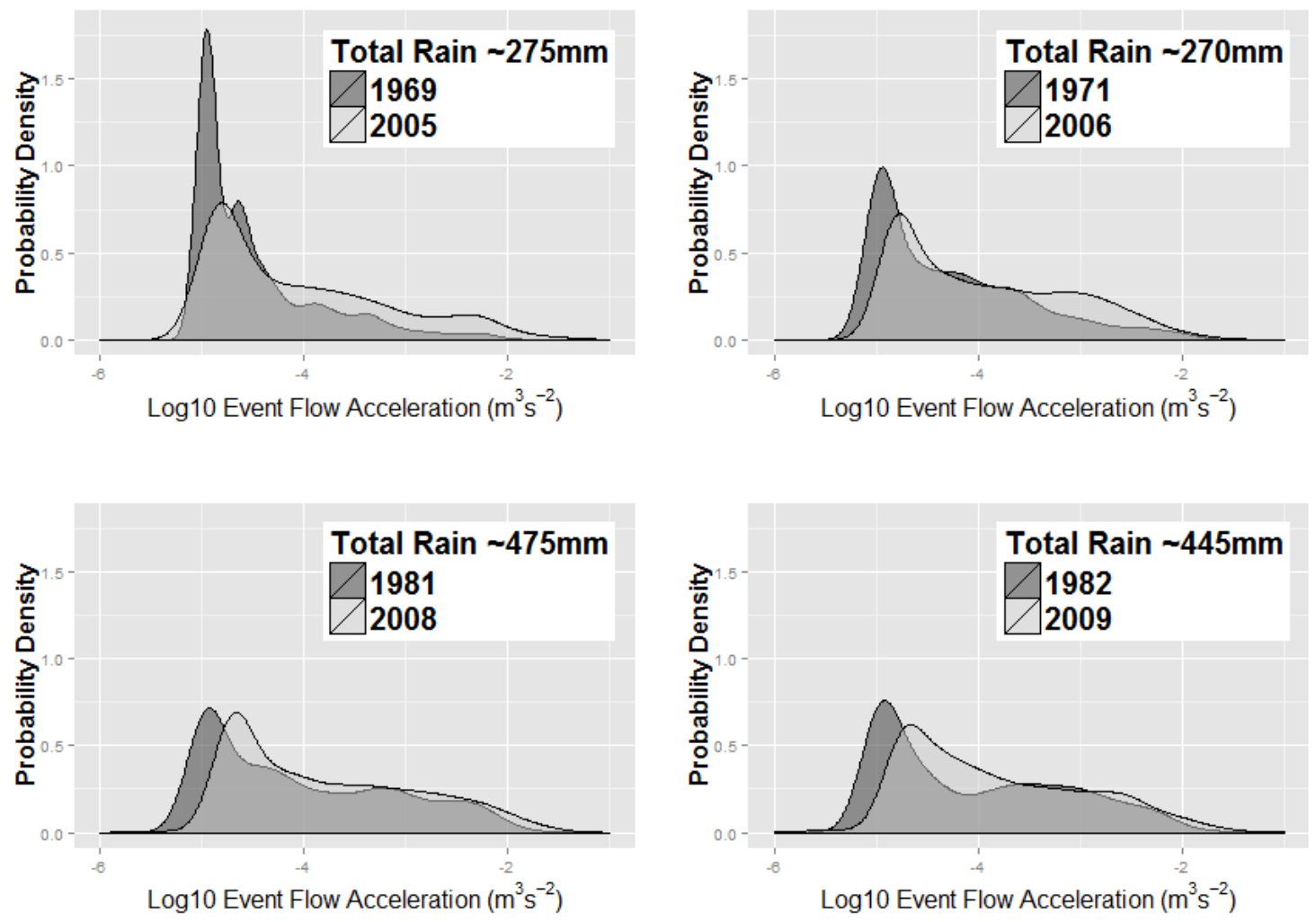

Illustration 4-9 Don River rising limb event flow acceleration probability density distributions for 4 pairs of early and late period years with similar total rainfall, for accelerations greater than zero.

The illustration plots pairs of years with similar total rainfall and low rates of missing records. 

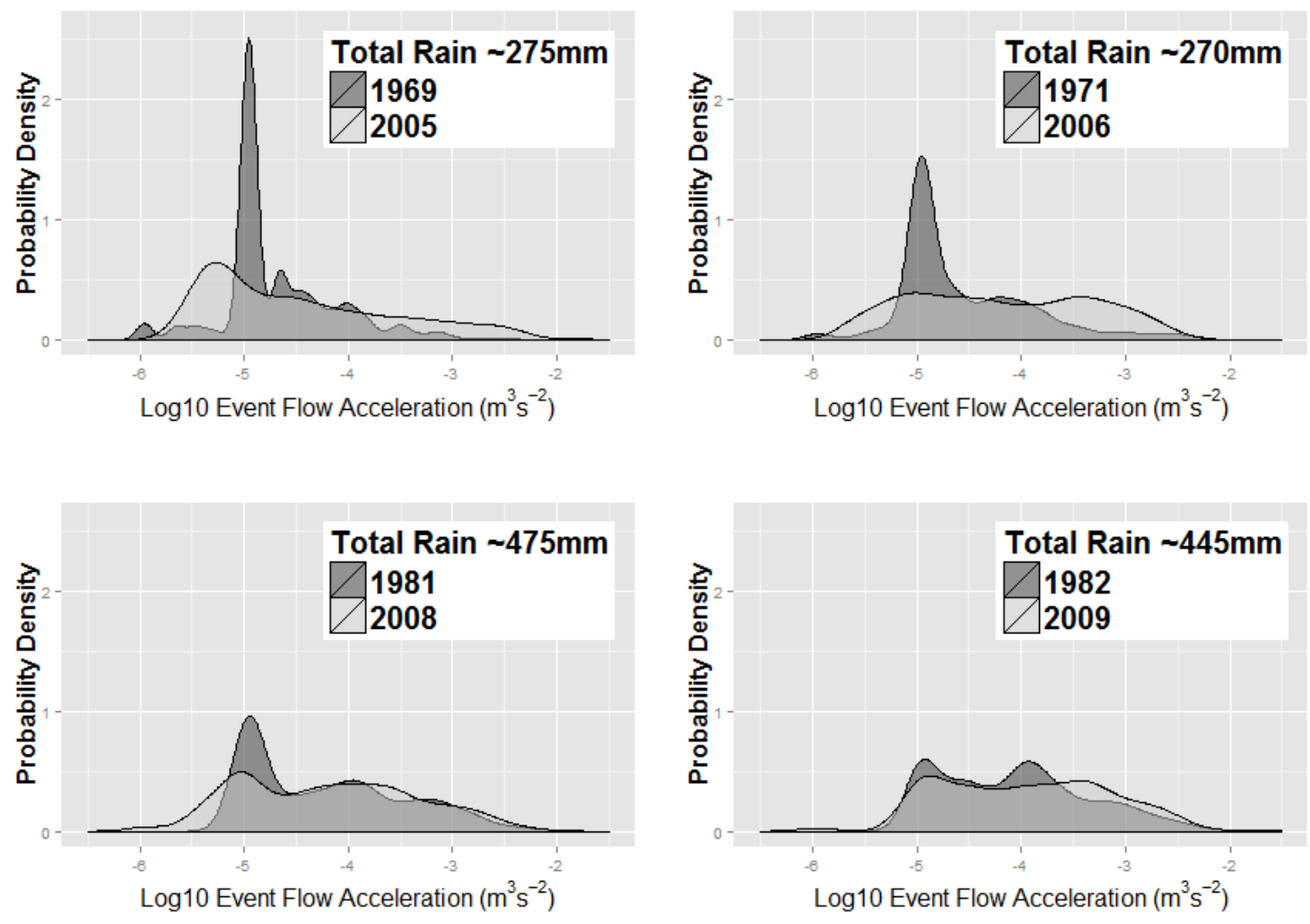

Illustration 4-10 Humber River rising limb event flow acceleration probability density distributions for 4 pairs of early and late period years with similar total rainfall, for accelerations greater than zero.

The illustration plots pairs of years with similar total rainfall and low rates of missing records. 
Table 4-4 Results for analyses of moments of rising limb acceleration.

Results for Thiel-Sen estimate of slope, with confidence intervals, for moments of the distribution of positive flow accelerations (in $\mathrm{m}^{3} \mathrm{~s}^{-2}$ ) during the rising limb of rain events, on year.

\begin{tabular}{||c|c|c|c||}
\hline Watershed & Moment & $\begin{array}{c}\text { Slope } \\
\text { (Upper CI, Lower CI) }\end{array}$ & Summary \\
\hline Don & Mean & $0.15 \mathrm{e}-04(0.09 \mathrm{e}-04,0.22 \mathrm{e}-04)$ & Increasing \\
\hline & St.Dev. & $0.37 \mathrm{e}-04(0.22 \mathrm{e}-04,0.54 \mathrm{e}-04)$ & Increasing \\
\hline & Skew & $-0.02(-0.07,0.03)$ & No Trend \\
\hline & Kurtosis & $-0.32(-1.11,0.48)$ & No Trend \\
\hline & CV & $-0.78(-2.56,0.69)$ & No Trend \\
\hline Humber & Mean & $0.06 \mathrm{e}-04(0.03 \mathrm{e}-04,0.09 \mathrm{e}-04)$ & Increasing \\
\hline & St.Dev. & $0.11 \mathrm{e}-04(0.01 \mathrm{e}-04,0.18 \mathrm{e}-04)$ & Increasing \\
\hline & Skew & $-0.08(-0.16,-0.01)$ & Decreasing \\
\hline & Kurtosis & $-1.19(-2.73,4.5 \mathrm{e}-03)$ & No Trend \\
\hline & CV & $-1.92(-3.95,0.45)$ & No trend \\
\hline
\end{tabular}


A Mann Kendall analysis of event flow acceleration with year, with total rain as a covariate, for the Don indicates an increase of $0.15 \mathrm{e}-04 \mathrm{~m}^{3} \mathrm{~s}^{-2}$ per year (MK Partial Score $=385.1, \mathrm{p}=5.2 \mathrm{e}-06)$ and for the Humber, an increase of $0.06 \mathrm{e}-04 \mathrm{~m}^{3} \mathrm{~s}^{-2}$ per year in the flow range (MK Partial Score $=324.5, \mathrm{p}=9.8 \mathrm{e}-05)$. A decadal time series plot conveys the differences in event flow response over time within the two watersheds (Illustration 4-11).

\subsubsection{Substitution of urban extent for year (Don watershed)}

A simple linear regression to estimate $\log _{10}$ total flow (mm/year) in the Don with $\log _{10}$ total rainfall $(\mathrm{mm})\left(\beta_{1}=0.81+/-0.08, \mathrm{t}=9.75, \mathrm{df}=39, \mathrm{p}=5 \mathrm{e}-12\right)$ and minimum urban area $\left(\mathrm{km}^{2}\right)\left(\beta_{2}=0.0013+/-0.0003, \mathrm{t}=4.65, \mathrm{df}=39, \mathrm{p}=4.0 \mathrm{e}-05\right)$ has $\mathrm{R}^{2}=0.720, \mathrm{p}=$ 6.2e-12, and residual $\mathrm{SE}=0.059$. For comparison purposes, the same model structure with $\log _{10}$ total rainfall $(\mathrm{mm})\left(\beta_{1}=0.78+/-0.08, \mathrm{t}=9.63, \mathrm{df}=39, \mathrm{p}=7.4 \mathrm{e}-12\right)$ and year $\left(\beta_{1}=0.0036+/-0.0007, \mathrm{t}=4.90, \mathrm{df}=39, \mathrm{p}=1.8 \mathrm{e}-05\right)$ has $\mathrm{R}^{2}=0.731, \mathrm{p}=3.0 \mathrm{e}-12$, residual $\mathrm{SE}=0.058$. Thus, year explains about $1 \%$ more variation than minimum urban area using the same model structure. A model using only $\log _{10}$ total rainfall $(\mathrm{mm})$ as an independent variable $\left(\beta_{1}=0.76+/-0.10, \mathrm{t}=7.53, \mathrm{df}=39, \mathrm{p}=3.5 \mathrm{e}-09\right)$ has $\mathrm{R}^{2}=0.576, \mathrm{p}=$ 3.5e-09, residual $\mathrm{SE}=0.072$. The addition of year or minimum urban area as an independent variable in the respective models explains about $13 \%$ and $12 \%$ additional variation, respectively. 

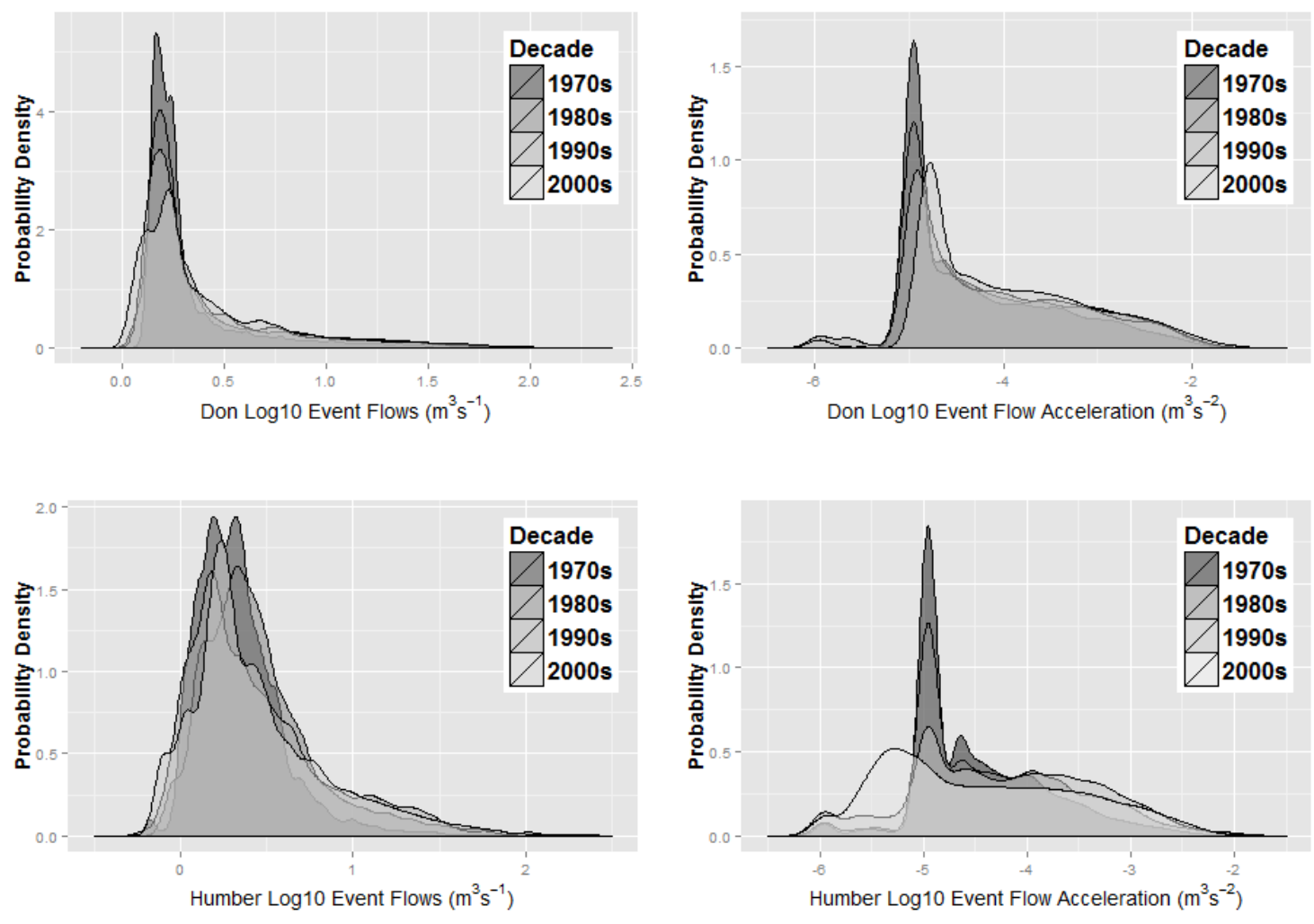

Illustration 4-11 Decadal time series for rising limb event flows and event flow acceleration for the Don and Humber watersheds.

As indicated by the statistical models, the change in event flow responses in the Don is more consistent with time than the response in the Humber. 


\subsection{Discussion}

In this discussion, we first address the results in context of potential confounding issues of rainfall trends, data quality and issues outside the scope of study. Following this, we discuss the implications of the results.

\subsubsection{Results in context of potential confounding issues}

In this study, the collective evidence from available rain gauges indicates there have been no statistically significant changes in precipitation patterns (rainfall depth, intensity and frequency) between 1969 and 2010 that could account for the observed changes in stream flow. The number of records decreases significantly with year, as does the number of hours with zero rainfall but there is no trend in total hours with rain. A decline in the number of records with year is unsurprising, given the decline in stations with time. The $90^{\text {th }}$ percentile record was consistently zero for all stations, so a decrease in the number of records (and stations) will most readily impact the number of zero rain hours. Thus, these statistically significant trends appear to reflect the number of rain records rather than a trend in rainfall itself. This conclusion is supported by the lack of trend in any other variable assessed, with the exception of an increase in the regional trend for hours with rain in class interval $40-30 \mathrm{~mm}$. There is no statistically significant decrease in another class interval so, as an isolated statistically significant result, it may be the chance generation of a statistically significant outcome when multiple tests are run (Livezey and Chen, 1983). Rain station MSC 6158350/ 6158355 can be used to represent rainfall within the two catchments of interest as no effect of proximity to Lake Ontario on rainfall was detected. 
Changes in snowpack do not contribute to the identified hydrologic trends during the May to November period. An increasing trend in snowpack would have confounded an analysis of temporal trends during the season of interest.

The rain storm literature for this region is consistent with our finding of no trend over time. There is little peer reviewed literature for the applicable time period, possibly because there is no trend in rainfall to report. Trends in more recent rainfall records, or over longer time periods (e.g. Karl and Knight, 1998), may be emerging but have no statistical relevance for the present study of temporal trends in flow from 1969 to 2010.

The question of data accuracy must also be addressed in a discussion of rainfall-flow trends. Rain gauge measurements are subject to inaccuracies of the equipment and event characteristics, such as strong winds. However, the length of the 42-year record helps to offset inaccuracies introduced by anomalous records. The rainfall gauge equipment at MSC 6158350/ 6158355 was changed in 2002, potentially introducing systematic differences in rainfall readings. Trends in flow relative to rainfall were detected in years and decades prior to and including the 2000's; systematic rain gauge error post-2002 would change the quantification of the trends but not the overall conclusions reached that flow trends relative to rainfall were detected. Convective storms in the upper reaches of the watershed may not have been captured by the single rain gauge location with a long term record. With respect to the flow level readings, for the Ontario 'instantaneous' flow dataset, $\sim 99 \%$ (Arsenault and Thompson, 2010) of the records fall within the best accuracy category, which means the "daily mean discharge calculated with the 
instantaneous data from this day is identical to the published value plus or minus one tenth of the trailing significant digit." (Arsenault and Thompson, 2010, p.121). The length of flow record and the comparable total flow results in two watersheds provide additional assurance that detected trends are not the result of flow gauging equipment error.

A limitation of the database is that precipitation records outside the May $26^{\text {th }}$ to November $15^{\text {th }}$ window are excluded, although antecedent winter snow statistics indicate no significant trends. The timing of spring freshet was not examined and may contribute to unexplained variation in the statistical models by influencing landscape response to rainfall in May and June. The statistical model results are consistent enough among years, and the May to November period long enough each year, to have confidence that the trends detected during the period examined are not a result of phenomena occurring strictly outside the seasonal time interval examined.

\subsubsection{Implications of Results}

Despite data limitations, it can be concluded that growing season flows have increased with time in the Don and Humber Rivers and that there is no trend in rainfall to explain this increase. An increase in total runoff of about $1 \mathrm{~mm}$ per season over 42 years is substantial. Cumulative changes in event flows are also substantial, with rising limb flows increasing in each river approximately two-fold over four decades, or roughly 0.1 $\mathrm{m}^{3} \mathrm{~s}^{-1} \mathrm{yr}^{-1}$. In addition to increased event flows, from the earliest decade to the most recent, the variability of event flows increased more than two-fold in the Don and almost five- 
fold in the Humber. Event flow accelerations increased roughly 2-fold in both rivers. The moments of distribution for flow acceleration in the Humber indicate changes in flow regime that can be most readily characterized as more variable than earlier decades. The magnitude of flow fluctuation (Konrad and Booth, 2005) and increased response of event flows relative to median flows (Gibbins et al., 2001; Clausen and Biggs, 1997) in the Don and the Humber are indicators of flow disturbances that have been associated with effects on aquatic biota.

Results for the Don River indicate that an increase in high event flows was off-set by a corresponding increase in low event flows; thus, there was no trend in skew for rising limb event flows. This response is consistent with an increasingly impervious watershed that is more sensitive to small rain events and, concurrently, generates more extreme high flows. In contrast, the trends in moments of distribution for event flows in the Humber are consistent with a watershed that is experiencing higher flows with time, but is not yet experiencing increased low flow responses.

This study examined aspects of magnitude, frequency and rate of change of flow conditions, all of which indicate significant changes with time. The empirical predictive models and statistical moments indicate these mainstem rivers are now experiencing chronically perturbed flow regimes and that the degree of perturbation has increased with time. In addition to aquatic biota, these perturbations also have potential implications for flood risk assessment and management, especially in consideration of expected future increases (e.g. Grillakis et al., 2011; Palynchuk, 2012) in rain event intensities with 
climate change.

Although significant trends in flow regime are detected with year, other mechanisms are responsible for these changes, not time itself. Potential causal factors for flow regime changes over the 42-year period include: increased impervious land cover (Schueler et al., 2009); reduced vegetative cover (Raymond et al., 2008; Costa et al., 2003); loss of wetlands and other natural water storage capacity (Hümann et al., 2011); changes in surface water-groundwater exchange (Barron et al., 2013; Ryan et al., 2010); drainage infrastructure changes (such as increased drainage efficiency through engineered infrastructure) (Navratil et al., 2013); changes in evaporative demand within the watershed (Tomer and Schilling, 2009), possibly complicated by heat island effects (Adamowski and Prokoph, 2013). Lower impervious land cover in more recent periurban subdivisions (Aichele and Andresen, 2013) and efforts to apply low impact development stormwater management techniques (Hood et al., 2007) may alter the relationship of urban land use to flow response in more recent years. Climate-related changes, such as increased evapotranspiration may also be effecting change in flow patterns (Grillakis et al., 2011). The empirical, cumulative effect on runoff generation and mainstem river flow regimes identified in this study may result from one, or a combination of several, of these factors.

Although only four data points were available to estimate minimum urban area over the time period, the fit of the statistical model for total flow explains almost the same variation as the model with year (difference in $\mathrm{R}^{2}=0.01$ ). This result is consistent with a 
hypothesis that mechanistic factors associated with increasing urban area explain the increase in total flow within the four decade timeframe. Our empirical model results also corroborate spatially-distributed simulated hydrologic modelling results (using MIKESHE and MIKE 11) reported by Chu et al. (2013) that show increases in high flow frequencies with increasing urbanization. Further empirical research is warranted to assess whether or not urban extent ultimately explains more variation than year or whether other temporal factors should also be examined to explain the trends.

Climate modelling studies predict rainfall intensity will increase and severe rainfall events will become more frequent (e.g. Grillakis et al., 2011), including within the Toronto region (Palynchuk, 2012). These changes will necessitate revision of urban infrastructure design standards (e.g. Willems, 2013; Langeveld et al., 2013) and influence multiple aspects of water-dependent ecosystems (Barron et al., 2012). Studies have estimated the respective contributions of changes in climate and changes in land use (e.g. Peña-Arancibia et al., 2012; Tu, 2009; Raymond et al., 2008). In contrast to the modelling predictions for the future, the empirical results of this study indicate stable rainfall patterns during the four decade study period. Our results indicate that hydrologic stationarity within the Don and Humber watersheds has been compromised by urbanization over the past four decades. As the loss of climatic stationarity progresses (Milly et al., 2008), studies of contemporary urban flow regime change will also need to consider the contributions of both urbanization and climate change to fully understand observed trends in event-scale hydrologic response. Our results for the study period indicate that the risks posed by urbanization to hydrologic stationarity have been more 
relevant than those posed by climate change.

\subsection{Conclusions}

The present study begins to characterize flow regime changes associated with urbanization using high resolution flow data. The results can be used to: 1) assess the limitations of coarser resolution data in defining flow regime changes; 2) assist hypothesis development regarding mechanistic causal factors associated with shifts in urban aquatic biodiversity; and, 3) assist in differentiating between loss of hydrologic stationarity associated with climate-induced change and hydrologic shifts attributable to urbanization.

Our findings demonstrate that long-term high temporal resolution mainstem flow patterns can be used to identify significant changes in event flow regimes, including peak event flows, rising limb flows and event flow accelerations, within urbanizing watersheds. These changes are indicative of marked cumulative hydrologic impacts of land cover change during a four decade period prior to detectable alterations in rainfall patterns. The results also point towards research opportunities to identify potential causal mechanisms associated with chronic alteration of event flows and flow accelerations that may contribute to reduced aquatic biodiversity in urbanized watersheds. In light of these results, a precautionary approach is warranted with respect to further hardening of the Don and Humber watershed land surfaces to protect aquatic communities and in consideration of increased flood risks. Overall, the results warrant further research into potential strategies for mitigating physical and biological damage to streams and 
floodplains within urbanizing watersheds.

\subsection{Acknowledgements}

The authors gratefully acknowledge Tom Arsenault (EC) and James Duncan (TRCA) for responding to data requests and follow-up questions; Pete Thompson for watershed shapefiles and discussion of his research; Junchi Li for assisting with Illustration 4-1; C. Scott Findlay, Doug King and Antoine Morin for review of an earlier draft; and, two anonymous reviewers. Funding for M.P. Trudeau's research through Carleton University scholarship and contributions from Environment Canada's research assistant program are gratefully acknowledged. Funders had no role in scoping or undertaking this study. 


\section{Chapter: Empirical Assessment of Watershed Scale Effects of Urbanization on Event Flow Hydrology in Watersheds of Canada's Great Lakes-St Lawrence Basin}

Material from this chapter is under review by Journal of Hydrology peers. Citations should be taken from the published article, once available.

\section{Key Words}

Urban hydrology; event-scale runoff; high temporal resolution; flow acceleration; hydrologic stationarity

\subsection{Introduction 9}

Urbanization alters natural stream flow regimes (e.g. Hammer, 1972; Booth and Jackson, 1997; Schueler et al., 2009) but the nature of these changes has not been fully characterized due to a lack of appropriate long-term, high-resolution records for flow, rainfall and land use. This empirical study examines flows in 27 urbanizing watersheds of

\footnotetext{
${ }^{9}$ Abbreviations: Organizations: Environment Canada (EC); Meteorological Service of Canada (MSC); Water Survey of Canada (WSC); Toronto and Region Conservation Authority (TRCA), Credit Valley Conservation Authority (CVCA). Analytical: $80 \%$ of rising limb event runoff (80RLER); $95 \%$ of rising limb event runoff (95RLER). Statistical: Akaike's Information Criterion with correction for finite sample sizes (AICc); Confidence Interval (CI); degrees of freedom (df); generalized additive model (GAM); Other: no date (n.d.).
} 
the Great Lakes Basin, between May $26^{\text {th }}$ and November $15^{\text {th }}$, at a temporal resolution of 15-minutes over a span of 42 years. This unique dataset allows for detailed estimates of peak flows, rising limb event flows and rising limb event flow accelerations.

Stream flows vary by watershed due to numerous variables including catchment size, channel and basin slope, geomorphology, groundwater discharge and land cover. With urbanization, impervious surface area increases while, concurrently, landscape vegetation is reduced. A reduction in vegetation reduces the infiltration capacity of soils (Boers and Ben-Asher, 1982) and also reduces water volumes transpired, intercepted and evaporated (Boers et al., 1986). A crust forms on bare soils from the impact of raindrops, further reducing soil infiltration (Morin and Benyamini, 1977). Surface storage is reduced where wetlands and surface depressions are filled in. Evaporation rates may be higher with heat island effects (Adamowski and Prokoph, 2013), which may offset some of the additional volume leaving as stream flow.

Stream degradation commences between $2 \%$ and $15 \%$ impervious cover, depending on the indicator and region (Schueler et al., 2009). Alterations in channel dimensions and the number of discharges exceeding bankfull change with time even after land use alterations cease (Dunne and Leopold, 1978). An impervious cover model, proposed as a management tool by Schueler (1994) to anticipate stream conditions based on impervious cover within a watershed, included headwater watersheds sized 5 to $50 \mathrm{~km}^{2}$ (Schueler et al., 2009). Larger watersheds ( 75 to $150 \mathrm{~km}^{2}$ ) had less consistent flow responses to urbanization (Schueler et al., 2009). Although overall flow responses are documented in 
the literature, changes on an event time-scale for a wide range of watershed sizes are not. This lack of resolution precludes a full understanding of associations of changes in urban hydrology with aquatic biota.

In addition to changes in flow regime, evidence from geographically diverse studies associate low impervious land use ( $10 \%$ or less) with negative biotic response (Schueler et al., 2009, Stanfield and Kilgour, 2006, Chin, 2006, Walsh et al., 2001). This present study examined flow responses in the low urban cover range (i.e. $0.1 \%$ to $25 \%$ urban cover) to assess whether runoff responses were quantifiably different (i.e. whether there was a 'threshold' in flow response) in watersheds with less than $10 \%$ urban cover from those over $10 \%$. Flow regime perturbations associated with stress to aquatic communities were of particular interest; thus, rising limb event flow characteristics (e.g. Clausen and Biggs, 1997; Gibbins et al., 2001) were examined. Increased event flows result in increased stream power with potential direct and indirect effects on habitat (flow velocities and substrate stability, for example). Flow regime changes that could trigger or contribute to documented negative biotic responses were of interest, although a full examination of potential causal and confounding factors was beyond the scope of this study.

Watershed protection and restoration efforts in urbanizing watersheds tend to focus on riparian zone protection and existing forested areas. For instance, in the TRCA's jurisdiction, forest cover is present in rural and upper headwater regions and "along the river and creek valleys" (TRCA, 2013, p.2). The riparian corridors within urban areas of 
the watersheds in this study region can be traced visually because urban areas were developed abutting riparian zones (see, for example, Illustration C.2 Appendix C). Study region Conservation Authorities are promoting low impact development (LID) techniques within new subdivisions (CVCA and TRCA, 2010), but there are many barriers to full implementation of these techniques.

The overarching objective of this study was to empirically determine if changes in flow regime are associated with increased urban land use through spatial analysis of catchments of various sizes (from $37.5 \mathrm{~km}^{2}$ to $806 \mathrm{~km}^{2}$ ) and varying proportions of urban land use (from less than $0.1 \%$ to over $87 \%$ ). Statistical models were developed for the change in seasonal and event-scale hydrologic response to rainfall as a function of urban percent (UP) cover and watershed size. The possibility of threshold changes in total runoff with increasing urban land cover was also examined. Specifically, we asked the following questions: 1) At what percent land use does an effect of urban cover on total runoff or runoff coefficient $(\mathrm{RC})$ become detectable and is there evidence of a threshold effect; 2) Are there scale effects in the response of total runoff or RC to increasing UP when other independent variables are taken into account, including total rainfall, channel slope, basin slope and groundwater contribution (measured as Baseflow Index (BFI)); 3) What is the influence of UP on event-scale hydrograph characteristics including peak event flows and rising limb flow accelerations; and, 4) Are there watershed scale effects evident in event flows with increasing UP? Changes in seasonal and event scale flow characteristics in response to urbanization have implications for aquatic biodiversity, 
infrastructure design and risk assessments, watershed management and land development protocols, and may exacerbate climate change risks.

\subsubsection{Study Region}

The 27 watersheds are located in 11 river systems confluent with Lake Ontario and Lake Erie in the vicinity of the Greater Toronto Region within the Canadian Great Lakes Basin (Illustration 5-1).

This region experienced heavy urbanization during the study period, 1969 to 2010, and the City of Toronto is now the fourth largest city by population in North America (City of Toronto, 2014).

Toronto Region's climate is moderate humid continental (Koppen climate classification Dfa) (AKCanada, n.d.) with average precipitation of $831 \mathrm{~mm} /$ year (Government of Canada, 2014), including rainfall in all months and snow in winter. The frost free period typically occurs between April 13 and November 3 (Government of Canada, 2014). 


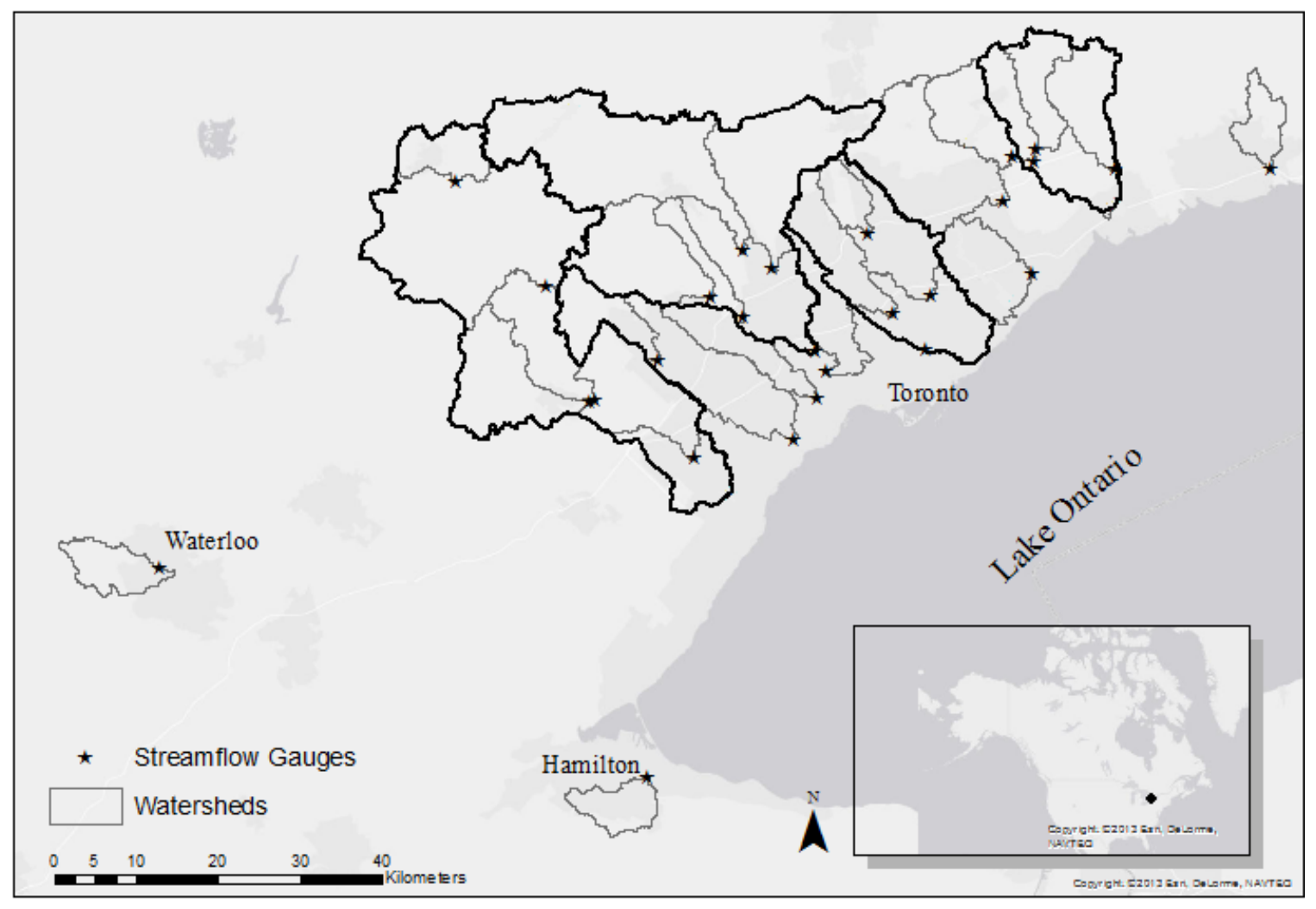

\section{Illustration 5-1 Watershed locations.}

Watersheds are located in the vicinity of Toronto, Ontario, Canada within the Great Lakes St Lawrence Basin. Some study watersheds are nested within others. Darker outlines indicate the four largest watersheds, from west to east: Credit, Humber, Don, Duffins. Light grey lines indicate mainstem and large branch channels. 


\subsection{Methods/ Materials}

\subsubsection{Introduction}

In this study, urban land use is defined as lands drained by engineered urban drainage systems. The term watershed is used in a generic sense without implications for nested relationships among watersheds. We focus our analysis on the annual period between May $26^{\text {th }}$ to November $15^{\text {th }}$ to exclude freshet variability and complications arising from lack of snowmelt records, and to include seasons with rainfall-dominated precipitation.

This spatial study developed empirical statistical models for total runoff and event-scale hydrologic characteristics using the potential independent variables watershed area, percent urban area, total seasonal rainfall, basin and channel slopes, and baseflow index (BFI). The rationale and methods for choice of location, hydrologic data preparation and analyses, and hourly rain data preparation and analyses are given in Trudeau and Richardson (2015). Data sources, data processing and statistical methods are described below.

\subsubsection{Data sources and study watersheds}

Hydrometric records from Environment Canada's (EC) Water Survey of Canada (WSC) 15 minute stream flow data were used, called the "instantaneous hydrometric dataset" by EC. Rainfall data were supplied by EC's Meteorological Service of Canada (MSC) in the Daily Record of Hourly Data (HLY) format. 
ESRI's ArcGIS shapefiles for tertiary watersheds were obtained from the Province of Ontario website (Government of Ontario, 2012). ArcGIS shapefiles to delineate study watersheds upstream of hydrologic gauge sites were developed using data sets from the Government of Ontario's Integrated Hydrology Data Part 2 (Southwest), including: enhanced flow direction grid; stream grid; and, enforced Digital Elevation Model (DEM) (Government of Ontario, 2013). Watershed delineation information was also provided by P. Thompson for the Don River years included in his study (Thompson, 2013). The Toronto and Region Conservation Authority (TRCA) provided ArcGIS files for two watersheds and the Credit Valley Conservation Authority (CVCA) provided watershed shapefiles with land use data.

UP estimates were obtained from three sources: 1) Thompson, 2013; 2) CVCA ArcGIS shapefiles for four years; and, 3) digitization of historic aerial photographs, purchased from Natural Resources Canada (NRCan).

An overview of the 27 watersheds is provided in Table 5-1. All river systems are confluent with Lake Ontario except Laurel Creek, which is a tributary to the Grand River confluent with Lake Erie. About half of the watershed rivers are regulated while the remainder have natural flows (Appendix F). Each hydrologic gauge was matched with a proximal rain gauge with matching years of record. Seven rain gauges were used in the analysis (Appendix E). 
Table 5-1 River systems, watersheds, gauges and urban land use sources.

River systems, watersheds, watershed areas, hydrologic and rainfall gauge stations, years with urban land use estimates and sources. ('Trudeau team' refers to the research assistants and GIS specialists who assisted in developing the database for this research.) See Appendices $F$, $G$ and $H$ for additional information.

\begin{tabular}{|c|c|c|c|c|c|}
\hline $\begin{array}{l}\text { River } \\
\text { system }\end{array}$ & $\begin{array}{l}\text { Hydrologic station location } \\
\text { for study watersheds }\end{array}$ & $\begin{array}{l}\text { Watershed } \\
\text { area }(\text { to } \\
\text { gauge }\left(\mathbf{k m}^{2}\right)\end{array}$ & $\begin{array}{l}\text { EC hydro } \\
\text { station }\end{array}$ & $\begin{array}{l}\text { EC rain } \\
\text { gauge }\end{array}$ & $\begin{array}{l}\text { Years with } \\
\text { urban land use } \\
\text { data (source) }\end{array}$ \\
\hline \multirow[t]{5}{*}{ Credit } & West Branch at Norval & 131.5 & 02HB008 & 6158733 & \multirow{5}{*}{$\begin{array}{ll}-1999,2003,2007, \\
2011(\mathrm{CVCA})\end{array}$} \\
\hline & Mainstem near Orangeville & 59.3 & $02 \mathrm{HB} 013$ & 6155790 & \\
\hline & Mainstem at Boston Mills & 414.0 & 02HB018 & 6158733 & \\
\hline & Mainstem at Norval & 641.4 & $02 \mathrm{HB} 025$ & 6158733 & \\
\hline & Mainstem at Streetsville & 770.7 & 02HB029 & 6158350 & \\
\hline \multirow[t]{4}{*}{ Don } & Mainstem at York Mills & 84.2 & $02 \mathrm{HC} 005$ & 6158350 & \multirow{4}{*}{$\begin{array}{ll}\text { - } & 1974,1985,1988 \\
\text { (Trudeau team) } \\
\text { 1970, 1978, 1995, } \\
\text { 2005 (Thompson, } \\
\text { 2013; adjusted) }\end{array}$} \\
\hline & Mainstem at Todmorden & 311.0 & $02 \mathrm{HC} 024$ & 6158350 & \\
\hline & Little Don at Don Mills & 127.4 & 02HC029 & 6158350 & \\
\hline & East Branch near Thornhill & 37.5 & $02 \mathrm{HC} 056$ & 6158350 & \\
\hline \multirow{3}{*}{ Duffins } & Mainstem above Pickering & 86.9 & 02HC019 & 6153020 & \multirow{3}{*}{$\begin{array}{l}1978 \text { (Trudeau } \\
\text { team) }\end{array}$} \\
\hline & West Branch at Green River & 107.4 & $02 \mathrm{HC} 026$ & 6155878 & \\
\hline & West Branch above Green River & 62.0 & $02 \mathrm{HC} 038$ & 6155878 & \\
\hline \multirow[t]{2}{*}{ Etobicoke } & Mainstem at Brampton & 72.0 & $02 \mathrm{HC} 017$ & 6158350 & \multirow{2}{*}{\begin{tabular}{|l} 
- $1974,1985,1988$ \\
(Trudeau team) \\
1970, 1978, 1995, \\
2005 (Thompson, \\
2013)
\end{tabular}} \\
\hline & Mainstem below QEW & 209.3 & $02 \mathrm{HC} 030$ & 6158350 & \\
\hline Harmony & Mainstem at Oshawa & 42.9 & $02 \mathrm{HD} 013$ & 6155878 & $\begin{array}{l}\text { 1995, 2005 } \\
\text { (Thompson, } \\
\text { 2013) } \\
\end{array}$ \\
\hline Highland & Mainstem near West Hill & 90.5 & $02 \mathrm{HC} 013$ & 6158350 & $\begin{array}{l}\text { - } 1985 \text { (Trudeau } \\
\text { team) } \\
\text { 1978, 1995, } 2010 \\
\text { (Thompson, } \\
\text { 2013) } \\
\end{array}$ \\
\hline \multirow{6}{*}{ Humber } & Mainstem near Weston & 805.6 & $02 \mathrm{HC} 003$ & 6158350 & \multirow{6}{*}{$\begin{array}{ll}-1969,1988 \\
\text { (Trudeau team) } \\
\text { 02HC027: 1970, } \\
\text { 1978, 1995, 2005 } \\
\text { (Thompson, } \\
\text { 2013) }\end{array}$} \\
\hline & East Branch near Pine Grove & 195.2 & 02HC009 & 6158350 & \\
\hline & Mainstem at Elder Mills & 296.4 & $02 \mathrm{HC} 025$ & 6158350 & \\
\hline & Black Creek near Weston & 63.7 & $02 \mathrm{HC} 027$ & 6158350 & \\
\hline & Mainstem at Highway 7 & 142.4 & $02 \mathrm{HC} 031$ & 6158350 & \\
\hline & West Branch below Dam & 183.3 & $02 \mathrm{HC} 034$ & 6158350 & \\
\hline
\end{tabular}




\begin{tabular}{|c|c|c|c|c|c|}
\hline $\begin{array}{l}\text { River } \\
\text { system }\end{array}$ & $\begin{array}{l}\text { Hydrologic station location } \\
\text { for study watersheds }\end{array}$ & $\begin{array}{l}\text { Watershed } \\
\text { area (to } \\
\text { gauge) }\left(\mathrm{km}^{2}\right)\end{array}$ & $\begin{array}{l}\text { EC hydro } \\
\text { station }\end{array}$ & $\begin{array}{l}\text { EC rain } \\
\text { gauge }\end{array}$ & $\begin{array}{ll}\text { Years with } \\
\text { urban land } \\
\text { use data } \\
\text { (source) }\end{array}$ \\
\hline $\begin{array}{l}\text { Laurel } \\
\text { (Upper } \\
\text { Grand) }\end{array}$ & Mainstem at Waterloo & 56.9 & 02GA024 & 6149387 & $\begin{array}{l}\text { - } 1971,1982,1990, \\
\text { 1995, 2005 } \\
\text { (Thompson, } \\
\text { 2013) }\end{array}$ \\
\hline Mimico & Mainstem at Islington & 68.8 & $02 \mathrm{HC} 033$ & 6158350 & $\begin{array}{ll}\text { - } & \text { 1974, 1985, } 1988 \\
\text { (Trudeau team) } \\
\text { 1995, 2005 } \\
\text { (Thompson, } \\
\text { 2013) } \\
\end{array}$ \\
\hline $\begin{array}{l}\text { Red Hill } \\
\text { (Niagara) }\end{array}$ & Mainstem at Hamilton & $\begin{array}{c}56.3 \\
\text { (Thompson, 2013) }\end{array}$ & 02НA014 & 6153300 & $\begin{array}{l}\text { 1978, } 1995 \\
\text { (Thompson, } \\
\text { 2013) } \\
\end{array}$ \\
\hline \multirow{2}{*}{ Rouge } & Mainstem near Markham & 187.0 & $02 \mathrm{HC} 022$ & 6158350 & \multirow{2}{*}{\begin{tabular}{|l} 
1969, 1974, 1978, \\
1981, 1985, 1988 \\
(Trudeau team) \\
1995, 2005, 2010 \\
(Thompson, \\
2013) \\
\end{tabular}} \\
\hline & Little Rouge near Locust Hill & 83.6 & $02 \mathrm{HC} 028$ & 6158350 & \\
\hline
\end{tabular}


Baseflow index (BFI) data were provided by Dr. J. Buttle (pers. comm., 2015; see Buttle et al., 2015) and a USGS study (G Model, HYSEP1 Method, Neff et al., 2005). Where BFI estimates were not available for a watershed, the BFI of an adjacent watershed or river network was assigned (Appendix F).

\subsubsection{Data preparation}

The data processing methods described in Trudeau and Richardson (2015) for two hydrologic stations $(02 \mathrm{HC} 024$ and $02 \mathrm{HC} 003)$ and rain gauge 6158350 were also applied to the additional hydrologic stations and rain gauges in this study. As described in the following sub-sections, additional data processing was required to: delineate watershed areas upstream of each hydrologic gauge; identify catchment slopes; digitize urban extent from aerial photographs; and, assemble data sets for each watershed.

\subsubsection{Watershed area upstream of hydrologic gauges}

Watershed areas were delineated in ESRI's ArcGIS mapping software. Three Province of Ontario data layers (enhanced flow direction grid, stream grid, and enforced DEM layers (Government of Ontario, 2013)) were extracted and clipped using the Ontario Tertiary Watersheds shapefiles (Government of Ontario, 2012). A point shapefile of pour points was generated for hydrologic stations using R package 'sp' (Pebesma et al., 2014) and snapped to a flow accumulation grid, created using the ArcGIS Flow Accumulation tool. Watersheds upstream of the pour points were delineated using custom script within the ArcGIS Hydrology tool and converted to polygons. These polygons delineated all watersheds, except for those within the Credit River system (where CVCA shapefiles 
were used) and Red Hill watershed (where the Thompson (2013) effective area was used).

\subsubsection{Catchment slopes}

Channel slopes (Appendix F) were defined by first creating a polyline file of longest flow path, generated using custom script within the ArcHydro Terrain Preprocessing tool. Input layers included the watershed polygons, Ontario enhanced flow direction grid and Ontario enforced DEM files. Channel slope was calculated using the Compute Line Parameters tool in ArcHydro. Mean basin slopes (Appendix F) were calculated using open source software, SAGA (SAGA GIS, n.d.), with the Ontario enforced DEM and Ontario stream grid. Slopes were computed in ArcGIS using the ArcHydro Slope tool. A slope grid was created using the ArcGIS Spatial Analyst Raster Calculator tool. SAGA, R code (R Core Team, 2012) and the ArcGIS Grid Statistics for Polygons tool were used to calculate mean basin slopes.

\subsubsection{Estimation of urban extent from aerial photographs}

Through contract, NRCan scanned selected aerial photos from negatives using the highest potential resolution available (80 dots per $\mathrm{mm})$. Photo scales included: 1:25000; $1: 30000 ; 1: 40000 ; 1: 50000$, resulting in nominal ground pixel sizes of approximately $0.31 \mathrm{~m}, 0.38 \mathrm{~m}, 0.50 \mathrm{~m}$, and $0.62 \mathrm{~m}$, respectively. Years for aerial photo analysis were chosen on the basis of: 1) good photo coverage of an entire watershed; and 2) coverage in years with available hydrologic and rainfall data. Partial coverage was accepted for years 
where earlier and later years' photos covered the missing area. Missing photo coverage tended to be in the upper, less urbanized areas of the watersheds (Appendix G).

Photos were georeferenced using ESRI's ArcMap Geo-referencing tool and ground control points from the 2005 Ontario road network (Statistics Canada, 2005). Urban areas were digitized using ArcMap's polygon feature. The methodology for urban area identification by Thompson (2013) was adopted to the extent possible so Thompson's UP estimates could be included in our analysis. Urban areas were identified by visual inspection on the basis of urban road patterns. Excluded from urban areas were green spaces larger than 1 ha, golf courses, quarries and farm operations, on the assumption that none of these land uses would generate runoff typical of urban landscapes. Identifiable new subdivisions, even if not yet paved, were included on the assumption that urban storm sewer infrastructure was already in place. Major highways, including cloverleaf interchanges, were included in the urban designation. Thompson (2013) UP estimates in the Don watershed were adjusted for the topographic watershed area rather than effective watershed area. Trends in UP by year for watersheds with multiple UP estimates were reviewed to check for consistent and feasible rates of change with time. Some UP estimates in Thompson (2013) were not used in this study because the trends were discontinuous with our estimates.

\subsubsection{Database assembly}

A database of observations by watershed was assembled, including flow, rain, watershed area, urban area, basin slope, channel slope, number of flow-rain pairs. The full record of 
flow-rain observations per year (May $26^{\text {th }}$ to November $15^{\text {th }}$ ) comprises 16,708 pairs of 15-minute records, created assuming rainfall is constant within each one-hour rainfall record (Trudeau and Richardson, 2015). Years with fewer than 30\% of the potential pairs were removed from the dataset.

Hydrologic responses to rain events with rising limbs lasting longer than 4.5 days to peak were removed from the record since they likely reflect other factors, such as a change in baseflow or unrecorded rainfall (due to the proximity of the available rain gauge to the hydrologic gauge). The number of events removed per watershed (all years) ranged from 0 to 9 , with an average of fewer than three events removed per watershed.

Some years with urban observation did not have flow-rain data available in that year. To maximize the number of records in the database, where no same-year flow-rain records were available, the urban observation was matched to the flow-rain data of the following year. The resulting dataset included 93 observations (Appendix I).

\subsubsection{Statistical analyses}

The first statistical analyses assessed the independence of rainfall with time because rainfall was an independent variable in the spatial analyses to predict flow characteristics. Subsequently, we explored the association between various characteristics of the flow regime, including: (1) total runoff; (2) runoff coefficient; (3) rising limb event runoff $\left(10^{\text {th }}\right.$ percentile, $20^{\text {th }}$ percentile, $80^{\text {th }}$ percentile and $95^{\text {th }}$ percentile $)$; and, (4) rising limb event flow accelerations. 
The 27 watersheds flow within 11 river systems and, therefore, some of the smaller watersheds are nested within larger watersheds. (See Appendix $\mathrm{H}$ for a schematic of the relationships of nested watersheds within river systems.) Preliminary analyses, including spatial and temporal auto-correlation assessments, supported an assumption that the nested watersheds in the database could be assumed to be independent for purposes of flow analyses.

Statistical model fit was compared using Akaike's Information Criterion with correction for finite sample sizes (AICc) (Mazerolle, 2013) and adjusted R-squared. Models were fit by sequentially adding independent variables and assessing improvement in fit with $\mathrm{F}$ tests. Linear models were tested for conformance to parametric inference assumptions using the following tests (R package 'Imtest'; Hothorn et al., 2015): Breusch-Pagan (heteroscedasticity); Durbin-Watson (serial autocorrelation); RESET (linearity); and, Shapiro-Wilk (normality of residuals). Where assumptions were violated, non-parametric tests, including Mann Kendall, Wilcoxon Rank Sum, Kendall rank sum correlation and Kruskal-Wallis, were employed for hypothesis-testing. Alternatively, in two cases $\left(80^{\text {th }}\right.$ percentile rising limb runoff and the relationship of event flow acceleration with 80RLER), a generalized additive model (GAM) was fit using R package 'mgcv' (Wood, 2015). To assess the effect size of independent variables in models, analyses of deviance were run using the R package 'car' (Fox and Weisberg, 2011) and the 'Anova type III' command; the partial $\mathrm{R}^{2}$ was calculated for each variable as the ratio of the sum of squares to total sum of squares.

\subsubsection{Variables}


Total runoff means all flow during the seasonal period, including baseflow and storm event flows, divided by watershed area $\left(\mathrm{mm}^{-s^{2}} \operatorname{son}^{-1}\right)$. Event runoff is a rising limb event flow estimation divided by watershed area $\left(\mathrm{mm} \mathrm{s}^{-1}\right)$. Event runoff analyses included the $80^{\text {th }}$ percentile rising limb event runoff (80RLER) and $95^{\text {th }}$ percentile (95RLER). The 95RLER was used to represent maximum flows in place of actual maximum flows to avoid variability introduced by very large individual large rain storms. The $80^{\text {th }}$ percentile

flow rate was used because flow distributions were highly positively skewed; $80^{\text {th }}$ percentile event flows were higher than mean flows for 56 database records and lower for 37 records. Event analyses also included $10^{\text {th }}$ and $20^{\text {th }}$ percentile flows to help inform results for the higher event flow trends; Mann Kendall slopes were estimated with total rainfall as a covariate.

Dependent and independent variables are described in Table 5-2. Year, in all cases, is seasonal year (May 26 to November 15 inclusive). BFI is not independent of stream flow since it is calculated as a ratio of baseflow to streamflow. However, BFI estimates used in the analyses were derived by researchers using multiple years of data (e.g. Neff et al., 2005) in research not connected to this study. BFI explained variation not attributable to UP and so it was used as an independent variable for statistical models.

\subsubsection{Rainfall}

Total rainfall gives an indication of whether the year was relatively wet, dry or average in terms of precipitation. It does not indicate the number or magnitude of individual rain events in the year. Analyses of three of the seven rain stations in this study (rain stations 
6155790, 6158733, 6158350) are described in Trudeau and Richardson (2015). Trends with year at the remaining four stations $(6153300,6149387,6153020,6158733)$ were analyzed with the Mann Kendall test (R Package 'rkt' (Marchetto, 2013)). 
Table 5-2 Dependent and independent variables used in statistical models.

Interactions of independent variables were also included using the independent variables as described in this Table.

\begin{tabular}{|c|c|c|c|c|c|}
\hline $\begin{array}{l}\text { Dependent } \\
\text { Variable }\end{array}$ & Description & Units & $\begin{array}{l}\text { Independent } \\
\text { variables } \\
\text { tested }\end{array}$ & Description & Units \\
\hline \multirow[t]{2}{*}{ Total rainfall } & \multirow[t]{2}{*}{$\begin{array}{l}\text { Total rainfall between May } \\
26 \text { to November } 15 \\
\text { inclusive }\end{array}$} & \multirow[t]{2}{*}{$\mathrm{mm} \mathrm{season}^{-1}$} & Year & Seasonal year & $\begin{array}{l}\text { Year (also } \\
\text { called } \\
\text { 'season') }\end{array}$ \\
\hline & & & $\begin{array}{l}\text { Total hours with } \\
\text { records }\end{array}$ & $\begin{array}{lr}\text { Number } & \text { of } \\
\text { hours } & \text { with } \\
\text { rainfall } & \text { records } \\
\text { (includes } & \text { zero } \\
\text { rainfall) } & \\
\end{array}$ & $\begin{array}{l}\text { hours } \\
\text { season }^{-1}\end{array}$ \\
\hline \multirow{2}{*}{$\begin{array}{l}\text { Rain event } \\
\text { frequency }\end{array}$} & \multirow[b]{2}{*}{$\begin{array}{l}\text { Number of rain events per } \\
\text { season. Rain events are } \\
\text { defined to have at least one } \\
\text { hourly period with at least } 5 \\
\text { mm of rain and with no } \\
\text { more than one hour break in } \\
\text { rainfall among consecutive } \\
\text { records }\end{array}$} & \multirow{2}{*}{$\begin{array}{l}\text { number } \\
\text { season }^{-1}\end{array}$} & Year & Seasonal year & year \\
\hline & & & $\begin{array}{l}\text { Total hours with } \\
\text { records }\end{array}$ & See above & \\
\hline $\begin{array}{l}\text { Rain event } \\
\text { maximum } \\
\text { intensity in } \\
\text { one hour }\end{array}$ & $\begin{array}{l}\text { Maximum rainfall in one } \\
\text { hour for each event in a } \\
\text { season }\end{array}$ & $\begin{array}{l}\text { mm } \text { hour }^{-1} \\
\text { event }^{-1}\end{array}$ & Year & See above & \\
\hline \multirow{2}{*}{$\begin{array}{l}\text { Total hours } \\
\text { with rain }\end{array}$} & \multirow{2}{*}{$\begin{array}{l}\text { Number of hours with } \\
\text { rainfall of any recorded } \\
\text { depth }\end{array}$} & \multirow{2}{*}{$\begin{array}{l}\text { number } \\
\text { season }^{-1}\end{array}$} & Year & See above & \\
\hline & & & $\begin{array}{l}\text { Total hours with } \\
\text { records }\end{array}$ & See above & \\
\hline $\begin{array}{lr}\text { Rain } & \text { event } \\
\text { depth } & \text { per } \\
\text { event } & \\
\end{array}$ & $\begin{array}{l}\text { Total depth of rainfall } \\
\text { during a rain event }\end{array}$ & $\mathrm{mm}$ event $^{-1}$ & Year & See above & \\
\hline \multirow[t]{4}{*}{ Total runoff } & \multirow[t]{4}{*}{$\begin{array}{l}\text { Total flow }\left(\mathrm{m}^{3} \mathrm{~s}^{-1}\right) \text { from } \\
\text { May } 26^{\text {th }} \text { to November } 15^{\text {th }} \\
\text { inclusive, divided by } \\
\text { watershed area }\end{array}$} & \multirow[t]{4}{*}{ mm season $^{-1}$} & $\begin{array}{l}\text { Urban percent } \\
\text { (UP) }\end{array}$ & $\begin{array}{l}\text { Urban land area } \\
\text { divided by total } \\
\text { watershed area } \\
\text { times } 100\end{array}$ & unitless \\
\hline & & & Total rainfall & See above & ${ }_{1}^{\mathrm{mm}}$ season $^{-}$ \\
\hline & & & $\begin{array}{l}\text { Baseflow Index } \\
\text { (BFI) }\end{array}$ & $\begin{array}{l}\text { Baseflow } \\
\text { relative to } \\
\text { stream flow } \\
\text { (Buttle et al., } \\
2015)\end{array}$ & unitless \\
\hline & & & $\begin{array}{l}\text { Mean channel } \\
\text { slope }\end{array}$ & $\begin{array}{l}\text { Mean estimated } \\
\text { slope of water } \\
\text { course }\end{array}$ & $\mathrm{m} \mathrm{km}^{-1}$ \\
\hline
\end{tabular}




\begin{tabular}{|c|c|c|c|c|c|}
\hline $\begin{array}{l}\text { Dependent } \\
\text { Variable }\end{array}$ & Description & Units & $\begin{array}{l}\text { Independent } \\
\text { variables } \\
\text { tested } \\
\end{array}$ & Description & Units \\
\hline & & & $\begin{array}{l}\text { Mean basin } \\
\text { slope }\end{array}$ & $\begin{array}{l}\text { Mean estimated } \\
\text { slope of } \\
\text { watershed basin }\end{array}$ & $\mathrm{m} \mathrm{km}^{-1}$ \\
\hline & & & Watershed area & $\begin{array}{l}\text { Area of the } \\
\text { watershed }\end{array}$ & $\mathrm{km}^{2}$ \\
\hline $\begin{array}{l}\text { Runoff } \\
\text { coefficient } \\
\text { (RC) }\end{array}$ & $\begin{array}{l}\text { Total runoff divided by } \\
\text { total rainfall }\end{array}$ & unitless & See total runoff & & \\
\hline $\begin{array}{l}80^{\text {th }} \text { percentile } \\
\text { rising limb } \\
\text { event runoff } \\
\text { (80RLER) }\end{array}$ & $\begin{array}{l}\text { Flow below which } 80 \% \text { of } \\
\text { rising limb event flows } \\
\text { occurred, pooled by year, } \\
\text { divided by watershed area }\end{array}$ & $\mathrm{mm} \mathrm{s}^{-1}$ & See total runoff & & \\
\hline $\begin{array}{l}95^{\text {th }} \text { percentile } \\
\text { event runoff } \\
\text { (95RLER) }\end{array}$ & $\begin{array}{l}\text { Flow below which } 95 \% \text { of } \\
\text { event flows occurred, } \\
\text { pooled by year, divided by } \\
\text { watershed area }\end{array}$ & $\mathrm{mm} \mathrm{s}^{-1}$ & See total runoff & & \\
\hline $\begin{array}{l}\text { Mean rising } \\
\text { limb event } \\
\text { flow } \\
\text { acceleration } \\
\text { (called mean } \\
\text { acceleration) }\end{array}$ & $\begin{array}{l}\text { Mean of rising limb event } \\
\text { flow accelerations greater } \\
\text { than zero, pooled by year; } \\
\text { acceleration was calculated } \\
\text { as the difference in flow } \\
\text { from one } 15 \text { minute record } \\
\text { to the next divided by the } \\
\text { time interval in seconds }\end{array}$ & $\mathrm{m}^{3} \mathrm{~s}^{-2}$ & $\begin{array}{l}\text { First model: see } \\
\text { total runoff } \\
\text { Second model: } \\
80 \text { RLER was } \\
\text { also an } \\
\text { independent } \\
\text { variable }\end{array}$ & & \\
\hline
\end{tabular}




\subsubsection{Assessment of threshold changes in total flow and runoff coefficient with}

\section{urban cover}

We used breakpoint analysis (R program 'SiZer' (Sonderegger, 2015); R program 'segmented' (Muggeo, 2015)) for records with UP between $0.1 \%$ and $25 \%$ to assess whether a threshold change was evident for total runoff and RC. Based on initial results indicating differing relationships with increasing urban cover at very low UP, the pool of selected observations was sub-divided into watersheds above and below the mean BFI, $\mathrm{BFI}<0.6$ and $\mathrm{BFI} \geq 0.6$.

\subsubsection{Data limitations and error}

Some judgement was required by GIS technicians in delineating urban areas, especially for: 1) rural areas in transition along the periphery of established urban areas; and, 2) former cottage regions in transition to year-round occupancy. Minor roads outside the urban area were not included in urban cover estimates. Catchment areas were kept the same through time within individual watersheds although, with increasing urbanization, engineered drainage systems redefine drainage boundaries. Urban area delineation is not directly equivalent to impervious area since urban areas include pervious surfaces (e.g. lawns, vegetated boulevards, etc.). No information was collected on historic baseflow data; BFI estimates likely underestimate baseflow at the time of the earliest UP estimates. Error is also potentially introduced with the assignment of BFI on the basis of adjacent watershed or river system. Data on change in channel dimensions and sediment loads were not available for the four decade time period. Limitations of the hydrologic and rainfall data are identified in Trudeau and Richardson (2015). 


\subsection{Results}

Analyses of the dataset revealed the following two tendencies in the dataset of potential relevance to inferences drawn. There is a statistically significant decrease in BFI for watersheds with higher urbanization (Kendall rank correlation, $\mathrm{z}=-3.1$, tau $=-0.23, \mathrm{p}=$ 0.002), consistent with Buttle et al. (2015) for this region. There is a non-significant tendency (at 95\% confidence) for UP to decrease with increasing basin slope $(-0.53 \mathrm{~m}$ $\left.\mathrm{km}^{-1}+/-0.29, \mathrm{t}=-1.83, \mathrm{p}=0.07 ; \mathrm{R}^{2}=0.02, \mathrm{RSE}=25.0, \mathrm{df}=91, \mathrm{p}=0.07\right)$.

\subsubsection{Rainfall}

There were no detectable temporal trends in any of the dependent rainfall variables for rain gauges 6158350,6155790 and 6158733 (Trudeau and Richardson, 2015). Similarly, there were no temporal trends for the dependent rainfall variables at any of the additional four rain gauges analyzed in this study (Table 5-3).

\subsubsection{Urban land use threshold tests}

Results for total runoff reflected the same trends as those reported for RC in this section. Illustration 5-2 shows the raw data for UP $<25 \%$, differentiated by BFI above and below 0.6. At urban cover less than $\sim 4 \%$, watersheds with higher groundwater influence (BFI $\geq$ 0.6) demonstrated a negative trend with increasing UP whereas those with lower influence $(\mathrm{BFI}<0.6)$ had a positive trend.

The breakpoint analysis indicated no significant UP threshold for BFI $<0.6$ : the breakpoint was estimated at 3.9\% UP (95\% CI spanned 0 indicating non-significance, from a 
mathematical result of $-0.39 \%$ to $8.12 \%)$; slope 1 estimate $=0.030(95 \%$ CI 0.013 to 0.047); slope 2 estimate $=0.0003(95 \%$ CI -0.005 to 0.005$)$. For BFI $\geq 0.6$, the estimated break-point was statistically significant at $2.2 \%(95 \%$ CI $0.64 \%$ to $3.82 \%)$ but slope 1 could not be reliably estimated (slope1 estimate $=-0.07$ (95\% CI -0.149 to 0.009$)$; slope2 estimate $=0.008(95 \%$ CI 0.003 to 0.013$))$.

\subsubsection{Total runoff}

A model fit to total runoff for the full population of 93 observations had six independent variables (Table 5-4; Illustration 5-3). Although total runoff is estimated as a ratio with watershed area, total runoff increased with an interaction of watershed area and UP. From the model, it is not possible to assess which, or both, of the variables of the interaction (i.e. UP or watershed size) had a greater influence on the interactive effect. Illustration 53 was plotted with raw data differentiated by type of flow regulation to explore the potential influence of river controls on the total runoff relationship; no discernable pattern emerged. (See Appendix F for identification of regulated and natural river systems.) RC results were similar to those for total runoff and are provided in Appendix K. 
Table 5-3 Results for trends with time in rainfall characteristics.

No temporal trends were identified at four rain gauges used in this study. The lower and upper range columns provide the lower and upper Mann Kendall scores for the four rain gauges.

\begin{tabular}{|l|l|l|}
\hline \multicolumn{1}{|c|}{ Rainfall variable } & \multicolumn{1}{c|}{ Covariate } & \multicolumn{1}{c|}{$\begin{array}{c}\text { MK Partial Score Range } \\
\text { (p-value) }\end{array}$} \\
\hline Total rainfall & Total hours with records & $-61.52(0.34)$ to $29.02(0.28)$ \\
\hline Rain event frequency & Total hours with records & $-33.26(0.61)$ to $99.6(0.15)$ \\
\hline $\begin{array}{l}\text { Maximum rain event } \\
\text { intensity }\end{array}$ & Not applicable & $-15(0.85)$ to $10(0.79)$ \\
\hline Total hours with rain & Total hours with records & $-57.61(0.37)$ to 34.33 (0.49) \\
\hline Rain event depth per event & Not applicable & $13(0.87)$ to $79(0.12)$ \\
\hline
\end{tabular}




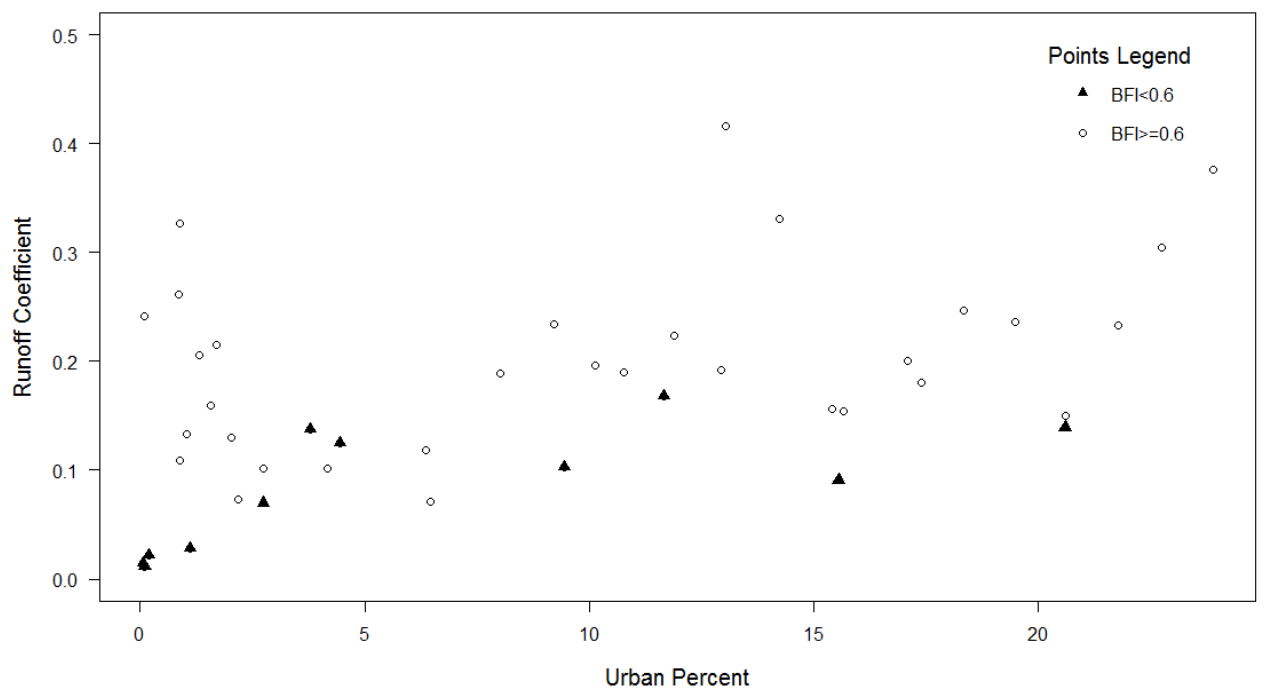

Illustration 5-2 Runoff coefficients versus UP.

Raw data plots illustrate the differing trends at $\mathrm{UP}<\sim 4 \%$ for watersheds with BFI $<0.6$ (solid triangles) versus BFI $\geq 0.6$ (open circles). 
Table 5-4 Model terms for total runoff and partial $\mathbf{R}^{2}$.

\begin{tabular}{|c|c|c|c|c|c|}
\hline $\begin{array}{l}\text { Dependent } \\
\text { Variable }\end{array}$ & Data & $\begin{array}{l}\text { Model } \\
\text { overview }\end{array}$ & $\begin{array}{l}\text { Independent } \\
\text { variable }\end{array}$ & $\begin{array}{l}\text { Coefficient +/- } \\
\text { SE } \\
\text { (p-value) }\end{array}$ & $\begin{array}{l}\text { Partial } \\
\mathbf{R}^{2}\end{array}$ \\
\hline \multirow{6}{*}{$\begin{array}{l}\text { Total runoff } \\
\text { (mm per } \\
\text { season) }\end{array}$} & \multirow[t]{6}{*}{$\begin{array}{l}\text { All } \\
\text { observations }\end{array}$} & \multirow{6}{*}{$\begin{array}{l}\text { Model.1 } \\
\mathrm{R}^{2}=0.87 \\
\mathrm{RSE}= \\
17.9, \mathrm{df}= \\
86 \\
\mathrm{p}<2.2 \mathrm{e}-16\end{array}$} & UP to power 2 & $\begin{array}{l}0.0113+/-2.52 \mathrm{e}-03 \\
(2.43 \mathrm{e}-05)\end{array}$ & 0.07 \\
\hline & & & Total rain & $\begin{array}{l}0.246+/-0.023 \\
(<2 \mathrm{e}-16)\end{array}$ & 0.40 \\
\hline & & & Basin slope & $\begin{array}{l}0.933+/-0.023 \\
(0.0001)\end{array}$ & 0.06 \\
\hline & & & BFI & $\begin{array}{l}75.50+/-37.24 \\
(0.046)\end{array}$ & 0.01 \\
\hline & & & $\begin{array}{l}\text { Interaction UP } \\
\text { with } \log _{10} \\
\text { watershed area } \\
\end{array}$ & $\begin{array}{l}0.364+/-0.0959 \\
(0.0003)\end{array}$ & 0.05 \\
\hline & & & Intercept & $\begin{array}{l}-110.3+/-21.9 \\
(2.44 \mathrm{e}-06)\end{array}$ & $\begin{array}{c}0.09 \text { (and } \\
\text { residuals } \\
0.31)\end{array}$ \\
\hline
\end{tabular}




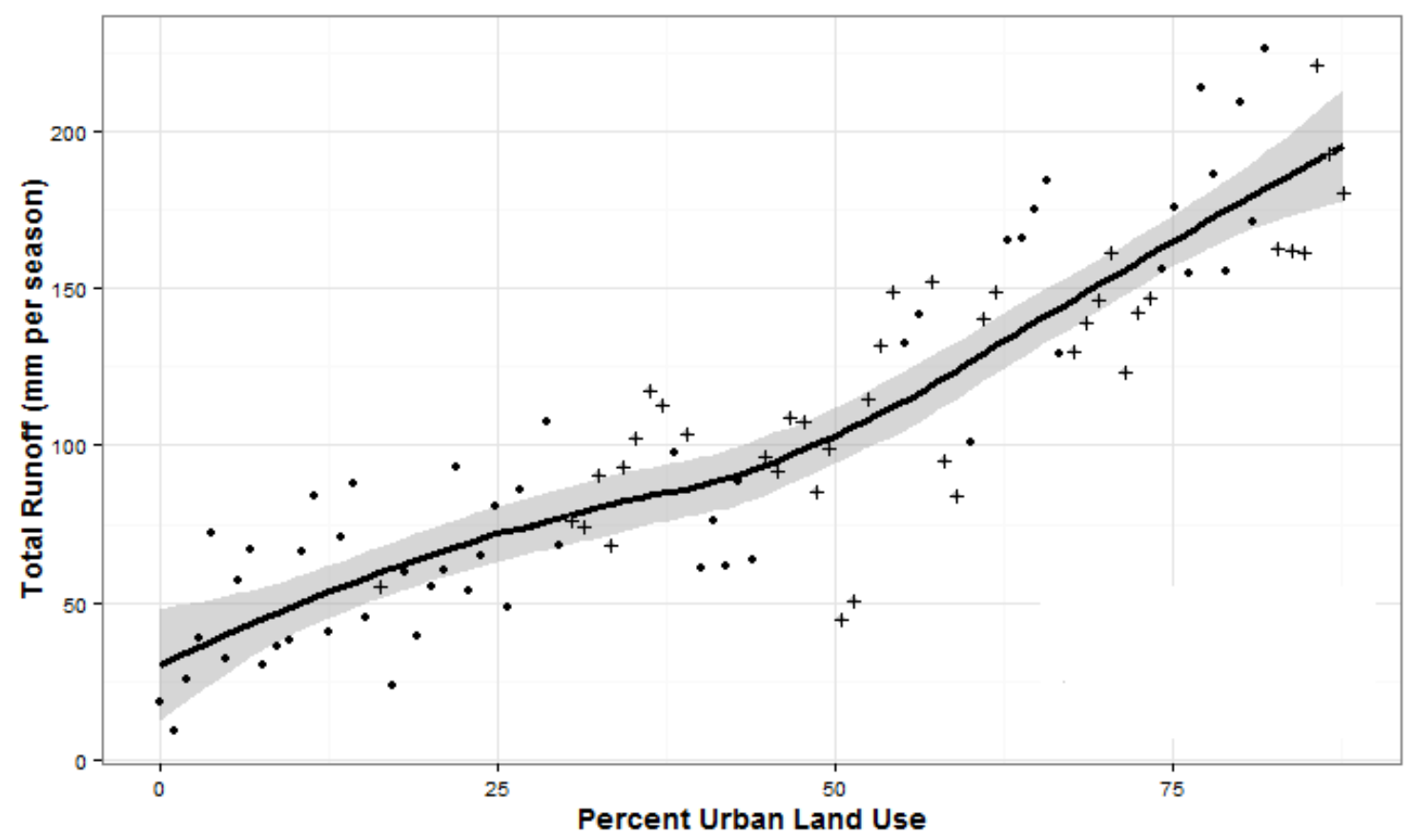

Illustration 5-3 Fitted model with urban cover.

The fitted model is plotted in a solid black line with shaded $95 \%$ CI. Actual data are plotted with differentiation by type of river regulation (dots regulated, crosses natural). 


\subsubsection{Relationship of Total Runoff and RC to Event Scale Flow Characteristics}

Bivariate correlations were estimated for total runoff and event flow characteristics in four groups: all observations; watersheds greater than $100 \mathrm{~km}^{2}$; watersheds less than 100 $\mathrm{km}^{2}$; and, watersheds with UP $<4 \%$ (Appendix J). Correlations of RC with event characteristics for urbanizing watersheds were not as strong as those for total runoff. RC is not interchangeable with total runoff in terms of its relationship to event scale flows and urban land use. By contrast, in watersheds under 4\% UP, total runoff and RC had the same correlations with 80RLER and acceleration.

Total runoff correlations in large watersheds were higher for 80RLER (0.72) than small watersheds $(0.35)$, whereas total runoff had the same correlation with acceleration $(\sim 0.73)$ in both watershed size groups. Total runoff was not correlated with mean event acceleration in watersheds $<4 \%$ UP (0.13). For small watersheds, 80RLER was not highly correlated with UP $(0.17)$ whereas other runoff characteristics were correlated with UP for both large and small watershed groups (between 0.58 and 0.86 ).

\subsubsection{Event Flow Results}

Density plots of rising limb event runoff and rising limb event accelerations provide a visual introduction to the trends identified in the results. Illustration 5-4 illustrates the relationship of event flows with increasing UP. The data were grouped within UP ranges. The plot displays the higher shift in event runoff from low urban cover to about $25 \%$ in comparison with shifts over $25 \%$ urban cover. The increased high range of event flows with higher urban cover is also evident. Illustration 5-5 shows increasing event 
accelerations with increasing UP. A double peak develops in the later profiles, indicating an increase in two acceleration profiles, likely reflecting an increase in smaller event accelerations as well as higher accelerations during larger rain events.

\subsubsection{Tenth and Twentieth Percentile Rising Limb Event Runoff}

Both $10^{\text {th }}$ percentile and $20^{\text {th }}$ percentile event runoff increased with increasing UP: $10^{\text {th }}$ percentile event runoff increased 2.20e- $08 \mathrm{~mm} \mathrm{~s}^{-1}$ per unit increase in UP (MK Partial Score $=1205.1, \mathrm{p}=6.4 \mathrm{e}-05) ; 20^{\text {th }}$ percentile event runoff increased $2.39 \mathrm{e}-08 \mathrm{~mm} \mathrm{~s}^{-1}$ per unit increase in UP $($ MK Partial Score $=1256.9, p=3.1 \mathrm{e}-05)$. The range of $10^{\text {th }}$ percentile runoff in the database was $6.4 \mathrm{e}-06 \mathrm{~mm} \cdot \mathrm{s}^{-1}$ to $436 \mathrm{e}-06 \mathrm{~mm} \mathrm{~s}^{-1}$; the range of $20^{\text {th }}$ percentile runoff was $6.7 \mathrm{e}-06 \mathrm{~mm} \mathrm{~s}^{-1}$ to $763.7 \mathrm{e}-06 \mathrm{~mm} \mathrm{~s}^{-1}$. 


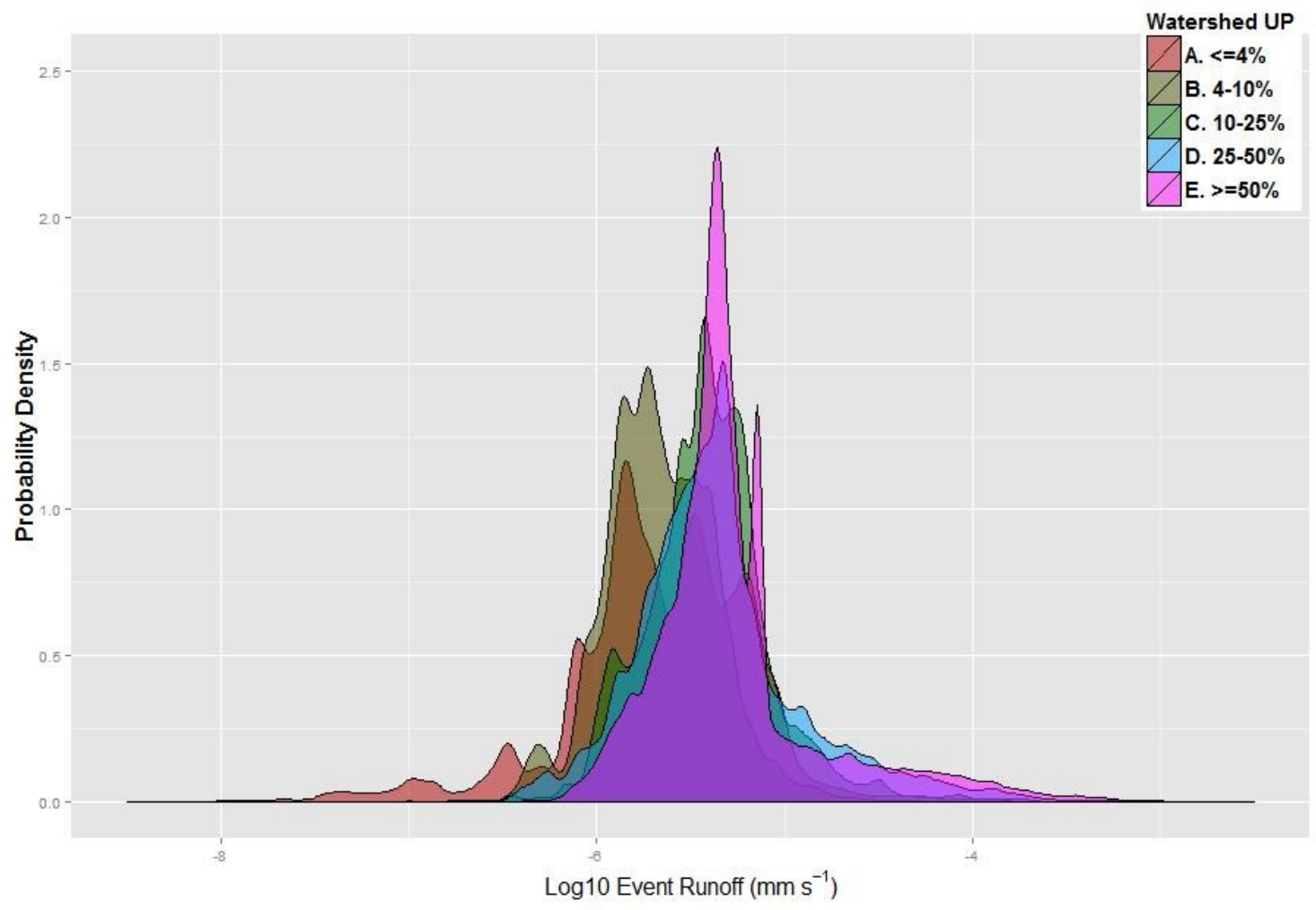

Illustration 5-4 Density plots of all rising limb event runoff observations for study watersheds. 


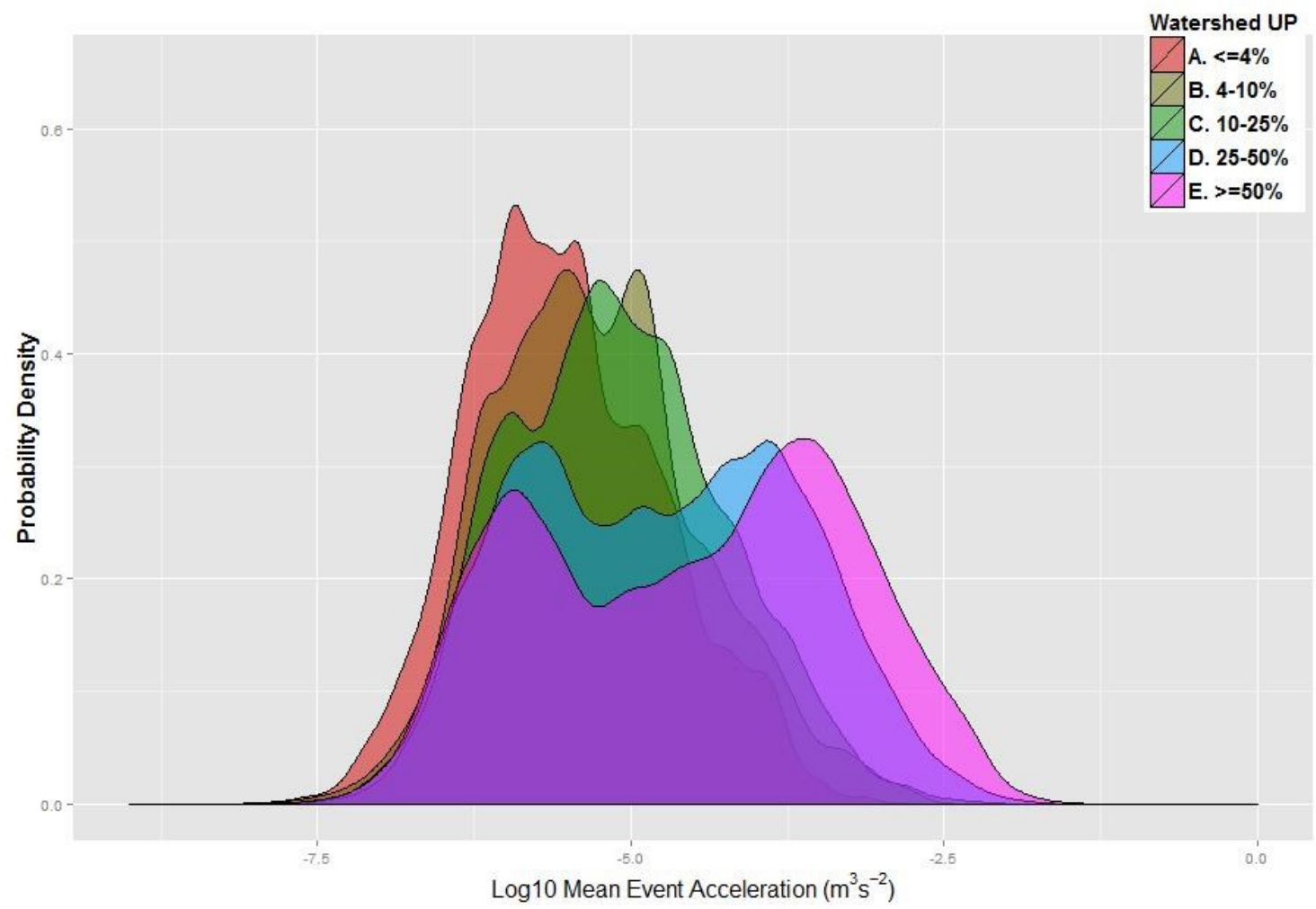

Illustration 5-5 Density plots of all rising limb event flow accelerations greater than zero for study watersheds. 


\subsubsection{Eightieth Percentile Rising Limb Event Runoff (80RLER)}

A simple linear regression model could not be fit to the 80RLER ( $\left.\mathrm{mm} \mathrm{s}^{-1}\right)$ data. A GAM was fit with 3 independent variables: total rainfall, UP and BFI. Total rainfall indicated a linear trend and was fit with a parametric coefficient (Table 5-5). The fitted model illustrates a curvilinear relationship of 80RLER to UP (Illustration 5-6).

\subsubsection{Ninety-fifth Percentile Rising Limb Event Runoff (95RLER)}

The 95RLER $\left(\mathrm{mm} \mathrm{s}^{-1}\right)(\log 10$ transformed) model had four independent variables (Table 5-6). The square of UP had a negative coefficient, indicating a decreasing effect of UP on 95RLER as UP increased (Illustration 5-7). The change in 95RLER resulting from increased UP in the lower UP range is much greater than the same increase once urban development is more prevalent in a watershed. For example, using the average channel slope in the database and total rain of $350 \mathrm{~mm}$, an increase in UP from $10 \%$ to $20 \%$ results in $\sim 56 \%$ increase in 95RLER, whereas an increase from $70 \%$ to $80 \%$ UP results in a $\sim 5 \%$ increase in 95RLER. 


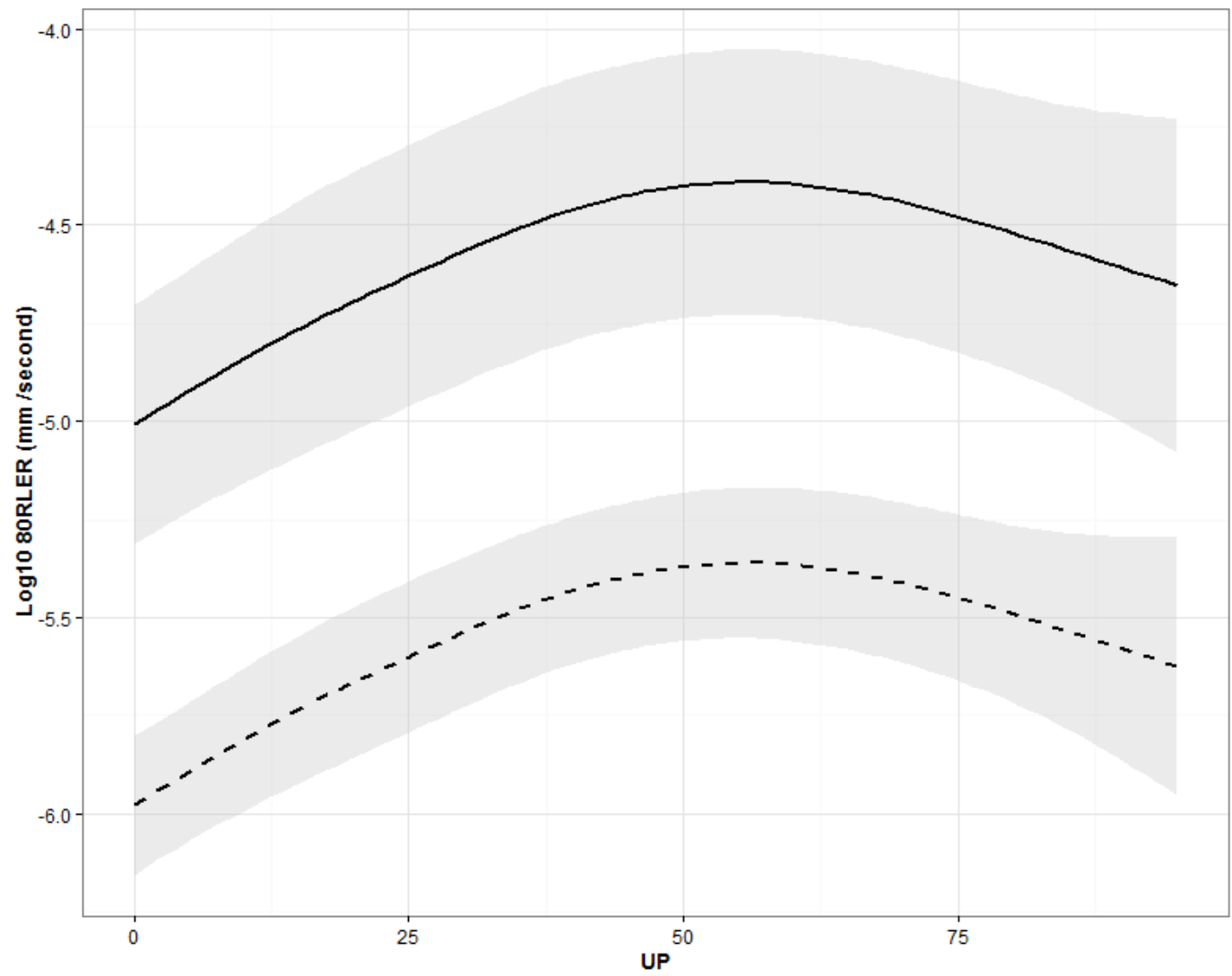

Illustration 5-6 Fitted 80RLER and UP for GAM model.

The relationship of $80 R L E R$ with UP indicates the $80^{\text {th }}$ percentile event runoff plateaus around $30 \%$ urban cover and declines beyond $\sim 60 \%$ UP. Shade indicates $95 \%$ CI of the estimates. The plot illustrates the effect of BFI through the range in the database (total rainfall $=350 \mathrm{~mm}$ ), with maximum BFI (0.72) (solid black line) about one order of magnitude greater than minimum BFI (0.44) (dashed black line). 
Table 5-5 GAM Model results for 80RLER (log transformed).

\begin{tabular}{|c|c|c|c|c|c|}
\hline $\begin{array}{l}\text { Dependent } \\
\text { Variable }\end{array}$ & Data & Model overview & $\begin{array}{l}\text { Independent } \\
\text { variable }\end{array}$ & $\begin{array}{l}\text { Modelled } \\
\text { form }\end{array}$ & $\begin{array}{l}\text { Coefficient +/- } \\
\text { SE } \\
\text { (p-value); } \\
\text { F (p-value) }\end{array}$ \\
\hline \multirow{4}{*}{$\begin{array}{l}\text { 80RLER, } \\
\log _{10} \\
\text { transformed }\end{array}$} & \multirow[t]{4}{*}{$\begin{array}{l}\text { All data (93 } \\
\text { observations) }\end{array}$} & \multirow{4}{*}{$\begin{array}{l}\text { Model } .2 \\
\text { Deviance } \\
\text { Explained = } \\
70.5 \% \text {; } \\
\text { Adjusted } \mathrm{R}^{2}= \\
0.67 \\
\mathrm{~N}=93\end{array}$} & Intercept & $\begin{array}{l}\text { Parametric } \\
\text { coefficient }\end{array}$ & $\begin{array}{l}-5.70+/-0.086 \\
(<2 \mathrm{e}-16)\end{array}$ \\
\hline & & & Total rain & $\begin{array}{l}\text { Parametric } \\
\text { coefficient }\end{array}$ & $\begin{array}{l}0.0015+/- \\
0.0003 \\
(2.14 \mathrm{e}-07)\end{array}$ \\
\hline & & & UP & $\begin{array}{l}\text { Gaussian, } \\
\text { Smoothed }\end{array}$ & $\begin{array}{l}F=21.27 \\
(6.64 \mathrm{e}-12)\end{array}$ \\
\hline & & & BFI & $\begin{array}{l}\text { Gaussian, } \\
\text { Smoothed }\end{array}$ & $\begin{array}{l}\mathrm{F}=7.78 \\
(2.83 \mathrm{e}-07)\end{array}$ \\
\hline
\end{tabular}


Table 5-6 Statistical model for 95RLER and partial $R^{2}$.

\begin{tabular}{|c|c|c|c|c|c|}
\hline $\begin{array}{l}\text { Dependent } \\
\text { Variable }\end{array}$ & Data & $\begin{array}{l}\text { Model } \\
\text { overview }\end{array}$ & $\begin{array}{l}\text { Independent } \\
\text { variable }\end{array}$ & $\begin{array}{l}\text { Coefficient +/- } \\
\text { SE } \\
\text { (p-value) }\end{array}$ & $\begin{array}{c}\text { Partial } \\
\mathbf{R}^{2}\end{array}$ \\
\hline \multirow[t]{5}{*}{$\begin{array}{l}\text { 95RLER, } \\
\log _{10} \\
\text { transformed }\end{array}$} & \multirow[t]{5}{*}{$\begin{array}{l}\text { All data (93 } \\
\text { observations) }\end{array}$} & \multirow{5}{*}{$\begin{array}{l}\text { Model.3 } \\
\mathrm{R}^{2}=0.69 \\
\mathrm{RSE}= \\
0.274, \mathrm{df}= \\
88 \\
\mathrm{p}<2 \mathrm{e}-16\end{array}$} & $\begin{array}{l}\text { Total rain to } \\
\text { the power } 2\end{array}$ & $\begin{array}{l}3.22 \mathrm{e}-06+/- \\
0.54 \mathrm{e}-06 \\
(6.5 \mathrm{e}-08)\end{array}$ & 0.011 \\
\hline & & & UP & $\begin{array}{l}0.024+/-0.004 \\
(2.63 \mathrm{e}-08)\end{array}$ & 0.012 \\
\hline & & & $\begin{array}{l}\text { UP to the } \\
\text { power } 2\end{array}$ & $\begin{array}{l}-1.45 \mathrm{e}-04+/- \\
0.50 \mathrm{e}-04 \\
(0.0047)\end{array}$ & 0.003 \\
\hline & & & Channel slope & $\begin{array}{l}4.61 \mathrm{e}-02+/- \\
1.76 \mathrm{e}-02 \\
(0.011)\end{array}$ & 0.002 \\
\hline & & & Intercept & $\begin{array}{l}-5.75+/-0.10 \\
(p<2 e-16)\end{array}$ & $\begin{array}{c}0.945 \\
\quad \text { and } \\
\text { residuals } \\
0.028 \text { ) }\end{array}$ \\
\hline
\end{tabular}




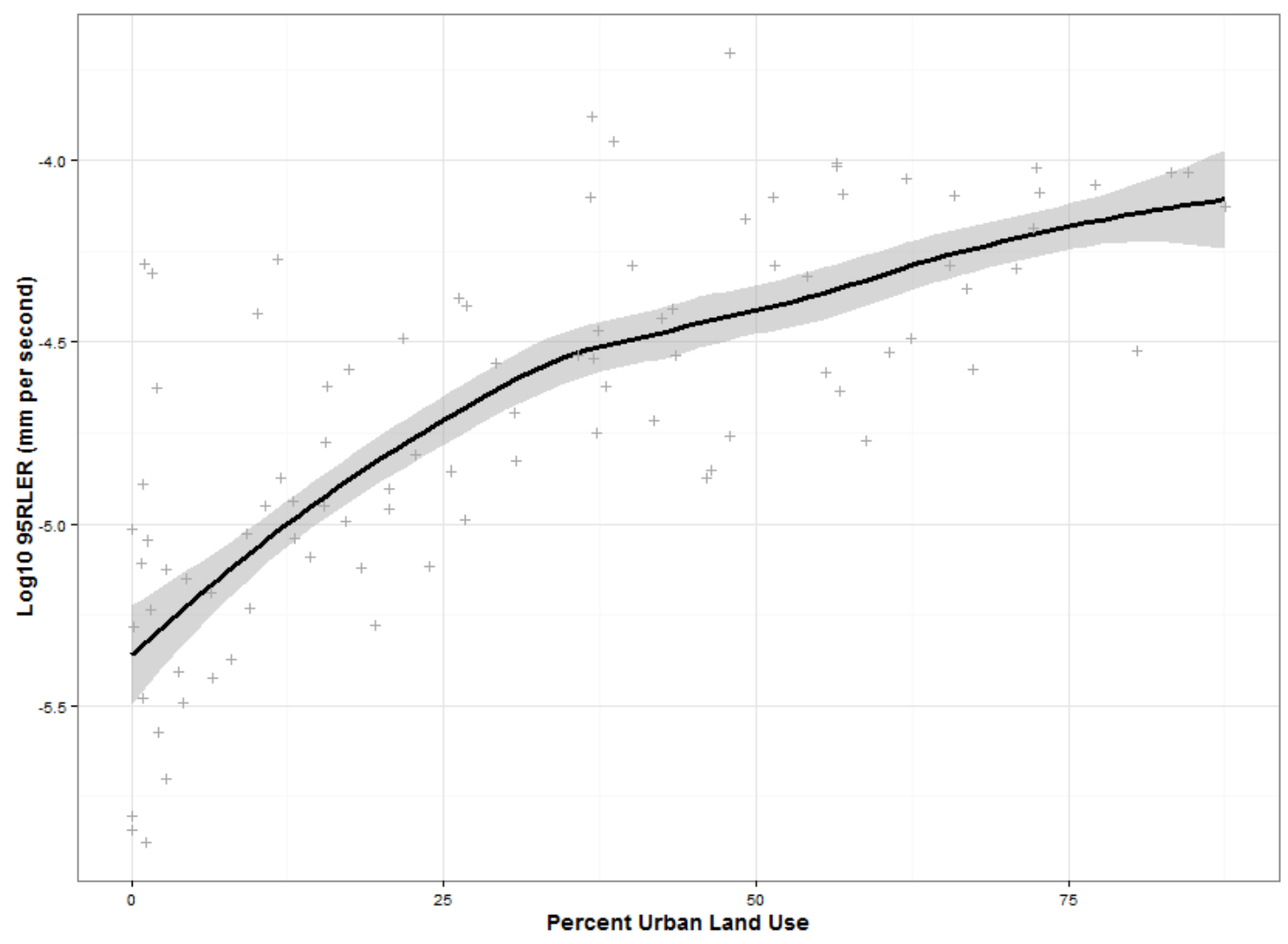

Illustration 5-7 Fitted model and illustration of the effect of increasing UP on 95RLER.

The model is plotted in a solid black line with shaded 95\% CI. Actual data are plotted in grey crosses. 


\subsubsection{Event Acceleration}

The model fit to event flow acceleration observations had five independent variables (Table 5-7). Watershed area had a positive coefficient, indicating flow acceleration is higher in larger rivers. The BFI coefficient was negative, indicating watersheds with higher BFI have lower event acceleration given similar other variables. UP had a positive coefficient but UP to the power 2 had a negative coefficient, indicating a decreasing effect on acceleration as UP increases (Illustration 5-8). The change in acceleration resulting from increased UP in the lower UP range is much greater than the same increase once urban development is more prevalent in a watershed. For example, for BFI $=0.57$ and total rain $=350 \mathrm{~mm}$, an increase in UP from $10 \%$ to $20 \%$ results in $\sim 106 \%$ increase in mean acceleration, whereas an increase from $70 \%$ to $80 \%$ UP results in a $\sim 0.5 \%$ increase in mean acceleration. 
Table 5-7 Statistical model for mean event acceleration and partial $\mathbf{R}^{2}$.

\begin{tabular}{|c|c|c|c|c|c|}
\hline $\begin{array}{l}\text { Dependent } \\
\text { Variable }\end{array}$ & Data & $\begin{array}{l}\text { Model } \\
\text { overview }\end{array}$ & $\begin{array}{l}\text { Independent } \\
\text { variable }\end{array}$ & $\begin{array}{l}\text { Coefficient }+/- \\
\text { SE } \\
\text { (p-value) }\end{array}$ & $\begin{array}{c}\text { Partial } \\
\mathbf{R}^{2}\end{array}$ \\
\hline \multirow[t]{6}{*}{$\begin{array}{l}\text { Mean event } \\
\text { flow } \\
\text { acceleration }\end{array}$} & \multirow[t]{6}{*}{$\begin{array}{l}93 \\
\text { observations }\end{array}$} & \multirow{6}{*}{$\begin{array}{l}\text { Model.4 } \\
\mathrm{R}^{2}=0.78 \\
\mathrm{RSE}= \\
0.303, \mathrm{df}= \\
87 \\
\mathrm{p}<2 \mathrm{e}-16\end{array}$} & Total rain & $\begin{array}{l}1.65 \mathrm{e}-03+/- \\
0.39 \mathrm{e}-03 \\
(5.41 \mathrm{e}-05)\end{array}$ & 0.04 \\
\hline & & & $\overline{\mathrm{UP}}$ & $\begin{array}{l}3.93 \mathrm{e}-02+/- \\
0.42 \mathrm{e}-02 \\
(1.25 \mathrm{e}-14)\end{array}$ & 0.21 \\
\hline & & & $\begin{array}{l}\text { Watershed } \\
\text { area, log10 } \\
\text { transformed }\end{array}$ & $\begin{array}{l}0.432+/-0.10 \\
(4.68 \mathrm{e}-05)\end{array}$ & 0.05 \\
\hline & & & $\begin{array}{l}\text { UP to power } \\
2\end{array}$ & $\begin{array}{l}-2.60 \mathrm{e}-04+/- \\
0.55 \mathrm{e}-04 \\
(7.79 \mathrm{e}-06)\end{array}$ & 0.06 \\
\hline & & & BFI & $\begin{array}{l}-1.59+/-0.59 \\
(0.0081)\end{array}$ & 0.02 \\
\hline & & & Intercept & $\begin{array}{l}-5.42+/-0.42 \\
(p<2 e-16)\end{array}$ & $\begin{array}{c}0.41 \text { (and } \\
\text { residuals } \\
0.21)\end{array}$ \\
\hline
\end{tabular}




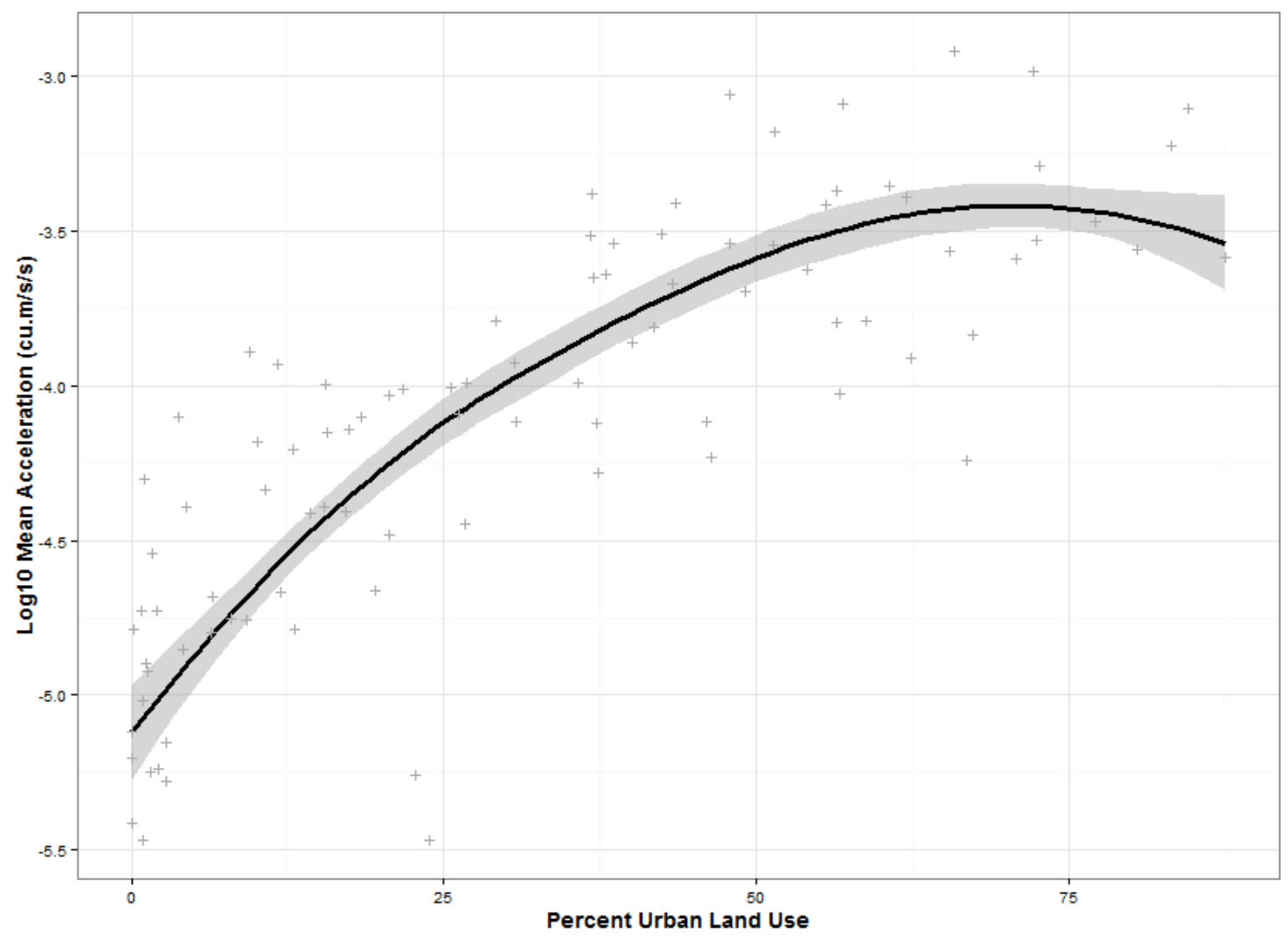

Illustration 5-8 Fitted model for rising limb event flow acceleration.

The fitted model is plotted in a solid black line with shaded 95\% CI. Actual data are plotted in grey crosses. 


\subsubsection{Relationship of event acceleration to 80RLER}

A model was fit for mean event acceleration with 80RLER as an independent variable, even though it is not certain that 80RLER is independent of acceleration. The model is useful to explore the relationship of the two variables, with each other and with UP. As indicated in Section 5.3.4.2, 80RLER had a curvilinear relationship with UP but, as indicated in Section 5.3.4.4, event acceleration dramatically increased in the early stages but leveled off at high UP (over $\sim 60 \%$ ). Event runoff and event acceleration changed concurrently but with different responses to UP; the relationship between these two event-scale hydrologic characteristics was not evident as UP changed.

A linear model could not be fit to the data. A GAM was fit with 5 independent variables. 80RLER and watershed area (both $\log _{10}$ transformed) demonstrated parametric relationships; UP, channel slope and BFI were fit with Gaussian smoothed relationships Table 5-8). This result indicates the change in event acceleration with 80RLER alone as an independent variable was linear, but other watershed conditions (UP, channel slope, BFI) made the overall relationship non-parametric. The linear relationship of event acceleration with 80RLER is plotted in Illustration 5-9, for the range of 80RLER in the database. In the Illustration, UP was manipulated from $4 \%$ to $90 \%$ and the modelled mean acceleration increased two orders of magnitude. In this Illustration, watershed size,

BFI and channel slope were held equal to their mean database values $\left(174 \mathrm{~km}^{2}, 0.60\right.$ and $4.15 \mathrm{~m} \mathrm{~km}^{-1}$, respectively). 
Note that the range of acceleration in the database for watersheds with low urban cover (i.e. less than $4 \%, \mathrm{n}=17)$ did not exceed $7.9 \mathrm{e}-05 \mathrm{~m}^{3} \mathrm{~s}^{-2}\left(\log _{10}-4.10\right)$. This maximum value occurred in a large watershed (Humber003, 1969, $805.6 \mathrm{~km}^{2}, \mathrm{UP}=3.8 \%$ ). The modelled watershed in the Illustration was only $174 \mathrm{~km}^{2}$ and it is possible that mean event acceleration at 4\% UP would never reach the modelled values. In other words, there are physical processes that likely intervene in the relationship of 80RLER with mean acceleration; the model can be manipulated to predict accelerations that may exceed those that would actually occur in non-urban watersheds. In a similar vein, in the least urbanized watershed (Duffins019, 1978, $86.9 \mathrm{~km}^{2}$, UP = 0.9\%), 80RLER did not exceed 9.6e- $06 \mathrm{~mm} \cdot \mathrm{s}^{-1}\left(\log _{10}-5.02\right)$. 
Table 5-8 GAM Model results for mean event acceleration with 80RLER as an independent variable.

\begin{tabular}{|c|c|c|c|c|c|}
\hline $\begin{array}{l}\text { Dependent } \\
\text { Variable }\end{array}$ & Data & $\begin{array}{l}\text { Model } \\
\text { overview }\end{array}$ & $\begin{array}{l}\text { Independent } \\
\text { variable }\end{array}$ & Modelled form & $\begin{array}{l}\text { Coefficient +/- SE } \\
\text { (p-value); F (p- } \\
\text { value) }\end{array}$ \\
\hline \multirow{6}{*}{$\begin{array}{l}\text { Mean rising } \\
\text { limb } \\
\text { acceleration, } \\
\log _{10} \\
\text { transformed }\end{array}$} & \multirow[t]{6}{*}{$\begin{array}{l}\text { All data (93 } \\
\text { observations) }\end{array}$} & \multirow{6}{*}{$\begin{array}{l}\text { Model.5 } \\
\text { Deviance } \\
\text { Explained } \\
=92 \% ; \\
\text { Adjusted } \\
\mathrm{R}^{2}= \\
0.898 \\
\mathrm{~N}=93\end{array}$} & Intercept & $\begin{array}{l}\text { Parametric } \\
\text { coefficient }\end{array}$ & $\begin{array}{l}-3.348+/-0.644 \\
(1.76 \mathrm{e}-06)\end{array}$ \\
\hline & & & $\begin{array}{l}\text { 80RLER, } \log _{10} \\
\text { transformed }\end{array}$ & $\begin{array}{l}\text { Parametric } \\
\text { coefficient }\end{array}$ & $\begin{array}{l}0.511+/-0.106 \\
(8.36 \mathrm{e}-06)\end{array}$ \\
\hline & & & $\begin{array}{l}\text { Watershed area, } \\
\log _{10} \text { transformed }\end{array}$ & $\begin{array}{l}\text { Parametric } \\
\text { coefficient }\end{array}$ & $\begin{array}{l}0.905+/-0.111 \\
(6.5 \mathrm{e}-12)\end{array}$ \\
\hline & & & UP & $\begin{array}{l}\text { Gaussian, } \\
\text { Smoothed }\end{array}$ & $\mathrm{F}=19.93(<2 \mathrm{e}-16)$ \\
\hline & & & $\begin{array}{l}\text { Channel Slope } \\
\text { ( } \log _{10} \text { transformed) }\end{array}$ & $\begin{array}{l}\text { Gaussian, } \\
\text { Smoothed }\end{array}$ & $\mathrm{F}=8.32(7.08 \mathrm{e}-06)$ \\
\hline & & & BFI & $\begin{array}{l}\text { Gaussian, } \\
\text { Smoothed }\end{array}$ & $\mathrm{F}=8.85(1.44 \mathrm{e}-09)$ \\
\hline
\end{tabular}




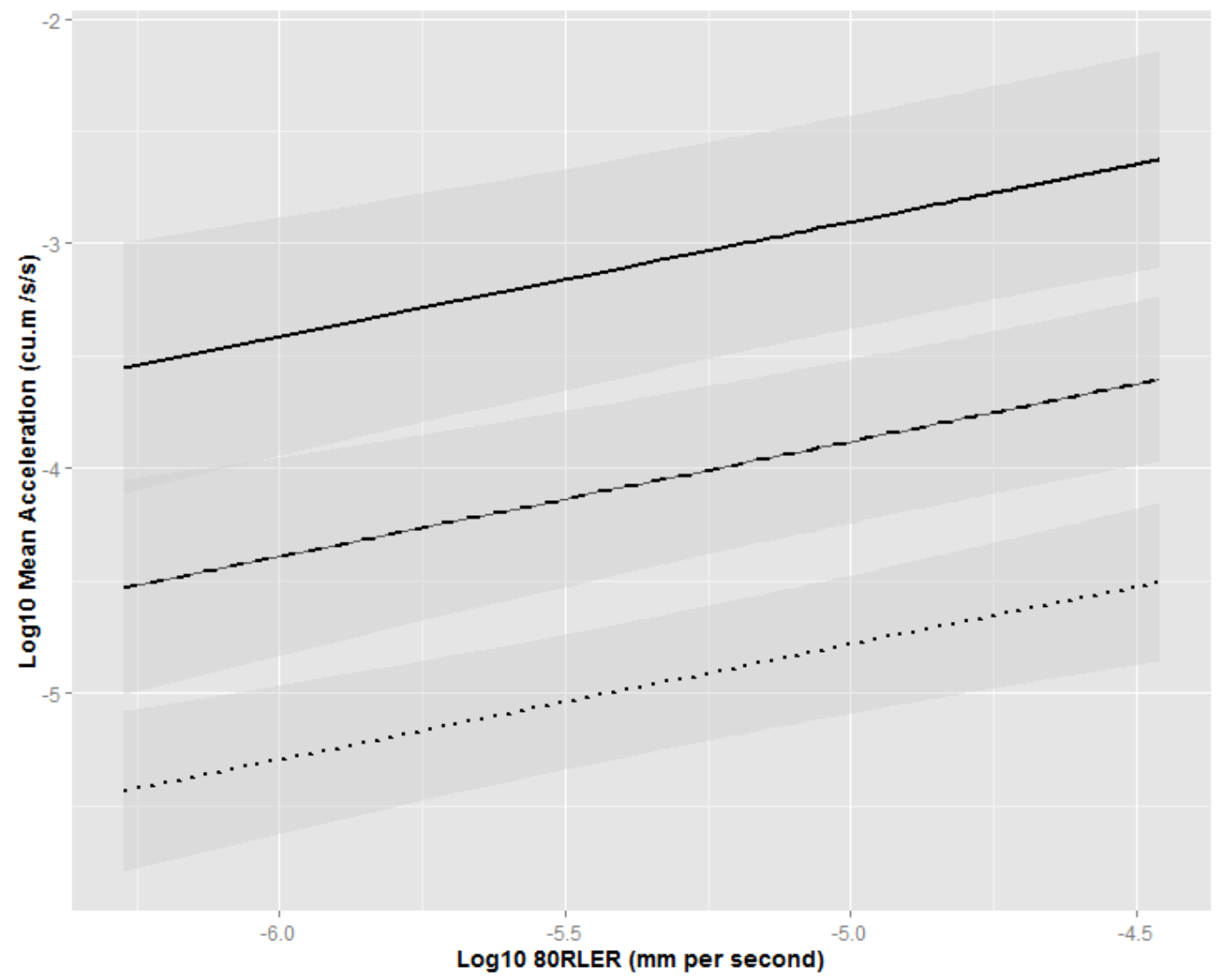

Illustration 5-9 Illustration of the effect of UP on the relationship of mean acceleration with 80RLER.

Three scenarios are plotted to the fitted GAM model: 4\% UP (grey dotted curve); 40\% UP (black dashed curve); 90\% UP (solid black curve). 


\subsection{Discussion}

\subsubsection{Research Questions}

There was insufficient evidence to characterize the change in relationship of runoff to UP as a threshold response (i.e. an abrupt change). However, runoff in non-urban watersheds is more influenced by basin processes and characteristics than by UP. By separately analyzing watersheds with higher groundwater influence $(\mathrm{BFI} \geq 0.6)$ versus those with lower influence $(\mathrm{BFI}<0.6)$, it is clear UP begins to influence total runoff at very low land cover for both groups of watersheds. At around 2 to $3 \%$ UP, the influence of UP was measurable in the higher BFI group. There were fewer data points for the lower BFI group, which likely contributed to the non-significant result. Nevertheless, a change in slope occurred around 4\% UP for this group.

There is a strong effect of UP on total runoff and RC in models fit for the study watersheds. Further, watershed scale interacts with UP to magnify the increase in total runoff with increasing UP. This result cautions against assuming runoff responses are uniform across scales of urbanizing watersheds. For the study watersheds, total runoff and $\mathrm{RC}$ were not interchangeable in terms of correlation with event scale responses; $\mathrm{RC}$ had lower correlations with event characteristics. Further investigation of RC was not within the scope of this study.

Event scale flows also demonstrated a very strong effect of UP, although not all event characteristics monotonically increased with increasing UP. $80^{\text {th }}$ percentile rising limb 
runoff demonstrated a curvilinear relationship with UP, with the greatest change in 80RLER occurring as UP increased to $\sim 30 \%$. Although 80RLER levelled off and even decreased at higher UP cover, rising limb acceleration increased sharply until at least $\sim 60 \%$ UP. Thus, 80RLER runoff was achieved sooner due to increased event acceleration. The relationship of flow acceleration with 80RLER is highly sensitive to urban cover, with acceleration increasing $\sim 2$ orders of magnitude from 4 to $90 \%$ UP. Meanwhile, total runoff also increased as UP increased. The reason can be seen in the trends at the lower and upper runoff ranges: $10^{\text {th }}$ percentile and $20^{\text {th }}$ percentile runoff increased with increasing UP, consistent with the increased efficiency of urban drainage infrastructure to drain smaller rain events; and, peak runoff (95RLER) continued to increase with increasing UP, with some leveling off at very high UP.

Rising limb event acceleration increased with increasing watershed size. Other event scale runoff characteristics did not have statistically detectable watershed scale effects. The range of UP for various watershed sizes was limited in some instances. For example, watersheds over $600 \mathrm{~km}^{2}$ all had UP $<20 \%$ and watersheds under $60 \mathrm{~km}^{2}$ had $17 \%>$ UP $<$ $55 \%$. Watersheds with additional UP-area combinations would support further analysis of potential watershed-UP interactions in event scale responses.

Higher baseflow conditions appear to mitigate the effects of urbanization on event accelerations (i.e. the coefficient is negative in the statistical model, Table 5-7). This study was undertaken during the post-spring freshet period when flows are normally lower than their water-year peak, leaving watersheds with channel capacity. Larger 
watersheds with high BFI may have had enough capacity in their channel cross sections to accommodate some event flows without trend detection. Baseflow in the channel may provide some inertia to flow acceleration. Alternatively, there may be other unidentified processes, such as urban development practices, that mitigated the acceleration effects of urbanization on watersheds with higher BFI. Soils and surficial geology could also offer potential explanatory factors. Soils data were not included within the scope of this study; inclusion of soils characteristics (for example, hydraulic conductivity) in future research, may explain additional variation in flow responses.

No discontinuities in flow characteristics were evident in the data (e.g. at $\sim 10 \%$ UP). Interestingly, the effects of urban cover were detectable at the event scale well before $10 \%$ UP. Investigation of the association of biotic effects with flow regime change is complicated by the potential for lagged effects to mask important transitions. For instance, with documented lagged effects of urbanization on stream stability (e.g. Hammer, 1972, Dunne and Leopold, 1978) and of urbanization on aquatic biota (Findlay and Bourdages, 2000; Harding et al., 1998; Löfvenhaft et al., 2004), it is possible that a 'threshold' UP is lower than $10 \%$ but the biotic effects are measured coincident with about $10 \%$ UP. On the basis of this study's findings, associations of increased flow accelerations with biotic response may be worth investigating. Also associations of biotic response to increased event power may be of interest. The absence of a flow threshold would not preclude effects of continuous flow regime change on aquatic habitat and, conversely, identification of a threshold would require research on causal mechanisms to support potential associations. 


\subsubsection{Implications}

Considering the low levels of UP to initiate hydrologic changes, dampening or reversal of hydrologic alterations would require mitigation measures across the watershed (such as LID stormwater techniques). Specifically, a focus on riparian zones would not be sufficient to reverse the hydrologic effects of urbanization: with event acceleration and event flow responses detectable by $4 \%$ UP, riparian treatments for overland flow are unlikely to offset hydrologic changes imparted by drainage via engineered infrastructure discharging directly to watercourses.

Although total runoff increased with UP and with time (Trudeau and Richardson, 2015), precipitation had no trend with time. BFI had a negative trend with UP and, concurrently, vegetation decreased (from qualitative observation of historic aerial photographs). Surface storage (such as depressions and gullies) likely also decreased; although data were not available to verify a trend, urban transportation and lot drainage standards in the study region, by design, reduce surface storage (e.g. Government of Ontario, 1997). Reduction in these mechanisms for rain water storage and sub-surface transmission (vegetation, surface storage and interflow) was concurrent with increased drainage efficiency (via engineered sewer infrastructure). This study scope included only growing season precipitation and flows, so definitive conclusions on the water balance cannot be drawn. However, the increase in total runoff with urban cover, coupled with the levellingoff and decline of $80^{\text {th }}$ percentile rising limb runoff, raises the possibility that the water balance in urban watersheds is negatively affected (i.e. the total volume of water within a 
highly urbanized watershed becomes depleted) by UP during the growing season. For instance, a watershed with $>\sim 50 \%$ UP may not have water to deliver increasingly higher flows in the $80^{\text {th }}$ percentile range. Water discharge becomes redistributed to runoff during smaller events and during the largest events, at increasing overall total volumes, without compensation from additional rainfall input. Groundwater and evaporation trends would need to be studied to assess changes in water balance and the degree to which these watersheds become 'dried out'. In addition, there may be water balance implications for larger scale watersheds with multiple, highly urbanized, nested sub-watersheds, as in the case of the Lake Ontario and Lake Erie basins.

The study results occurred during a period with no detectable changes in rainfall patterns thereby demonstrating that hydrologic stationarity was compromised by urbanization prior to measurable effects of climate change on rainfall. The trends identified in this study may be exacerbated by expected climatic changes, for example by further increased runoff due to higher precipitation (Jyrkama and Sykes, 2007). Climate change may also mask urbanization effects.

This study raises many potential research questions. In particular:

- At what level of urban cover do engineering drainage systems begin to dominate stream flow response versus basin processes and characteristics? To what degree can LID techniques off-set the hydrologic effects?

- What are the long term implications of altered event flow patterns for the water balance in urbanizing watersheds? 
- Are there detectable trends associated with urbanization in total runoff or event flows for the larger scale basins in this study region (i.e. Lakes Ontario and Erie or the Great Lakes St. Lawrence Basin)?

- Are specific characteristics of the modified flow regime associated with effects on aquatic biodiversity, for example increased event accelerations?

\subsection{Conclusions}

Hydrologic stationarity was compromised during a period of increasing urbanization but no detectable trends in rainfall. Changes in flow characteristics are detectable at very low urban cover $(<4 \%)$. To mitigate the effects of urbanization on flow regime, measures would be needed across the entire watershed to reverse flow regime trends. Event flow distribution is altered in highly urbanized watersheds, with potential implications for long term water balances. In the face of anticipated climate changes and the clear effect of urbanization on event flows, additional research is warranted into hydrologic trends with urbanization on larger spatial scales within the Great Lakes St Lawrence Basin. Research into the implications for aquatic biota of changing hydrologic regimes, in particular event flow accelerations, is also warranted.

\section{Acknowledgements}

The authors are grateful for the research advice provided by Dr. Doug King (Geography and Environmental Studies, Carleton University) and Dr. Antoine Morin (Biology, University of Ottawa). The Credit Valley Conservation Authority provided ArcGIS shapefiles delineating land use in the Credit watershed. The Toronto and Region 
Conservation Authority contributed funding for digitization of aerial photos. P. Thompson provided ArcGIS files for the Don watershed. Funding for aerial photo georeferencing and digitization was provided by NSERC Discovery Grants to Murray Richardson and Dr. Doug King (Carleton University). Funding for M.P. Trudeau's research through a Carleton University scholarship and contributions from Environment Canada's research assistant program are gratefully acknowledged. The authors wish to thank Dan Clayton (TRCA), Adrienne Ockenden (CVCA), Jon Clayton (CVCA), Deb Martin-Downs (CVCA), Gord Argo (NRCan), Francois Savopol (NRCan), Jim Buttle (Trent U.), P. Thompson and GIS specialists Rachel Plewes, Scott Page and Kent Jacobs for their cooperation and assistance with data collection and database development. 


\section{Chapter: Associations of Hydrological Characteristics with Fish}

\section{Richness}

\section{Key Words}

Fish richness, urbanization, event-scale hydrology, event acceleration, aquatic biodiversity

\subsection{Introduction}

Aquatic biodiversity is negatively associated with urban land use and impervious cover (Klein, 1979; Löfvenhaft et al., 2004; Paul and Meyer, 2001; Schueler, 1994; Stanfield et al., 2006; Stanfield and Kilgour, 2006). Urban land use brings with it multiple concurrent environmental changes (e.g. Dudgeon et al., 2006; Brabec et al., 2002; Costa et al., 2003; Adamowski and Prokoph, 2013; Boers et al., 1986; Morin and Benyamini, 1977), including to lotic flow regimes (e.g. Hammer, 1972; Dunne and Leopold 1978; Trudeau and Richardson, 2015). The term "urban stream syndrome" (Walsh et al., 2005) has been coined to capture the degraded condition of urban watercourses.

Detection of biological trends in riverine systems is challenged by the natural variability inherent in numerous processes and interactions of biotic and abiotic factors on multiple spatial and temporal scales (e.g. Giller and Malmqvist, 1998; Vannote et al., 1980; Wipfli, 2005; Burcher et al., 2007; Dudgeon et al., 2006). Further, assessment of biodiversity is challenging because there are numerous potential end points, comprehensive datasets can be difficult to locate and data collection protocols vary. Single trophic level analyses of ecosystems are common (Petchey et al., 2004) yet are 
recognized as inadequate to fully characterize biotic communities. Fish are common freshwater bioindicators but can be labour-intensive to sample and differing collection methods introduce sampling bias (Grabarkiewicz and Davis, 2008). In Ontario, the Ministry of Natural Resources recognized the problem of incompatible data collection protocols for both invertebrates and fish. The Province of Ontario's systematic sampling methodologies for wadable stream biota were introduced around the year 2000 (Stanfield, 2003) as the Ontario Stream Assessment Protocol (OSAP) (Stanfield, 2013).

Despite numerous sources of potential variability, negative aquatic biotic responses to impervious cover at about $10 \%$ have been identified in very different locations globally (Schueler et al., 2009), including the Ontario Great Lakes Region (e.g. Stanfield and Kilgour, 2006), Washington State (e.g. Chin, 2006) and Australia (e.g. Walsh et al., 2001). This fairly consistent response to increased impervious cover supports the hypothesis that hydrological changes are one cause of biodiversity decline.

Changes in hydrologic regime of relevance for biota are poorly understood because few studies have been undertaken at the appropriate temporal scales. Specifically, few studies have assessed the relationship of hydrologic changes during rain events with urban land use and biota. The event-scale is commensurate with changing water column conditions experienced instantaneously by biota, or by habitat features affected by high energy water and sediment impulses during rain events. Study of hydrologic indicators on coarse temporal scales (i.e. daily, monthly) has identified correlations of aquatic biotic community response to changes in flow frequency, magnitude and duration (Poff and 
Zimmerman, 2010). Burcher et al. (2007) identified negative influences on fish density associated with cascading geomorphic and erosional factors propagated from urban land use change. However, event scale hydrologic changes, including rising limb event flows, event flow accelerations and event flow power, cannot be assessed at daily or monthly temporal scales. Tetzlaff et al. (2005a) examined the relationship of urban land use with flow acceleration but no consistent relationship was identified. Trudeau and Richardson (under review) identified dramatic changes in event-scale hydrology with urbanization, including increased rising limb event flow accelerations. This study builds on the Trudeau and Richardson (under review) results to examine associations of event-scale hydrologic characteristics with biota, specifically, fish richness.

In this study, we used hydrologic data at 15-minute increments for eight river systems confluent with Lake Ontario (Illustration 6-1) to empirically determine rain event flow characteristics during the post-freshet year (May $26^{\text {th }}$ to November $15^{\text {th }}$ ) at locations matched with fish observation sites in an intensively urbanizing region. Rising limb flows, rising limb flow accelerations and rising limb stream power were estimated using high-temporal resolution hydrologic data available from Environment Canada for a 42year period (1969 to 2010). Other non-event flow characteristics were also estimated. A database with fish records from the early- $20^{\text {th }}$ century to 2010 was compiled through collaboration with the Credit Valley Conservation Authority (CVCA), the Toronto and Region Conservation Authority (TRCA), Ontario Government agencies and individual researchers. The Greater Toronto Region has undergone intensive urbanization during the study period, making the City of Toronto now the fourth largest city by population in 
North America (City of Toronto, 2014). Study watersheds ranged in size from $37 \mathrm{~km}^{2}$ to $806 \mathrm{~km}^{2}$ and had urban percent land use from $0.06 \%$ to $87.6 \%$.

It was expected that urban percent land use would be a better predictor of fish species richness than any of the hydrologic characteristics. Although a comprehensive high temporal resolution hydrologic study of urban biota had not previously been undertaken, correlative studies have identified negative associations in urban areas of water chemistry and thermal regime change with biota (e.g. Wallace et al., 2013; Chu and Jones, 2011). In urbanizing watersheds, it was assumed that changes in water chemistry and thermal regime occur concurrently with changes in hydrologic regime. For this reason, the statistical signal from urban extent was expected to integrate changes associated with all urban effects, including hydrologic, if detectable.

In this exploratory empirical analysis, we ask what characteristics of urbanizing watersheds and hydrologic characteristics explain the highest proportion of variation in fish species richness. We also examine biases and issues in the fish database to inform the question whether recent data (i.e. space in current time) can substitute for long term fish records in this type of study. 


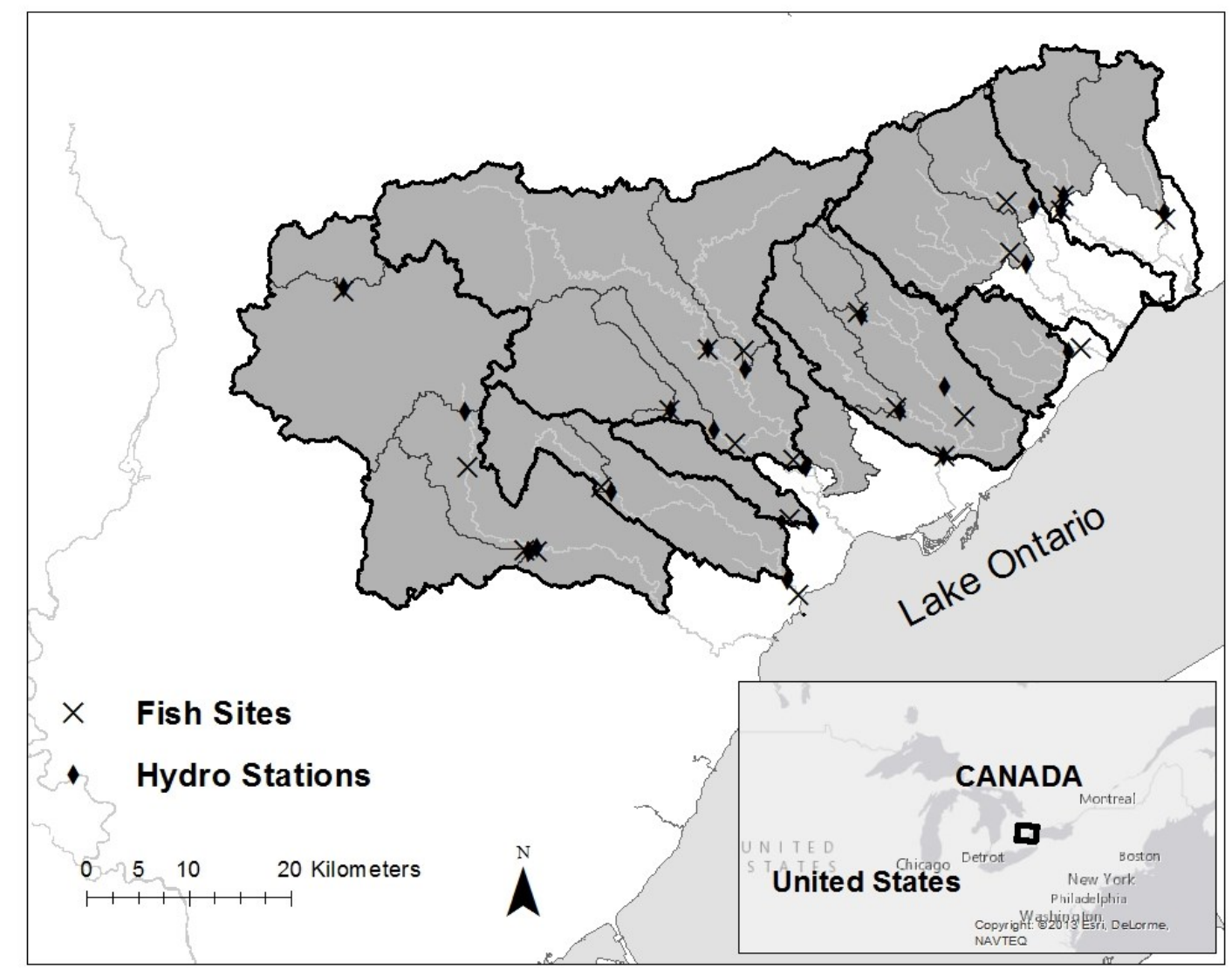

\section{Illustration 6-1 Study map.}

The study area is on the north shore of Lake Ontario in the Greater Toronto Region, Ontario, Canada. The eight study river systems, from west to east by confluence with Lake Ontario, were: Credit, Etobicoke, Mimico, Humber, Don, Highland, Rouge, Duffins (solid lines). Fish sites are indicated by crosses and paired WSC hydrologic stations by diamonds. (See Appendix C for urban extent of watersheds, except Credit). 


\subsection{Materials and Methods}

\subsubsection{Database}

Data for this study were obtained from multiple sources:

- Environment Canada (EC) hydrologic data with 15 minute temporal resolution from 1969 to 2010, although some watersheds were missing data for whole or part years;

- Watershed scale urban land use delineation estimated by year, with scattered temporal coverage between 1969 and 2011 (multiple sources, described in Trudeau and Richardson, under review);

- Baseflow index estimates (Dr. J Buttle pers.comm. (2015) and Neff et al., 2005)

- Fish species characterization such as nursing and feeding habits, and including invasive species (R. Eakins, pers. comm., 2013)

- Fish data were available for eight river systems: Credit, Don, Duffins, Etobicoke, Highland, Humber and Rouge at day or month temporal resolution, with scattered spatial coverage between 1928 and 2011. Agencies and individuals providing fish data for this study included:

- The Credit Valley Conservation Authority (CVCA)

- The Toronto and Region Conservation Authority (TRCA)

- The Ontario Ministry of Natural Resources (OMNR)

- The Royal Ontario Museum (ROM)

- Dr. Gordon Wichert, SLR Consulting (Canada) Ltd.

Fish were the only biotic community with sufficient temporal and spatial data for 
analyses; provincial macroinvertebrate data prior to the late 1990's are not accessible in database format.

Fish data from Conservation Authorities and the Province were accessed through agreement with Conservation Authorities from the Provincial database, Flowing Waters Information System (FWIS) and through the Royal Ontario Museum. Dr. Wichert's PhD (1995) database was translated from Lotus123 format. Published reports and theses reporting fish data were also consulted, including Wichert (1995), D. Martin-Downs (1988), R. Steedman (1987), Wainio and Hester (1973), Johnson and Owen (1966), Wainio (1959), and the Ontario Department of Planning and Development (ODPD) (1956).

Preparation of the hydrologic data, matched to hourly rainfall data, was reported in Trudeau and Richardson (2015). Development of urban extent estimates was reported in Trudeau and Richardson (under review). Watershed area, channel slope and basin slope upstream of fish observation sites were estimated using the methodology described in Trudeau and Richardson (under review) for hydrologic stations. Estimated urban land use by watershed was the urban extent upstream of hydrologic stations.

An event stream power measure was estimated per unit length of stream, normalized for watershed basin area. Stream power per unit length of stream (Gordon et al., 2004) is expressed as (Eq.1) (see Section 2.2.3). 
Larger streams have larger event flows, so the power per unit length estimate was divided by watershed area for comparison across the study fish basins. Note that channel sinuosity was not estimated or included in the calculation; the power measure was intended to be exploratory with respect to change in unit stream power with change in event flows across heterogeneous watersheds.

Because fish data were collected by various agencies over several decades, site locations and identifiers were inconsistent. For some older sites, locations were approximated from paper map records. All sites were plotted in ArcGIS and grouped based on proximity to each other within the same stretch of watercourse with no intervening tributary confluences (called 'Grouped Sites'); sites were up to approximately 1600 meters of river length from the database site location. Sites with less than two records (i.e. two years with data) were eliminated from the database. The latitude and longitude of fish site locations and site identifiers were based on one record within each Grouped Site, without preference for collecting agency or study. Fish species identification followed OMNR Fish Codes (Stirling, 1999).

The year of fish data collection and the year of air photos used to estimate urban land cover often did not match. Temporal matching of fish to urban observations was made according to the following rules:

1. For an urban percent land use (UP) estimate that was less than $0.5 \%$ in 1969 , records as early as 1949 were matched to 1969 because there was virtually no urban development in the watershed. 
2. For a UP estimate over $0.5 \%$ but less than $3 \%$, fish records up to 10 years earlier were matched because very little urban development had taken place during the earlier decade (e.g. some 1959 fish records were matched to 1969 land use estimates).

3. For other UP estimates, fish records were matched within 5 years of the available UP estimate; most fish records were matched to UP estimates within 3 years of the fish record.

Error could have been introduced into the fish database through inappropriate grouping of fish sampling sites, discrepancies in site locations resulting from reference systems (e.g. from NAD27 to NAD83) or estimates from paper maps, and inconsistent site identification codes and site descriptions.

\subsubsection{Statistical Analyses}

The entire set and two subsets of fish data were analyzed. The two subsets were: 1) only records for fish species present in the earliest comprehensive surveys (1940's and 1950's) (55 species) (called the Long-term record database); and, 2) all fish species records from 2000 to 2010 (called the Recent database). The two subsets of data were used to eliminate some of the temporal bias in the dataset. By including only species with a longterm record, the presence of these fish across sites and through time was assumed to be comparable, except where effort bias potentially affected the number of species identified (see Discussion). Since about 2000, fish surveys in the study region were undertaken using OSAP or compatible protocols. By including only records subsequent to 1999 , the database potentially excludes sampling methodology bias. The full dataset was analyzed 
to illustrate temporal bias. Table 6-1 describes variables used in statistical analyses. Year is the year of fish observation.

There were numerous multi-collinear independent variables and relatively few degrees of freedom due to the limited number of hydrologic sites matching urban extent and fish sites. To minimize multicollinearity issues, the analysis was undertaken in two phases: 1) independent variable selection; and, 2) fish richness model fitting using the selected independent variables.

The goal of the first phase was to identify independent variables that explained the highest proportion of variance for 1) site or watershed characteristic; and, 2) hydrology. As a preliminary step, the inter-relationships of variables were assessed with principal component analysis (PCA) using the R package 'vegan' (Oksanen et al., 2013). PCA analyses included fitting a fish richness vector to the PCA plots of the first two components. Predicted species richness was also estimated and plotted based on 999 permutations and the PCA scores. Also as part of the first phase, a 'dredge' analysis (R package 'MuMIn' (Barton, 2015)) was undertaken to assess the frequency with which candidate independent variables were selected. The 'dredge' command undertakes automated model selection to identify which subsets of independent variables best predict a dependent variable. The dredge command was not used for model selection. 
Table 6-1 Variables included in statistical analyses.

A summary of potential explanatory variables and the dependent variable used in the analyses.

\begin{tabular}{|c|c|c|c|}
\hline $\begin{array}{c}\text { Explanatory } \\
\text { Variable } \\
\end{array}$ & Description & Units & Notes \\
\hline \multicolumn{4}{|c|}{ Location } \\
\hline Distance from mouth & $\begin{array}{l}\text { Euclidean distance of } \\
\text { fish site from mouth of } \\
\text { Lake Ontario }\end{array}$ & $\mathrm{m}$ & $\begin{array}{l}\text { Tested in GLMM for } \\
\text { long-term records }\end{array}$ \\
\hline \multicolumn{4}{|c|}{ Watershed Characteristics } \\
\hline Drainage area & $\begin{array}{l}\text { Watershed area upstream } \\
\text { of the fish sampling site }\end{array}$ & $\mathrm{m}^{2}$ and $\mathrm{km}^{2}$ & $\begin{array}{l}\text { Tested in GLMM for } \\
\text { long-term records }\end{array}$ \\
\hline Channel slope & $\begin{array}{l}\text { Slope of the watercourse } \\
\text { upstream of a fish } \\
\text { observation site }\end{array}$ & $\mathrm{m} \mathrm{m}^{-1}$ & \\
\hline Basin slope & $\begin{array}{l}\text { Slope of the watershed } \\
\text { basin upstream of a fish } \\
\text { observation site }\end{array}$ & $\mathrm{m} \mathrm{m}^{-1}$ & $\begin{array}{l}\text { Tested in GLMM for } \\
\text { long-term records }\end{array}$ \\
\hline $\begin{array}{l}\text { Total length of stream } \\
\text { upstream of fish } \\
\text { sampling site }\end{array}$ & $\begin{array}{l}\text { Estimated from total } \\
\text { length of upstream } \\
\text { tributaries }\end{array}$ & $\mathrm{m}$ & $\begin{array}{l}\text { Tested in GLMM for } \\
\text { long-term records }\end{array}$ \\
\hline Baseflow index (BFI) & $\begin{array}{l}\text { Ratio of baseflow to } \\
\text { streamflow }\end{array}$ & unitless & \\
\hline \multicolumn{4}{|c|}{ Hydrologic Variables (applicable to May $26^{\text {th }}$ to November $15^{\text {th }}$ in all cases) } \\
\hline $\begin{array}{l}10^{\text {th }} \text { percentile event } \\
\text { stream power per unit } \\
\text { length of stream per } \\
\text { square meter } \\
\text { watershed area }\end{array}$ & $\begin{array}{l}\text { Watts per channel length } \\
\left(\mathrm{kg} \mathrm{m}^{2} \mathrm{~s}^{-3} \text { per } \mathrm{m}\right) \text { divided } \\
\text { by drainage basin area } \\
\left(\mathrm{m}^{2}\right) . \text { Watts calculated as } \\
\text { the product of water } \\
\text { density }\left(1000 \mathrm{~kg} \mathrm{~m}^{-3}\right) \text {, } \\
\text { gravity acceleration } \\
\left(9.8 \mathrm{~m} . \mathrm{s}^{-2}\right) \text {, rising limb } \\
\text { event flow }\left(\mathrm{m}^{3} \mathrm{~s}^{-1}\right), \\
\text { channel slope }\left(\mathrm{m} \mathrm{m}^{-1}\right) .\end{array}$ & $\begin{array}{l}\text { Watts per } \\
\text { channel unit } \\
\text { length }(\mathrm{m}) \text { per } \\
\mathrm{m}^{2}\end{array}$ & $\begin{array}{l}10^{\text {th }} \text { percentile calculated } \\
\text { on a yearly basis using } \\
\text { all available events; Q } \\
\text { equals the } 15 \text {-minute } \\
\text { increment rising limb } \\
\text { event flows }\end{array}$ \\
\hline $\begin{array}{l}90^{\text {th }} \text { percentile event } \\
\text { stream power per unit } \\
\text { length of stream per } \\
\text { square meter } \\
\text { watershed area }\end{array}$ & $\begin{array}{l}\text { Watts per channel length } \\
\text { divided by drainage } \\
\text { basin area }\left(\mathrm{m}^{2}\right) .\end{array}$ & $\begin{array}{l}\text { Watts per } \\
\text { channel unit } \\
\text { length }(\mathrm{m}) \text { per } \\
\mathrm{m}^{2}\end{array}$ & $\begin{array}{l}90^{\text {th }} \text { percentile calculated } \\
\text { on a yearly basis using } \\
\text { all available events; Q } \\
\text { equals the } 15 \text {-minute } \\
\text { increment rising limb } \\
\text { event flows }\end{array}$ \\
\hline $\begin{array}{l}\text { Mean flow per square } \\
\text { meter drainage area } \\
\left(\mathrm{MF} \cdot \mathrm{m}^{2}\right) \text {; also referred } \\
\text { to as mean } \\
\text { instantaneous runoff }\end{array}$ & $\begin{array}{l}\text { Mean flow }\left(\mathrm{m}^{3} \mathrm{~s}^{-1}\right) \\
\text { divided by basin area } \\
\left(\mathrm{m}^{2}\right)\end{array}$ & $\mathrm{m} \mathrm{s}^{-1}$ & $\begin{array}{l}\text { Mean flow calculated on } \\
\text { a yearly basis using as Q } \\
\text { the } 15 \text {-minute increment } \\
\text { flows, including event } \\
\text { and non-event flows } \\
\text { Included event and non- } \\
\text { event instantaneous } \\
\text { flows }\end{array}$ \\
\hline
\end{tabular}




\begin{tabular}{|c|c|c|c|}
\hline $\begin{array}{c}\text { Explanatory } \\
\text { Variable }\end{array}$ & Description & Units & Notes \\
\hline $\begin{array}{l}\text { Skew of MF.m }{ }^{2} \\
\text { (called Skew in } \\
\text { runoff) }\end{array}$ & $\begin{array}{l}\text { Skew of the mean } \\
\text { instantaneous runoff }\end{array}$ & unitless & $\begin{array}{l}\text { Calculated on a yearly } \\
\text { basis including all flows } \\
\text { for the year (event and } \\
\text { non-event). } \\
\text { Tested in GLMM for } \\
\text { long-term records }\end{array}$ \\
\hline $\begin{array}{l}\text { Mean rising limb } \\
\text { event acceleration }\end{array}$ & $\begin{array}{l}\text { Mean flow acceleration } \\
\left(\mathrm{m}^{3} \mathrm{~s}^{-2}\right) \text { from one } 15 \\
\text { minute increment to the } \\
\text { next during the rising } \\
\text { limb of event flows, up } \\
\text { to peak event flow }\end{array}$ & $\mathrm{m}^{3} \mathrm{~s}^{-2}$ & $\begin{array}{l}\text { Calculated on a yearly } \\
\text { basis for event } \\
\text { acceleration }>0 \mathrm{~m}^{3} \mathrm{~s}^{-1} \\
\text { during the rising limb of } \\
\text { events up to peak flow. } \\
\text { Tested in GLMM for } \\
\text { long-term records }\end{array}$ \\
\hline $\begin{array}{l}\text { Maximum event } \\
\text { acceleration }\end{array}$ & $\begin{array}{l}\text { Maximum flow } \\
\text { acceleration }\left(\mathrm{m}^{3} \mathrm{~s}^{-2}\right) \\
\text { during event flows }\end{array}$ & $\mathrm{m}^{3} \mathrm{~s}^{-2}$ & $\begin{array}{l}\text { Maximum event } \\
\text { acceleration in a year. } \\
\text { Tested in GLMM for } \\
\text { long-term records }\end{array}$ \\
\hline $\begin{array}{l}\text { Skew of rising limb } \\
\text { event acceleration }\end{array}$ & $\begin{array}{l}\text { Skew of the mean rising } \\
\text { limb event acceleration }\end{array}$ & unitless & $\begin{array}{l}\text { Skew calculated on a } \\
\text { yearly basis including } \\
\text { the mean rising limb } \\
\text { acceleration of all } \\
\text { recorded events }\end{array}$ \\
\hline \multicolumn{4}{|c|}{ Land use and temporal variables } \\
\hline Urban percent (UP) & $\begin{array}{l}\text { Percent of the watershed } \\
\text { upstream of the } \\
\text { hydrologic gauge that is } \\
\text { urban land use }\end{array}$ & unitless & $\begin{array}{l}\text { Tested in GLMM for } \\
\text { long-term records }\end{array}$ \\
\hline Dependent Variable & Description & Units & Notes \\
\hline Fish species Richness & $\begin{array}{l}\text { Number of fish species } \\
\text { per site; species are } \\
\text { defined by OMNR } \\
\text { species codes (Stirling, } \\
\text { 1999) }\end{array}$ & Count & $\begin{array}{l}\text { Some species codes are } \\
\text { generic for a group } \\
\text { rather than an individual } \\
\text { species. See Stirling, } \\
1999 \text { and Appendix M. }\end{array}$ \\
\hline
\end{tabular}


The goal of the second phase of statistical analysis was to fit models using the selected independent variables to predict fish richness. Two types of models were fit: 1) generalized linear mixed models (GLMM) with random intercepts by site and Poisson distribution using two independent variables (one physiographical and one hydrologic or urban extent); and, 2) fixed effects linear models with Poisson distribution using up to four independent variables. Where more than one independent variable was fit in a model, the variables were fit simultaneously, not sequentially.

GLMM were fit using the R package 'Ime4' (Bates et al., 2015). Due to limited degrees of freedom, the models were fit with only two variables and random intercepts by site. Response, Pearson and deviance residuals of the best GLMMs were plotted and visually inspected for structure per R code developed by Zuur et al. (2009). GLMM estimates for p-values and AIC are approximate (Zurr et al., 2009). Over-dispersion in the residuals was assessed by the ratio of Chi-square to model degrees of freedom using publicly posted R code (http://glmm.wikidot.com/faq). Where there is over dispersion in GLMMs, Bates et al. (2015) recommend against a quasi-Poisson distribution for GLMMs and the lme4 R package cannot be used for this alternative distribution. One GLMM model for the long-term database had over-dispersion in the residuals so a negative binomial model (with fixed effects only) was fit for comparison using the R package 'MASS' (Ripley, 2015).

Linear models, with fixed effects only, were fit using the 'glm' command (R Core Team, 2012) for four variables in combination, representing: time; physiography; hydrology; 
and, urban extent. Models were compared based on AIC, F-tests using the 'anova' command (R Core Team, 2012) and a calculated residual deviance relative to the null (1(residual deviance/null deviance), reported as Pseudo $R^{2}$. The 'Anova' command in the R Package 'car' (Fox and Weisberg, 2011) was used to assess the partial $\mathrm{R}^{2}$ of fixed effects model variables; Type II where there were no interactions in the model and Type III where there were interactions.

\subsection{Results}

\subsubsection{Overview of trends in the database}

The database had 2700 records for fish at 497 sites between 1927 and 2010. Although there were 93 potential records with detailed urban and hydrologic data, only 49 records at 22 sites could readily be matched to urban-hydrologic data in our database (indicated in Illustration 6-1). There were 60 more fish species recorded in 2011 compared with the 1940's and 1950's fish surveys. Only seven of the 60 were introduced species not included in the long-term species record (R. Eakins database, n.d.). Sixteen additional species were in the Cyprinidae - Carps and Minnows group (see Stirling, 1999). Some of the additional species codes may indicate misclassification error (or introduced species) rather than bias (e.g. coho salmon). 


\subsubsection{Long-term Record: Relationship of Fish Species and Hydrologic}

\section{Characteristics}

There were 55 species in the Long-term database. Fish richness ranged from 0 to 18 per site. Raw data plots indicated there was potential positive bias in fish richness with time; the highest fish richness records per site were recorded in more recent years, potentially indicating effort bias (Illustration 6-2, top left panel). The highest maximum acceleration records occurred during the most recent years (Illustration 6-2, top right panel), consistent with high correlation with increased urban land use $(r=0.77)$ which also increased over the time period. The highest fish richness records occurred at sites that had the lowest maximum accelerations (Illustration 6-2, lower left panel). The highest fish richness records also occurred at lower urban percent land use (Illustration 6-2, lower right panel).

Increased fish richness with time was observed at many sites (Illustration 6-3, left panel), likely indicating effort and/or methodological bias in the dataset. Many individual observation sites recorded increased fish richness with increased urban percent and increased fish richness with maximum acceleration (Illustration 6-3, middle and right panels, respectively). Increased event acceleration is positively associated with urban extent (Trudeau and Richardson, under review). 

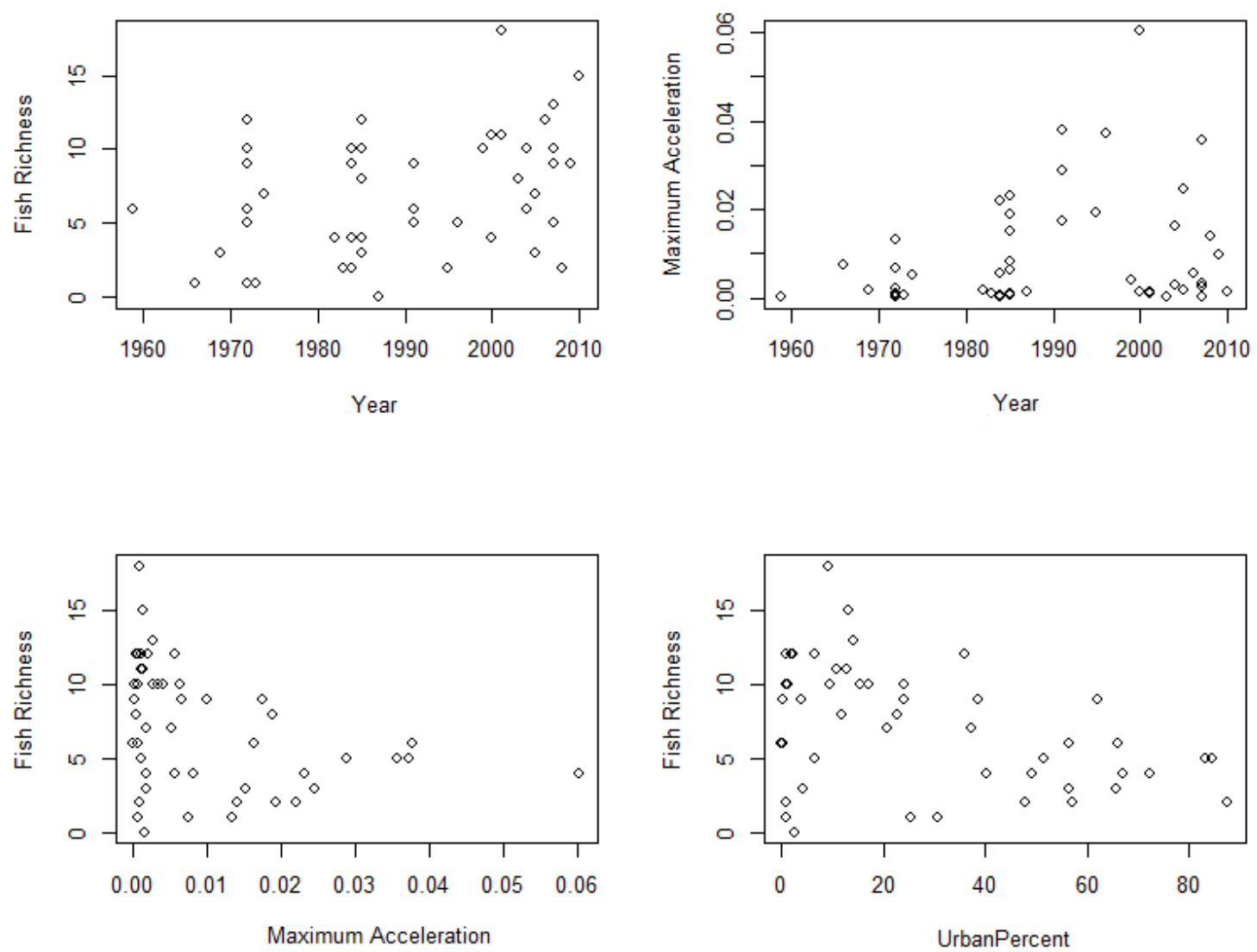

Illustration 6-2 Raw data plots.

The illustration plots fish species richness, using the Long term record database, by year (upper left, Spearman rho $=0.28, S=14173.3$, approximate $p=0.05)$, by maximum acceleration (lower left, Spearman rho $=-0.39, S=27275.7$, approximate $p=0.005$ ) and by urban percent (lower right, Spearman $r h o=-0.37, S=26883.9$, approximate $p=0.009)$; maximum acceleration $\left(\mathrm{m}^{3} \mathrm{~s}^{-2}\right)$ is also plotted by year (upper right, Spearman rho $=0.26, S=14433.5$, approximate $p=0.07$ ). 

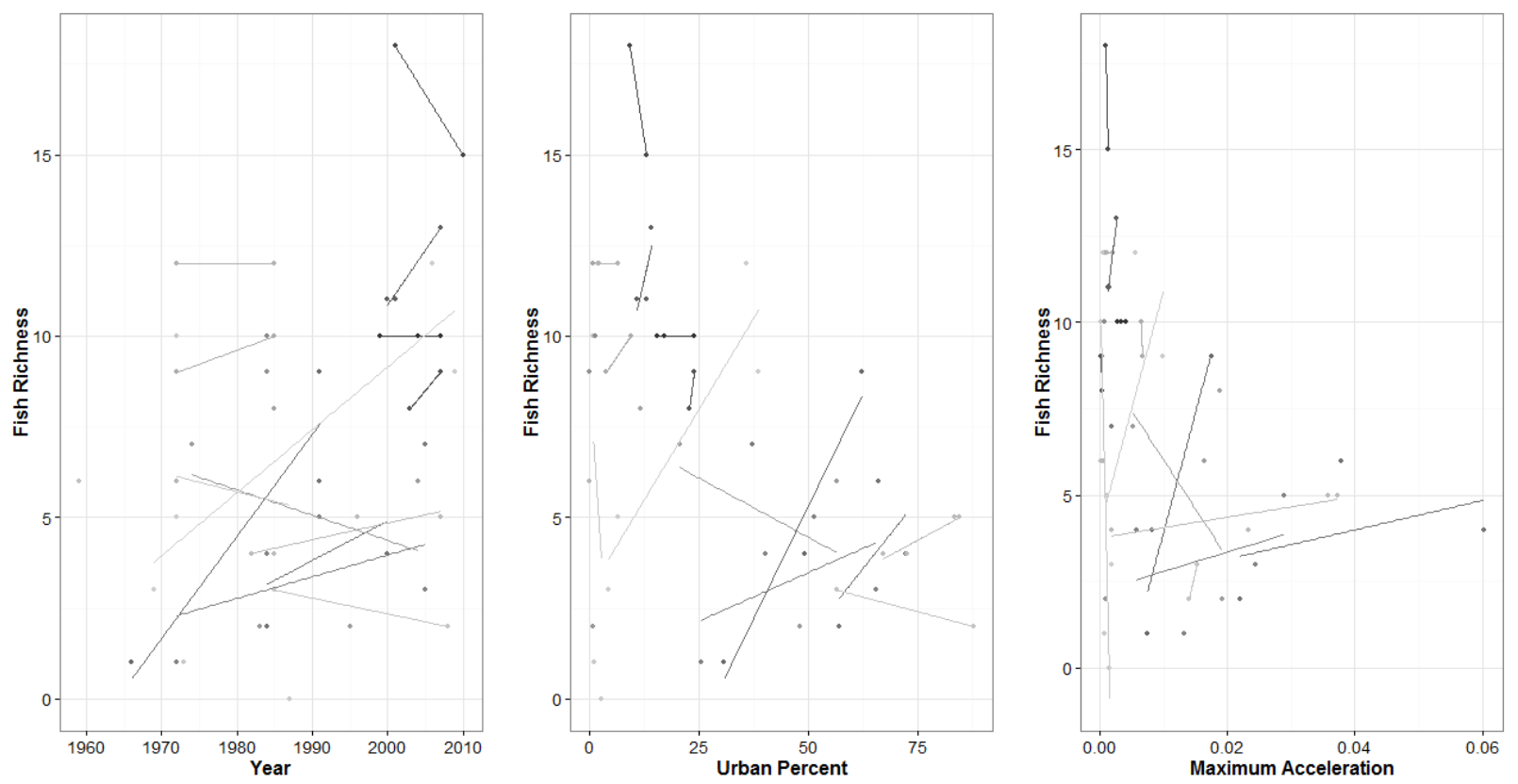

Illustration 6-3 Raw data plot of fish richness with year, urban percent and maximum acceleration $\left(\mathrm{m}^{3} \mathrm{~s}^{-2}\right)$ by site.

Linear trend lines by site are superimposed. 
Using all potential independent variables in Table 6-1, the first two principal components explained $59.6 \%$ of the variance (37.2\% and $22.4 \%$, respectively) (Illustration $6-4$; Appendix N.1). Distance from Mouth (-0.83) and Total Length (-0.75) had the most negative loadings on PC1, whereas the acceleration variables, Maximum Acceleration (1.11) and Mean Acceleration (1.19), and $90^{\text {th }}$ Percentile Power (1.16) had the most positive loadings on PC1. PC1 thus reflected the negative relationship of event acceleration and highest power with the length of stream network and distance of watershed from Lake Ontario. Basin slope $(-1.07), 10^{\text {th }}$ percentile event power $(-1.13)$, BFI (-1.11) had the most negative loadings on PC2 and Skew in runoff $(0.58)$ had the most positive loading on the second component. This component reflected characteristics of watersheds in the study region (e.g. basin slope, BFI) that are negatively associated with skew in runoff (which generally increases with increasing urban cover). The two event power variables $\left(10^{\text {th }}\right.$ and $90^{\text {th }}$ percentiles $)$ were in the same quadrant of the PCA, indicating other variables more strongly influence the span of these two components. The Fish Richness vector was most highly correlated with PC1 (-0.84) $(\mathrm{PC} 2$ correlation $=$ $0.54)$; vector $\mathrm{R}^{2}=0.37(\mathrm{p}$-value $=0.001)$.

Using the process described in Methods, for the Long-term database, the number of independent variables was reduced to eight, from the original 14 , four of which pertained to physiographical characteristics of the watersheds and fish site locations (Total length; Distance from mouth; Drainage area; and, Basin slope). The remaining four pertained to hydrologic characteristics (Maximum acceleration; Mean acceleration; Skew in runoff) and Urban percent land use. To model the bias in the database, Year was also tested as an independent variable. 


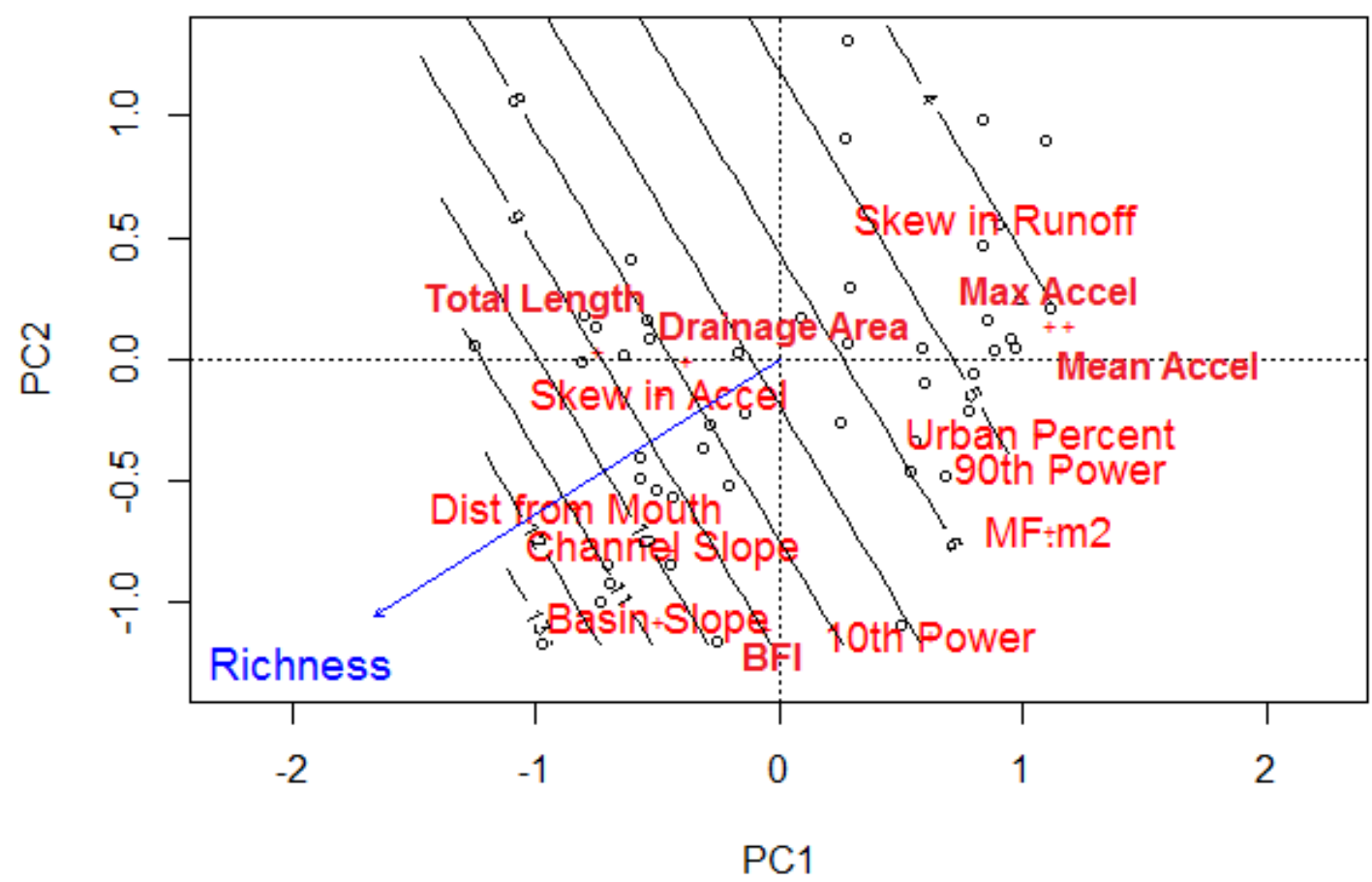

Illustration 6-4 Principal Component Analysis plot for Long term database.

PCA results for fish monitoring sites (black circles) and independent variables (text) with species richness vector (lower left quadrant) for the Long-term database (55 fish species). Predicted species richness, estimated from PCA scores with 999 permutations, is overlain (black diagonal lines with predicted number of species). 
Generalized linear mixed models (GLMM) with random intercepts by site were fit to predict fish richness. Total length of stream explained the largest proportion of variation in fish richness when each of the four independent physiographical variables was fit individually (Table 6-2). The difference between Total length and Distance from mouth, was small but statistically significant $(0.6 \%$ additional deviance explained; Chisq $=0.58$, $\mathrm{p}=2.2 \mathrm{e}-16$ ). Total length also had the advantage that it was not highly correlated with the four additional variables fit in the next step of model development (i.e. three hydrologic variables and urban percent) (see Appendix O). The model with Total length did not have over-dispersion (ratio Pearson Chi-square to model degrees of freedom $=$ $1.10, \mathrm{p}=0.28)$. For comparison, a statistical model with only $U P$ was fit in keeping with the methodology of Table 6-2. As the only independent variable, $U P$ is not statistically significant, although the coefficient does have a negative tendency (coefficient estimate $=$ $-0.05+/-0.11, \mathrm{p}=0.639 ; \mathrm{AIC}=103.5)$. By contrast, with Maximum Acceleration used as the only independent variable, the result is statistically significant and AIC indicates an improvement over just the intercept $($ coefficient estimate $=-0.23+/-0.12, p=0.0497$; AIC $=100.4)$. GLMM models were next fit with Total length and a second independent variable representing hydrology or urban cover (Table 6-3). 
Table 6-2 GLMM model comparisons for watershed and fish site characteristics for the long-term record database.

Total length of stream upstream of the fish monitoring sites (in bold) explained a higher proportion of variation than the 3 other independent variables for watershed or site characteristics.

\begin{tabular}{|c|c|c|c|c|c|}
\hline $\begin{array}{c}\text { Independent } \\
\text { Variable }\end{array}$ & AIC & $\begin{array}{c}\text { Log } \\
\text { Likelihood }\end{array}$ & $\begin{array}{c}\text { Coefficient } \\
\text { Estimate } \\
\text { +/- SE }\end{array}$ & $\begin{array}{c}\text { p- } \\
\text { value }\end{array}$ & $\begin{array}{c}\text { Pseudo } \\
\mathbf{R}^{2}\end{array}$ \\
\hline $\begin{array}{l}\text { Intercept } \\
\text { (with no } \\
\text { independent } \\
\text { variables) }\end{array}$ & 101.70 & -48.83 & & & \\
\hline $\begin{array}{c}\log _{10} \text { Total } \\
\text { Length } \\
\end{array}$ & 95.04 & -44.52 & $\begin{array}{c}0.68+/- \\
0.20\end{array}$ & 0.0008 & 0.088 \\
\hline $\begin{array}{c}\log _{10} \\
\text { Distance from } \\
\text { Mouth }\end{array}$ & 95.62 & -44.81 & $\begin{array}{c}0.61+/- \\
0.20\end{array}$ & 0.0019 & 0.082 \\
\hline $\begin{array}{c}\log _{10} \text { Basin } \\
\text { Slope }\end{array}$ & 97.21 & -45.6 & $\begin{array}{c}1.81+/- \\
0.63\end{array}$ & 0.004 & 0.066 \\
\hline $\begin{array}{c}\log _{10} \\
\text { Drainage } \\
\text { Area }\end{array}$ & 98.40 & -46.2 & $\begin{array}{c}0.66+/- \\
0.27\end{array}$ & 0.0133 & 0.054 \\
\hline
\end{tabular}


Table 6-3 GLMM model comparisons for two independent variables for the long-term database.

Models were fit with Poisson distribution. Non-significant terms are indicated with bold p-values.

\begin{tabular}{|c|c|c|c|c|c|}
\hline $\begin{array}{c}\text { Independent } \\
\text { Variable (in } \\
\text { addition to } \\
\text { Total } \\
\text { Length) }\end{array}$ & AIC & $\begin{array}{c}\text { Log } \\
\text { Likelihood }\end{array}$ & $\begin{array}{c}\text { Independent } \\
\text { Variable } \\
\text { p-value }\end{array}$ & $\begin{array}{c}\text { Total } \\
\text { Length } \\
\text { p-value }\end{array}$ & $\begin{array}{c}\text { Pseudo } \\
\mathbf{R}^{2}\end{array}$ \\
\hline $\begin{array}{c}\log _{10} \\
\text { Maximum } \\
\text { Acceleration }\end{array}$ & 92.08 & -42.04 & 0.011 & 0.0001 & 0.139 \\
\hline $\begin{array}{l}\log _{10} \text { Mean } \\
\text { Acceleration }\end{array}$ & 93.36 & -42.68 & 0.015 & $3.8 \mathrm{e}-05$ & 0.126 \\
\hline $\begin{array}{l}\log _{10} \text { Skew } \\
\text { in runoff* }\end{array}$ & 92.23 & -42.12 & 0.005 & 0.0026 & 0.138 \\
\hline $\begin{array}{c}\log _{10} \text { Urban } \\
\text { Percent land } \\
\text { use }\end{array}$ & 97.04 & -44.52 & 0.983 & 0.0012 & 0.088 \\
\hline
\end{tabular}


The model with Skew in runoff had some over-dispersion (ratio Pearson Chi-square to model degrees of freedom $=1.38, p=0.045$ ). A negative binomial model was fit with fixed effects only; the predicted means were very consistent with the fixed effects predictions of the GLMM (see Appendix P).

Compared with only Total length, the addition of Maximum acceleration was a significant improvement (5.1\% additional deviance explained; Chisq $=4.96, \mathrm{p}=0.026)$; Mean acceleration was not a clear improvement (3.8\% additional deviance explained; Chisq $=3.68, \mathrm{p}=0.055)$; Skew in runoff was an improvement $(5.0 \%$ additional deviance explained; Chisq $=4.81, \mathrm{p}=0.028)$ although the over-dispersion reduces the reliability of this estimate. The addition of Urban percent did not statistically improve the Total length model $(0 \%$ additional deviance explained; Chisq $=4 \mathrm{e}-04, \mathrm{p}=0.98)$. Residuals of the model with Maximum acceleration and Total length did not have discernable structure or over-dispersion $($ ratio $=1.25, \mathrm{p}=0.12)$.

Results for the four-variable analyses were consistent with those for the GLMM analysis. Richness was predicted using four groups of variables (brackets indicate the independent variable used): 1) time (Year); 2) physiography (Total length upstream of the fish site, $\log _{10}$ transformed); 3 ) hydrologic (Maximum event acceleration, $\log _{10}$ transformed); 4) Urban extent (UP, $\log _{10}$ transformed). Models were fit with combinations of these variables (Table 6-4). 
Table 6-4 Fish richness four variable model comparisons for the long-term database.

The dependent variable for all models was fish richness. Bolding indicates non-significant p-value results. Intercepts are not provided for simplicity.

\begin{tabular}{|c|c|c|c|c|c|c|}
\hline Model & $\begin{array}{c}\text { Independent } \\
\text { Variables }\end{array}$ & $\begin{array}{c}\text { Coefficient } \\
+/- \text { SE }\end{array}$ & p-value & $\begin{array}{c}\text { Residual } \\
\text { Deviance } \\
\text { (RD) }\end{array}$ & AIC & Pseudo $R^{2}$ \\
\hline Null & & & & $\begin{array}{c}\text { Null } \\
\text { Deviance } \\
\text { (ND): } 129.0 \\
\text { on } 48 \mathrm{df} \\
\end{array}$ & & \\
\hline \multirow{2}{*}{$\begin{array}{l}\text { A. Time and } \\
\text { Physiography } \\
\qquad(1,2)\end{array}$} & $\begin{array}{l}\log _{10} \text { Total } \\
\text { Length }\end{array}$ & $0.74+/-0.13$ & $3.95 \mathrm{e}-09$ & \multirow{2}{*}{85.1 on $46 \mathrm{df}$} & \multirow{2}{*}{265.96} & \multirow{2}{*}{0.340} \\
\hline & Year & $\begin{array}{c}0.014+/- \\
0.004\end{array}$ & 0.00034 & & & \\
\hline \multirow{3}{*}{$\begin{array}{l}\text { B. Time, } \\
\text { Physiography } \\
\text { and Hydrology } \\
\quad(1,2,3)\end{array}$} & $\begin{array}{l}\log _{10} \text { Total } \\
\text { Length }\end{array}$ & $0.69+/-0.13$ & $7.54 \mathrm{e}-08$ & \multirow{3}{*}{65.1 on $45 \mathrm{df}$} & \multirow{3}{*}{248.05} & \multirow{3}{*}{0.495} \\
\hline & Year & $\begin{array}{c}0.018+/- \\
0.0039\end{array}$ & $4.62 \mathrm{e}-06$ & & & \\
\hline & $\begin{array}{c}\log _{10} \\
\text { Maximum } \\
\text { Acceleration }\end{array}$ & $\begin{array}{c}-0.36+/- \\
0.08\end{array}$ & 7.86e-06 & & & \\
\hline \multirow{3}{*}{$\begin{array}{l}\text { C. Time, } \\
\text { Physiography } \\
\text { and UP }(1,2,4)\end{array}$} & $\begin{array}{l}\log _{10} \text { Total } \\
\text { Length }\end{array}$ & $0.62+/-0.13$ & $2.50 \mathrm{e}-06$ & \multirow{3}{*}{72.2 on $45 \mathrm{df}$} & \multirow{3}{*}{255.07} & \multirow{3}{*}{0.440} \\
\hline & Year & $\begin{array}{c}0.025+/- \\
0.005\end{array}$ & 7.26e-07 & & & \\
\hline & $\log _{10} \mathrm{UP}$ & $\begin{array}{c}-0.32+/- \\
0.088\end{array}$ & 0.000253 & & & \\
\hline
\end{tabular}




\begin{tabular}{|c|c|c|c|c|c|c|}
\hline \multirow{4}{*}{$\begin{array}{c}\text { D. Time, } \\
\text { Physiography, } \\
\text { Hydrology and } \\
\text { UP }(1,2,3,4)\end{array}$} & $\begin{array}{c}\log _{10} \text { Total } \\
\text { Length }\end{array}$ & $0.67+/-0.13$ & $4.95 \mathrm{e}-07$ & \multirow{4}{*}{65.1 on $44 \mathrm{df}$} & \multirow{4}{*}{249.96} & \multirow{4}{*}{0.495} \\
\hline & Year & $\begin{array}{c}0.019+/- \\
0.005\end{array}$ & 0.00045 & & & \\
\hline & $\begin{array}{c}\log _{10} \\
\text { Maximum } \\
\text { Acceleration }\end{array}$ & $\begin{array}{c}-0.33+/- \\
0.124\end{array}$ & 0.0070 & & & \\
\hline & $\log _{10} U P$ & $\begin{array}{c}-0.042+/- \\
0.14\end{array}$ & 0.763 & & & \\
\hline \multirow{3}{*}{$\begin{array}{c}\text { E. Time, } \\
\text { Physiography, } \\
\text { and interaction } \\
\text { of Hydrology } \\
\text { with UP } \\
(1,2,3: 4)\end{array}$} & $\begin{array}{l}\log _{10} \text { Total } \\
\text { Length }\end{array}$ & $\begin{array}{c}0.716+/- \\
0.128\end{array}$ & $2.39 \mathrm{e}-08$ & \multirow{3}{*}{82.5 on $45 \mathrm{df}$} & \multirow{3}{*}{265.36} & \multirow{3}{*}{0.360} \\
\hline & Year & $\begin{array}{c}0.019+/- \\
0.005\end{array}$ & 0.00017 & & & \\
\hline & $\begin{array}{c}\log _{10} \\
\text { Maximum } \\
\text { Acceleration: } \\
\log _{10} \text { UP }\end{array}$ & $\begin{array}{c}0.060+/- \\
0.0365\end{array}$ & 0.100 & & & \\
\hline
\end{tabular}


The results for all models indicated a positive effect of Year, which was likely the result of sampling and other bias in the dataset. A comparison of AIC and Pseudo $\mathrm{R}^{2}$ indicated Model B (Time, Physiography and Hydrology) explained 5.5\% additional deviance compared with Model C (Time, Physiography and UP). Table 6-5 summarizes the results of an Analysis of Deviance to assess the partial $R^{2}$ of the four variables in three of the models (D, B and C). In Model B (with Maximum acceleration), Year explained less variation than Year in Model C (with $U P$ ), indicating that Maximum acceleration explained some of the variation through time encompassed by Year in Model C. In Model D, with Year, Maximum acceleration and $U P, U P$ explained virtually none of the variation. 
Table 6-5 LR Chi square of independent variables for three linear models for the long term database.

The dependent variable for all models was fish richness. Bold indicates non-significant p-value.

\begin{tabular}{|c|c|c|c|}
\hline Model & $\begin{array}{l}\text { Independent } \\
\text { Variable }\end{array}$ & LR Chi square & p-value \\
\hline \multirow{4}{*}{$\begin{array}{c}\text { D Time, } \\
\text { Physiography, } \\
\text { Hydrology and UP } \\
(1,2,3,4)\end{array}$} & $\log _{10}$ Total Length & 24.77 & $6.5 \mathrm{e}-07$ \\
\hline & Year & 12.67 & 0.0004 \\
\hline & $\begin{array}{c}\log _{10} \text { Maximum } \\
\text { Acceleration }\end{array}$ & 7.12 & 0.0076 \\
\hline & $\log _{10} \mathrm{UP}$ & 0.09 & 0.763 \\
\hline \multirow{3}{*}{$\begin{array}{c}\text { B Time, } \\
\text { Physiography and } \\
\text { Hydrology }(1,2,3)\end{array}$} & $\log _{10}$ Total Length & 28.22 & $1.1 \mathrm{e}-07$ \\
\hline & Year & 21.20 & $4.1 \mathrm{e}-06$ \\
\hline & $\begin{array}{l}\log _{10} \text { Maximum } \\
\text { Acceleration }\end{array}$ & 19.92 & $8.1 \mathrm{e}-06$ \\
\hline \multirow{3}{*}{$\begin{array}{c}\text { C Time, } \\
\text { Physiography and UP } \\
(1,2,4)\end{array}$} & $\log _{10}$ Total Length & 21.6 & $3.3 e-06$ \\
\hline & Year & 25.5 & $4.4 \mathrm{e}-07$ \\
\hline & $\log _{10} \mathrm{UP}$ & 12.9 & 0.0003 \\
\hline
\end{tabular}




\subsubsection{Analyses using all fish records}

The database with all fish observations had 115 fish species with richness ranging from 1 to 18 species per site. Thirteen of the 49 records with matching hydrological data had between 1 and 3 additional fish species in comparison with the long term database, whereas none of the remaining 36 sites had fewer fish species.

Although this database had positive bias in fish richness with time, the model results were similar to those for the Long term database in models fit to predict fish richness with Total length and one hydrologic variable or UP (Table 6-6); coefficients were within the range of standard error for model coefficients fit to the Long-term database. However, models with hydrologic characteristics had over-dispersion in the residuals; overdispersion was not corrected due to the limited value this detailed analysis would offer, given biases in database. Over-dispersion for models with Maximum Acceleration, Mean Acceleration and Skew in runoff was indicated, respectively, by ratio $=1.38, \mathrm{p}=0.045$; ratio $=1.47, \mathrm{p}=0.022 ;$ and ratio $=1.53, \mathrm{p}=0.031$

Compared with only Total length, the addition of Maximum acceleration was a significant improvement $($ Chisq $=7.785, \mathrm{p}=0.029)$; Mean acceleration was not an improvement $($ Chisq $=3.586, \mathrm{p}=0.058)$; Skew in runoff was an improvement $($ Chisq $=$ 7.402, $\mathrm{p}=0.007)$; over-dispersion reduces the reliability of all these estimates. 
Table 6-6 GLMM model comparisons for two independent variables for the database with all fish records.

The first two rows provide model results for an intercept and the physiological variable only. The remainder of the table provides models with two independent variables. Non-significant terms are indicated with bold p-values.

\begin{tabular}{|c|c|c|c|c|c|}
\hline $\begin{array}{l}\text { Independent } \\
\text { Variable }\end{array}$ & AIC & $\begin{array}{c}\text { Log } \\
\text { Likelihood }\end{array}$ & & $\begin{array}{l}\text { Total Length } \\
\text { p-value }\end{array}$ & Pseudo $\mathrm{R}^{2}$ \\
\hline $\begin{array}{l}\text { Intercept (with no } \\
\text { independent } \\
\text { variables) }\end{array}$ & 102.4 & -49.19 & & & \\
\hline $\begin{array}{l}\log _{10} \text { Total } \\
\text { Length }\end{array}$ & 95.26 & -44.63 & & 0.0005 & 0.093 \\
\hline $\begin{array}{c}\text { Independent } \\
\text { Variable (in } \\
\text { addition to Total } \\
\text { Length) } \\
\end{array}$ & AIC & $\begin{array}{c}\text { Log } \\
\text { Likelihood }\end{array}$ & $\begin{array}{l}\text { Additional } \\
\text { Variable } \\
\text { p-value }\end{array}$ & $\begin{array}{l}\text { Total Length } \\
\text { p-value }\end{array}$ & Pseudo $\mathbf{R}^{2}$ \\
\hline $\begin{array}{l}\log _{10} \text { Maximum } \\
\text { Acceleration* }\end{array}$ & 92.48 & -42.24 & 0.0096 & $4.93 e-05$ & 0.141 \\
\hline $\begin{array}{c}\log _{10} \text { Mean } \\
\text { Acceleration* }\end{array}$ & 93.67 & -42.84 & 0.013 & $1.73 \mathrm{e}-05$ & 0.129 \\
\hline $\begin{array}{l}\log _{10} \text { Skew in } \\
\text { runoff* }\end{array}$ & 89.86 & -40.93 & 0.0005 & 0.0025 & 0.168 \\
\hline $\begin{array}{c}\log _{10} \text { Urban } \\
\text { Percent land use }\end{array}$ & 97.25 & -44.63 & 0.932 & 0.0009 & 0.093 \\
\hline
\end{tabular}


As was the case for the Long term database, the addition of Urban percent did not statistically improve the Total length model $(0 \%$ additional variance, Chisq $=0.007, p=$ 0.93). With this dataset, the model with Skew in runoff and Total length had the lowest residual variance and AIC, with a pseudo $\mathrm{R}^{2}$ of $16.8 \%$.

The results for the four-variable analyses were also similar to those for the Long term database. Table 6-7 reports the model with four independent variables, in which UP is not significant and Year has a positive effect and Maximum acceleration has a statistically significant negative effect. 
Table 6-7 Fish richness results for one four- variable model for the database with all fish records.

Bold indicates non-significant p-value. Intercepts are not provided for simplicity.

\begin{tabular}{|c|c|c|c|c|c|c|c|}
\hline Model & $\begin{array}{c}\text { Independent } \\
\text { Variables }\end{array}$ & $\begin{array}{c}\text { Coefficient } \\
\text { +/- SE }\end{array}$ & $\begin{array}{c}\text { p- } \\
\text { value }\end{array}$ & $\begin{array}{c}\text { LR } \\
\text { Chi } \\
\text { square }\end{array}$ & $\begin{array}{c}\text { p- } \\
\text { value, } \\
\text { LR Chi } \\
\text { square }\end{array}$ & $\begin{array}{l}\text { Residual } \\
\text { Deviance } \\
\text { (RD) }\end{array}$ & $\begin{array}{c}\text { Pseudo } \\
\mathbf{R}^{2}\end{array}$ \\
\hline Null & & & & & & $\begin{array}{c}\text { Null } \\
\text { Deviance } \\
\text { (ND): } 126.8 \\
\text { on } 48 \mathrm{df} \\
\end{array}$ & \\
\hline \multirow{4}{*}{$\begin{array}{c}\text { D. Time, } \\
\text { Physiography, } \\
\text { Hydrology } \\
\text { and UP } \\
(1,2,3,4)\end{array}$} & $\begin{array}{l}\log _{10} \text { Total } \\
\text { Length }\end{array}$ & $\begin{array}{c}0.63+/- \\
0.13\end{array}$ & $\begin{array}{l}1.29 \\
\mathrm{e}-06\end{array}$ & 22.9 & $\begin{array}{l}1.67 \\
\mathrm{e}-06\end{array}$ & \multirow{4}{*}{$\begin{array}{c}65.3 \text { on } 44 \\
\text { df }\end{array}$} & \multirow{4}{*}{0.49} \\
\hline & Year & $\begin{array}{c}0.02+/- \\
0.005\end{array}$ & 0.0003 & 13.5 & 0.0002 & & \\
\hline & $\begin{array}{c}\log _{10} \\
\text { Maximum } \\
\text { Acceleration }\end{array}$ & $\begin{array}{c}-0.29+/- \\
0.12\end{array}$ & 0.015 & 5.8 & 0.016 & & \\
\hline & $\log _{10} \mathrm{UP}$ & $\begin{array}{c}-0.08+/- \\
0.13\end{array}$ & 0.560 & 0.3 & 0.561 & & \\
\hline
\end{tabular}




\subsubsection{Analyses using the Recent database}

The Recent database (2000 to 2010) had 17 records with 99 species at 11 sites. Sites had between two and 18 species each. The consistent data collection methods since 2000 could be expected to reduce bias in fish richness. Although the number of species was higher overall than the Long-term database (99 versus 55), there were six species codes missing from the Recent database (codes as identified by Stirling, 1999): Moxostoma sp. (S177); eastern silvery minnow (S190); channel catfish (S234); tadpole madtom (S236); Noturus sp. (S242); banded killifish (S261). Note that these species may have been recorded at other locations within the timeframe of the Recent database.

PCA analysis indicated different relationships among independent variables of the Recent database. The first two principal components explained $72.9 \%$ of the variance $(52.7 \%$ and 20.2\%, respectively) (Illustration 6-5; Appendix N.2). For the first component, variables loaded most heavily on Urban Percent (0.96), Mean acceleration (0.93), Maximum acceleration (0.92), Distance from Mouth (-0.87) and Basin slope (-0.91). The Fish Richness vector was most highly correlated with PC1 (-0.91) (PC2 correlation = $0.42)$; vector $\mathrm{R}^{2}=0.64(\mathrm{p}=0.002)$.

Total length of stream explained the largest proportion of variation when each of the four independent variables for watershed/ site characteristics was fit individually. 
Table 6-8 provides results of GLMM models fit with Total length and a second independent variable, with random intercepts by site. There was no over-dispersion in model residuals for the Recent database.

The results for the GLMM models using the Recent database differ from those for the Long term database. Urban percent was a statistically significant improvement (Chisq = $7.30, \mathrm{p}=0.007$ ) with a negative coefficient but Total length was not significant in the model. This model had the lowest residual variance and AIC of the four models compared. Relative to the model with only Total length, the addition of Maximum acceleration was a significant improvement $(\mathrm{Chisq}=5.80, \mathrm{p}=0.016)$, as was Mean acceleration $($ Chisq $=6.28, \mathrm{p}=0.012)$; Skew in runoff was not an improvement $($ Chisq $=$ $2.90, \mathrm{p}=0.089)$

Results for the four-variable analyses differed from those for the Long term database: Year was not statistically significant in any model and was removed. Maximum acceleration and Urban percent were statistically significant when fit individually with Total length. Multicollinearity was present in a model with three independent variables (excluding Year), with no statistically significant independent variables.

In the Recent database (2000 to 2010), the range of hydrologic variables was reduced by half in some cases compared with the Long-term database (see Appendix Q). Also, minimum values in the Recent database for maximum acceleration and mean runoff were 2 times higher than those in the Long-term database. 


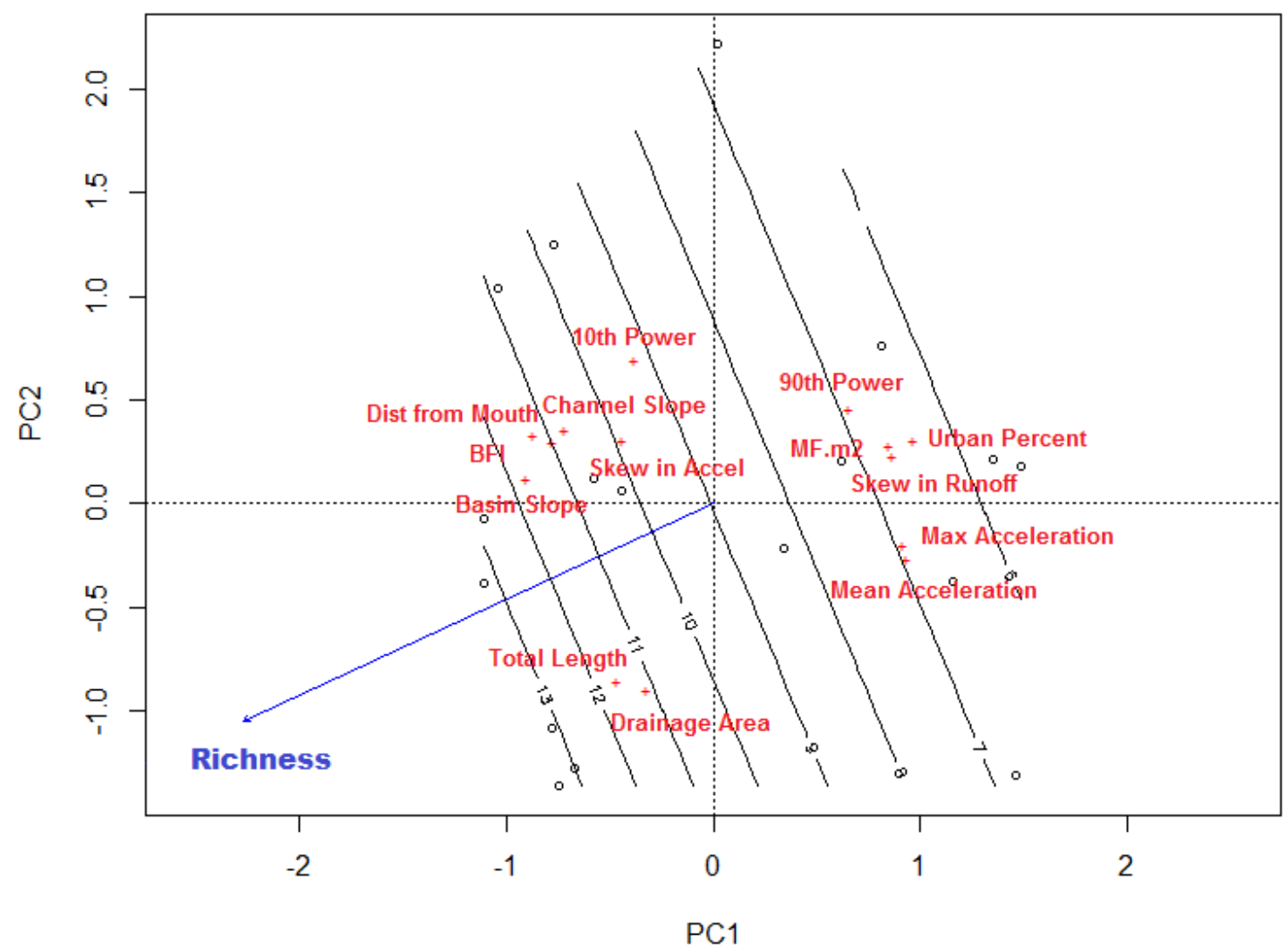

Illustration 6-5 Principal Component Analyses plot for the recent database.

PCA results for fish monitoring sites (black circles) and independent variables (text) with species richness vector (lower left quadrant). There were 99 fish species in the Recent database (2000-2010). Predicted species richness, estimated from PCA scores with 999 permutations, is overlain (black diagonal lines with predicted number of species). 
Table 6-8 GLMM model comparisons for the recent database.

Bold indicates non-statistically significant p-values.

\begin{tabular}{|c|c|c|c|c|c|}
\hline $\begin{array}{c}\text { Independent } \\
\text { Variable }\end{array}$ & AIC & $\begin{array}{c}\text { Log } \\
\text { Likelihood }\end{array}$ & & $\begin{array}{c}\text { Total Length } \\
\text { p-value }\end{array}$ & Pseudo $\mathbf{R}^{2}$ \\
\hline $\begin{array}{c}\text { Intercept } \\
\text { (with no } \\
\text { independent } \\
\text { variables) }\end{array}$ & 28.5 & -12.25 & & & \\
\hline $\begin{array}{c}\log _{10} \text { Total } \\
\text { Length }\end{array}$ & 24.6 & -9.299 & & 0.0042 & 0.241 \\
\hline $\begin{array}{l}\text { Independent } \\
\text { Variable (in } \\
\text { addition to } \\
\text { Total } \\
\text { Length) } \\
\end{array}$ & AIC & $\begin{array}{c}\text { Log } \\
\text { Likelihood }\end{array}$ & $\begin{array}{c}\text { Additional } \\
\text { Variable } \\
\text { Coefficient } \\
\text { +/- S.E. } \\
\text { (p-value) }\end{array}$ & $\begin{array}{c}\text { Total Length } \\
\text { p-value }\end{array}$ & \\
\hline $\begin{array}{c}\log _{10} \\
\text { Maximum } \\
\text { Acceleration }\end{array}$ & 20.79 & -6.397 & $\begin{array}{c}-0.318+/- \\
0.126 \\
(0.0114)\end{array}$ & 0.0025 & 0.478 \\
\hline $\begin{array}{l}\log _{10} \text { Mean } \\
\text { Acceleration }\end{array}$ & 20.32 & -6.16 & $\begin{array}{c}-0.325+/- \\
0.123 \\
(0.0084) \\
\end{array}$ & 0.0012 & 0.497 \\
\hline $\begin{array}{l}\log _{10} \text { Skew in } \\
\text { runoff }\end{array}$ & 23.7 & -7.849 & $\begin{array}{c}-0.575+/- \\
0.326 \\
(0.078)\end{array}$ & 0.051 & 0.359 \\
\hline $\begin{array}{c}\log _{10} \text { Urban } \\
\text { Percent land } \\
\text { use }\end{array}$ & 19.29 & -5.647 & $\begin{array}{c}-1.06+/- \\
0.383 \\
(0.0056)\end{array}$ & 0.731 & 0.539 \\
\hline
\end{tabular}




\subsection{Discussion}

The fish richness database showed evidence of positive bias with time, possibly introduced through multiple factors, including effort, methodological sampling, and classification/ scientific advances. In addition, the Credit River system had relatively rich fish sites, but only more recent urban land use records were available (i.e. 1999 and more recent). This bias resulted in many individual sites having higher fish richness in later years. Nevertheless, addition of the hydrologic characteristics maximum acceleration of the rising limb event flows and skew in runoff to a model with only total length each made a larger improvement to the explained variation than urban percent. Increasing positive skew in runoff indicates an increasing right tail of the distribution, which is characteristic of increasing flashiness of urbanizing streams. Maximum acceleration also improved the explained variation in models fit with year, total length and urban percent in combination. Similar results even held for empirical models fit to a database with all fish records, which had 13 additional species in later years.

The result that urban percent did not provide improvement in the explained variation, while hydrologic variables did, was surprising considering that numerous concurrent changes, also negatively associated with fish richness, occur with urbanization. Some of the concurrent changes with urbanization are listed in Appendix R. Year served as a surrogate for other temporal changes through the 42-year study period. In addition to bias in the database, there may have been additional sampling efforts in watersheds as their urban cover increased, which would have served to reduce the signal from urban cover (assuming more fish species were identified with the increased effort). In addition, 
changes in event flow acceleration may have occurred in rural areas as a result of changed agricultural or other practices through time. These changes would have increased the acceleration signal without a coincident change in urban cover.

The results were somewhat different for models fit to the Recent database (2000 to 2010), with the addition of urban percent and maximum acceleration to a model with only total length. Each made an improvement to the explained variation while skew in runoff did not. The Recent database had reduced power (17 versus 49 records), but it also had reduced span of the hydrologic variables. In other words, the range of hydrologic data was lower for this short period than for the full dataset. This reduced span raises questions about the adequacy of studies substituting space for time to assess hydrologic change and associations with fish richness in a region with decades of intense urbanization. Space will not substitute for time unless enough is known about the historic conditions to ensure the range of hydrologic conditions and fish richness across the space selected are proxy for the historic conditions.

Potential causal agents that could explain decreased fish diversity with increased flow acceleration are numerous and include direct effects, such as displacement of young or disruption and stress for biota when flows change at unnatural and unpredictable rates. Indirect effects could arise related to the increased power associated with accelerating flows, including sediment transport, substrate displacement, bank erosion, etc. Interestingly, variables for stream power per unit length of channel, standardized for watershed size, were not dominant in the PCA. Additional research would be needed to 
assess whether this unit of estimated stream power is suitable to compare power across very different watersheds. Research is needed to assess whether a negative association of fish richness with event acceleration reflects causal agents associated with changes in stream power (and subsequent changes to habitat) or changes in instantaneous water column conditions that disrupt fish. Event flow acceleration is higher in wetter years (Trudeau and Richardson, 2015); research would be needed to assess whether rainfall contributes to variation in fish richness.

Urbanization of the north shore of Lake Ontario started along the lakefront and progressed in the upstream direction of river systems confluent with the lake. In nonurbanized watersheds, the number of fish species would be expected to decrease with distance from the confluence of the river system with Lake Ontario. In addition to resident fish species in Lake Ontario tributaries, many lake fish species use tributaries for spawning and nursery habitat (Stewart et al., 2013). However, the empirical models indicate a positive relationship of fish richness with distance from the lake. Additional sources of long term data would need to be located to assess whether a negative trend with distance was historically present for fish richness (i.e. prior to intensive urbanization). Fish richness did increase with drainage basin area and total length of stream in the watershed.

The analysis did not have sufficient power to explore potential interactions of independent variables with respect to associations with fish richness. For example, it would be interesting to research interactions of flow acceleration with urban land use to assess whether the fish richness relationship with flow acceleration differs at low levels 
of urban land use (i.e. less than 10\%). The effects of land use change on ecosystems are not necessarily immediate (Löfvenhaft et al., 2004; Findlay and Bourdages, 2000; Harding et al., 1998), so the potential for lagged biotic response would need to be considered, with data collection well before $10 \%$ cover is attained.

\subsubsection{Fish Data Bias, Limitations and Issues}

The myriad problems with the historical fish dataset are worth identifying because, unless an additional source of scientific data is located, these are the only data available with which to assess changes in fish richness since the mid-20th century for the study area. Additional historic fish data sources in other regions of the Great Lakes Basin or St Lawrence River may assist in supplementing scientific understanding.

Bias was potentially introduced into the fish dataset as a consequence of four factors: 1) advances in fish identification; 2) methodological sampling differences; 3) varying sampling intent; and 4) level of sampling effort. There was insufficient information to parse the effects of these potential sources of bias. Taxonomic advances increased species richness temporally in the database. The intent of fish surveys evolved from locating indicator species (in the 1940's and 1950's) to comprehensive surveys including estimation of abundance. The ODPD surveys were undertaken for indicator species using a Bayesian sampling approach based on observed stream conditions (H. Regier, pers. comm., 2014). A focus on specific fish species is evident from a field note in the 1946 
ODPD survey, quantifying the number of fish present as 'zero', but with the note: "Intermittent pools with several small fish observed" (Lotus Data File, Wichert, n.d.). By contrast, the OSAP Multiple Pass Survey is intended to identify all species at a site (Stanfield, 2013). Similarly, the Steedman study (1987) objective was to fully characterize fish communities. One objective of Wichert's research (1995) was to develop a species association tolerance index of water quality. Sampling sites were selected upstream and downstream of known pollution sources, introducing additional variation into the dataset. As wastewater treatment plant effluent releases ceased, fish community richness improved, potentially masking biodiversity trends associated with urbanization (Wichert, 1994). The ODPD studies were conducted with seine nets (e.g. ODPD, 1956) whereas more recent surveys primarily use electrofishing equipment (e.g. TRCA, 2009). Seine nets are not as efficient as electrofishing techniques because they cannot be effectively deployed in areas with branches, rocky or very soft substrate or in high velocity currents (Syracuse Research Corporation, 2001). Electrofishing is most effective in shallow streams (Syracuse Research Corporation, 2001). Steedman (1987) used both electrofishing and seine netting, which may account, in part, for a relatively high species diversity in the 1984/85 records. Species favouring deeper watercourses may be under-represented in the database due to the methodological bias towards wadable streams. Effort records are not available for some studies (e.g. ODPD surveys) and units of sampling effort differ among others (e.g. Steedman, 1987; Martin, 1984). Intensive efforts may be employed to confirm the presence of endangered or rare species (e.g. TRCA, 2009). As a consequence, there may be bias towards fish communities occupying endangered species' habitats. Also, the apparent occurrence of threatened and endangered 
species in records subsequent to their designation may reflect increased efforts to locate them. For example, several redhorse species are recorded in the Recent database but not in the Long-term database.

\subsection{Conclusions and Recommendations}

The relationship of flow acceleration and skew in instantaneous runoff with fish richness warrant further investigation because, considering the fish record limitations, the database was not expected to have sufficient statistical power to detect any trends other than the

most blatant signals. In addition to examination of associations in other watersheds, research is warranted into potential causal agents contributing to reduced fish richness associated with increasing event flow accelerations. 
Historic fish data are difficult to obtain and pose analytical challenges due to bias. Use of only recent records may not present the same opportunities for analyses of flow with fish richness unless sufficient range in flow conditions is present in the database.

Long term fish study sites should be aligned with flow sites to the extent possible and other transdisciplinary considerations kept in mind (e.g. data needs to assess trends in rainfall, geomorphology, water quality, water temperature, sediment transport, habitat features). Flow data should be collected on fine temporal scales such that event flow accelerations and instantaneous runoff can be estimated. Given the problems with historic fish data bias, data collection may need to be undertaken in watersheds as they transition from very low urban cover.

\subsection{Acknowledgements}

The author wishes to thank Dr. Antoine Morin, Dr. Murray Richardson and Dr. Doug King for guidance on the analytical methodologies and comments on earlier drafts. Dr. Gord Wichert was instrumental in making available the historic fish database and Dr. Earling Holm of ROM also contributed to this effort. TRCA, CVCA and OMNR provided access to recent fish records through the FWIS system. CVCA provided shapefiles for urban cover in the Credit watershed and TRCA provided funding towards digitization of urban cover in its watersheds. Hydrologic and precipitation data were provided by Environment Canada and BFI data by Dr. Jim Buttle. Rob Eakins provided fish species information that will continue to be applicable in future work. Other individuals with whom the author had very informative conversations include J. Duncan 
(TRCA), Jon Clayton (CVCA), L. Stanfield, Dr. H. Regier and OMNR Library staff.

Laura Salisbury assisted with the illustrative map. Environment Canada provided some financial support to the author as did Dr. King and Dr. Richardson through their NSERC grants. 


\section{Chapter: Discussion and Conclusions}

In this chapter, the discussion highlights the significance and novelty of the research findings, placing them in context of existing literature. The discussion also identifies additional research topics and implications, gaps and limitations of the research. This section also draws conclusions and summarizes key implications and future directions.

\subsection{Discussion}

The immediate objective of this research was to examine empirical relationships of eventbased flows and biotic community diversity in freshwater systems associated with cumulative increases in urban land cover. More broadly, this research was motivated by the need for informed land use decisions and revised engineered urban system designs to better respond to the imperiled state of aquatic biodiversity in urban areas. The research was designed to address the very significant gap in the literature with respect to event scale hydrologic associations with aquatic biodiversity. The premise of the research was that changes in hydrologic regime characteristics with increased urban land use are important for the prediction of changes in aquatic biodiversity.

Each phase of research built on previous results. The analysis was initiated without knowing whether changes in event-based hydrologic response would be statistically detectable, although later during the research Thompson (2013) published his work indicating event peak discharge increased with time in the study region as the first phase was completed. The annual period May $26^{\text {th }}$ to November $15^{\text {th }}$ was selected to reduce 
variation introduced by winter precipitation and snowmelt. If longitudinal and spatial trends were not detectable in this highly urbanized region, it would be unrealistic to expect detection in other areas of Canada. Further, if urban land use and biotic data were not available for this region, this research would not likely be feasible elsewhere in Canada considering research interest in the Great Lakes Basin and the data collection capacity of area agencies, including Conservation Authorities.

The literature had identified associations of urbanization with flashiness of lotic systems based on daily and monthly records but the long-term temporal relationship of urban land use with hydrology at a fine temporal scale had not been studied. This research differed in intent from that of Thompson (2013) with its focus on rising limb event flows and inclusion of high resolution precipitation data. Specifically, the relationship of urban land use with rising limb event flows and event accelerations was previously unknown. Moreover, hydrologic responses to urban land use had not been analyzed in the context of detailed understanding of precipitation patterns. While historic rainfall gauges were not adequate for analyses of matched rain events to hydrologic events, the available precipitation data were sufficient to estimate annual rainfall totals and to ensure hydrologic event records could be analyzed in context of matched precipitation quantity.

The first phase of research indicated long-term temporal changes in both event scale hydrology and total runoff were not only detectable, but dramatic. Over a 42-year period, total discharge in the mainstem rivers of the Don and Humber watersheds increased about $45 \%$ during a period of stable rainfall patterns. Peak event flow rates increased almost 
$0.1 \mathrm{~m}^{3} \mathrm{~s}^{-1} \mathrm{yr}^{-1}$ in both watersheds and event flow variability increased two-fold in the Don and almost five-fold in the Humber. In the Don, rising limb event flow acceleration increased 2.4-fold over 4 decades and slightly more in the Humber. Analyses of longterm rainfall patterns at multiple gauges in the region confirmed that the loss of hydrologic stationarity in the study watersheds was not attributable to climate change. While the post-freshet period reduced variation introduced by winter and early spring, there is a gap in knowledge regarding temporal changes in event-scale rising limb spring freshet patterns.

The hydrologic trends identified in the first phase coincided with intensive increases in urban land use within the two watersheds. Thus, as a follow-up to the temporal study, a spatial analysis along a gradient of urban land use was warranted. Spatial empirical modelling of event-scale hydrologic response to urban cover had not previously been done. The range in watershed scales studied further added to the novelty of the research.

As a result of this second research phase, new empirical relationships, fit using a database of 27 watersheds located in 11 river systems ranging in size from $37.5 \mathrm{~km}^{2}$ to $806 \mathrm{~km}^{2}$ with urban percent land cover $<0.1 \%$ to $87.6 \%$, indicated very strong effects of urban land use on total runoff and event-scale characteristics. Changes in total runoff began at very low urban land use $(<4 \%)$, which is within the range identified in the literature for urbanization effects on hydrology using coarse-grain hydrologic data. In a newly identified relationship, rising limb event flow acceleration increased with increasing urban cover (until about $60 \%$ UP). The results of Phase Two support the preliminary 
finding from Phase One that compromised hydrologic stationarity in the region's watersheds is correlated with urbanization. As climate change progresses, the results may assist in differentiating between loss of hydrologic stationarity associated with climateinduced change and hydrologic shifts associated with urbanization. Fine temporal scale hydrologic records may assist in assessment of the limitations of coarser resolution data in defining flow regime changes or to help develop correlates where no fine temporal resolution data are available.

Concurrent with increasing total runoff, event flow distribution changed (i.e. the $10^{\text {th }}, 20^{\text {th }}$ and $95^{\text {th }}$ percentile event runoff each increased), which is consistent with literature results for coarser grained hydrologic trends. However, in a newly identified and unanticipated trend, $80^{\text {th }}$ percentile rising limb event flows had a curvilinear relationship with urban cover. Coupled with the information that total runoff increased dramatically with urban land use, the cap and decline of $80^{\text {th }}$ percentile runoff raises questions about long term water balance. Additional research is needed on temporal trends in water supply and losses in urbanizing watersheds because, at some point, water lost via all routes (runoff, evaporation, vegetation removal) may exceed precipitation (by depleting groundwater reserves), leading to depleted groundwater resources and overall drying of the watershed. Urban water infrastructure factors, such as groundwater drainage or recharge via cracked sewers or groundwater recharge due to leaking potable watermains, may also need to be included in water balance calculations for urbanized watersheds (e.g. Yang et al., 1999). Increased evaporation rates with increasing temperatures due to climate change may exacerbate water losses on a watershed scale. Water balance research is warranted for the 
study watersheds and on a Great Lakes Basin watershed scale.

The spatial database was limited in terms of combinations of urban cover with watershed size. The largest watersheds $\left(>600 \mathrm{~km}^{2}\right)$ had urban cover less than $19 \%$. The smallest watersheds $\left(<60 \mathrm{~km}^{2}\right)$ had urban cover over $17 \%$. The empirical model for total runoff had an interaction term of urban cover with watershed area. However, there were insufficient data to analyze event-scale trends for watersheds grouped by size and an interaction term of watershed size with urban cover was not statistically significant in the event scale models for $80^{\text {th }}$ and $95^{\text {th }}$ percentile event runoff. Additional research is warranted on event-scale hydrology in smaller watersheds with less than $\sim 25 \%$ urban cover.

The low level of urban cover correlated with hydrologic change warrants research to assess when urban engineered drainage begins to dominate stream flow response and to what degree low impact development techniques can off-set the hydrologic effects. From the results of Phase 3, change in event flow acceleration may be of particular interest for protection of fish richness. Given the limitations of estimating length of watershed networks identified in the fractal literature (see Appendix L), and the subsequent difficulties in estimating the rate of stream length replacement by engineered drainage, empirical study of the relationships would offer an appropriate opportunity to assess changes to event flow hydrology with urban land use conversion.

Study of event-scale hydrologic regimes in non-urban watersheds smaller than $100 \mathrm{~km}^{2}$ 
as land use transitions from $<1 \%$ urban through to higher land cover $(>20 \%)$ would fill a gap in the study data. Duffins Creek sub-watersheds may offer opportunities in the study region. Maximization of $80^{\text {th }}$ percentile event flows is expected to occur at lower urban cover (possibly less than $20 \% \mathrm{UP}$ ) in watersheds $<100 \mathrm{~km}^{2}$ compared with larger watersheds at the same percent urban cover because more length of stream is affected for the same area of new subdivision (Appendix L).

This research focused on the rising limb of events up to, and including, peak flows. The rising limb was selected because biota within the water column would be most immediately affected during this stage of event flows; also the greatest power impulses occur on substrates and channel features during the rising limb. However, this focus leaves a gap in understanding of falling limb and recession flows at high temporal resolution. Thompson (2013) examined the year-round event profile and made recommendations for future work in this area. Falling and recession limb flows may be of interest for better prediction of urban flood recession patterns and associated risks or costs of infrastructure and dwellings. The spatial analysis also did not attempt to examine the effects of more recent low impact development stormwater approaches on event flow response or variation associated with soils profiles of study watersheds. Some of the unexplained variation in the empirical models may reflect predominant stormwater management infrastructure design within the watersheds, which, in turn, must take into consideration predominant soils types within each subdivision. Undertaking further analyses to assess the influence of stormwater infrastructure on rising limb event-scale flows is highly recommended and would be consistent with a longer term objective to 
better inform land use and engineered infrastructure design. This research would benefit from inclusion of soils data to potentially explain additional variation in event flow responses to urbanization.

The third phase of the research entailed re-designation of the dependent variables of the first two phases (i.e. hydrologic characteristics) as independent variables to identify empirical relationship(s) of event-based flows with fish diversity. Benthic invertebrate data were originally envisioned for this phase, but longitudinal data to match the timeframe of the hydrologic data were not available. Fish data were compiled through cooperation of generous collaborators (especially Dr. G. Wichert and Conservation Authorities) and fortunate circumstances. Prior to initiating the third phase of research, temporal analyses of the fish database, and discussion with researchers (including Dr. H. Regier), revealed the sobering database biases detailed in Chapter 6. Further database limitations were imposed by mismatched locations of fish observations with hydrologic gauges. Given the natural variation of biotic systems, the limitations of presence-absence data and the limited number of records, expectations were very low that associations of fish richness would be identified with hydrologic characteristics. Fish richness was assessed for 55 species with long term records spanning approximately five decades in 22 watersheds of eight river systems with percent urban cover from $0.06 \%$ to $87.6 \%$.

The identification of a negative association of fish richness with maximum acceleration is an important new contribution of this research. No long-term associations of event-scale hydrology with fish richness were identified in the literature. Tetzlaff et al. (2005b) 
suspected acceleration would be of interest for associations with biota. It is particularly surprising that the maximum acceleration signal was stronger than percent urban land use. This difference could be an artifact of the database; urban cover was expected to have a stronger association with fish richness because hydrologic change is only one of numerous negative consequence of urbanization. Given the database bias, additional research to confirm an association of fish diversity with flow acceleration is warranted. However, hydrologic data used in follow-up studies should be assessed for sufficient range in flow characteristics because associations may not be detectable with records that do not reflect the full range of historic change.

Observational studies are naturally limited to identification of correlational relationships. However, the study results can assist in hypothesis development regarding shifts in functional and/or structural properties of lotic systems related to event-scale hydrology, in particular linking increased acceleration and skew in instantaneous runoff with reduced fish richness. Direct and/or indirect alterations may contribute to richness reduction, including instantaneous water column conditions and habitat alteration. Habitat alteration from secondary effects may relate to power imparted by accelerating water on the channel features. Interestingly, stream power was not a predominant independent variable in the correlation analyses; no definitive conclusions can be reached given the database limitations and the observational nature of the study.

Abundance data could not be developed from the available data, so evenness and diversity were not estimated. However, the historic database may still be very useful to 
model particular species presence based on predictions of potential causal agents related to flow acceleration or other independent variables. To off-set the low number of matching hydrologic stations, and to take advantage of more records in the fish database, urban cover could be calculated upstream of fish sites and acceleration estimated for the year of observation using the empirical flow models. Better association of urban cover with fish richness in the region may help in hypotheses development by identifying fish characteristics, traits, behaviours or habitat most closely associated with change in event flow acceleration and skew.

Scale effects of watershed size with urban cover could not be assessed for fish richness. More generally, potential interactions of watershed size, percent urban land use, eventscale hydrologic response and fish richness could not be fully assessed due to database gaps. Raw data plots of fish richness by watershed size suggested a possible interaction of watershed size with urban land use (i.e. greater reductions in fish richness in smaller watersheds with similar urban cover) but the database was not robust enough to statistically test this potential trend.

No event-scale thresholds were identified that would help explain literature findings that aquatic biota decline at around $10 \%$ impervious cover, although total runoff response to urban land use changes at $<4 \%$ impervious cover. No conclusions can be drawn from this research on potential threshold effects of urban land use, hydrologic response and effects on fish richness. Similarly, lagged effects of change in event scale flow characteristics on fish richness were not quantifiable with this database. Research into 
threshold responses of biota should consider the potential for lagged responses to hydrologic change.

The research was carried out within a relatively uniform geographic region. Additional research in other regions would be needed to verify the degree to which results can be extrapolated to other climates, watershed characteristics or urban development patterns.

This thesis has contributed to understanding temporal and spatial scales relevant for assessing cumulative effects of urbanization on hydrology and associations of event-scale hydrologic change with fish richness. It has also highlighted the effort and collaboration needed to gather sufficient data to undertake long term studies with interdisciplinary needs. The database and empirical relationships did not include geomorphology, sediment transport, groundwater (except BFI), evapotranspiration, instream habitat features, water chemistry, or thermal regimes.

\subsection{Conclusions from the Research Results}

Further to the four research objectives identified in Section 1.2, several conclusions can be reached.

Changes in event-scale flows over four decades in two study area urbanizing watersheds were detectable with statistical confidence and, in fact, urbanization is associated with loss of hydrologic stationarity. During the stable precipitation patterns of the study period, the effects of urbanization were much more relevant for hydrologic risk assessments than climate change. 
Event scale hydrologic characteristics began to change at very low percent urban land use. The relationships of rising limb event flows, acceleration and urban percent land use were not simple and were not necessarily predictable. A full empirical analysis of spatial scale effects could not be undertaken, but fractal theory (Appendix L) supports greater hydrologic effects of urban land use in headwaters and smaller watersheds (i.e. watersheds with higher drainage density).

The results point to the possibility that event-scale flows, especially flow acceleration, are key variables in understanding urban lotic system fish richness.

The study results indicate additional research is warranted on the relationship of event-based flows with aquatic biodiversity and that understanding the relationships may be important for protection of aquatic biodiversity in urban watersheds.

The underlying hypotheses for the research can be confirmed. Specifically, changes in urban land cover explain variance in hydrologic characteristics, including total runoff, rising limb event-scale runoff and rising limb event acceleration.

Changes in the hydrologic regime can explain variance in biotic response, specifically fish richness, to land use change when changes in the hydrologic regime are measured on an appropriate temporal scale and in the context of rainfall events. 


\subsection{Summary of Implications}

Each of the conclusions has implications for urban land use and associated infrastructure design.

Given the early effects of urbanization and the severity of the alterations, a focus on riparian zones alone will not be sufficient to mitigate hydrologic changes arising from urbanization. Measures will be needed throughout the watershed, including low impact development techniques. Empirical investigations into larger scale basin effects of urbanization on flows and water balance is also warranted.

A precautionary approach is needed with respect to further hardening of land surfaces in urbanized watersheds of the study region. Urbanization has dramatic effects on total runoff and, thus, implications for increased flood risk should be assessed as hardening of surfaces progresses. Climate change can be expected to exacerbate the risks to infrastructure, flooding and biodiversity associated with the loss of hydrologic stationarity attributable to urbanization.

Overall, the results warrant further research into potential strategies for mitigating physical and biological damage to streams and floodplains within urbanizing watersheds. Research into potential causal agents contributing to reduced fish richness associated with increasing event flow accelerations is warranted. 
However, work to assess the potential for alternative stormwater management techniques to mitigate event flow acceleration should proceed in parallel with causal factor research. In particular, low impact development options should be assessed for potential to mitigate event flow acceleration. The possibility that lagged effects of past practices may mask improvements should be kept in mind during assessments of new approaches.

Coordinated data collection for lotic systems is imperative and institutional stewardship of long term datasets is required. Long term fish study sites should be aligned with flow sites to the extent possible and other transdisciplinary needs considered (e.g. rainfall, geomorphology, water quality, water temperature, sediment transport, habitat features). Ontario's FWIS system provides a model for current records.

\subsection{Approach for Protection of Lotic Biodiversity Arising from the Research}

Urbanization negatively impacts aquatic biodiversity. Causal factors operate on multiple spatial and temporal scales, requiring expertise and collaboration among numerous disciplines. A full understanding of the causal factors will take time to develop scientifically, if it is indeed possible to fully understand systems as complex as lotic ecosystems. Consequences for aquatic biodiversity appear to manifest on a timescale offset from implementation of associated anthropogenic changes, further confounding scientific understanding. In the study region, opportunities to properly document historic fish diversity appear to be irretrievable, obscuring the extent of biodiversity loss because 
analyses must necessarily rely on a subset of records.

Emerging climatic trends, especially changes to aquatic thermal regime, and unrelenting and concurrent addition of anthropogenic stressors invite re-examination of any assumptions that scientific understanding will be complete in the study region prior to mitigation measures being urgently needed to protect biodiversity. Rehabilitation efforts will be difficult to assess given the multiple dimensions of both stressors and responses.

A key question for aquatic biodiversity recovery, then, will be how to proceed in the absence of complete scientific knowledge. At a minimum, a case can be made for widespread use of low impact development techniques that mitigate flow, thermal and chemical changes in receiving waters.

Aquatic biodiversity does not exist solely within the ecosystem, but also operates within human economic and social spheres. As complicated as human systems are, it is these spheres that humans control, not biodiversity. Humans need to incorporate precaution, humility and a profound respect for aquatic ecosystems, indeed the biosphere, into land use and infrastructure decision-making to make space for aquatic biodiversity recovery. 


\section{References}

Adamowski, K. and J. Bougadis, 2003. Detection of trends in annual extreme rainfall. Hydrological Processes, 17(18):3547-3560.

Adamowski, J. and A. Prokoph, 2013. Assessing the impacts of the urban heat island effect on streamflow patterns in Ottawa, Canada. Journal of Hydrology, 496(1):225-237. doi:10.1016/j.jhydrol.2013.05.032

Aichele, S. S. and J. A. Andresen, 2013. Spatial and temporal variations in land development and impervious surface creation in Oakland County, Michigan, 19452005. Journal of Hydrology, 485:96-102. doi:10.1016/j.jhydrol.2012.12.049

AKCanada, n.d. Living in Canada: Ontario. URL https://www.akcanada.com/lic ontario.php (Accessed December 2015).

Allan, J. D., 1995. Stream Ecology: Structure and function of running waters. Kluwer Academic Publishers, The Netherlands: Chapman and Hall.

Allan, J. D. and M. Castillo, 2007. Stream Ecology: Structure and function of running waters. $2^{\text {nd }}$ ed. Dordrecht, The Netherlands: Springer.

Armanini, D. G., N. Horrigan, W. A. Monk, D. L. Peters and D. J. Baird, 2011. Development of a benthic macroinvertebrate flow sensitivity index for Canadian rivers. 
River Research and Applications, 27:723-737.

Arsenault, T. and P. Thompson, 2010. ArkWSC: Automating the Extraction of Instantaneous Data from archived STREAM Formats, Appendix A in Thompson, P. 2013. Event Based Characterization of Hydrologic Change in Urbanizing Southern Ontario Watersheds via High Resolution Stream Gauge Data, Master of Applied Science Thesis, Waterloo, Ontario.

Auerbach, D. A. and N. L. Poff, 2011. Spatiotemporal controls of simulated metacommunity dynamics in dendritic networks. Journal of the North American Benthological Society, 30(1):235-251.

Bates, D., M. Maechler, B. Bolker and S. Walker, 2015. Fitting Linear Mixed-Effects Models Using lme4. Journal of Statistical Software, 67(1):148. doi:10.18637/jss.v067.i01

Barron, O. V., A. D. Barr and M. J. Donn, 2013. Effect of urbanisation on the water balance of a catchment with shallow groundwater. Journal of Hydrology, 485:162-176. doi:10.1016/j.jhydrol.2012.04.027

Barron, O., R. Silberstein, R. Ali, R. Donohue, D. J. McFarlane, P. Davies, G. Hodgson, N. Smart and M. Donn, 2012. Climate change effects on water-dependent ecosystems in South-Western Australia. Journal of Hydrology, 434-435:95-109. 
doi:10.1016/j.jhydrol.2012.02.028

Barton, K., 2015. R Package 'MuMIn'. URL: https://cran.rproject.org/web/packages/MuMIn/MuMIn.pdf, (Accessed December 2015).

Blann, K. L., J. L. Anderson, G. R. Sands and B. Vondracek, 2009. Effects of Agricultural Drainage on Aquatic Ecosystems: A Review. Critical Reviews in Environmental Science and Technology, 39(11):909-1001.

Boers, T. and J. Ben-Asher, 1982. A review of rainwater harvesting. Agricultural Water Management, 5:145-158.

Boers, T., M. DeGraaf, R. A. Feddes and J. Ben-Asher, 1986. A linear regression model combined with a soil water balance model to design micro-catchment for water harvesting in arid zones, Agricultural Water Management, 11:187-206.

Booth, D. B. and L. Reinelt, 1993. Consequences of Urbanization on Aquatic Systems Measured Effects, Degradation Thresholds and Corrective Strategies, Watershed '93 Proceedings, Alexandria, Virginia

Booth, D. B. and C. R. Jackson, 1997. Urbanization of Aquatic Systems: Degradation Thresholds, Stormwater Detection, and the Limits of Mitigation. Journal of the American Water Resources Association, 33(5):1077-1090. 
Brabec, E., S. Schulte and P. Richards, 2002. Impervious surfaces and water quality: A review of current literature and its implications for watershed planning. Journal of Planning Literature, 16(4):499-514. doi:10.1177/088541202400903563

Brunetti, M., L. Buffoni, M. Maugeri and T. Nanni, 2000. Precipitation intensity trends in northern Italy. International Journal of Climatology, 20(9):1017-1031.

Bunn, S. E. and A. H. Arthington, 2002. Basic Principles and Ecological Consequences of Altered Flow Regimes for Aquatic Biodiversity. Environmental Management, 30(4):0492-0507.

Burcher, C. L., H. M. Valett and E. F. Benfield, 2007. The land-cover cascade: Relationships coupling land and water. Ecology, 88(1):228-242.

Butchart, S. H., M. Walpole, B. Collen, A. Van Strien, J. Scharlemann, R. E. Almond, J. E. Baillie, B. Bomhard, C. Brown, J. Bruno, K. E. Carpenter, G. M. Carr, J. Chanson, A. M. Chenery, J. Csirke, N. C. Davidson, F. Dentener, M. Foster, A. Galli and J. N. Galloway, 2010. Global Biodiversity: Indicators of Recent Declines. Science, 328(5982):1164-1168.

Buttle, J. M., W. J. Greenwood, R. E. Gerber, 2015. Spatiotemporal patterns of baseflow metrics for basins draining the Oak Ridges Moraine, southern Ontario, Canada, Canadian Water Resources Journal, 40(1):3-22. 
Cannarozzo, M., L. V. Noto and F. Viola, 2006. Spatial distribution of rainfall trends in Sicily (1921-2000). Physics and Chemistry of the Earth, 31(18):1201-1211.

Carl, P. and B. G. Peterson, 2013. PerformanceAnalytics: Econometric tools for performance and risk analysis. R package version 1.1.0. URL: http://CRAN.Rproject.org/package=PerformanceAnalytics, (Accessed December 2015).

Carpenter, S. R., H. A. Mooney, J. Agard, D. Capistrano, R. S. DeFries, S. Díaz, T. Dietz, A. K. Duraiappah, A. Oteng-Yeboah, H. M. Pereira, C. Perrings, W. V. Reid, J. Sarukhan, R. J. Scholes, A. Whyte and W. C. Clark, 2009. Science for Managing Ecosystem Services: Beyond the Millennium Ecosystem Assessment, Proceedings of the National Academy of Sciences of the United States of America, 106(5):1305-1312.

Castree, N., 2005. Nature: the adventures of a concept. London: Routledge.

Chin, A., 2006. Urban transformation of river landscapes in a global context. Geomorphology, 79(3-4):460-487.

Chocat, B., R. Ashley, J. Marsalek, M. R. Matos, W. Rauch, W. Schilling and B. Urbonas, 2007. Toward the sustainable management of urban storm-water. Indoor and Built Environment, 16(3):273-285. doi:10.1177/1420326X07078854

Chu, M. L., J. H. Knouft, A. Ghulam, J. A. Guzman and Z. Pan, 2013. Impacts of 
urbanization on river flow frequency: A controlled experimental modeling-based evaluation approach. Journal of Hydrology, 495:1-12. doi:10.1016/j.jhydrol.2013.04.051

Chu, C. and N. E. Jones, 2011. Spatial variability of thermal regimes and other environmental determinants of stream fish communities in the Great Lakes Basin, Ontario, Canada. River Research and Applications, 27(5):646-662.

City of Toronto, 2014. Profile on Toronto, City of Toronto website, URL: http://www.toronto.ca, (Accessed December 2014).

Clausen, B. and B. Biggs, 1997. Relationships between benthic biota and hydrological indices in New Zealand streams, Freshwater Biology, 38(2):327-342.

Cook C. and K. Bakker, 2012. Water security: Debating an emerging paradigm. Global Environmental Change, 22(1):94-102.

Costa, M. H., A. Botta, and J. A. Cardille, 2003. Effects of large-scale changes in land cover on the discharge of the Tocantins River, Southeastern Amazonia. Journal of Hydrology, 283(1-4):206-217. doi:10.1016/S0022-1694(03)00267-1

Crawley, M. J., 2005. Statistics: An Introduction using R. Imperial College London, U.K.: John Wiley \& Sons, Ltd., ISBN 13:978-0-470-02298-6. 
Credit Valley Conservation Authority and Toronto Region Conservation Authority, 2010. Low Impact Development Stormwater Management Planning and Design Guide, Version 1.0, 2010. A publication of CVCA and TRCA, Downsview and Mississauga, Ontario.

Dinda, S., 2004. Environmental Kuznets Curve hypothesis: A survey. Ecological Economics, 49(4):431-455. doi:10.1016/j.ecolecon.2004.02.011

Demographia, undated. Canada: 20 Top Census Metropolitan Area: Population from 1931, URL: http://www.demographia.com/db-cancma.htm, (Accessed October 2014).

Dodds, P. S. and D. H. Rothman, 2001. Geometry of river networks. I. Scaling, fluctuations, and deviations, Physical Review E - Statistical, Nonlinear, and Soft Matter Physics. 63(1):016115.

Du, J., L. Qian, H. Rui, T. Zuo, D. Zheng, Y. Xu and C. Y. Xu, 2012. Assessing the effects of urbanization on annual runoff and flood events using an integrated hydrological modeling system for Qinhuai River Basin, China. Journal of Hydrology, 464-465:127139. doi:10.1016/j.jhydrol.2012.06.057

Dudgeon, D., A. H. Arthington, M. O. Gessner, Z. Kawabata, D. J. Knowler, C. Lévêque, R. J. Naiman, A. Prieur-Richard, D. Soto, M. L. Stiassny and C. A. Sullivan, 2006. Freshwater biodiversity: Importance, threats, status and conservation challenges. Biological Reviews of the Cambridge Philosophical Society, 81(2):163-182. 
Dunne, T. and L. B. Leopold, 1978. Water in Environmental Planning. New York: W.H. Freeman and Company.

Eakins, R., n.d. Ontario Freshwater Fishes Life History Database, URL: http://www.ontariofishes.ca/home.htm (Accessed December 2015).

ESRI, 2009. Georeferencing a raster dataset, ArcGIS Desktop 9.3 Help, URL: http://webhelp.esri.com/arcgisdesktop/9.3/index.cfm?TopicName=Georeferencing_a_rast er dataset (Accessed December 2015).

Findlay, C. S. and J. Bourdages. 2000. Response Time of Wetland Biodiversity to Road Construction on Adjacent Lands. Conservation Biology, 14(1):86-94.

Flecker, A. S., and B. Feifarek, 1994. Disturbance and the temporal variability of invertebrate assemblages in two Andean streams. Freshwater Biology, 31(2):131-142.

Freedman, B., 2011. Biodiversity in Ecology: A Canadian Context. Ed. Freedman, Hutchings, Gwynne, Smol, Suffling, Turington, Walker. Toronto ON: Nelson Education Limited.

Fox, H. L., 1976. Channel Alteration in an Urbanizing Watershed: A Case History in Maryland. University of Kentucky Bulletin, 111:105-113. 
Fox, J. and S. Weisberg, 2011. An R Companion to Applied Regression (car), Second Edition. Thousand Oaks CA: Sage.

URL:http://socserv.socsci.mcmaster.ca/jfox/Books/Companion (Accessed December 2015).

Ghetti, P. F. and O. Ravera, 1994. European Perspective on Biological Monitoring. in Biological Monitoring of Aquatic Systems, Loeb and Spacie ed., Boca Raton, Florida: CRC Press.

Gibbins, C. N., C. F. Dilks, R. Malcolm, C. Soulsby, and S. S. Juggins, 2001. Invertebrate communities and hydrological variation in Cairngorm mountain streams. Hydrobiologia, 462:205-219.

Giller, P. and B. Malmqvist, 1998. The Biology of Streams and Rivers. New York: Oxford University Press.

Gilroy, K. L. and R.H. McCuen, 2012. A nonstationary flood frequency analysis method to adjust for future climate change and urbanization. Journal of Hydrology, 414-415:4048. doi:10.1016/j.jhydrol.2011.10.009

Gordon, N. D., T. A. McMahon, B. L. Finlayson, C. J. Gippel and R. J. Nathan, 2004. Stream Hydrology: An Introduction for Ecologists. $2^{\text {nd }}$ ed., West Sussex, England: Wiley \& Sons. 
Government of Canada, 2013. Documentation for the Digital Archive of Canadian Climatological Data (Surface) Identified by Element, URL:

http://climate.weather.gc.ca/prods_servs/documentation_index_e.html\#dly, (Accessed October 2014).

Government of Canada, 2014. Canadian Climate Normals 1981-2010 Station Data (Toronto Station), URL:

http://climate.weather.gc.ca/climate_normals/results $1981 \_2010$ e.html?stnID=5051\&la

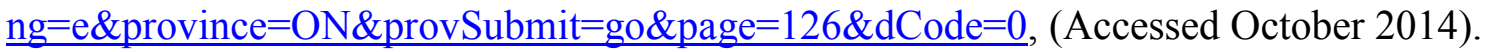

Government of Ontario, 2013. Ontario Integrated Hydrology Data: Elevation and Mapped Water Features for Provincial Scale Hydrology Applications, Technical Release, Ontario Ministry of Natural Resources, URL: https://www.sse.gov.on.ca/sites/MNRPublicDocs/EN/CMID/Ontario\%20Integrated\%20Hydrology\%20\%E2\%80\%93\%20Tech nical\%20Report.pdf, (Accessed December 2014).

Government of Ontario, 2012. Land Information Ontario Metadata Management Tool, Watershed, Tertiary, URL:

https://www.javacoeapp.lrc.gov.on.ca/geonetwork/srv/en/metadata.show? uuid=c445f2d3f92c-47ec-8f59-9afccf2fdd55\&currTab=simple, (Accessed May 2014).

Government of Ontario, Ministry of Transportation, 1997. Drainage Management Manual, URL: 
http://www.mto.gov.on.ca/english/publications/drainage/stormwater/section11.shtml, (Accessed December 2015).

Grabarkiewicz, J. and W. Davis, 2008. An Introduction to Freshwater Fishes as Biological Indicators. EPA-260-R-08-016. United States Environmental Protection Agency, Office of Environmental Information, Washington, DC.

Graham, W. D., J. E. Thorpe and N. B. Metcalfe, 1996. "Seasonal current holding performance of juvenile Atlantic salmon in relation to temperature and smolting." Canadian Journal of Fisheries and Aquatic Sciences, 53(1):80-86.

Grillakis, M. G., A. G. Koutroulis and I. K. Tsanis, 2011. Climate change impact on the hydrology of Spencer Creek Watershed in Southern Ontario, Canada. Journal of Hydrology, 409(1-2):1-19. doi:10.1016/j.jhydrol.2011.06.018

Gunderson, L. and C. S. Holling, 2002. Panarchy. Washington, DC: Island Press.

Hack, J. T., 1957. Studies of longitudinal profiles in Virginia and Maryland, U.S. Geological Survey, Professional Paper 294-B.

Hammer, T., 1972. Stream Channel Enlargement Due to Urbanization, Water Resources Research, 8(6):1530-1541. 
Hanski, I. and O. Ovaskainen. 2002. Extinction Debt at Extinction

Threshold. Conservation Biology 16(3):666-73.

Harding, J. S., E. F. Benfield, P. V. Bolstad, G. S. Helfman and E. B. Jones, 1998. Stream Biodiversity: The Ghost of Land Use Past, Proceedings of the National Academy of Sciences of the United States of America, 95(25):14843-14847.

Harrell, F. E., 2015. R Package Harrell Miscellaneous (Hmisc). URL: https://cran.rproject.org/web/packages/Hmisc/Hmisc.pdf, (Accessed December 2015).

Health Economics Resource Center (HERC), website. What is retransformation bias, and how can it be corrected? URL: http://www.herc.research.va.gov/resources/faq e02.asp, (Accessed July 2013).

Helsel, D. R. and L. M. Frans, 2006. Regional Kendall Test for Trend. Environmental Science \& Technology, 40(13):4066-4073.

Hodgkins, G. A., R. W. Dudley, S. S. Aichele, 2007. Historical changes in precipitation and streamflow in the US Great Lakes Basin, 1915-2004. Scientific Investigations Report 2007-5118. US Geological Survey, Reston, VA.

Hogg, W. D. and A. R. Hogg, n.d. Historical Trends in Short Duration Rainfall in the Greater Toronto Area, Toronto and Region Conservation Authority, URL: 
http://trca.on.ca/dotAsset/105189.pdf, (Accessed May 2014).

Horton, R. E., 1945. Erosional development of streams and their drainage basins; hydrophysical approach to quantitative morphology, Geological Society of America Bulletin, 56:275-360.

Hothorn, T., A. Zeileis, R. Farebrother, C. Cummins, G. Millo, D. Mitchell, 2015. R Package 'Imtest', URL: http://cran.r-project.org/web/packages/lmtest/lmtest.pdf, (Accessed May 2015).

Hood, M. J., J. C. Clausen and G. S. Warner, 2007. Comparison of Stormwater Lag Times for Low Impact and Traditional Residential Development. Journal of the American Water Resources Association, 43:1036-1046. doi: 10.1111/j.17521688.2007.00085.

Hümann, M., G. Schüler, C. Müller, R. Schneider, M. Johst and T. Caspari, 2011. Identification of runoff processes - the impact of different forest types and soil properties on runoff formation and floods. Journal of Hydrology, 409(3-4):637-649. doi:10.1016/j.jhydrol.2011.08.067

Hundecha, Y. and A. Bárdossy, 2004. Modeling of the effect of land use changes on the runoff generation of a river basin through parameter regionalization of a watershed model. Journal of Hydrology, 292(1-4):281-295. doi:10.1016/j.jhydrol.2004.01.002 
Hutchens, J. J., J. A. Schuldt, C. Richards, L. B. Johnson, G. E. Host and D. H. Breneman, 2009. Multi-scale mechanistic indicators of Midwestern USA stream macroinvertebrates. Ecological Indicators, 9(6):1138-1150.

Jyrkama, M. I. and J. F. Sykes, 2007. The impact of climate change on spatially varying groundwater recharge in the Grand River Watershed (Ontario), Journal of Hydrology, 338:237-250.

Jacobson, C. R., 2011. Identification and quantification of the hydrological impacts of imperviousness in urban catchments: A review. Journal of Environmental Management, 92(6):1438-1448.

Johnson, M. G. and G. E. Owen, 1966. Biological Survey of the Upper Credit River 1965. Ontario Water Resources Commission.

Karl, T. R. and R. W. Knight, 1998. Secular Trends of Precipitation Amount, Frequency, and Intensity in the United States. Bulletin of the American Meteorological Society, 79(2):231-241.

Kevinsen, J., R. J. Patrick, and L. A. Bharadwaj, 2014. A framework for assessing effective urban water management: Lessons from the Canadian Prairie. Water International, 39(1):113-127. doi:10.1080/02508060.2014.865300 
Klein, R. D., 1979. Urbanization and Stream Quality Impairment. Journal of the American Water Resources Association 15(4):948-963.

Kondolf, G. M., D. R. Montgomery, H. Piegay and L. Schmitt, 2003. Geomorphic Classification of Rivers and Streams, in Tools in Fluvial Geomorphology, eds. M. Kondolf and H. Piegay. West Sussex, England: John Wiley \& Sons.

Konrad, C. P. and D. B. Booth, 2005. Hydrologic changes in urban streams and their ecological significance. American Fisheries Society Symposium, 47:157-177.

Langeveld, J. G., R. P. Schilperoort and S. R. Weijers, 2013. Climate change and urban wastewater infrastructure: There is more to explore. Journal of Hydrology, 476:112-119. doi:10.1016/j.jhydrol.2012.10.021

Langbein, W. B. and L. B. Leopold. 1964. Quasi-equilibrium states in channel morphology. American Journal of Science, 262:782-794.

Leopold, L. B. and T. Maddock, 1953. The hydraulic geometry of stream channels and some physiographic implications. United States Government Printing Office.

Levin, S., 1992. The Problem of Pattern and Scale in Ecology. Ecology, 73(6):19431967. 
Livezey, R. E. and W. Y. Chen, 1983. Statistical field significance and its determination by Monte Carlo techniques. Monthly Weather Review, 111(1):46-59.

Löfvenhaft, K., S. Runborg and P. Sjögren-Gulve, 2004. Biotope patterns and amphibian distribution as assessment tools in urban landscape planning. Landscape and Urban Planning, 68(4):403-427.

Lytle, D. A. and N. L. Poff, 2004. Adaptation to natural flow regimes. Trends in Ecology \& Evolution, 19(2):94-100.

Malmqvist, B. and S. Rundle, 2002. Threats to the running water ecosystems of the world. Environmental Conservation, 29(2):134-153. doi:10.1017/S0376892902000097

Mandelbrot, B. B., 1983. The fractal geometry of nature. New York: W.H. Freeman.

Marchetto, A., 2013. Package 'rkt', URL: http://cran.rproject.org/web/packages/rkt/rkt.pdf, (Accessed June 2013).

Martin, D., 1984. The fishes of the Credit River: Cultural Effects in Recent Decades. Master of Science Thesis, University of Toronto.

Martin-Downs, D., 1988, Don River Biological Inventory Past, Present and Future Evaluation Technical Report \#16. A report of the Toronto Area Watershed Management 
Strategy Steering Committee, Queen's Printer for Ontario.

Mazerolle, M., 2013. Package 'AICcmodavg', URL: http://cran.rproject.org/web/packages/AICcmodavg/AICcmodavg.pdf, (Accessed August 2013).

McGlynn, B., J. McDonnell, M. Stewart and J. Seibert, 2003. On the relationships between catchment scale and streamwater mean residence time. Hydrological Processes, $17(1): 175-181$.

Meyer, J. L., M. J. Paul, and W. K. Taulbee, 2005. Stream ecosystem function in urbanizing landscapes. Journal of the North American Benthological Society, 24(3):602612. doi:10.1899/04-021.1

Millennium Ecosystem Assessment, 2005. Ecosystems and Human Well-Being: Current State and Trends. Washington, D.C.: Island Press.

Milly, P. C., J. Betancourt, M. Falkenmark, R. M. Hirsch, Z. W. Kundzewicz, D. P. Lettenmaier and R. J. Stouffer, 2008. Stationarity Is Dead: Whither Water Management? Science, 319(5863):573-574.

Mims, M. C. and J. D. Olden, 2012. Life history theory predicts fish assemblage response to hydrologic regimes. Ecology, 93(1):35-45. 
Monk, W. A., D. L. Peters and D. J. Baird, 2012. Assessment of ecologically relevant hydrological variables influencing a cold-region river and its delta: the Athabasca River and the Peace-Athabasca Delta, northwestern Canada. Hydrological Processes, 26(12):1828-1840.

Morin, J. and Y. Benyamini, 1977. Rainfall Infiltration into Bare Soils. Water Resources Research, 13(5):813-817.

Moustakas, A. and I. Karakassis, 2005. How Diverse is Aquatic Biodiversity Research? Aquatic Ecology, 39(3):367-375. doi:10.1007/s10452-005-6041-y

Muggeo, V., 2015. Package 'segmented', URL: https://cran.rproject.org/web/packages/segmented/segmented.pdf, (Accessed August 2015).

Muma, M., A. A. Assani, R. Landry, J. Quessy, and M. Mesfioui, 2011. Effects of the change from forest to agriculture land use on the spatial variability of summer extreme daily flow characteristics in Southern Quebec (Canada). Journal of Hydrology, 407(14):153-163. doi:10.1016/j.jhydrol.2011.07.020

Navratil, O., P. Breil, L. Schmitt, L. Grosprêtre, and M. B. Albert, 2013.

Hydrogeomorphic adjustments of stream channels disturbed by urban runoff (Yzeron River Basin, France). Journal of Hydrology, 485:24-36.

doi:10.1016/j.jhydrol.2012.01.036 
Neff, B. P., S. M. Day, A. R. Piggott and L. M. Fuller, 2005. Base Flow in the Great Lakes Basin. U.S. Geological Survey (USGS) Scientific Investigations Report 20055217.

Nikora, V. I. and V. B. Sapozhnikov, 1993. River network fractal geometry and its computer simulation. Water Resources Research, 29(10):3569-3575.

Olden, J. D. and N. L. Poff. 2003. Redundancy and the choice of hydrologic indices for characterizing streamflow regimes. River Research and Applications, 19(2):101-121.

Ontario Department of Planning and Development, 1956. Rouge, Duffin, Highland, Petticoat Conservation Report, Toronto.

Oksanen, J., F. G. Blanchet, R. Kindt, P. Legendre, P. R. Minchin, R. B. O'Hara, G. L. Simpson, P. Solymos, M. Henry, H. Stevens and H. Wagner, 2013. R Package 'vegan', Community Ecology Package. URL: http://CRAN.R-project.org/package=vegan, (Accessed December 2015).

Palmer, M., 2010. Water resources: Beyond infrastructure. Nature (London). 467(7315):534-535.

Palynchuk, B., 2012. The Probabilistic Characterization of Severe Rainstorm Events: Applications of Threshold Analysis. PhD Thesis, McMaster University, Ontario. 
Partnership Group for Science and Engineering (PAGSE), Science Pages: Biodiversity, Volume 1, October 2010. URL: http://www.sciencepages.ca/oct2010_en.pdf, (Accessed November 2010).

Paul, M. J. and J. L. Meyer. 2001. Streams in the urban landscape. Annual Review of Ecology and Systematics, 32:333-365.

Pauly, D., 1995. Anecdotes and the shifting baseline syndrome of fisheries, Trends in Ecology and Evolution, 10(10):430.

Pebesma, E., R. Bivand, B. Rowlingson, and V. Gomez-Rubio, 2014. R Package 'sp'. URL: http://cran.r-project.org/web/packages/sp/sp.pdf, (Accessed December 2015).

Peña-Arancibia, J. L., A. I. van Dijk, J. P. Guerschman, M. Mulligan, L. A. Bruijnzeel and T.R. McVicar, 2012. Detecting changes in streamflow after partial woodland clearing in two large catchments in the seasonal tropics. Journal of Hydrology, 416-417:60-71. doi:10.1016/j.jhydrol.2011.11.036

Petchey, O. L., A. L. Downing, G. G. Mittelbach, L. Persson, C. F. Steiner, P. H. Warren, and G. Woodward, 2004. Species loss and the structure and functioning of multitrophic aquatic systems. Oikos, 104(3):467-478.

Peter, C. and B. G. Peterson, 2013. PerformanceAnalytics: Econometric tools for 
performance and risk analysis. URL: https://cran.rproject.org/web/packages/PerformanceAnalytics/PerformanceAnalytics.pdf (Accessed December 2015).

Poff, N. L. and J. K. Zimmerman, 2010. Ecological responses to altered flow regimes: a literature review to inform the science and management of environmental flows. Freshwater Biology, 55(1):194-205.

Poff, N. L., B. D. Richter, A. H. Arthington, S. E. Bunn, R. J. Naiman, E. Kendy, M. Acreman, C. Apse, B. P. Bledsoe, M. C. Freeman, J. Henriksen, R. B. Jacobson, J. G. Kennen, D. M. Merritt, J. H. O'Keeffe, J. D. Olden, K. Rogers, R. E. Tharme and A. Warner, 2010. The ecological limits of hydrologic alteration (ELOHA): a new framework for developing regional environmental flow standards. Freshwater Biology, 55(1):147170.

Poff, N. L., B. P. Bledsoe and C. O. Cuhacivan, 2006. Hydrologic variation with land use across the contiguous United States: Geomorphic and ecological consequences for stream ecosystems. Geomorphology, 79(3-4):264-285.

Poff, N. L., J. D. Allan, M. B. Bain, J. R. Karr, K. L. Prestegaard, B. D. Richter, R. E. Sparks and J. C. Stromberg, 1997. The natural flow regime. Bioscience, 47(11):769-784. doi:10.2307/1313099 
Poff, N. L., 1997. Landscape Filters and Species Traits: Towards Mechanistic Understanding and Prediction in Stream Ecology. Journal of the North American Benthological Society, 16(2):391-409.

Poff, N. L. and J. V. Ward, 1989. Implications of streamflow variability and predictability for lotic community structure: A regional analysis of streamflow patterns. Canadian Journal of Fisheries and Aquatic Sciences, 46(10):1805-1818.

Power, M. E., A. Sun, G. Parker, W. E. Dietrich and J. T. Wootton, 1995. Hydraulic Food-Chain Models. Bioscience, 45(3):159-167.

Preston, E. M. and B. L. Bedford, 1988. Evaluating cumulative effects on wetland functions: a conceptual overview and generic framework. Environmental Management, 12(5):565-583.

R Core Team. 2012. R: A language and environment for statistical computing. R Foundation for Statistical Computing, Vienna, Austria. ISBN 3-900051-07-0, URL http://www.R-project.org/, (Accessed December 2015).

Raymond, P. A., N. H. Oh, R. E. Turner and W. Broussard, 2008. Anthropogenically enhanced fluxes of water and carbon from the Mississippi River. Nature, 451(24):449452. 
Ricciardi, A. and J. B. Rasmussen, 1999. Extinction Rates of North American Freshwater Fauna. Conservation Biology, 13(5):1220-1222. doi:10.1046/j.1523-1739.1999.98380.x.

Richter, B. D., J. V. Baumgartner, J. Powell and D. P. Braun, 1996. A method for assessing hydrologic alteration within ecosystems. Conservation Biology 10:1163-1174.

Rigon, R., I. Rodriguez-Iturbe, A. Maritan, A. Giacometti, D. G. Tarboton and A. Rinaldo, 1996. On Hack's Law, Water Resources Research, 32(11):3367-3374. doi:10.1029/96WR02397

Ripley, B., 2015. R Package 'MASS', Support Functions and Datasets for Venables and Ripley's MASS. URL: https://cran.r-project.org/web/packages/MASS/MASS.pdf, (Accessed December 2015).

Rothery, P., 1988. A cautionary note on data transformation: bias in back-transformed means, Bird Study, 35(3):219-221.

Roper, B. B., J. L. Kershner, E. Archer, R. Henderson and N. Bouwes, 2002. An Evaluation of Physical Stream Habitat Attributes Used to Monitor Streams. Journal of the American Water Resources Association, 38:1637-1646. doi: 10.1111/j.17521688.2002.tb04370.x

Ryan, R. J., C. Welty and P. C. Larson, 2010. Variation in surface water-groundwater 
exchange with land use in an urban stream. Journal of Hydrology, 392(1-2):1-11. doi:10.1016/j.jhydrol.2010.06.004

SAGA GIS, n.d. SAGA Wiki, Available at URL: http://sourceforge.net/p/sagagis/wiki/Home, (Accessed December 2014).

Schueler, T., L. Fraley-McNeal and K. Cappiella, 2009. Is impervious cover still important? Review of recent research. Journal of Hydrologic Engineering, 14(4):309315.

Schueler, T., 1994. The Importance of Imperviousness. Watershed Protection Techniques. 1(3):100-111.

Schuller, D., A. Rao and G. Jeong, 2001. Fractal characteristics of dense stream networks. Journal of Hydrology, 243(1-2):1.

Scott, M. K. and D. D. Magoulick, 2008. Swimming Performance of Five Warmwater Stream Fish Species. Transactions of the American Fisheries Society, 137(1):209-215.

Simon, A. and J. Castro, 2003. Measurement and Analysis of Alluvial Channel Form. in Tools in Fluvial Geomorphology, eds. M. Kondolf and H. Piegay. West Sussex, England: John Wiley \& Sons. 
Siriwardena, L., B. Finlayson and T. McMahon, 2006. The impact of land use change on catchment hydrology in large catchments: The Comet River, Central Queensland, Australia. Journal of Hydrology, 326(1-4):199-214. doi:10.1016/j.jhydrol.2005.10.030

Smith, R., L. Alexander and W. Lamp, 2009. Dispersal by terrestrial stages of stream insects in urban watersheds: a synthesis of current knowledge. Journal of the North American Benthological Society, 28(4):1022-1037.

Sonderegger, D., 2015. Package ‘SiZer', URL: https://cran.rproject.org/web/packages/SiZer/SiZer.pdf, (Accessed December 2015).

Stanfield, L. (ed.), 2013. Ontario Stream Assessment Protocol. Version 9.0. Fisheries Policy Section. Ontario Ministry of Natural Resources. Peterborough, Ontario. 505 pages.

Stanfield, L. (ed.), 2003. Guidelines for designing and interpreting stream surveys: A compendium manual to the Ontario Stream Assessment Protocol. Ontario Ministry of Natural Resources, Aquatic Research and Development Section, Picton. Internal document.

Stanfield, L., S. Gibson and J. Borwick, 2006. Using a Landscape Approach to Identify the Distribution and Density Patterns of Salmonids in Lake Ontario Tributaries. American Fisheries Society Symposium, 48:601-621. 
Stanfield, L. and B. Kilgour, 2006. Effects of Percent Impervious Cover on Fish and Benthos Assemblages and Instream Habitats in Lake Ontario Tributaries. American Fisheries Society Symposium, 48:577-599.

Stankiewicz, J. and M. de Wit, 2005. River networks of southern Africa: Scaling laws governing their geometry and deviations from scaling. Geochemistry, Geophysics, Geosystems, 6(9):1-19. doi:10.1029/2005GC000928

Statistics Canada, 2014. Population and dwelling counts, for Canada, census metropolitan areas, census agglomerations and census subdivisions (municipalities), 2011 and 2006 censuses. URL: http://www12.statcan.gc.ca/census-recensement/2011/dp-pd/hlt-fst/pdpl/Table-Tableau.cfm?LANG=Eng\&T $=203 \& C M A=535 \& S=0 \& O=D \& R P P=25$ (Accessed October 2014).

Statistics Canada, 2011. Census of Population (2011). URL: http://www.statcan.gc.ca/tables-tableaux/sum-som/101/cst01/demo62a-eng.htm, (Accessed July 2015).

Statistics Canada, 2005. Road Network File - 2005 - Ontario, URL: http://ata.gc.ca/data/en/dataset/60a8e30c-cdb2-4a2e-bda7-ab727338bb4f, (Accessed December 2014).

Steedman, R. J., 1987. Comparative Analysis of Stream Degradation and Rehabilitation 
in the Toronto Area. PhD Thesis, University of Toronto.

Steffen, W., A. Sanderson, P. D. Tyson, J. Jäger, P. A. Matson, B. Moore III, F. Oldfield, K. Richardson, H. J. Schellnhuber, B. L. Turner and R. J. Wasson, 2004. Global Change and the Earth System: A Planet Under Pressure. New York: Springer-Verlag. ISBN 3540-40800-2.

Stevens, C. E., T. Council and M. G. Sullivan, 2010. Influences of Human Stressors on Fish-Based Metrics for Assessing River Condition in Central Alberta. Water Quality Research Journal of Canada, 45(1):35-46.

Stewart, T. J., A. Todd and S. LePan, 2013. Fish Community Objectives for Lake Ontario. Lake Ontario Management Unit, Picton, Ontario. URL:

http://www.glfc.org/lakecom/loc/LO-FCO-2013-Final.pdf, (Accessed December 2015).

Stirling, M. R., 1999, Manual of Instructions: Nearshore Community Index Netting (NSCIN) Report. Ontario Ministry of Natural Resources, Queen's Printer for Ontario; URL: https://dr6j45jk9xcmk.cloudfront.net/documents/2664/226869.pdf, (Accessed December 2015).

Stoate, C., A. Báldi, P. Beja, N. D. Boatman, I. Herzon, A. van Doorn, G. R. de Snoo, L. Rakosy and C. Ramwell, 2009. Ecological impacts of early 21 st century agricultural change in Europe - A review. Journal of Environmental Management, 91(1):22-46. 
Suriya, S. and B. V. Mudgal, 2012. Impact of urbanization on flooding: The thirusoolam sub watershed - A case study. Journal of Hydrology, 412-413:210-219. doi:10.1016 /j.jhydrol.2011.05.008

Syracuse Research Corporation, 2001. Fish Collection by Seining or Electrofishing (SOP\#SRC-OGDEN-03). Technical Standard Operating Procedure. URL: http://www2.epa.gov/sites/production/files/documents/r8-src src-ogden-03.pdf, (Accessed December 2015).

Takayasu, H., 1990. Fractals in the physical sciences. New York: Manchester University Press.

Tetzlaff, D., M. Grottker and C. Leibundgut, 2005a. Hydrological criteria to assess changes of flow dynamic in urban impacted catchments. Physics and Chemistry of the Earth, 30(6-7):426-431.

Tetzlaff, D., S. Uhlenbrook, M. Grottker and C. Leibundgut, 2005b. Hydrological assessment of flow dynamic changes by storm sewer overflows and combined sewer overflows on an event-scale in an urban river. Urban Water Journal, 2(4):201-214.

Tetzlaff, D., C. Soulsby, A. F. Youngson, C. Gibbins, P. J. Bacon, I. A. Malcolm and S. Langan, 2005c. Variability in stream discharge and temperature: A preliminary assessment of the implications for juvenile and spawning Atlantic salmon. Hydrology and 
Earth System Sciences, 9(3):193-208.

Tetzlaff, D., C. Soulsby, C. Gibbins, P. J. Bacon and A. F. Youngson, 2005d. An Approach to Assessing Hydrological Influences on Feeding Opportunities of Juvenile Atlantic Salmon (Salmo salar): A Case Study of Two Contrasting years in a Small, Nursery Stream. Hydrobiologia, 549(1):65-77.

Thompson, P., 2013. Event Based Characterization of Hydrologic Change in Urbanizing Southern Ontario Watersheds via High Resolution Stream Gauge Data. Master of Applied Science Thesis, Waterloo, Ontario.

Thuiller, W., 2007. Biodiversity: Climate change and the ecologist. Nature, 448(7153):550-552.

Tomer, M. and K. Schilling, 2009. A simple approach to distinguish land-use and climate-change effects on watershed hydrology. Journal of Hydrology. 376:24-33.

Toronto and Region Conservation Authority, 2013. Toronto and Region Watersheds Report Card, 2013. URL: http://trca.on.ca/dotAsset/157180.pdf, (Accessed December 2015).

Toronto and Region Conservation Authority and City of Toronto, 2009. Don River Watershed Plan, Aquatic System - Report on Current Conditions. Toronto, Ontario. URL: 
http://trca.on.ca/dotAsset/55393.pdf, (Accessed December 2015).

Toronto and Region Conservation Authority and City of Toronto, 1999. Highland Creek State of the Watershed Report. Toronto, Ontario. URL:

http://trca.on.ca/dotAsset/91720.pdf, (Accessed December 2015).

Trudeau, M. P. and M. Richardson, 2015. Change in event-scale hydrologic response in two urbanizing watersheds of the Great Lakes St Lawrence Basin 1969-2010. Journal of Hydrology, 517:1174-1188.

Trudeau, M. P. and M. Richardson, Under Review 2015. Empirical Assessment of watershed scale effects of urbanization on event flow hydrology in watersheds of Canada's Great Lakes - St. Lawrence Basin, Journal of Hydrology.

Tu, M., 2009. Combined impact of climate and land use changes on streamflow and water quality in Eastern Massachusetts, USA. Journal of Hydrology 379:268-283.

U.S. Geological Survey (USGS), 1996. HYSEP: A computer program for streamflow hydrograph separation and analysis. Water-Resources Investigations Report 96-4040, URL:http://pa.water.usgs.gov/reports/wrir96-4040.pdf, (Accessed July 2013).

Vannote, R. L., G. W. Minshall, K. Cummins, J. R. Sedell and C. E. Cushing,1980. The River Continuum Concept. Canadian Journal of Fisheries and Aquatic Sciences, 
$37(1): 130-137$.

Veneziano, D. and J. D. Niemann, 2000. Self-similarity and multifractality of fluvial erosion topography: 2. Scaling properties. Water Resources Research, 36(7):1937-1951.

Vörösmarty, C. J., P. B. McIntyre, M. O. Gessner, D. Dudgeon, A. Prusevich, P. Green, S. Glidden, S. E. Bunn, C. A. Sullivan, C. R. Liermann and P. M. Davies, 2010. Global threats to human water security and river biodiversity. Nature, 467(7315):555-561.

Wainio, A. and B. Hester, 1973. The Fish of the Humber River Watershed. Ministry of Natural Resources, Ontario.

Wainio, A. A., 1959. Humber River Fish Survey. Department of Lands and Forests and Metropolitan Toronto and Region Conservation Authority.

Wallace, A. M., M. V. Croft-White and J. Moryk, 2013. Are Toronto's streams sick? A look at the fish and benthic invertebrate communities in the Toronto region in relation to the urban stream syndrome. Environmental Monitoring and Assessment, 185(9):78577875.

Walsh, C. J., A. H. Roy, J. W. Feminella, P. D. Cottingham, P. M. Groffman and R. P. Morgan, 2005. The urban stream syndrome: current knowledge and the search for a cure. Journal of the North American Benthological Society, 24(3):706-723. 
Walsh, C. J., A. K. Sharpe, P. F. Breen and J. A. Sonneman, 2001. Effects of urbanization on streams of the Melbourne region, Victoria, Australia. I. Benthic macroinvertebrate communities. Freshwater Biology, 46(4):535-551.

Wichert, G. A., 1994. Fish as indicators of ecological sustainability: historical sequences in Toronto Area Streams. Water Pollution Research Journal of Canada, 29(4):599-617.

Wichert, G. A., 1995. Effects of Toronto Regional development processes on the dynamics of stream ecosystems as reflected by fish associations. PhD Thesis, University of Toronto.

Wickham, H., 2009. ggplot2: Elegant graphics for data analysis. New York: Springer.

Willems, P., 2013. Revision of urban drainage design rules after assessment of climate change impacts on precipitation extremes at Uccle, Belgium. Journal of Hydrology, 496:166-177. doi:10.1016/j.jhydrol.2013.05.037

Wipfli, M., 2005. Trophic linkages between headwater forests and downstream fish habitats: implications for forest and fish management. Landscape and Urban Planning, $72: 205-213$.

Wood, S., 2015. Package 'mgcv', URL: https://cran.rproject.org/web/packages/mgcv/mgcv.pdf, (Accessed December 2015). 
Yang, Y., D. N. Lerner, M. H. Barrett and J. H. Tellam, 1999. Quantification of groundwater recharge in the City of Nottingham, UK. Environmental Geology, 38(3):183-198. doi:10.1007/s002540050414

Yue, S., P. Pilon and B. Phinney, 2003. Canadian streamflow trend detection: impacts of serial and cross-correlation. Hydrological Sciences Journal, 48(1):51-63.

Yue, S., P. Pilon and G. Cavadias, 2002. Power of the Mann-Kendall and Spearman's rho tests for detecting monotonic trends in hydrological series. Journal of Hydrology, 259(14):254-271.

Zambrano-Bigiarini, M., 2012. hydroTSM: Time series management, analysis and interpolation for hydrological modelling. R package version 0.3-6. URL: http://CRAN.Rproject.org/package=hydroTSM, (Accessed December 2015).

Zhang, K. and D. H. Burns, 2009. Analysis of Trends in Extreme Rainfall, Canadian Foundation for Climate and Atmospheric Sciences, URL: http://www.eng.uwo.ca/research/iclr/fids/publications/cfcasquantifying uncertainty/Reports/kan-report 4.pdf, (Accessed May 2014).

Zuur, A. F., E. N. Ieno, N. J. Walker, A. A. Saveliev and G. M. Smith, 2009. Mixed effects models and extensions in ecology with $R$. New York: Springer. 
Appendices 


\section{Appendix A Number of Flow-Rainfall Record Pairs}

The analyses of event flows rely on high resolution flow and rainfall data. At full season of records (May $26^{\text {th }}$ to November $15^{\text {th }}$ inclusive) comprises 16,708 records. The actual number of records available by watershed and year are identified in Table A.1.

Shaded cells indicate years for which insufficient records were available; these years were eliminated from the database. 
Table A.1 Number of flow-rainfall record pairs 1969 to 1979

\begin{tabular}{|c|c|c|c|c|c|c|c|c|c|c|c|c|}
\hline Watershed & Station & 1969 & 1970 & 1971 & 1972 & 1973 & 1974 & 1975 & 1976 & 1977 & 1978 & 1979 \\
\hline Black Creek near Weston & $02 \mathrm{HCO} 27$ & 11732 & 9406 & 15936 & 15274 & 15652 & 15080 & 15523 & 16706 & 7500 & 16103 & 15000 \\
\hline Credit River at Boston Mills & $02 \mathrm{HB} 018$ & & & & & & & & & & & \\
\hline Credit River at Erindale & 02HB002 & 16616 & 12970 & 13823 & 15266 & 15040 & & 16708 & 15525 & 13375 & 16455 & 16427 \\
\hline Credit River at Norval & $02 \mathrm{HB} 025$ & & & & & & & & & & & \\
\hline Credit River at Streetsville & $02 \mathrm{HB} 029$ & & & & & & & & & & & \\
\hline Credit River near Orangeville & $02 \mathrm{HB} 013$ & & & & & & & & & & & \\
\hline Credit West Branch at Norval & 02HB008 & 16613 & 15143 & 15939 & 16706 & 16574 & 16520 & 16706 & 16582 & 13663 & 16585 & 16427 \\
\hline Don (Little) at Don Mills & 02HCO29 & 16148 & 13710 & 9979 & 14986 & 14404 & 16616 & 16488 & 14019 & 10655 & 16107 & 15000 \\
\hline Don East Branch near Thornhill & $02 \mathrm{HCO56}$ & & & & & & & & & & & \\
\hline Don River at Todmorden & $02 \mathrm{HCO} 24$ & 16147 & 13712 & 16127 & 14699 & 16708 & 16616 & 16583 & 15938 & 15275 & 9802 & 14516 \\
\hline Don River at York Mills & $02 \mathrm{HCOO5}$ & 6060 & 8888 & 9702 & 8350 & 15938 & 14888 & 16584 & 14593 & 15274 & 13891 & 13270 \\
\hline Duffins at Pickering & $02 \mathrm{HCOO6}$ & 4320 & 16194 & 15140 & 12025 & 15151 & 8875 & 14579 & 14964 & & 72 & \\
\hline Duffins Creek above Pickering & 02HC019 & & 16525 & 15276 & 15090 & 11719 & 12315 & & 15240 & 12303 & 12366 & 9296 \\
\hline Duffins Creek at Ajax & 02HCO49 & & & & & & & & & & & \\
\hline Duffins West Branch above Green River & $02 \mathrm{HCO} 38$ & & & & & & 8492 & 14579 & 14964 & 10484 & 15004 & 14783 \\
\hline Duffins West Branch at Green River & $02 \mathrm{HCO} 26$ & & & & & & 4440 & 14387 & 10253 & 6688 & 14620 & 14685 \\
\hline Etobicoke Creek at Brampton & $02 \mathrm{HC} 017$ & & & 16127 & 15274 & 16419 & 15368 & 14660 & 12004 & 11050 & 1728 & 15000 \\
\hline Etobicoke Creek below QEW & $02 \mathrm{HCO} 30$ & 14804 & 11887 & 15355 & 14314 & 16612 & 16231 & 16485 & 16707 & 15275 & 12739 & 15000 \\
\hline Harmony Creek @ Oshawa & 02HD013 & & & & & & & & & & & \\
\hline Highland Creek & $02 \mathrm{HCO} 013$ & 15760 & 10243 & 16128 & 12107 & 15411 & & 3792 & 16027 & 5963 & & 6548 \\
\hline Highland West Branch & $02 \mathrm{HC} 058$ & & & & & & & & & & & \\
\hline
\end{tabular}


Table A.1 Number of flow-rainfall record pairs 1969 to 1979 (continued)

\begin{tabular}{|c|c|c|c|c|c|c|c|c|c|c|c|c|}
\hline Watershed & Station & 1969 & 1970 & 1971 & 1972 & 1973 & 1974 & 1975 & 1976 & 1977 & 1978 & 1979 \\
\hline Humber & $02 \mathrm{HCOO3}$ & 16148 & 13712 & 16126 & 15275 & 8643 & 16615 & 16584 & 16708 & 12300 & 16057 & 15000 \\
\hline Humber (East) near Pine Grove & 02HCOO9 & 16148 & 13710 & 16127 & 15276 & 16708 & 16520 & 16488 & 16706 & 13259 & 9237 & 13176 \\
\hline Humber at Elder Mills & $02 \mathrm{HCO} 25$ & 15473 & 12656 & & 15276 & & 16615 & 14472 & 15747 & 12104 & 12840 & \\
\hline Humber at Highway 7 & $02 \mathrm{HCO} 1$ & 16148 & 13712 & & & & & 16578 & 15262 & 14012 & 5855 & 11828 \\
\hline Humber near Ballycroy & $02 \mathrm{HCO} 057$ & & & & & & & & & & & \\
\hline Humber West Branch below C Dam & $02 \mathrm{HCO} 34$ & 16147 & 13527 & 15551 & 15274 & 16707 & 16615 & 16584 & 16515 & 14795 & 15535 & 14998 \\
\hline Laurel Creek at Waterloo & 02GA024 & & 5436 & 4495 & 15274 & 15276 & 15184 & 13440 & 15276 & 15276 & 13833 & 14992 \\
\hline Mimico Creek at Islington & $02 \mathrm{HCO} 03$ & 16148 & 13711 & 16128 & 14218 & 16419 & 16136 & 16583 & 15843 & 15276 & 8968 & 7223 \\
\hline Redhill Creek at Hamilton & $02 \mathrm{HA} 014$ & & & & & & & & & & 15059 & 15275 \\
\hline Rouge (Little) River near Locust Hill & $02 \mathrm{HCO} 28$ & 16147 & 13711 & 16127 & 15269 & 15172 & 15356 & 16584 & 16707 & 15275 & 16067 & 14904 \\
\hline Rouge Little near Dicksons Hill & $02 \mathrm{HCO} 053$ & & & & & & & & & & & \\
\hline Rouge River near Markham & $02 \mathrm{HCO} 22$ & 16147 & 12460 & 16128 & 15273 & 16324 & 16424 & 16484 & 16706 & 15273 & 16062 & 14904 \\
\hline
\end{tabular}


Table A.1 Number of flow-rainfall record pairs 1980 to 1990

\begin{tabular}{|c|c|c|c|c|c|c|c|c|c|c|c|c|}
\hline Watershed & Station & 1980 & 1981 & 1982 & 1983 & 1984 & 1985 & 1986 & 1987 & 1988 & 1989 & 1990 \\
\hline Black Creek near Weston & $02 \mathrm{HCO} 27$ & 14768 & 14530 & 14803 & 12187 & 14953 & 13646 & 15182 & 15276 & 11247 & 11343 & 15150 \\
\hline Credit River at Boston Mills & 02HB018 & & & 7646 & 16524 & 16406 & 15183 & 16142 & 16672 & 16616 & 16616 & 16615 \\
\hline Credit River at Erindale & $02 \mathrm{HB} 002$ & 16600 & 16156 & 16521 & 15756 & 20840 & 4936 & 16236 & 16672 & 16616 & 16615 & 16614 \\
\hline Credit River at Norval & $02 \mathrm{HB} 025$ & & & & & & & & & & & 16616 \\
\hline Credit River at Streetsville & 02HB029 & & & & & & & & & & & \\
\hline Credit River near Orangeville & $02 \mathrm{HB} 013$ & & & & & & & & & & & \\
\hline Credit West Branch at Norval & $02 \mathrm{HB} 008$ & 16599 & 14520 & 16524 & 16521 & 16408 & 12583 & 16231 & 16672 & 16616 & 16610 & 16614 \\
\hline Don (Little) at Don Mills & 02HCO29 & 15151 & 14532 & 14804 & 12188 & 15141 & 13356 & 14928 & 15270 & & 15183 & 15152 \\
\hline Don East Branch near Thornhill & $02 \mathrm{HCO} 56$ & & & & & & & & & & & \\
\hline Don River at Todmorden & $02 \mathrm{HCO} 24$ & 15248 & 13860 & 14802 & 12188 & 15154 & 14319 & 14990 & 15271 & 15180 & 15180 & 15152 \\
\hline Don River at York Mills & $02 \mathrm{HCOO5}$ & 15247 & 12018 & 10734 & 12090 & 10637 & 11920 & 12193 & 7772 & 15171 & 7783 & 14575 \\
\hline Duffins at Pickering & $02 \mathrm{HCOO6}$ & & 12709 & 12792 & 14990 & 14120 & 12256 & 12590 & 13546 & 15062 & 12704 & \\
\hline Duffins Creek above Pickering & 02HC019 & 15218 & 15084 & 15270 & 15276 & 14989 & 15276 & 14559 & 14719 & 12116 & & \\
\hline Duffins Creek at Ajax & $02 \mathrm{HCO} 49$ & & & & & & & & & & 13951 & 12979 \\
\hline Duffins West Branch above Green River & $02 \mathrm{HCO} 8$ & 16060 & 12715 & 15000 & & & & & & & 14524 & 15092 \\
\hline Duffins West Branch at Green River & $02 \mathrm{HCO} 26$ & 16060 & 12716 & 15000 & 15183 & 12683 & 13554 & 11722 & 12195 & & & \\
\hline Etobicoke Creek at Brampton & $02 \mathrm{HCO} 017$ & 15246 & 13660 & 14804 & 12091 & 15152 & 14319 & 15184 & 14017 & 7983 & 15164 & 15151 \\
\hline Etobicoke Creek below QEW & $02 \mathrm{HCO} 030$ & 13527 & 14532 & 14803 & 12187 & 15156 & 13359 & 15183 & 12874 & & 15176 & 14672 \\
\hline Harmony Creek @ Oshawa & 02HD013 & & & & & & & & & & & \\
\hline Highland Creek & $02 \mathrm{HCO} 013$ & 13335 & 13499 & 14513 & 12188 & 15154 & 14319 & 12199 & 11421 & 14794 & 15179 & 15152 \\
\hline Highland West Branch & $02 \mathrm{HCO} 058$ & & & & & & & & & & & \\
\hline
\end{tabular}


Table A.1 Number of flow-rainfall record pairs 1980 to 1990 (continued)

\begin{tabular}{|c|c|c|c|c|c|c|c|c|c|c|c|c|}
\hline Watershed & Station & 1980 & 1981 & 1982 & 1983 & 1984 & 1985 & 1986 & 1987 & 1988 & 1989 & 1990 \\
\hline Humber & $02 \mathrm{HCOO3}$ & 13328 & 14531 & 13927 & 12184 & 15153 & 14312 & 15183 & 15273 & 15183 & 15184 & 15150 \\
\hline Humber (East) near Pine Grove & $02 \mathrm{HCOO9}$ & 15248 & 14531 & 14803 & 11800 & 932 & 14317 & 15184 & 15179 & 15183 & 15182 & 15152 \\
\hline Humber at Elder Mills & $02 \mathrm{HCO} 25$ & & & & & & & & & & & \\
\hline Humber at Highway 7 & $02 \mathrm{HCO} 1$ & 15247 & 12324 & 14323 & 9327 & 15047 & 12592 & 13645 & 14964 & 12965 & 14121 & 13026 \\
\hline Humber near Ballycroy & $02 \mathrm{HCO} 057$ & & & & & & & & & & & \\
\hline Humber West Branch below C Dam & $02 \mathrm{HCO} 34$ & 15246 & 14531 & 9743 & & & & & & & & \\
\hline Laurel Creek at Waterloo & 02GA024 & 15092 & 15112 & 12335 & 13156 & 14407 & 12297 & 12332 & 14610 & 30552 & 15276 & 15276 \\
\hline Mimico Creek at Islington & $02 \mathrm{HCO} 33$ & 8058 & 14244 & 14228 & 12186 & 30307 & 14318 & 15184 & 15266 & & 15177 & 15151 \\
\hline Redhill Creek at Hamilton & 02HA014 & 14567 & 14768 & 14907 & 14986 & 13073 & 12699 & 12110 & 10248 & 15183 & 15276 & 14560 \\
\hline Rouge (Little) River near Locust Hill & $02 \mathrm{HCO} 28$ & 15247 & 14526 & 14610 & 12187 & 15153 & 14320 & 15184 & 15081 & 15085 & 14991 & 15152 \\
\hline Rouge Little near Dicksons Hill & $02 \mathrm{HCO} 53$ & & & & & & & & & & & \\
\hline Rouge River near Markham & $02 \mathrm{HCO} 22$ & 15248 & 14532 & 14803 & 12188 & 15155 & 14224 & 15180 & 15275 & 12971 & 15087 & 15152 \\
\hline
\end{tabular}


Table A.1 Number of flow-rainfall record pairs 1991 to 2001

\begin{tabular}{|c|c|c|c|c|c|c|c|c|c|c|c|c|}
\hline Watershed & Station & 1991 & 1992 & 1993 & 1994 & 1995 & 1996 & 1997 & 1998 & 1999 & 2000 & 2001 \\
\hline Black Creek near Weston & $02 \mathrm{HCO} 27$ & 11628 & & 15300 & 15304 & 15303 & 15106 & 15212 & 15120 & 15249 & 14999 & 15304 \\
\hline Credit River at Boston Mills & 02HB018 & 16515 & 16663 & 16351 & 14990 & 16520 & 13551 & 16708 & 13832 & 15269 & 15280 & 15204 \\
\hline Credit River at Erindale & $02 \mathrm{HB} 002$ & 15938 & 16663 & 10399 & & & & & & & & \\
\hline Credit River at Norval & $02 \mathrm{HB} 025$ & 15460 & 15704 & 16351 & 10576 & 16518 & 13167 & 16617 & 13832 & 15225 & 15280 & 15204 \\
\hline Credit River at Streetsville & 02НВ029 & & & & & & & & & & & \\
\hline Credit River near Orangeville & 02HB013 & & 5179 & 14379 & 15122 & 7208 & 6388 & 5640 & & & & \\
\hline Credit West Branch at Norval & $02 \mathrm{HB} 008$ & 16707 & 16662 & 14623 & 15182 & 16615 & 12015 & 16655 & 13797 & 15280 & 15280 & 15204 \\
\hline Don (Little) at Don Mills & $02 \mathrm{HCO} 29$ & 15276 & 14730 & 15300 & 15303 & 15298 & 9697 & & & & & \\
\hline Don East Branch near Thornhill & $02 \mathrm{HCO} 056$ & & & & & & & & & & & \\
\hline Don River at Todmorden & $02 \mathrm{HCO} 24$ & 15276 & 14728 & 15301 & 15299 & 15300 & 15200 & 15212 & 15120 & 15305 & 15212 & 15304 \\
\hline Don River at York Mills & $02 \mathrm{HCOO5}$ & 11147 & 8588 & 1920 & 13767 & 15292 & 15208 & 15212 & & & & \\
\hline Duffins at Pickering & $02 \mathrm{HCO} 06$ & & & & & & & & & & & \\
\hline Duffins Creek above Pickering & 02HC019 & & 6267 & 2884 & & & & & & & & \\
\hline Duffins Creek at Ajax & $02 \mathrm{HCO} 049$ & 12298 & 12771 & 13400 & 8278 & 11921 & 11920 & 15028 & 14692 & 8796 & & 9228 \\
\hline Duffins West Branch above Green River & $02 \mathrm{HCO} 8$ & 12296 & 15276 & 11086 & & & & & & & & \\
\hline Duffins West Branch at Green River & $02 \mathrm{HCO} 26$ & & & & & & & & & & & \\
\hline Etobicoke Creek at Brampton & $02 \mathrm{HCO} 017$ & 15275 & 14728 & 10944 & & & & & & & & \\
\hline Etobicoke Creek below QEW & $02 \mathrm{HCO} 030$ & 15275 & 14156 & 15299 & 14913 & 10302 & 15147 & 15212 & 15063 & 15304 & 15212 & 15304 \\
\hline Harmony Creek @ Oshawa & 02HD013 & & & & & & 11896 & 15028 & 14692 & 8796 & & 9228 \\
\hline Highland Creek & $02 \mathrm{HCO} 013$ & 15274 & 14728 & 12190 & 14054 & 14139 & 15203 & 15212 & 8406 & & & \\
\hline Highland West Branch & $02 \mathrm{HCO} 058$ & & & & & & & & & & & \\
\hline
\end{tabular}


Table A.1 Number of flow-rainfall record pairs 1991 to 2001 (continued)

\begin{tabular}{|c|c|c|c|c|c|c|c|c|c|c|c|c|}
\hline Watershed & Station & 1991 & 1992 & 1993 & 1994 & 1995 & 1996 & 1997 & 1998 & 1999 & 2000 & 2001 \\
\hline Humber & $02 \mathrm{HCOO3}$ & 15276 & 14732 & 15013 & 15303 & 15298 & 15197 & 15204 & 15023 & 15304 & 15212 & 15304 \\
\hline Humber (East) near Pine Grove & $02 \mathrm{HCOO9}$ & 9415 & 14732 & 15303 & 15296 & 15303 & & 15212 & 15120 & 15263 & 15212 & 15304 \\
\hline Humber at Elder Mills & $02 \mathrm{HCO} 25$ & & & & & & 15208 & 15212 & 15120 & 15293 & 15212 & 15304 \\
\hline Humber at Highway 7 & $02 \mathrm{HCO} 1$ & 15275 & 14731 & 15304 & 15304 & 15303 & & 8848 & 8792 & 15241 & 15212 & 15292 \\
\hline Humber near Ballycroy & $02 \mathrm{HCO} 057$ & & & & & & & & & & & \\
\hline Humber West Branch below C Dam & $02 \mathrm{HCO} 034$ & & & & & & & & & & & \\
\hline Laurel Creek at Waterloo & 02GA024 & 15275 & 12048 & 14651 & 15304 & 13642 & 12127 & 14028 & & & & \\
\hline Mimico Creek at Islington & $02 \mathrm{HCO} 33$ & 15275 & 14732 & 15303 & 15300 & 15303 & 15208 & 15212 & 15120 & 15304 & 15212 & 15304 \\
\hline Redhill Creek at Hamilton & 02HA014 & & 16369 & 16704 & 14264 & 12320 & 12331 & & & & & \\
\hline Rouge (Little) River near Locust Hill & $02 \mathrm{HCO} 28$ & 17985 & 14444 & 15301 & 15303 & 15202 & 15206 & 15212 & 15120 & 15304 & 15212 & 15281 \\
\hline Rouge Little near Dicksons Hill & $02 \mathrm{HCO} 053$ & & & & & & & & & & & \\
\hline Rouge River near Markham & $02 \mathrm{HCO} 22$ & 15274 & 5952 & & 12422 & 15302 & 10696 & 15212 & 15120 & 15304 & 15212 & 15304 \\
\hline
\end{tabular}


Table A.1 Number of flow-rainfall record pairs 2002 to 2010

\begin{tabular}{|c|c|c|c|c|c|c|c|c|c|c|}
\hline Watershed & Station & 2002 & 2003 & 2004 & 2005 & 2006 & 2007 & 2008 & 2009 & 2010 \\
\hline Black Creek near Weston & $02 \mathrm{HCO} 27$ & 15080 & 12308 & 15280 & 14996 & 11456 & 16616 & 16692 & 16704 & 16708 \\
\hline Credit River at Boston Mills & 02HB018 & 15280 & 15280 & 5504 & & 15263 & 15276 & & & \\
\hline Credit River at Erindale & $02 \mathrm{HB} 002$ & & & & & & & & & \\
\hline Credit River at Norval & $02 \mathrm{HB} 025$ & 15280 & 15280 & 5504 & & 15136 & 15276 & & & \\
\hline Credit River at Streetsville & 02HB029 & & & & & 16646 & 15549 & 16617 & 16637 & 16707 \\
\hline Credit River near Orangeville & $02 \mathrm{HB} 013$ & 15120 & 11008 & 14832 & 14589 & 13424 & 14840 & & & \\
\hline Credit West Branch at Norval & $02 \mathrm{HB} 008$ & 15280 & 15195 & 5504 & & 15280 & 15276 & & & \\
\hline Don (Little) at Don Mills & O2HCO29 & & & & & & & & & \\
\hline Don East Branch near Thornhill & $02 \mathrm{HCO} 56$ & & & & & 11456 & 16581 & 16692 & 16704 & \\
\hline Don River at Todmorden & $02 \mathrm{HCO} 24$ & 15080 & 12254 & 15280 & 14950 & 11456 & 16616 & 16692 & 16704 & 16473 \\
\hline Don River at York Mills & $02 \mathrm{HCOO5}$ & 14727 & & & 14959 & 11456 & 16616 & 16639 & 16704 & \\
\hline Duffins at Pickering & $02 \mathrm{HCOO6}$ & & & & & & & & & \\
\hline Duffins Creek above Pickering & 02HC019 & & & & & & & & & \\
\hline Duffins Creek at Ajax & $02 \mathrm{HCO} 49$ & 15210 & 11764 & 15247 & 10570 & 12024 & 12184 & & & \\
\hline Duffins West Branch above Green River & $02 \mathrm{HCO} 8$ & & & & & 6012 & 6092 & & & \\
\hline Duffins West Branch at Green River & $02 \mathrm{HCO} 26$ & & & & & & & & & \\
\hline Etobicoke Creek at Brampton & $02 \mathrm{HCO} 017$ & & & 15280 & 14996 & 11456 & 16616 & 16692 & 9734 & 16708 \\
\hline Etobicoke Creek below QEW & $02 \mathrm{HCO} 30$ & 15080 & & & 14996 & 11355 & 16616 & 16692 & 16704 & 16678 \\
\hline Harmony Creek @ Oshawa & 02HD013 & 15304 & 11764 & 15279 & 9172 & 6012 & 6064 & & & \\
\hline Highland Creek & $02 \mathrm{HCO} 013$ & & & & & 11452 & 16616 & 16692 & 16704 & 16708 \\
\hline Highland West Branch & $02 \mathrm{HCO} 058$ & & & & & 11359 & 16616 & 16692 & 16704 & 16708 \\
\hline
\end{tabular}


Table A.1 Number of flow-rainfall record pairs 2002 to 2010 (continued)

\begin{tabular}{|c|c|c|c|c|c|c|c|c|c|c|}
\hline Watershed & Station & 2002 & 2003 & 2004 & 2005 & 2006 & 2007 & 2008 & 2009 & 2010 \\
\hline Humber & $02 \mathrm{HCOO3}$ & 15080 & 12226 & 15243 & 14996 & 11456 & 16528 & 16692 & 16704 & 16708 \\
\hline Humber (East) near Pine Grove & 02HCOO9 & 15080 & 12308 & 15280 & 14996 & 11456 & 16616 & 16692 & 16533 & 16708 \\
\hline Humber at Elder Mills & $02 \mathrm{HCO} 25$ & 15064 & 8299 & & & & 13588 & 16597 & 16704 & 9744 \\
\hline Humber at Highway 7 & $02 \mathrm{HCO} 1$ & 8792 & 12226 & 15280 & 14996 & 11456 & 16616 & 16692 & 16642 & 16180 \\
\hline Humber near Ballycroy & $02 \mathrm{HCO} 057$ & & & & & 11456 & 16296 & 16692 & 16704 & 16708 \\
\hline Humber West Branch below C Dam & $02 \mathrm{HCO} 34$ & & & & & & & & & \\
\hline Laurel Creek at Waterloo & 02GA024 & & & & 12308 & 15000 & 15276 & & & \\
\hline Mimico Creek at Islington & $02 \mathrm{HCO} 33$ & 15080 & 12308 & & 14996 & 11456 & 16570 & 16692 & 16704 & 16708 \\
\hline Redhill Creek at Hamilton & $02 \mathrm{HA} 014$ & & & & & & & & & \\
\hline Rouge (Little) River near Locust Hill & $02 \mathrm{HCO} 28$ & 15080 & 12308 & 15280 & 14996 & 11456 & 16616 & 16692 & 16704 & 16707 \\
\hline Rouge Little near Dicksons Hill & $02 \mathrm{HCO} 053$ & & 12294 & 15280 & 14996 & 11456 & 16616 & 16692 & 16704 & 16708 \\
\hline Rouge River near Markham & $02 \mathrm{HCO} 22$ & 15080 & 12308 & 15280 & 14996 & 11456 & 16616 & 16692 & 16704 & 16708 \\
\hline
\end{tabular}




\section{Appendix B Summary of event records removed in data cleaning}

This Appendix provides information not detailed in Chapter 5 regarding data cleaning for rising limb events. The Hysep program output in some cases resulted in very long hydrologic

responses. Events lasting longer than 4.5 days to peak were removed from the record since they reflect a change in baseflow and/or hysep anomalies rather than events to be analyzed. Table B.1 indicates events removed for each watershed station.

Table B.1 Summary of hydrologic events removed from records by watershed

\begin{tabular}{|c|c|c|}
\hline Watershed & $\begin{array}{c}\text { Number of Events } \\
\text { removed }\end{array}$ & $\begin{array}{c}\text { Approximate length of events } \\
\text { removed (Days) }\end{array}$ \\
\hline Black Creek (Humber027) & 9 & 4.5 (3 events), $6,13,16,18,20,40$ \\
\hline Credit008 & 3 & $4.5,5,18$ \\
\hline Credit13 & 2 & $4.6,5$ \\
\hline Credit18 & 3 & $5.4,5.7,5.8,6.2$ \\
\hline Credit025 & 1 & 10 \\
\hline Credit29 & 0 & \\
\hline Don056 & 0 & \\
\hline Don029 & 4 & $4.6,5.6,14,23$ \\
\hline Don024 & 2 & $4.5,6$ \\
\hline Don005 & 3 & 4.6 (2 events), $25,79,43,17$ \\
\hline Duffins26 & 3 & 5 (2 events), 23 \\
\hline Duffins 19 & 1 & 5 \\
\hline Duffins38 & 2 & $4.8,5.7$ \\
\hline Etobicoke017 & 4 & $4.7,4.8,6,14$ \\
\hline Etobicoke030 & 3 & $4.8,5.2,10$ \\
\hline Harmony013 & 1 & 5 \\
\hline Highland013 & 4 & $4.5,12,21,22$ \\
\hline Humber003 & 3 & $5.6,6,30$ \\
\hline Humber009 & 4 & $4.7,4.9,5.8,7.5$ \\
\hline Humber025 & 3 & $4.5,4.8(2)$ \\
\hline Humber031 & 3 & $4.6,5.9,23$ \\
\hline Humber034 & 6 & $4.5,5,5.1,5.2,5.7,6.6$ \\
\hline Laurel Creek & 4 & $4.6,5.1,5.6,6.1$ \\
\hline Mimico & 3 & $4.9,5.2,5.7$ \\
\hline Redhill & 4 & $4.6,5.6,7.2,21.5$ \\
\hline Rouge 022 & 4 & $4.5,5.4,10,23$ \\
\hline Rouge 028 & 3 & $4.8,4.9,5$ \\
\hline
\end{tabular}




\section{Appendix C Illustrations of urban area delineation by watershed and year}

This appendix provides visual snapshots of urban delineation and also provides additional information on UP estimate development where there were gaps in aerial photo coverage. Readers are referred to Thompson (2013) for other watershed based urban estimates. Credit Valley Conservation Authority shapefiles are not published. Refer to Chapter 5 for additional information.

Illustrations are presented in alphabetical order by watershed from earliest to latest years.

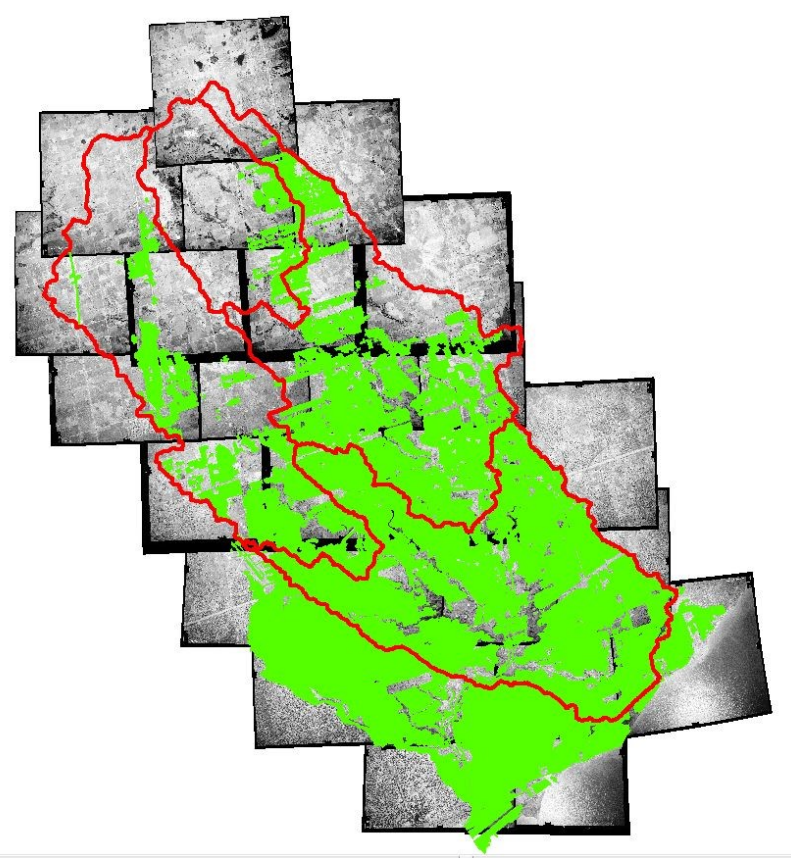

Illustration C.1 Don watersheds 1974. Red line shapes depict watersheds. Green indicates urban land use. Delineated watersheds and corresponding EC hydrologic gauge identifier (from upstream top (east) to downstream) include: Don East Branch near Thornhill (02HC056), Little Don at Don Mills (02HC029), Don River at York Mills (02HC005) and Don River at Todmorden (02HC024). 


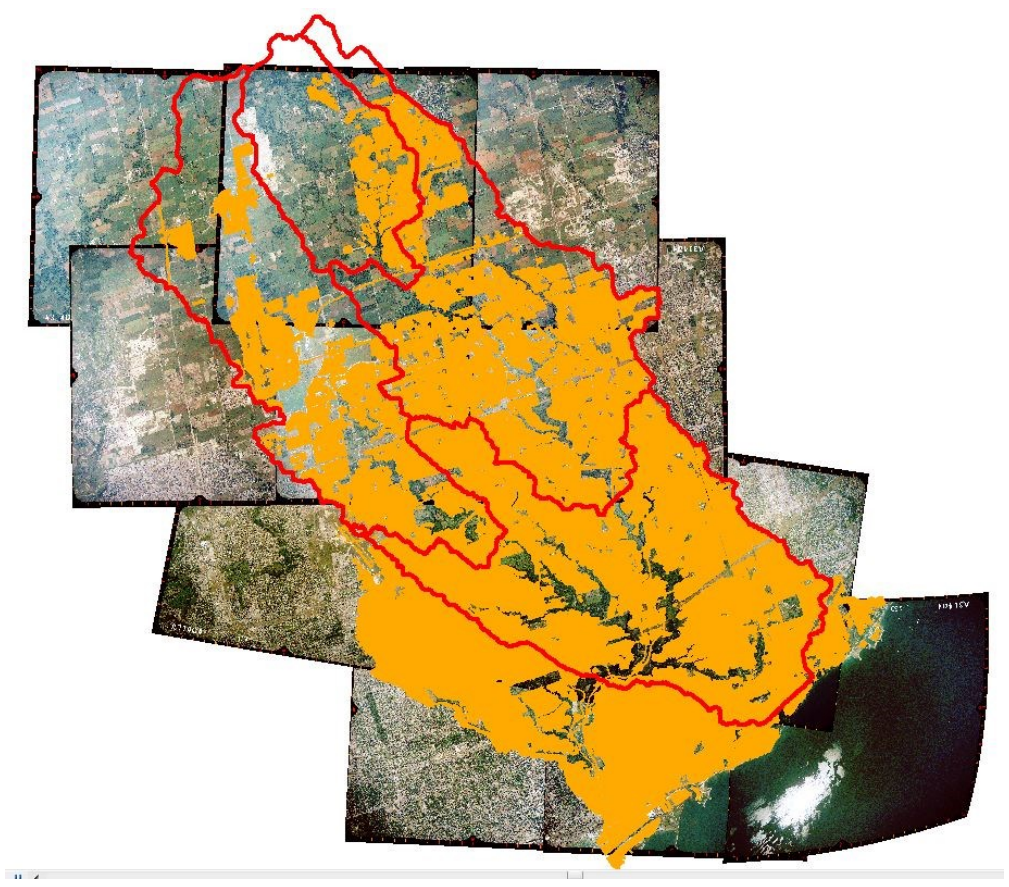

Illustration C.2 Don watersheds 1985. See Illustration C.1 for watersheds and corresponding hydrologic gauges. Gold indicates urban land use. Note the gap in coverage at the north tip, which was still not urbanized in 1988 so no urban extent was missed. The NRCan photos for 1985 had colour; other years were grey scale. 


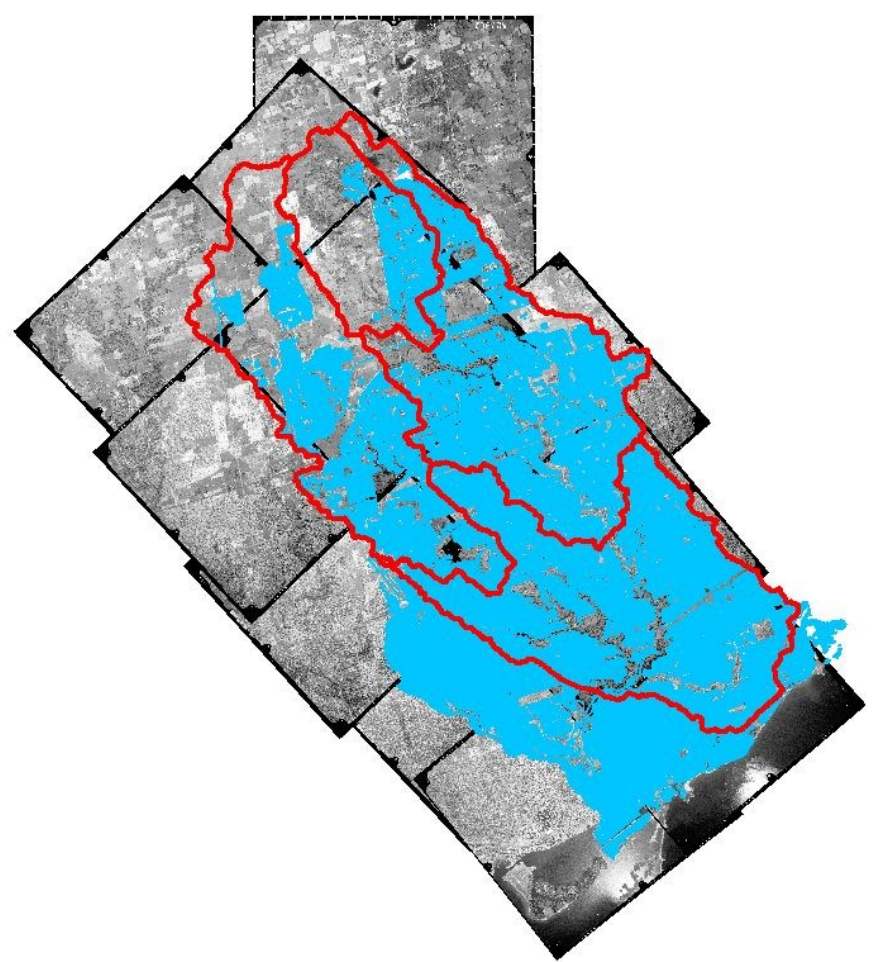

Illustration C.3 Don watersheds1988. See Illustration C.1 for watersheds and corresponding hydrologic gauges. Blue indicates urban land use. 


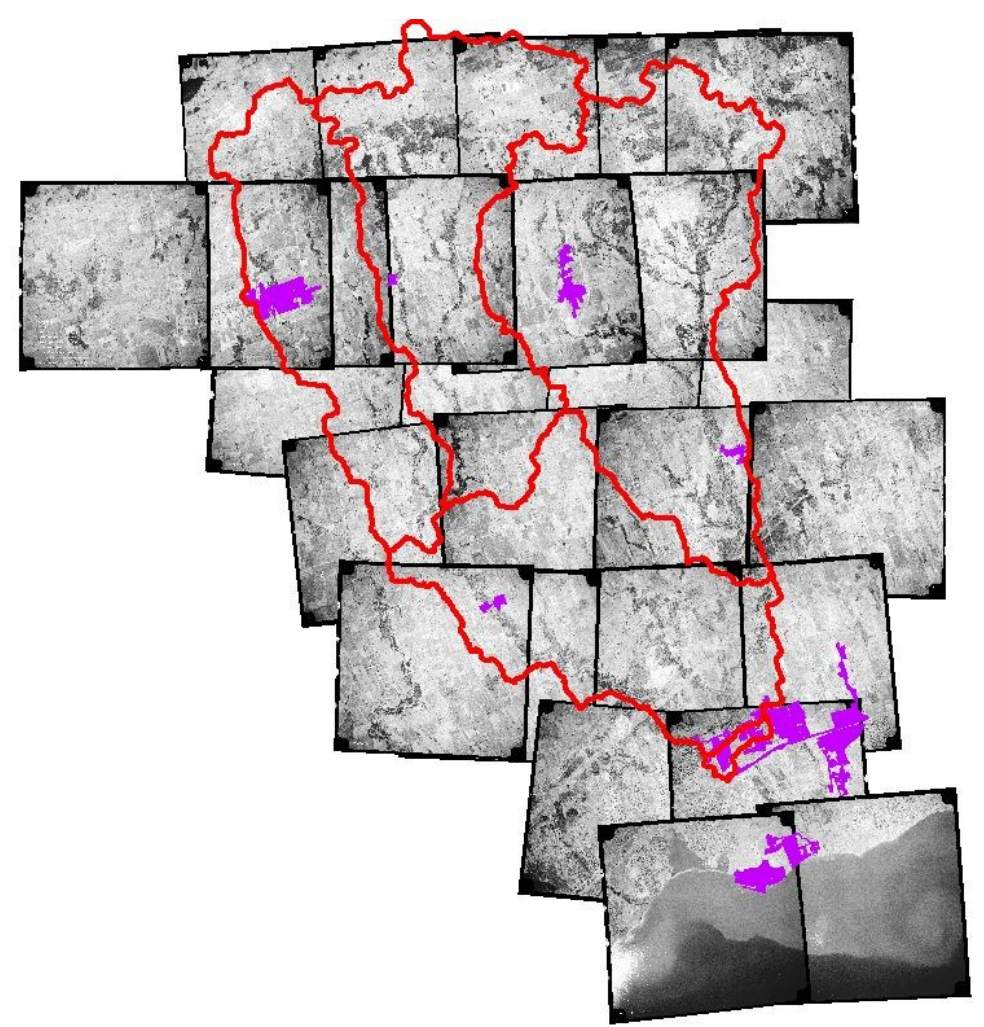

Illustration C.4 Duffins watersheds 1978. This year was the only one with full coverage of the Duffins watershed identified in NRCan's aerial photo record. The very small area in the north was assumed to be rural in 1978 because it lies within the Oak Ridges Moraine, a region that is still protected from development in 2015. Red line shapes depict watersheds corresponding to hydrologic gauge locations. Purple indicates urban land use. Delineated watersheds and corresponding EC hydrologic gauge identifier (from east to west) include: Duffins Creek above Pickering (02HC019), Duffins Creek at Green River (02HC026), which is the larger western watershed that includes Duffins Creek above Green River (02HC038). The mainstem gauges did not have hydrologic data corresponding to years of available urban cover (Duffins at Pickering (02HC006) and Duffins at Ajax (02HC049)). 


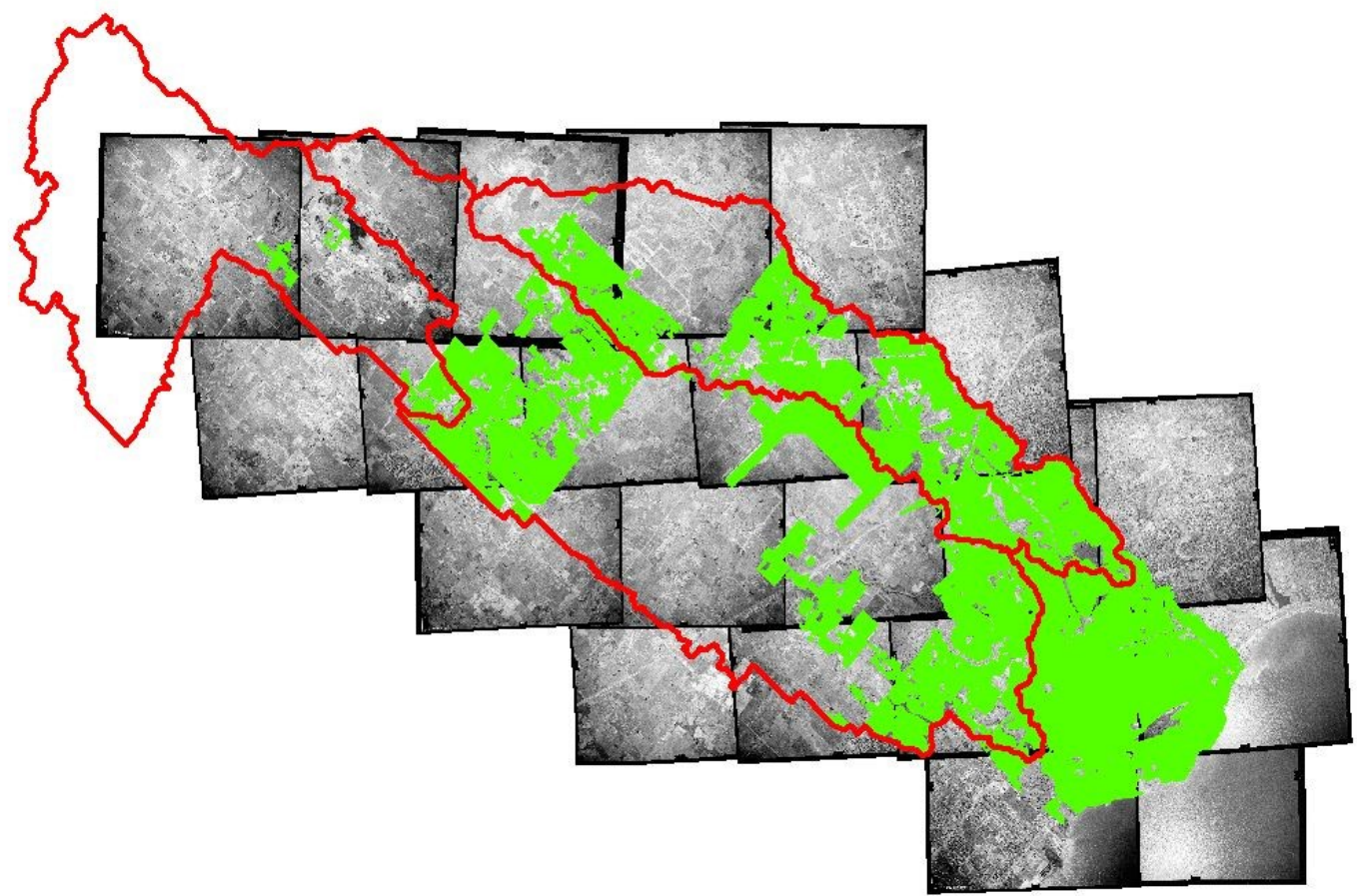

Illustration C.5 Mimico and Etobicoke watersheds 1974. The missing area was still not urbanized in 1985, so no there was no missing urban area. Red line shapes depict watersheds corresponding to hydrologic gauge locations. Green indicates urban land use. Delineated watersheds and EC hydrologic gauge identifier (from upstream top (east) to downstream) include: Mimico Creek at Islington (02HC033), Etobicoke Creek at Brampton (02HC017), and Etobicoke Creek below the Queen Elizabeth Way (a 400-series Provincial Highway) (02HC030). 


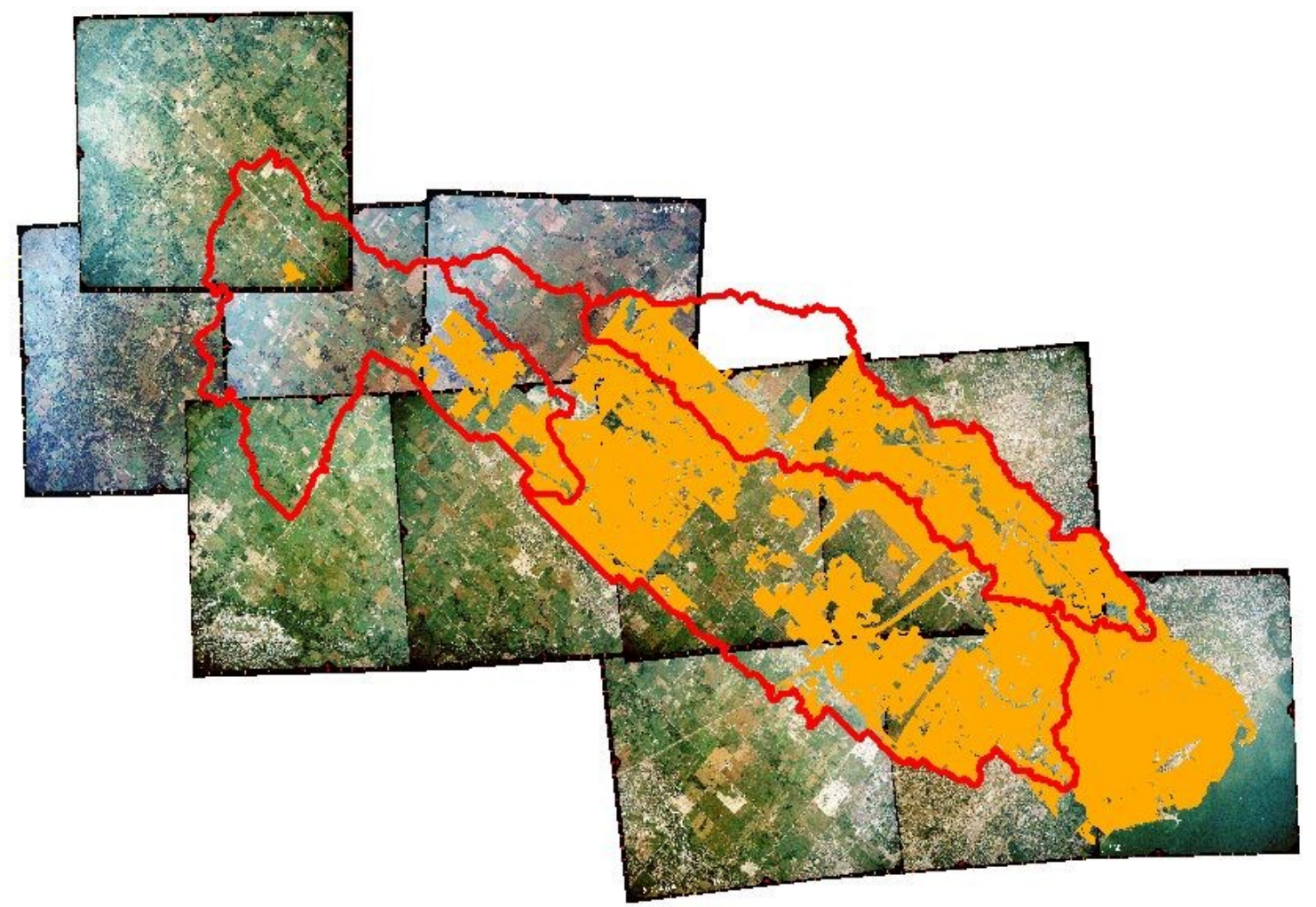

Illustration C.6 Mimico and Etobicoke watersheds 1985. See Illustration C.5 for watersheds and corresponding hydrologic gauges. Red line shapes depict watersheds. Gold indicates urban land use. The 1974 urban area for Mimico was applied for the missing photo coverage. The difference for Mimico's urban extent between 1974 and 1988 was $11.06 \mathrm{~km}^{2}$. The difference in urban extent between 1985 and 1988 was $4.1 \mathrm{~km}^{2}$ without correction for the gap in photo coverage. From the 1988 photos, the gap was mostly still rural. No estimate for missing urban extent in Mimico was made for $1985 ; 4.1 \mathrm{~km}^{2}$ is $6 \%$ of the Mimico watershed and represents a very unlikely upper limit for the error introduced by not adding an estimated urban extent for the gap. The NRCan photos for 1985 had colour; other years were grey scale. 


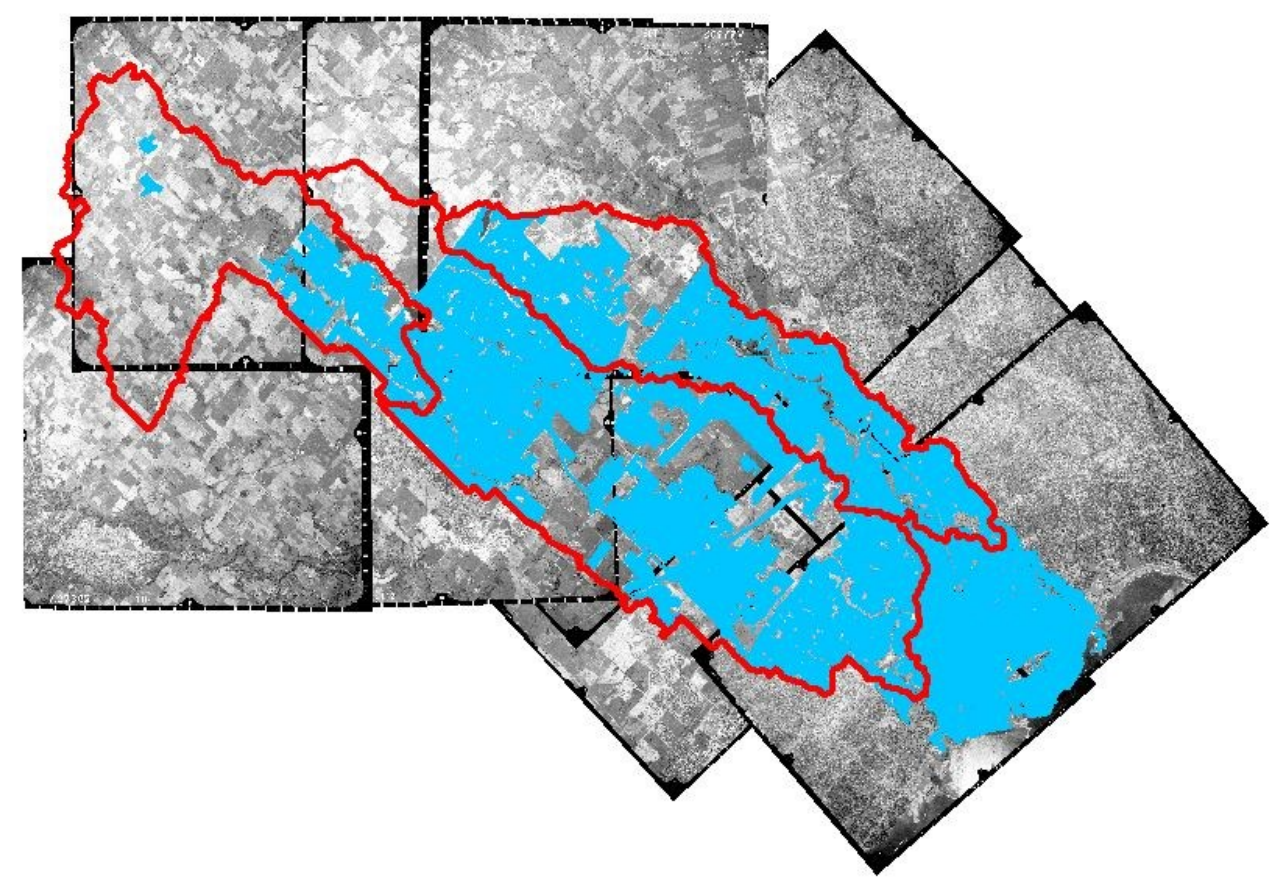

Illustration C.7 Mimico and Etobicoke watersheds 1988. See Illustration C.5 for watersheds and hydrologic gauges. Red line shapes depict watersheds corresponding to hydrologic gauge locations. Blue indicates urban land use. 


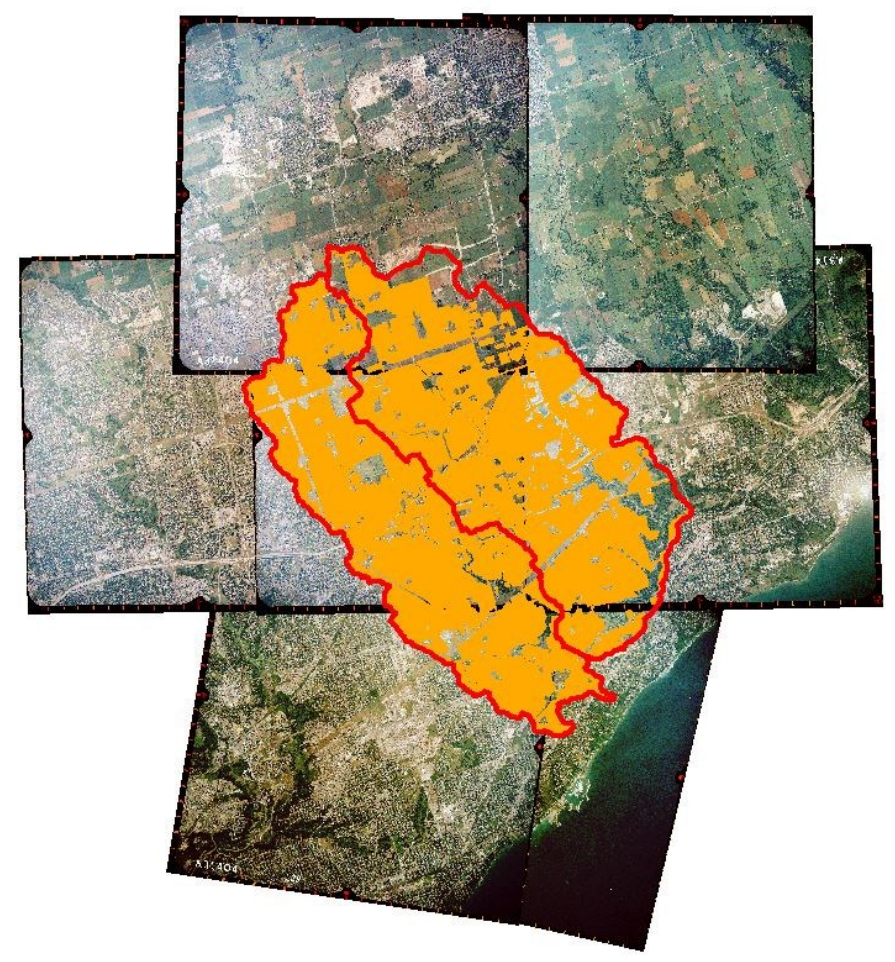

Illustration C.8 Highland watersheds 1985. Two watersheds are delineated (in red shapes) but only the largest downstream watershed had hydrologic data for 1985 (Highland Creek, 02HC013). Gold indicates urban land use. The NRCan photos for 1985 had colour; other years were grey scale. 


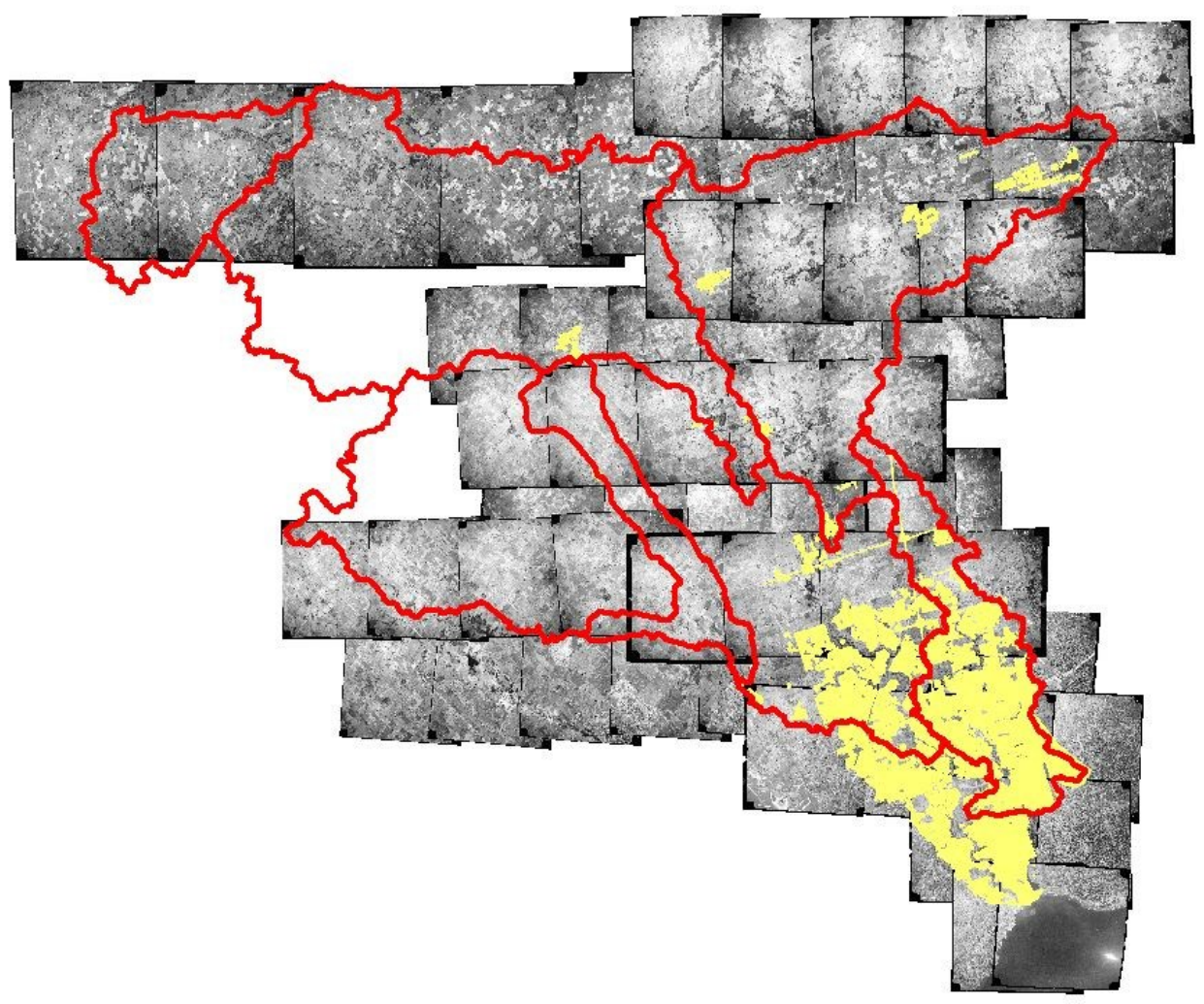

Illustration C.9 Humber watersheds 1969. This year and 1988 offered the best coverage of the Humber watershed among all photos available from NRCan. Fortunately, most of the missing area was still not urban by 1988. See Appendix G, Notes for Table G.1 for the estimate made of missing urban extent. Delineated watersheds (in red) and corresponding EC hydrologic gauge identifier (from east to west from upstream to downstream) include: Humber East near Pine Grove (02HC009), Humber at Elder Mills (02HC025) (note the smaller sub-watershed in the northwestern most corner of the Humber system had no hydrologic data corresponding to available urban cover (Humber near Ballycroy (02HC057)), Black Creek near Weston (02HC027), Humber River below Claireville Dam (02HC034) (mid-west watershed) which contains Humber at Highway 7 (02HC031). The large mainstem site, 02HC003, contains all subwatershed stations except Black Creek, which outlets downstream of the station. Yellow indicates urban land use. 


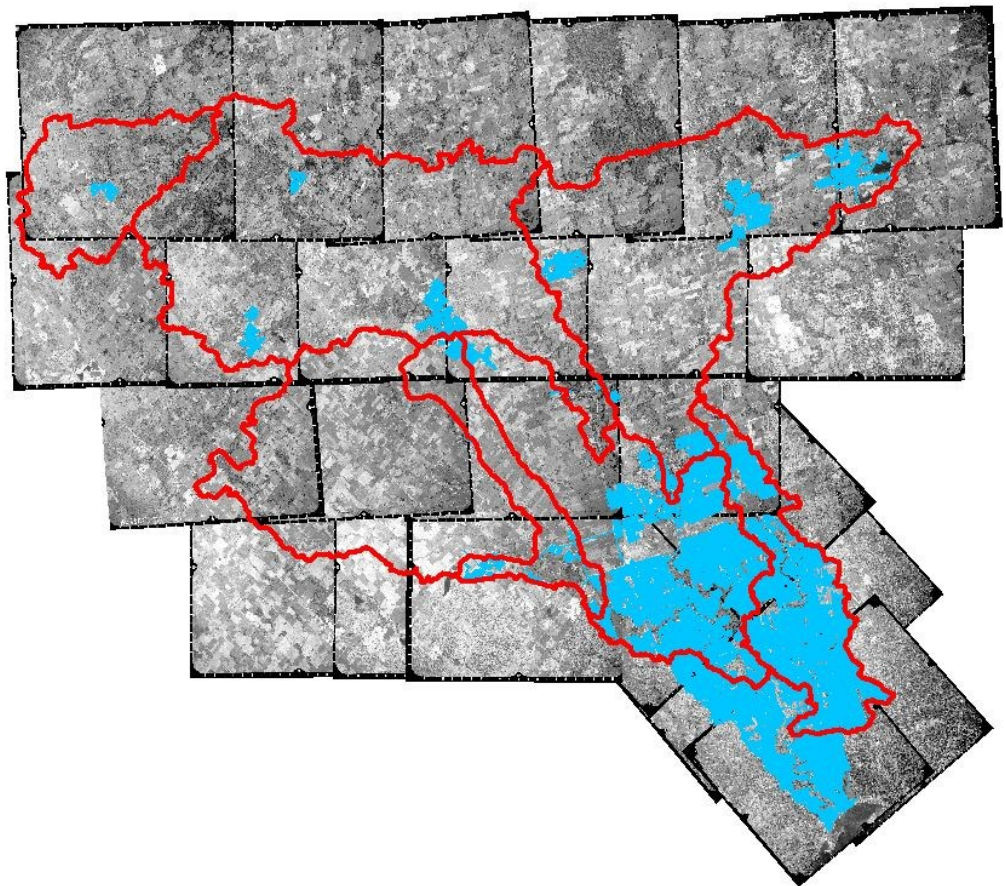

Illustration C.10 Humber watersheds 1988. This set of photos was the only one identified in historic aerial photographs from NRCan that fully covered the Humber watershed. See Illustration C.9 for watersheds (delineated by red shapes) and corresponding hydrologic gauges. Blue indicates urban land use. 


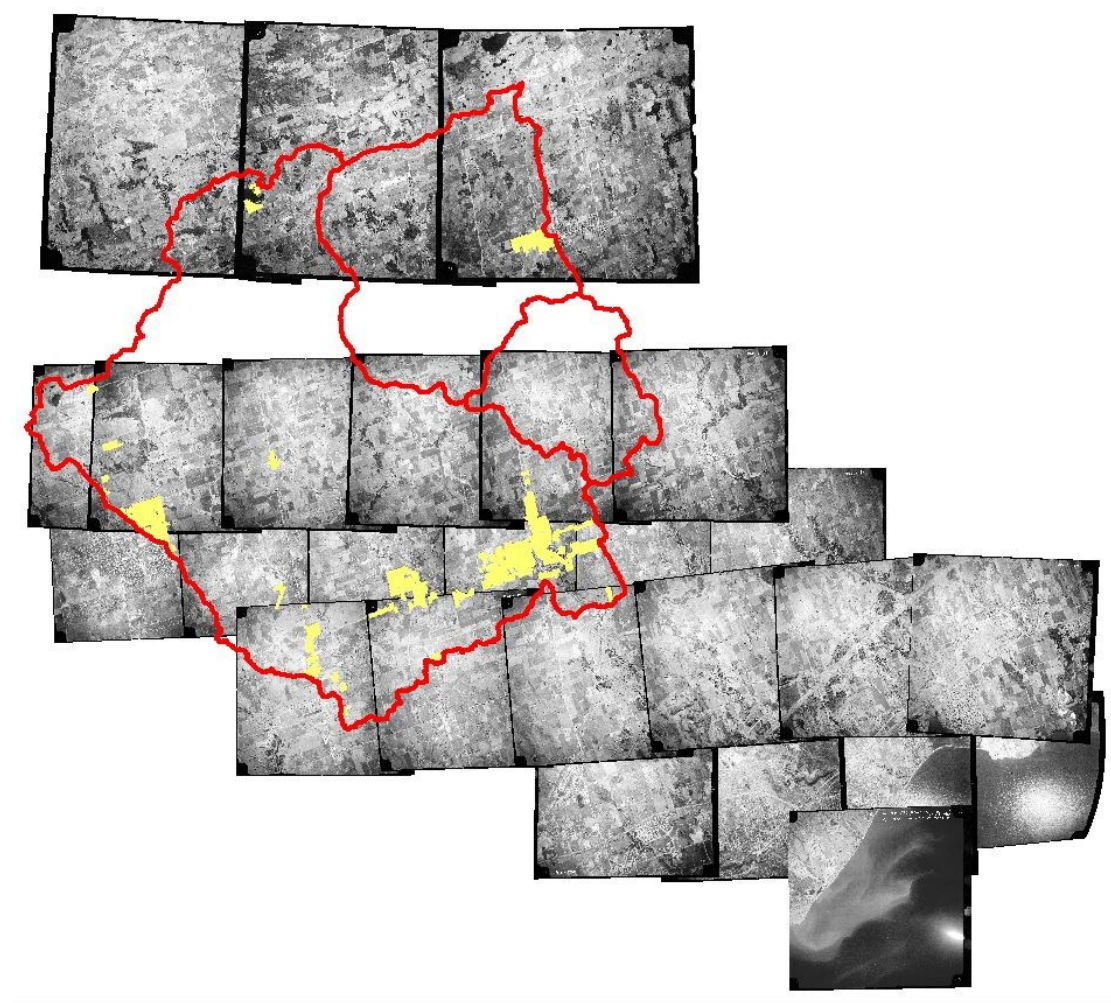

Illustration C.11 Rouge watersheds 1969. The missing area was still not urbanized in 1974, so no estimate of missing urban extent was necessary. Delineated watersheds (delineated by red shapes) and corresponding EC hydrologic gauge identifier (from upstream top (east) to downstream) include: Little Rouge near Dicksons Hill (02HC053), Little Rouge near Locust Hill (02HC028) and Rouge River near Markham (02HC022). Yellow indicates urban land use. 


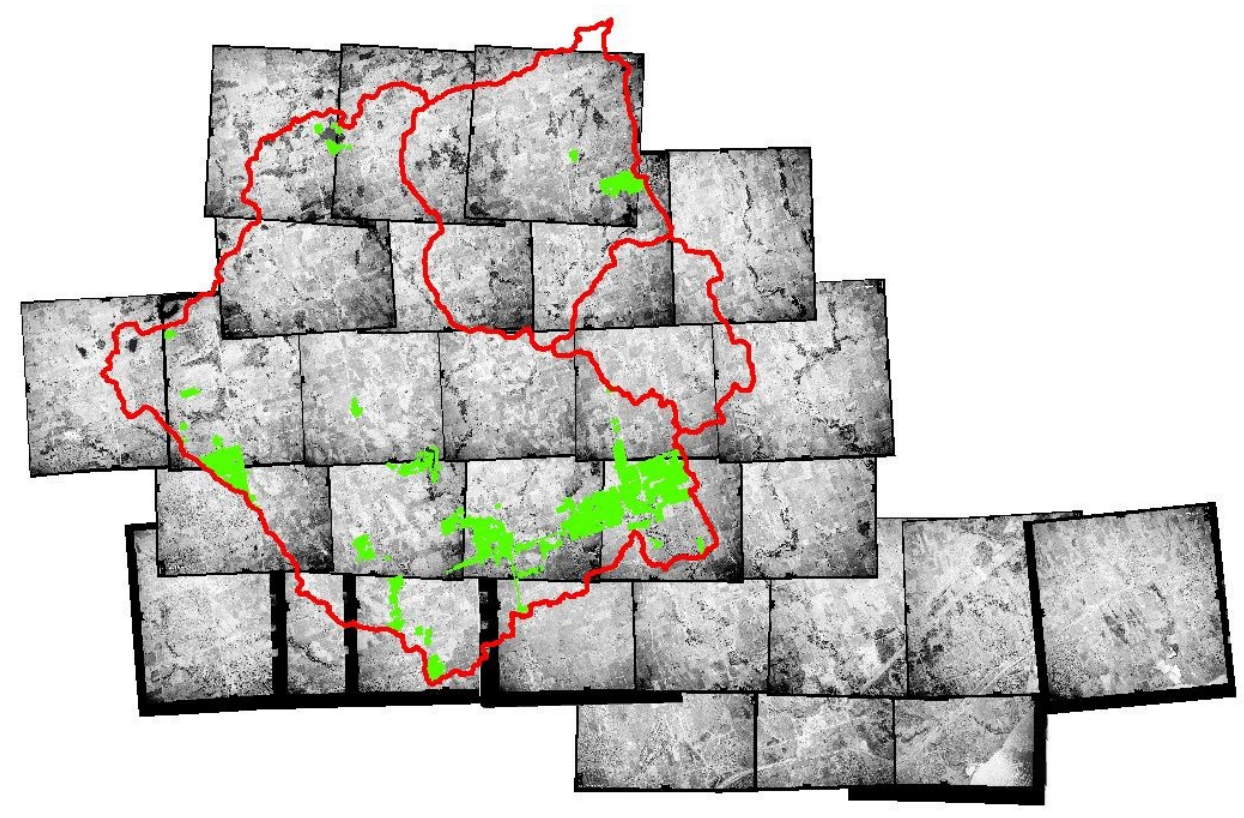

Illustration C.12 Rouge watersheds 1974. The small missing area in the north-most corner was still not urbanized in 1988, so no estimate of missing urban extent was necessary. See Illustration C.11 for watersheds and corresponding hydrologic gauges. Green indicates urban land use. 


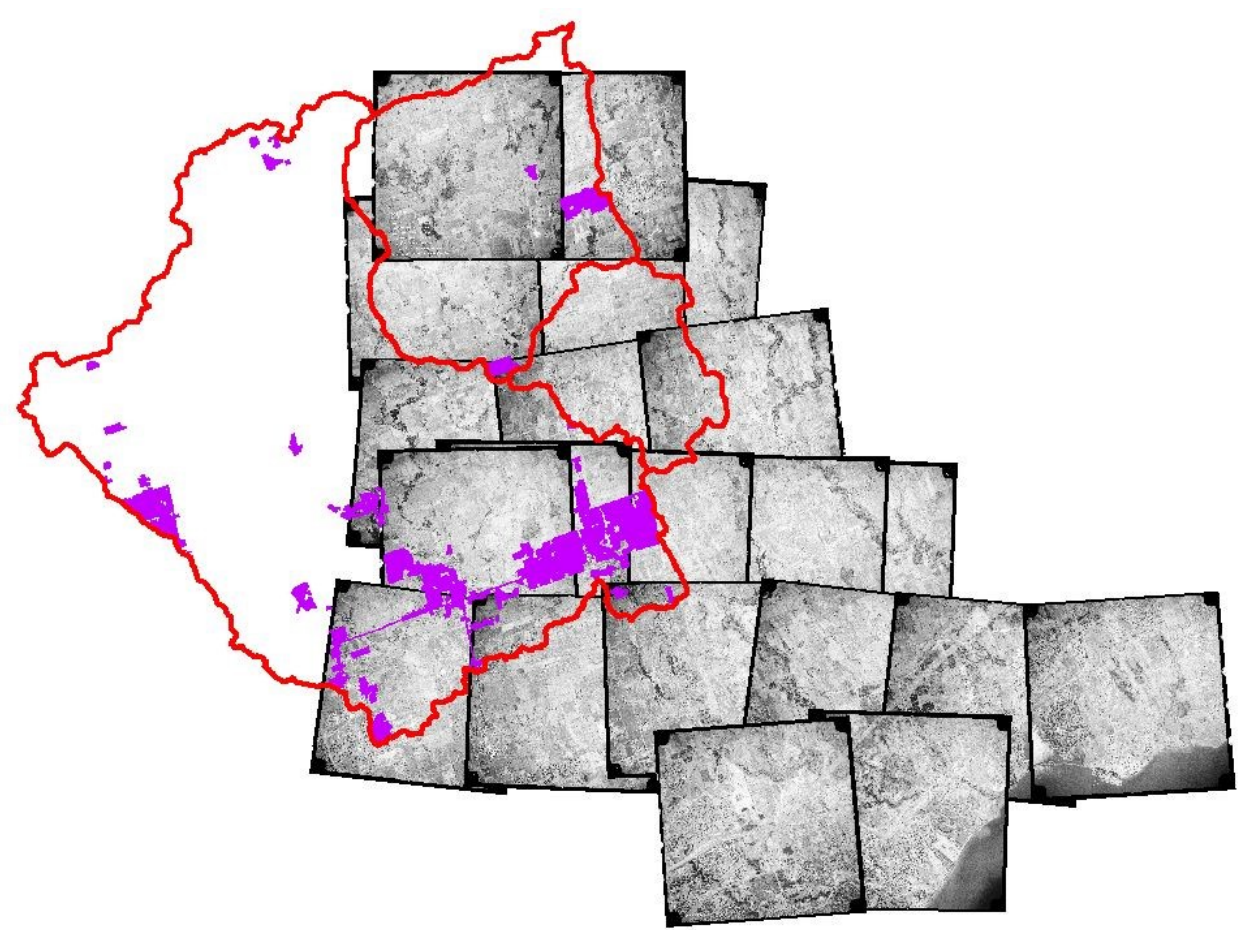

Illustration C.13 Rouge watersheds 1978. See Illustration C.11 for watersheds and

corresponding hydrologic gauges. See Appendix G, Notes for Table G.1 for the estimate made of missing urban extent. Purple indicates urban land use. 


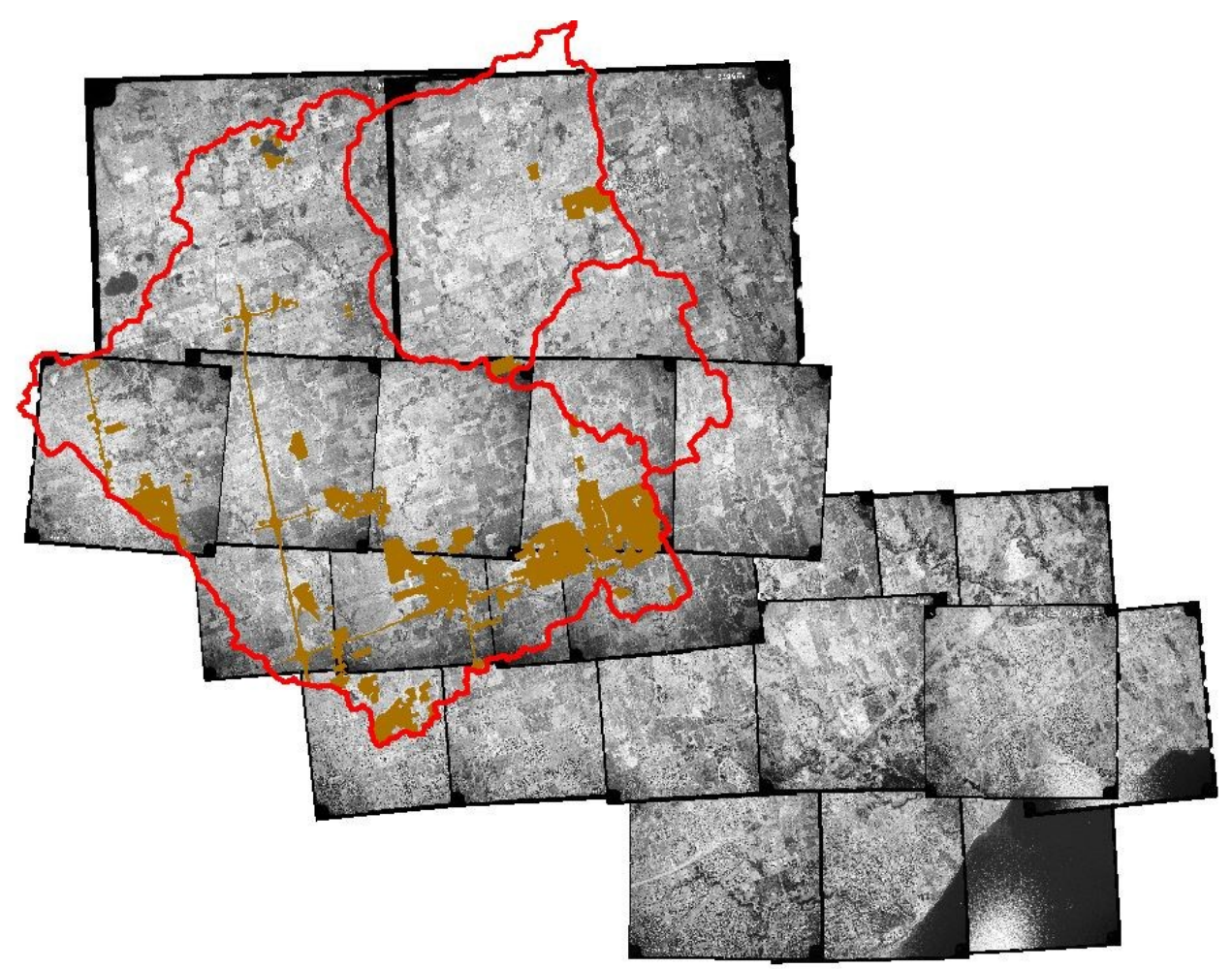

Illustration C.14 Rouge watersheds 1981. The small missing area in the north-most corner was still not urbanized in 1988, so no estimate of missing urban extent was necessary. See Illustration C.11 for watersheds and corresponding hydrologic gauges. Brown indicates urban land use. 


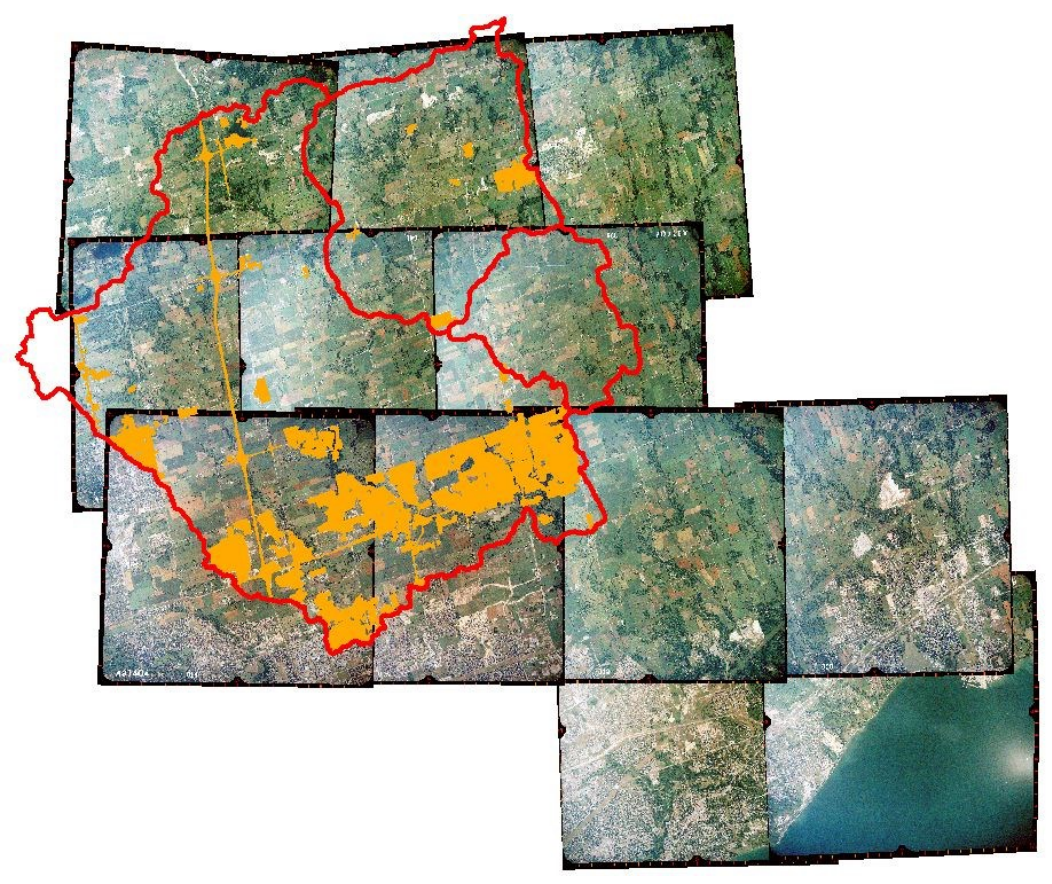

Illustration C.15 Rouge watersheds 1985. The small missing areas in the north-most corner and western edge were still not urbanized in 1988, so no estimate of missing urban extent was necessary. See Illustration C.11 for watersheds and corresponding hydrologic gauges. Gold indicates urban land use. The NRCan photos for 1985 had colour; other years were grey scale. 


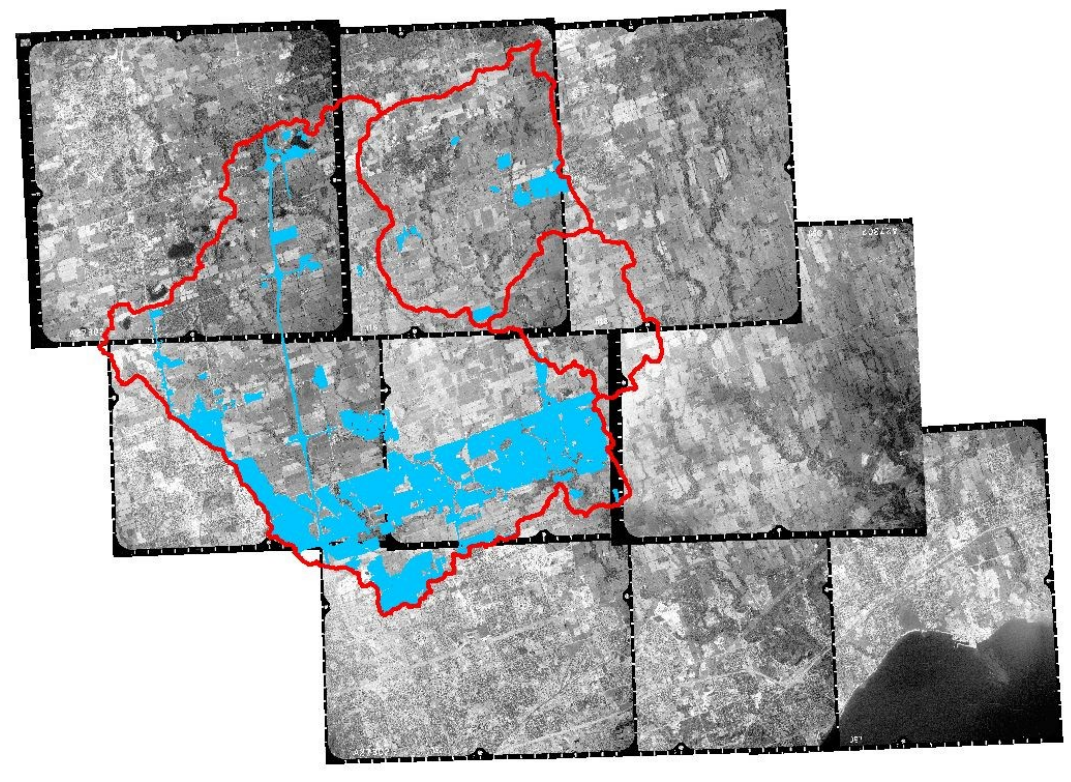

Illustration C.16 Rouge watersheds 1988. See Illustration C.11 for watersheds and corresponding hydrologic gauges. Blue indicates urban land use. 


\section{Appendix D Protocols for geo-referencing and digitization of urban areas}

This appendix contains notes compiled during georeferencing and digitization of aerial photographs. Through contract, selected photos were scanned by NRCan from negatives using the highest resolution option (2032 dots per inch; 80 dots per mm). Photos were received from NRCan with little information on position and no known orientation. An accompanying NRCan database included photo corner and centre coordinates and other metadata pertaining to the camera, altitude and scale. Photo scales included: 25000; 30000; 40000; and, 50000. A mix of up to two scales of photo was needed for some year-watershed combinations to obtain full coverage of the watershed in that year.

\section{D.1 Georeferencing}

This text was written by Scott Page, GIS specialist, with edits by M. Trudeau. Not all of the GIS technicians working on the project retained records of control points and trans-formations, as noted following. ESRI's ArcMap Geo-referencing tool was used for georeferencing. This tool uses ground control points (GCP) to position the image with a first, second or third order transformation being applied across the full photo.

\section{Georeferencing Procedure}

Photos were geo-referenced to Ontario's 2005 road network (Statistics Canada, 2005-09-29 (http://data.gc.ca/data/en/dataset/60a8e30c-cdb2-4a2e-bda7-ab727338bb4f).

Procedural steps to position each photo: 
- A distinct and easily recognizable feature (a unique intersection or neighbourhood pattern) in a single photo was identified and used as a control point to identify the position and or orientation of the photo.

- After this first photo was geo-referenced subsequent photos in a line were positioned against overlapping features with either side. When a new row was started, the photos were aligned to overlapping features above and below in the previous line.

- Photos were aligned based on distinctive road features such as intersections where these features were present and spatially consistent between the GCP Ontario road network and the photo from the year being referenced.

- A ground control point was established where the feature in the photo was matched to the position of the feature in the known (established) feature position in the 2005 Ontario road network.

- A GCP was established on a distinct and recognizable feature or at a position which was known from overlap with a previous photo; this established initial photo position.

- To achieve an even and consistent distribution and density of GCPs on a given photo, a consistent procedure in establishing GCPs was used.

- GCPs were established first in proximity to the four corners of the image with GCPs being established moving inward from the perimeter where GCPs were added to areas with poor coverage or poor positioning compared to the known road feature position.

- This distribution method was used where possible. GCPs were subject to the availability of road features. There were no GCPs where the roads were sparse, where road networks were built or significantly altered between photo and control dates. 
- In rare cases, the positions of secondary photo features were matched between earlier and later photos (that is, a rural area with no roads was urban at a later time). In these cases, the rural area had no roads so there were no GCP opportunities but the later urban area was easily georeferenced. Secondary feature such as buildings or field corners of the better-referenced later photos were used as GCP for the earlier rural photo.

- Image transformation was taken from $1^{\text {st }}$ to $2^{\text {nd }}$ to (as required) $3^{\text {rd }}$ order. Transformations were used to improve photo fit and control for image warp or distortion resulting from variation in the sensor platform (aircraft).

\section{Georeferencing error}

The Residual Mean Square error (RMSE) for photo georeferencing, a measure of the consistency of the transformation of air photos to control points (ESRI, 2009), was highest where there was no road network. Thus, the highest RMSE was in rural areas.

The RMSE (in metres) was calculated and, if high, an assessment of the GCPs was undertaken (i.e. can the control applied be better defined or do the existing control points positions need adjustment). Even though a photo may have had an above-average, or even high RMS error, it did not necessarily mean the digitized urban areas produced unreliable numbers. Urban areas will generally not be highly skewed because a large number of control points can always be found. Street layouts generally do not change between the photo years and 2005. It is the areas that were rural in photo years, but have since transformed to be heavily urbanized in 2005 , that had higher RMS errors. 
During georeferencing, it was noticed that the corners of the photos were often slightly skewed. For some of these areas it was difficult to georeference at a high quality level. Because of this, when digitizing urban space, the corners and edges of photos were often not digitized, but rather when the technician moved on to the next photo, he would then digitize that area - as it was now located in the middle of the photo and not likely to be skewed.

RMSE was not always reliable, especially in areas where water encompasses much of the photo. In order to not significantly skew the photo when rectifying a georeferenced photo, control points have to be placed in the water. There are no reference points in the water, so the control points have to be estimated - thus often raising the RMS error. Even though the urban area may be georeferenced at a high quality, the inclusion of a significant waterbody, as was the case for many photos along the waterfront, can result in a high RMSE.

It was often difficult to find control points in the centre and in some northern sections of the Humber watershed because of significant development and changes between 1969-2005 and 1988-2005. This often resulted in higher RMS error. The RMSE for photos such as A19506_38, A19506_36, and others in this area had abnormally high error because, in 1969, this area was entirely farmland. By 2005 , a significant portion of this area was urban, changing the road networks drastically. The overall RMSE average was also higher in northern photos for the Rouge watersheds for the same reasons.

Fortunately, most of the photos with high RMSE did not contain much urban area; while the 
RMSE is higher, urban digitization and the resulting calculation of urban per cent cover should not be greatly affected.

RMSE is generally very low in the highly urban areas, especially those near the waterfront that excluded large areas of water (e.g. RMSE was less than $2 \mathrm{~m}$ in southern Highland and Etobicoke/Mimico). RMSE are missing for all Don estimates and for photos received in a later batch from NRCan, including Etobicoke/ Mimico and Humber. RMSE was estimated for 61\% of the georeferenced photos. See Table D.1 for estimates for four river systems. Of the 200 photos with RMSE data (of 328 photos used), the average $\mathrm{x}$, y RMSE was $4.66 \mathrm{~m}$, with a range from $1.27 \mathrm{~m}$ to $20.21 \mathrm{~m}$ (an outlier); the next highest RMSE were $13.00 \mathrm{~m}$ and $10.16 \mathrm{~m}$.

Table D.1 RMSE estimates for four river systems.

\begin{tabular}{|c|c|c|c|c|}
\hline River System & $\begin{array}{c}\text { Number of } \\
\text { photos with } \\
\text { calculated } \\
\text { RMSE }\end{array}$ & $\begin{array}{c}\text { Average x, y } \\
\text { RMSE (m) }\end{array}$ & $\begin{array}{c}\text { Average } \\
\text { number of } \\
\text { control points }\end{array}$ & Transformation \\
\hline Humber & 48 (of 85) & 6.28 & 32 & $\begin{array}{c}\text { Majority use } 3^{\text {rd }} \\
\text { order polynomial } \\
\text { transformation }\end{array}$ \\
\hline Etobicoke/Mimico & $\begin{array}{c}31 \text { (of 45) - no } \\
\text { data for 1988 }\end{array}$ & 3.33 & 32 & $\begin{array}{c}\text { Majority use } 3^{\text {rd }} \\
\text { order polynomial } \\
\text { transformation }\end{array}$ \\
\hline Rouge & 94 (of 120) & 4.82 & Unknown & Unknown \\
\hline Duffins & 27 (of 27) & 4.19 & Unknown & Unknown \\
\hline
\end{tabular}

\section{D.2 Digitization of urban areas}

Digitization of urban areas was done using ESRI's ArcMap built-in polygon (.shp/Shapefile) creation tool. Photo interpretation and urban feature tracing was done visually at an appropriate 
zoom level to be able to discern and click on street, lot or field corners and other features. To the extent possible, the definitions and procedures identified in Thompson (2013) were used so the data from Thompson could be used. Urban areas were identified through a set of criteria and GIS technician judgement (see Chapter 5). Urban areas were identified through:

- Evidence of drainage - Paved areas and paved roads in proximity to urban areas, or with recognizable residential/industrial urban structures. Photos were inspected for evidence of suburban sprawl or industrial complexes.

- $\quad$ Residential structures - Drained areas near buildings and maintained yards or paved areas.

- Excluded areas - Country roads, farms, fields with tile drainage and golf courses.

- Minimum mapping unit: green spaces, such as parks or fields smaller than approximately 10,000 square meters were digitized as urban space. Larger green spaces, including larger parks, golf courses, and larger school fields, are not included within the urban area designation.

- Quarries were not included in the urban designation

- For sub-divisions under construction, where the road layout was visible (but not necessarily yet paved), the area under construction was included in the urban designation. This decision was based on the assumption that sewer infrastructure would be in place and the sub-division would be completed within the year.

\section{D.3 Assessment of Digitization Values and Potential Error}

Once estimates of urban extent were available for each watershed, trends in urban area increases with time were assessed for consistency and feasibility. Where available, estimates from other 
sources were included in the trend analyses, specifically Thompson 2013. Temporal decreases in urban land use were assumed to be impossible and sudden jumps in rates of urban change were assumed to be unlikely. Through this process, the zoom level for analyses was refined and some earlier work had to be re-done due to deficiencies in required precision for delineation of subdivision border lines and road edges.

There were no methodological issues to raise concerns regarding consistent bias towards over- or under-estimation of urban delineation estimates. However, the UP estimates were based on topographic watershed delineation. In urban areas, drainage area is determined by the drainage infrastructure (i.e. the effective drainage area), which is not necessarily evident from topographic features. Based on calculations using available Thompson (2013) estimates for both topographic and effective urban areas, the difference between the two ranged from $4 \%$ higher to $2 \%$ lower; on average, the effective area was $0.60 \%+/-0.02 \%$ larger than topographic area. For watersheds with an effective area larger than topographic area, the urban extent would be under-estimated, and vice versa. Considering both the potential error introduced by use of topographic watershed delineation and by urban digitization, there was unlikely to be systematic bias resulting in consistent over or under-estimation of urban extent. To evaluate error in urban extent estimates, detailed sewer maps of each watershed at the time of the historic urban estimate would be needed and the effective drainage area delineated. It is anticipated that other research efforts would be more productive, such as incorporation of soils and surficial geology into the database, or estimation of historic baseflow indices where appropriate temporal hydrologic records are available. 


\section{Appendix E Rain gauge metadata}

Table E.1 Rain gauge locations, first year of data collection, last year of data collection and number of years with record for the gauge. Rain gauge 6158350 was replaced with new equipment in 2002 but maintained the same location and was re-numbered 6158355 .

\begin{tabular}{|l|c|c|c|c|c|}
\hline $\begin{array}{c}\text { Rain Gauge } \\
\text { MSC } \\
\begin{array}{c}\text { Station } \\
\text { Number }\end{array}\end{array}$ & $\begin{array}{c}\text { Latitude } \\
\text { (decimal } \\
\text { degrees N) }\end{array}$ & $\begin{array}{c}\text { Longitude } \\
\text { (decimal } \\
\text { degrees } \\
\text { W) }\end{array}$ & First Year & Last Year & $\begin{array}{c}\text { Years with } \\
\text { record }\end{array}$ \\
\hline 6149387 & 43.4500 & -80.3833 & 1970 & 2007 & 36 \\
\hline 6153020 & 43.9000 & -79.0667 & 1960 & 1993 & 31 \\
\hline 6153300 & 43.2833 & -79.8833 & 1962 & 1996 & 35 \\
\hline 6155790 & 43.9184 & -80.0864 & 1992 & 2007 & 12 \\
\hline 6155878 & 43.8667 & -78.8333 & 1969 & 2007 & 38 \\
\hline $6158350 / 355$ & 43.6667 & -79.4000 & 1937 & on-going & $>75$ \\
\hline 6158733 & 43.6772 & -79.6306 & 1960 & 2007 & 47 \\
\hline
\end{tabular}




\section{Appendix F Watershed Baseflow Index, Channel and Slope Estimates}

Table F.1 Watershed BFI, Channel and Slope estimates for study watersheds. BFI data sources:

J. Buttle (pers. comm., 2015) and Neff et al., 2005; an asterisk indicates assignment of BFI from an adjacent watershed.

\begin{tabular}{|c|c|c|c|c|c|}
\hline $\begin{array}{l}\text { River } \\
\text { system }\end{array}$ & $\begin{array}{c}\text { Watershed } \\
\text { EC hydro } \\
\text { station }\end{array}$ & $\begin{array}{c}\text { Regulation } \\
\text { Type }\end{array}$ & BFI & $\begin{array}{c}\text { Channel } \\
\text { Slope(units: } \\
\text { m/m) }\end{array}$ & $\begin{array}{l}\text { Mean Basin Slope } \\
\quad \text { (units: } \mathrm{m} / \mathrm{m} \text { ) }\end{array}$ \\
\hline \multirow{5}{*}{ Credit } & 02HB008 & Regulated & 0.64 & 0.0056 & 0.0399 \\
\hline & $02 \mathrm{HB} 013$ & Regulated & 0.64 & 0.0034 & 0.0430 \\
\hline & 02HB018 & Regulated & 0.64 & 0.0038 & 0.0438 \\
\hline & $02 \mathrm{HB} 025$ & Regulated & 0.64 & 0.0031 & 0.0432 \\
\hline & 02НB029 & Natural & 0.64 & 0.0028 & 0.0399 \\
\hline \multirow{4}{*}{ Don } & $02 \mathrm{HC} 005$ & Regulated & $0.66^{*}$ & 0.0047 & 0.0271 \\
\hline & $02 \mathrm{HC} 024$ & Regulated & 0.57 & 0.0040 & 0.0344 \\
\hline & $02 \mathrm{HC} 029$ & Natural & 0.57 & 0.0052 & 0.0371 \\
\hline & $02 \mathrm{HC} 056$ & Natural & 0.66 & 0.0087 & 0.0449 \\
\hline \multirow{3}{*}{ Duffins } & $02 \mathrm{HC} 019$ & Natural & 0.71 & 0.0073 & 0.0578 \\
\hline & $02 \mathrm{HC} 026$ & Regulated & 0.63 & 0.0059 & 0.0365 \\
\hline & $02 \mathrm{HC} 038$ & Natural & 0.69 & 0.0060 & 0.0403 \\
\hline \multirow{2}{*}{ Etobicoke } & $02 \mathrm{HC} 017$ & Regulated & 0.57 & 0.0019 & 0.0186 \\
\hline & $02 \mathrm{HC} 030$ & Natural & 0.57 & 0.0026 & 0.0192 \\
\hline Harmony & $02 \mathrm{HD} 013$ & Natural & 0.47 & 0.0103 & 0.0393 \\
\hline Highland & $02 \mathrm{HC} 013$ & Natural & 0.57 & 0.0038 & 0.0266 \\
\hline \multirow{6}{*}{ Humber } & $02 \mathrm{HC} 003$ & Regulated & 0.57 & 0.0026 & 0.0406 \\
\hline & $02 \mathrm{HC} 009$ & Natural & 0.64 & 0.0020 & 0.0435 \\
\hline & $02 \mathrm{HC} 025$ & Natural & 0.72 & 0.0029 & 0.0571 \\
\hline & $02 \mathrm{HC} 027$ & Regulated & 0.57 & 0.0033 & 0.0313 \\
\hline & $02 \mathrm{HC} 031$ & Natural & 0.44 & 0.0035 & 0.0210 \\
\hline & $02 \mathrm{HC} 034$ & Regulated & $0.44 *$ & 0.0030 & 0.0206 \\
\hline Laurel & 02GA024 & Regulated & 0.62 & 0.0030 & 0.0412 \\
\hline Mimico & $02 \mathrm{HC} 033$ & Natural & 0.57 & 0.0036 & 0.0195 \\
\hline Red Hill & 02НA014 & Natural & 0.44 & 0.0080 & 0.0302 \\
\hline \multirow{2}{*}{ Rouge } & $02 \mathrm{HC} 022$ & Regulated & $0.63 *$ & 0.0039 & 0.0284 \\
\hline & $02 \mathrm{HC} 028$ & Natural & 0.61 & 0.0057 & 0.0248 \\
\hline
\end{tabular}




\section{Appendix G Urban Land Use Database Summary}

Table G.1 Database Summary: Urban extent in square kilometers for watersheds in years with available flow and rainfall data.

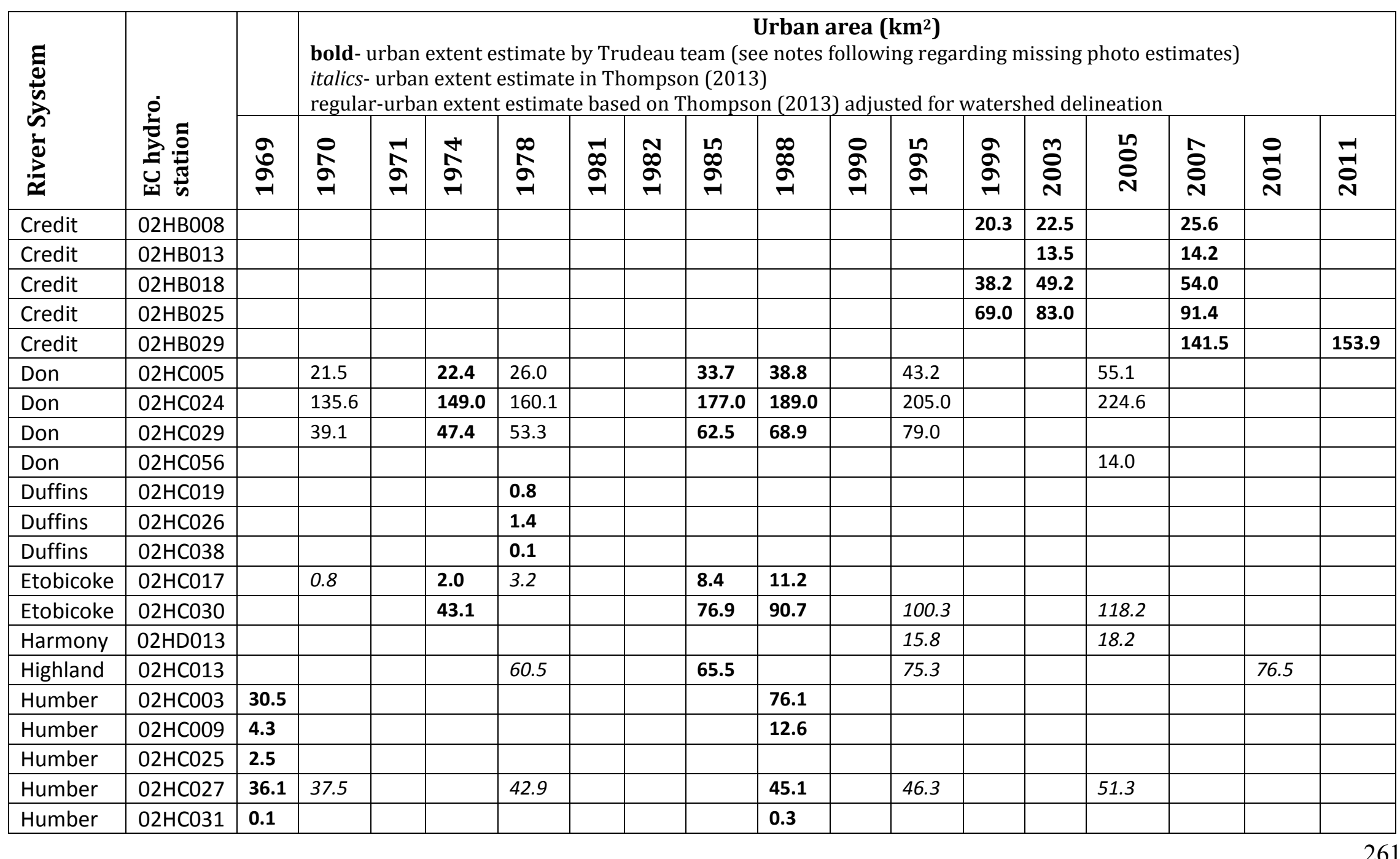




\begin{tabular}{|c|c|c|c|c|c|c|c|c|c|c|c|c|c|c|c|c|c|c|}
\hline \multirow{2}{*}{ 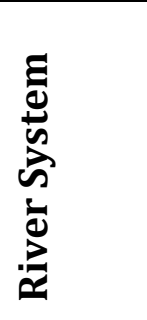 } & \multirow{2}{*}{ 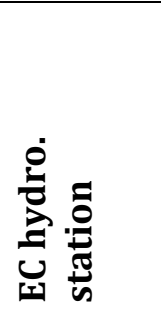 } & \multirow[b]{2}{*}{$\begin{array}{l}\text { gి } \\
\text { ŏ }\end{array}$} & \multicolumn{16}{|c|}{$\begin{array}{l}\text { Urban area }\left(\mathbf{k m}^{2}\right) \\
\text { bold- urban extent estimate by Trudeau team (see notes following regarding missing photo estimates) } \\
\text { italics- urban extent estimate in Thompson (2013) } \\
\text { regular-urban extent estimate based on Thompson (2013) adjusted for watershed delineation }\end{array}$} \\
\hline & & & 옹 & $\stackrel{-1}{\widehat{N}}$ & $\stackrel{+}{\stackrel{N}{\sigma}}$ & $\begin{array}{l}\infty \\
\stackrel{1}{\sigma} \\
\stackrel{\sim}{\sim}\end{array}$ & $\begin{array}{l}-1 \\
\infty \\
\sigma \\
\sigma\end{array}$ & 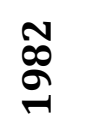 & $\begin{array}{l}\text { 노 } \\
\stackrel{2}{2} \\
\stackrel{9}{\sim}\end{array}$ & $\begin{array}{l}\infty \\
\infty \\
\stackrel{\infty}{\sim}\end{array}$ & ஓ & ํㅕㅇ & & ֻి & $\begin{array}{l}\text { L } \\
\text { O̊ } \\
\text { N }\end{array}$ & 송 & $\stackrel{\circ}{\stackrel{ }{\circ}}$ & $\underset{\text { 공 }}{-}$ \\
\hline Humber & $02 \mathrm{HCO} 34$ & 0.2 & & & & & & & & & & & & & & & & \\
\hline Laurel & 02GA024 & & & 9.9 & & & & 12.4 & & & 14.9 & 16.6 & & & 21.6 & & & \\
\hline Mimico & $02 \mathrm{HCO} 33$ & & & & 31.9 & & & & 38.8 & 42.9 & & 53 & & & 60.2 & & & \\
\hline Red Hill & 02HA014 & & & & & 20.8 & & & & & & 31.3 & & & & & & \\
\hline Rouge & $02 \mathrm{HCO} 22$ & 7.8 & & & 11.9 & 15.0 & 19 & & 29.3 & 38.5 & & 50.1 & & & 66.9 & & 72.2 & \\
\hline Rouge & $02 \mathrm{HCO} 28$ & 0.7 & & & 0.9 & 1.3 & 1.4 & & 1.7 & 2.29 & & & & & & & & \\
\hline
\end{tabular}




\section{Notes:}

Estimates for urban extent in the missing areas of watersheds without full photo coverage were made as follows:

1) Rouge 1969: the later year, 1974, had no urbanization in the missing area, so no adjustment made

2) Etobicoke 1974: the later year, 1985, had no urbanization in the missing area, so no adjustment made

3) Rouge 1978: in the missing area of $95.6 \mathrm{~km}^{2}$, the later year (1981) had $2.3 \mathrm{~km}^{2}$ more urban area than the earlier year (1974); $2 \mathrm{~km}{ }^{2}$ was added to the 1978 extent estimated from available photos.

4) Humber 1969: in the missing area of $60.9 \mathrm{~km}^{2}$, the later year (1988) had $2.5 \mathrm{~km}^{2}$ of urban extent. The missing area is in the northwest region of the Humber watershed, including the town of East Caledon. An urban area of $1.5 \mathrm{~km}^{2}$ was added to the 1969 urban estimate for the applicable nested watersheds $(02 \mathrm{HC} 025$ and $02 \mathrm{HC} 003)$ on the assumption that the town footprint was in place in 1969; the area surrounding East Caledon was still rural in 1988. 
Table G.2 Database Summary: Percent urban coverage for watersheds in years with available flow and rainfall data for at least one of the databases with urban area, hydrologic and rainfall records. Sources identified in Table 5.1 and Table G.1.

\begin{tabular}{|c|c|c|c|c|c|c|c|c|c|c|c|c|c|c|c|c|c|c|}
\hline \multirow[b]{2}{*}{ 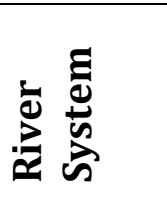 } & \multirow[b]{2}{*}{ ن } & & \multicolumn{16}{|c|}{ Percent urban area } \\
\hline & & $\begin{array}{l}9 \\
6 \\
a \\
\text { a }\end{array}$ & $\begin{array}{l}0 \\
\hat{n} \\
\text { a }\end{array}$ & ล̊ & Na & 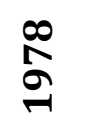 & $\begin{array}{l}\text { a } \\
\infty \\
\sigma \\
\sigma\end{array}$ & $\begin{array}{l}\text { N } \\
\infty \\
\sigma \\
\sim\end{array}$ & $\begin{array}{l}1 \\
\infty \\
\sigma \\
1\end{array}$ & $\begin{array}{l}\infty \\
\infty \\
\infty \\
\sigma\end{array}$ & $\begin{array}{l}\text { ̊̊ } \\
\text { ล் }\end{array}$ & 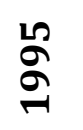 & $\begin{array}{l}\text { g } \\
\text { a } \\
-1\end{array}$ & $\overbrace{0}^{n}$ & $\stackrel{1}{8}$ & $\stackrel{N}{0}$ & $\underset{0}{\stackrel{0}{0}}$ & $\stackrel{-1}{0}$ \\
\hline Credit & $02 \mathrm{HB} 008$ & & & & & & & & & & & & 15.4 & 17.1 & & 23.9 & & \\
\hline Credit & $02 \mathrm{HB} 013$ & & & & & & & & & & & & & 22.8 & & 23.9 & & \\
\hline Credit & 02HB018 & & & & & & & & & & & & 9.2 & 11.9 & & 13.0 & & \\
\hline Credit & $02 \mathrm{HBO} 25$ & & & & & & & & & & & & 10.8 & 12.9 & & 14.2 & & \\
\hline Credit & 02HB029 & & & & & & & & & & & & & & & 18.4 & & 15.4 \\
\hline Don & 02HCOO5 & & 25.5 & & 26.7 & 30.8 & & & 40.1 & 46.1 & & 51.4 & & & 65.5 & & & \\
\hline Don & $02 \mathrm{HCO} 24$ & & 43.6 & & 47.9 & 51.5 & & & 56.9 & 60.7 & & 65.9 & & & 72.2 & & & \\
\hline Don & $02 \mathrm{HCO} 29$ & & 30.7 & & 37.2 & 41.8 & & & 49.1 & 54.1 & & 62.0 & & & & & & \\
\hline Don & $02 \mathrm{HCO} 056$ & & & & & & & & & & & & & & 37.3 & & & \\
\hline Duffins & 02HC019 & & & & & 0.9 & & & & & & & & & & & & \\
\hline Duffins & $02 \mathrm{HCO} 26$ & & & & & 1.3 & & & & & & & & & & & & \\
\hline Duffins & 02HC038 & & & & & 0.1 & & & & & & & & & & & & \\
\hline Etobicoke & $02 \mathrm{HCO} 017$ & & 1.1 & & 2.7 & 4.4 & & & 11.7 & 15.6 & & & & & & & & \\
\hline Etobicoke & $02 \mathrm{HCO} 30$ & & & & 20.6 & & & & 36.8 & 43.3 & & 47.9 & & & 56.5 & & & \\
\hline Harmony & $02 \mathrm{HD} 013$ & & & & & & & & & & & 36.8 & & & 42.4 & & & \\
\hline Highland & $02 \mathrm{HCO} 13$ & & & & & 66.9 & & & 72.4 & & & 83.2 & & & & & 84.5 & \\
\hline Humber & $02 \mathrm{HCOO3}$ & 3.8 & & & & & & & & 9.4 & & & & & & & & \\
\hline Humber & 02HCOO9 & 2.2 & & & & & & & & 6.5 & & & & & & & & \\
\hline Humber & $02 \mathrm{HCO} 25$ & 0.8 & & & & & & & & & & & & & & & & \\
\hline Humber & $02 \mathrm{HCO} 27$ & 56.6 & 58.8 & & & 67.3 & & & & 70.8 & & 72.7 & & & 80.5 & & & \\
\hline Humber & $02 \mathrm{HCO} 31$ & 0.06 & & & & & & & & 0.2 & & & & & & & & \\
\hline Humber & $02 \mathrm{HCO} 34$ & 0.1 & & & & & & & & & & & & & & & & \\
\hline Laurel & 02GA024 & & & 17.4 & & & & 21.8 & & & 26.2 & 29.2 & & & 38.0 & & & \\
\hline
\end{tabular}




\begin{tabular}{|c|c|c|c|c|c|c|c|c|c|c|c|c|c|c|c|c|c|c|}
\hline \multirow[b]{2}{*}{ 㐫 } & \multirow[b]{2}{*}{ ن } & & \multicolumn{16}{|c|}{ Percent urban area } \\
\hline & & $\begin{array}{l}\text { ஒి } \\
\text { ŏ }\end{array}$ & $\begin{array}{l}\text { م̂ } \\
\text { م }\end{array}$ & $\stackrel{1}{\text { م }}$ & 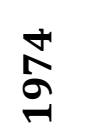 & $\begin{array}{l}\stackrel{\infty}{\hat{\sigma}} \\
\stackrel{\sigma}{\sim}\end{array}$ & $\underset{\stackrel{\infty}{\sim}}{\stackrel{-}{\sim}}$ & 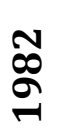 & $\begin{array}{l}\text { L2 } \\
\text { O̊ } \\
\stackrel{\sim}{\sim}\end{array}$ & $\begin{array}{l}\infty \\
\stackrel{\infty}{ } \\
\stackrel{\sigma}{\sim}\end{array}$ & 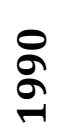 & ำ & 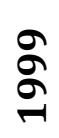 & ̊̊̊ి & $\begin{array}{l}\text { L } \\
\text { ᄋ̊ } \\
\text { N }\end{array}$ & $\begin{array}{l}\text { S̊ } \\
\text { ᄋ }\end{array}$ & 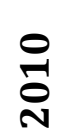 & 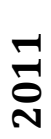 \\
\hline Mimico & $02 \mathrm{HCO} 33$ & & & & 46.4 & & & & 56.4 & 62.4 & & 77.1 & & & 87.6 & & & \\
\hline Red Hill & 02HA014 & & & & & 36.9 & & & & & & 55.6 & & & & & & \\
\hline Rouge & $02 \mathrm{HCO} 22$ & 4.2 & & & 6.4 & 8.0 & 10.1 & & 15.7 & 20.6 & & 26.8 & & & 35.8 & & 38.6 & \\
\hline Rouge & $02 \mathrm{HCO} 28$ & 0.9 & & & 1.0 & 1.6 & 1.7 & & 2.0 & 2.7 & & & & & & & & \\
\hline
\end{tabular}




\section{Appendix H Relationships of nested watersheds within river systems}

\section{Illustration H.1 Schematic relationship of nested watersheds within river systems.}

Only river systems with more than two watersheds with dependent flows are depicted. Codes in the boxes indicate the Environment Canada hydrologic gauge identification code.

\begin{tabular}{|c|c|c|c|c|c|}
\hline & Credit & & & Duffins & \\
\hline & $02 \mathrm{HB} 029$ & & & $02 \mathrm{HCOO} 6$ & \\
\hline & $02 \mathrm{HB} 025$ & & $02 \mathrm{HCO} 26$ & & $02 \mathrm{HCO} 19$ \\
\hline $02 \mathrm{HB} 018$ & & $02 \mathrm{HB} 008$ & $02 \mathrm{HCO} 83$ & & \\
\hline $02 \mathrm{HB} 013$ & & & & & \\
\hline & Don & & & Rouge & \\
\hline & $02 \mathrm{HCO} 24$ & & & $02 \mathrm{HCO} 22$ & \\
\hline $02 \mathrm{HCO} 5$ & & $02 \mathrm{HCO} 29$ & & & $02 \mathrm{HCO} 28$ \\
\hline & & $02 \mathrm{HCO} 56$ & & & $02 \mathrm{HCO53}$ \\
\hline & & Humber & & & \\
\hline & & $02 \mathrm{HCOO3}$ & & & \\
\hline & & & & $02 \mathrm{HCO} 27$ & \\
\hline $02 \mathrm{HCOO9}$ & $02 \mathrm{HCO} 4$ & & $02 \mathrm{HCO} 25$ & & \\
\hline & $02 \mathrm{HCO} 31$ & & $02 \mathrm{HCO57}$ & & \\
\hline
\end{tabular}




\section{Appendix I Data Points by River System in the Maximized Data Set}

Table I.1 Number of data points combining available hydrologic, rainfall and urban land use estimates by watershed for the maximized data set.

The dataset with the maximized number of observations combines urban percent matching same-year flow-rain and, where no same-year flow-rain records were available, matched to the following year.

\begin{tabular}{|l|l|c|}
\hline \multicolumn{1}{|c|}{$\begin{array}{c}\text { River } \\
\text { System }\end{array}$} & \multicolumn{1}{|c|}{$\begin{array}{c}\text { EC hydro } \\
\text { station }\end{array}$} & $\begin{array}{c}\text { Maximized } \\
\text { Dataset } \\
\text { Points }\end{array}$ \\
\hline Credit & $02 \mathrm{HB} 008$ & 3 \\
\hline Credit & $02 \mathrm{HB} 013$ & 2 \\
\hline Credit & $02 \mathrm{HB} 018$ & 3 \\
\hline Credit & $02 \mathrm{HB} 025$ & 3 \\
\hline Credit & $02 \mathrm{HB} 029$ & 1 \\
\hline Don & $02 \mathrm{HC} 005$ & 7 \\
\hline Don & $02 \mathrm{HC} 024$ & 7 \\
\hline Don & $02 \mathrm{HC} 029$ & 6 \\
\hline Don & $02 \mathrm{HC} 056$ & 1 \\
\hline Duffins & $02 \mathrm{HC} 019$ & 1 \\
\hline Duffins & $02 \mathrm{HC} 026$ & 1 \\
\hline Duffins & $02 \mathrm{HC} 038$ & 1 \\
\hline Etobicoke & $02 \mathrm{HC} 017$ & 5 \\
\hline Etobicoke & $02 \mathrm{HC} 030$ & 5 \\
\hline Harmony & $02 \mathrm{HD} 013$ & 2 \\
\hline Highland & $02 \mathrm{HC} 013$ & 4 \\
\hline Humber & $02 \mathrm{HC} 003$ & 2 \\
\hline Humber & $02 \mathrm{HC} 009$ & 2 \\
\hline Humber & $02 \mathrm{HC} 025$ & 1 \\
\hline Humber & $02 \mathrm{HC} 027$ & 6 \\
\hline Humber & $02 \mathrm{HC} 031$ & 2 \\
\hline Humber & $02 \mathrm{HC} 034$ & 1 \\
\hline Laurel & $02 \mathrm{GA} 024$ & 5 \\
\hline Mimico & $02 \mathrm{HC} 033$ & 5 \\
\hline Red Hill & $02 \mathrm{HA} 014$ & 2 \\
\hline Rouge & $02 \mathrm{HC} 022$ & 9 \\
\hline Rouge & $02 \mathrm{HC} 028$ & 6 \\
\hline & Total & $\mathbf{9 3}$ \\
\hline
\end{tabular}




\section{Appendix J Correlations of hydrologic variables}

Table J.1. Bivariate correlations of hydrologic variables and three independent variables. Correlations in bold highlight relationships that contrast with corresponding values in other data sub-sets in the table.

\begin{tabular}{|c|c|c|c|c|c|c|c|}
\hline $\begin{array}{c}\text { Hydrologic } \\
\text { Variable }\end{array}$ & $\begin{array}{c}\text { Total } \\
\text { Runoff }\end{array}$ & $\mathbf{R C}$ & 80RLER & $\begin{array}{c}9^{\text {th }} \\
\text { RLER }\end{array}$ & $\begin{array}{c}\text { Watershed } \\
\text { size }\end{array}$ & $\begin{array}{c}\text { Percent } \\
\text { urban }\end{array}$ & $\begin{array}{c}\text { Total } \\
\text { Rainfall }\end{array}$ \\
\hline \multicolumn{8}{|c|}{ All observations (93 observations) } \\
\hline Total Runoff & & & & & -0.12 & 0.80 & 0.53 \\
\hline $\mathrm{RC}$ & 0.83 & & & & 0.09 & 0.84 & 0.01 \\
\hline 80RLER & 0.52 & 0.37 & & & -0.05 & 0.35 & 0.45 \\
\hline 95RLER & 0.68 & 0.52 & 0.80 & & -0.18 & 0.62 & 0.41 \\
\hline $\begin{array}{l}\text { Mean Event } \\
\text { Acceleration }\end{array}$ & 0.68 & 0.57 & 0.56 & 0.71 & 0.04 & 0.68 & 0.27 \\
\hline \multicolumn{8}{|c|}{ Watersheds over $100 \mathrm{~km}^{2}$ (46 observations) } \\
\hline Total Runoff & & & & & -0.11 & 0.86 & 0.49 \\
\hline $\mathrm{RC}$ & 0.88 & & & & 0.00 & 0.83 & 0.06 \\
\hline 80RLER & 0.72 & 0.51 & & & -0.10 & 0.59 & 0.57 \\
\hline 95RLER & 0.68 & 0.53 & 0.91 & & -0.20 & 0.68 & 0.44 \\
\hline $\begin{array}{l}\text { Mean Event } \\
\text { Acceleration }\end{array}$ & 0.72 & 0.67 & 0.69 & 0.73 & -0.02 & 0.81 & 0.24 \\
\hline \multicolumn{8}{|c|}{ Watersheds under $100 \mathrm{~km}^{2}$ (47 observations) } \\
\hline Total Runoff & & & & & 0.04 & 0.76 & 0.56 \\
\hline $\mathrm{RC}$ & 0.79 & & & & -0.01 & 0.85 & -0.01 \\
\hline 80RLER & 0.35 & 0.23 & & & -0.29 & 0.17 & 0.37 \\
\hline 95RLER & 0.69 & 0.51 & 0.62 & & 0.02 & 0.58 & 0.41 \\
\hline $\begin{array}{l}\text { Mean Event } \\
\text { Acceleration }\end{array}$ & 0.75 & 0.53 & 0.24 & 0.73 & -0.02 & 0.73 & 0.35 \\
\hline \multicolumn{8}{|c|}{ Watersheds with $<4 \%$ UP (17 observations) } \\
\hline Total Runoff & & & & & -0.06 & 0.04 & 0.64 \\
\hline $\mathrm{RC}$ & 0.95 & & & & 0.01 & 0.02 & 0.37 \\
\hline 80RLER & 0.88 & 0.89 & & & -0.15 & -0.04 & 0.44 \\
\hline 95RLER & 0.48 & 0.34 & 0.69 & & -0.21 & 0.02 & 0.55 \\
\hline $\begin{array}{l}\text { Mean Event } \\
\text { Acceleration }\end{array}$ & 0.13 & 0.13 & 0.24 & 0.42 & 0.75 & 0.47 & 0.05 \\
\hline
\end{tabular}




\section{Appendix K Runoff Coefficient Analyses}

A model fit to RC with five independent variables is summarized in Table K.1.

Table K.1.Model Terms for runoff coefficient

\begin{tabular}{|c|c|c|c|c|}
\hline $\begin{array}{l}\text { Dependent } \\
\text { Variable }\end{array}$ & Data & $\begin{array}{l}\text { Model } \\
\text { overview }\end{array}$ & $\begin{array}{l}\text { Independent } \\
\text { variable }\end{array}$ & $\begin{array}{l}\text { Coefficient }+/- \text { SE } \\
\text { (p-value) }\end{array}$ \\
\hline \multirow[t]{6}{*}{$\begin{array}{l}\text { Runoff } \\
\text { coefficient }\end{array}$} & \multirow[t]{6}{*}{$\begin{array}{l}\text { All } \\
\text { observations }\end{array}$} & \multirow{6}{*}{$\begin{array}{l}\text { Model.S1 } \\
\mathrm{R}^{2}=0.80 \\
\mathrm{RSE}=0.062 \\
\mathrm{df}=87 \\
\mathrm{p}<2.2 \mathrm{e}-16\end{array}$} & UP to power 2 & $\begin{array}{l}3.06 \mathrm{e}-05+/-8.78 \mathrm{e}-06 \\
(0.0008)\end{array}$ \\
\hline & & & Total rain & $\begin{array}{l}-1.99 \mathrm{e}-04+/-8.03 \mathrm{e}-05 \\
(0.0152)\end{array}$ \\
\hline & & & Basin slope & $\begin{array}{l}3.153 \mathrm{e}-03+/-8.01 \mathrm{e}-04 \\
(0.00017)\end{array}$ \\
\hline & & & BFI & $\begin{array}{l}0.347+/-0.130 \\
(0.0088)\end{array}$ \\
\hline & & & $\begin{array}{l}\text { Interaction UP } \\
\text { with } \log _{10} \\
\text { watershed area }\end{array}$ & $\begin{array}{l}1.42 \mathrm{e}-03+/-3.34 \mathrm{e}-04 \\
(5.4 \mathrm{e}-05)\end{array}$ \\
\hline & & & Intercept & $\begin{array}{l}-0.120+/-0.076 \\
(0.118)\end{array}$ \\
\hline
\end{tabular}

According to runoff coefficient (RC) literature, $\mathrm{RC}$ increases with decreasing watershed size (Boers and Ben-Asher, 1982). The trend in RC with watershed size was assessed using Kendall's rank correlation for two datasets: 1) the full 93 record database; and 2) 20 records comprising the earliest available RC prior to 1976 and excluding watersheds known to have over $40 \%$ urbanized cover (prior to 1976). Contrary to literature results documenting an inverse relationship of runoff coefficient with watershed size, there was no evidence of this relationship of RC using all 93 record in the database (Kendall's rank correlation tau $=-0.07 ; \mathrm{p}=0.32$ ). There was also no relationship for the earliest records, excluding the most highly urbanized watersheds (Kendall's rank correlation tau $=-0.06 ; \mathrm{p}$ $=0.72$ ). Likely, there were insufficient historical records during times of low UP to assess whether or not an inverse relationship existed prior to urbanization. 


\section{Appendix L A theoretical basis for greater effects of urban land use on smaller watersheds}

\section{Key Words}

Fractal relationship, network dimension, watershed area, disproportionate effect, urbanization

\section{Introduction}

This appendix follows up on a result of Phase 2 of the research (documented in Chapter 5) that could not be fully explored empirically due to gaps in the database. A theoretical basis was developed, drawing on fractal literature (identified following), to explain trends hinted at by raw data plots in Phase 2 . The theoretical relationship confirms that differing flow regime responses should be expected with urban land use due to characteristics of watershed drainage density with size. Watersheds which are smaller and/or have higher drainage density will be more affected by urbanization because more stream length is replaced by engineered infrastructure for the same percentage urban land use.

\section{Fractal Nature of Watersheds}

Hydraulic geometry (Leopold and Maddock, 1953), now known as a field of fractal geometry (Mandelbrot, 1983), identifies power function relationships of river networks, including discharge with channel cross section (Leopold and Maddock, 1953), watershed area with mainstem length (Hack, 1957) and watershed area with network stream length (Schuller et al., 2001). 
Individual streams and their networks are fractals, with the fractal dimension, $\mathrm{d}$, of streams indicating meander and the fractal dimension, D, of networks indicating how fully a network fills the watershed plane (Schuller et al., 2001). Networks with higher drainage densities have higher network fractal dimensions since they are more spacefilling (Schuller et al., 2001). Estimating the fractal dimension of a watershed network is inherently difficult given the importance of scale and measurement method in making the estimation (Veneziano and Niemann, 2000; Schuller et al., 2001). Any watershed fractal dimension calculation is an approximation with no means to assess the best choice among estimates arising from various methodologies (Schuller et al., 2000).

Natural watersheds may be self-similar or they may be self-affine (Nikora and Sapozhnikov, 1993; Schuller et al., 2001). Self-affine networks require two scaling dimensions (for longitudinal and transverse sizes) to estimate the network fractal dimension (Nikora and Sapozhnikov, 1993). Within a single network, up to four changes in scaling regimes have been identified as a result of varying controls on basin formation (Dodds and Rothman, 2001). In addition, watershed fractal dimensions vary from one location to another (Schuller et al., 2001). Despite these various complications, relationships among the number of streams, length of streams and the area of watersheds, identified by Horton (1945) and Hack (1957) with the additional mathematics of Mandelbrot (1983), provide remarkably good estimations. The general form for Hack's law is given in Eq. L.1 (Hack, 1957; Dodds and Rothman, 2001). 


$$
\mathrm{L}=\mathrm{cA} \mathrm{A}^{\mathrm{h}}
$$

where:

$\mathrm{L}$ is the length of the mainstem river;

$\mathrm{A}$ is the watershed area;

c is an empirical constant, about 1.4 in Hack's (1957) study;

$\mathrm{h}$ is an empirical scaling parameter, usually between 0.5 and 0.7 (Dodds and

Rothman, 2001) and was 0.6 in Hack’s (1957) study.

Takayasu (1990) identifies a stream fractal dimension to be $\mathrm{d}=2 \mathrm{~h}$.

Schuller et al. (2001) identify an equivalent general relationship for network stream length and area ( Eq.L.2).

$$
\mathrm{Z} \propto \mathrm{A}^{\mathrm{D} / 2}
$$

Where:

$\mathrm{Z}$ is the length of streams in the network;

A is the watershed area;

$\mathrm{D}$ is the network fractal dimension.

The average network dimension, D, for self-affine networks (which, for self-affine watersheds, is also called the lacunarity dimension (Nikora and Sapozhnikov, 1993) in recognition that the network is not self-similar) in Schuller et al. (2001, Table 5) was estimated at $\mathrm{D}=1.54$. 
For broad application, Hack's law (Hack, 1957) is more complicated than originally conceived (Dodds and Rothman, 2001). Schuller et al. (2001) found drainage density is not constant within watersheds but, rather, increases with decreasing area for smaller watersheds relative to the larger watersheds in which they were nested. Stankiewicz and de Wit (2005) also found the exponent $\mathrm{h}$ decreases with increasing basin size, as did Dodds and Rothman (2001) who found the exponent $\mathrm{h}$ varied among networks and with scale within a single network. Stankiewicz and de Wit (2005) found the exponent $h$ depends on the roughness of the topography, with lower values of $\mathrm{h}$ associated with rougher surfaces for basin sizes relevant for the present study (i.e. less than $800 \mathrm{~km}^{2}$ ).

\section{Relevant Results in this Research}

From Chapter 5, the empirical model for total runoff (Table 5-4, Section 5.3.2) demonstrated a positive interaction between urban percent (UP) land use and watershed area. Visually, raw data plots for 80RLER also indicated a tendency for differing rates of response of flow characteristics to urbanization in smaller watersheds (less than $100 \mathrm{~km}^{2}$ ) relative to larger watersheds. Specifically, in the raw data plots, event-scale hydrology in smaller watersheds seemed to have no relationship with UP within the range of UP for the database ( $\sim 17 \%$ to $56 \%$ UP). By contrast, the empirical model fit to the full population of watersheds indicated 80RLER increased with UP until about 50\% (Illustration 5-6, Section 5.3.4.2). However, an interaction of UP with watershed size was not statistically significant in the empirical modelling of event-scale runoff (i.e. 80RLER, 95RLER). The database did not have sufficient statistical power to analyze event-scale hydrologic characteristics by category of watershed size (e.g. $<100 \mathrm{~km}^{2}$ 
versus other groups).

Although more data would be needed to empirically explore the effects on event-scale runoff of increasing UP by watershed size, a theoretical basis for watershed scale effects can be developed based on the fractal relationship of watershed area and length of stream network.

\section{Fractal theory for greater effect of UP on smaller watersheds}

Stating Eq.L.2 as an equation with a constant, instead of a proportional relationship, gives:

$$
\mathrm{L}=\mathrm{kA}^{\mathrm{D} / 2}
$$

where:

$\mathrm{L}$ is the length of streams in a network;

$\mathrm{D}$ is the fractal dimension of the river network;

$\mathrm{k}$ is a constant.

For a small watershed that is a fraction, $\chi$, of a larger watershed,

$$
\mathrm{A}_{\text {small }}=\chi \mathrm{A}_{\text {large }}
$$

Restating Eq.L.4 for the large watershed:

$$
\mathrm{A}_{\text {large }}=\left[\frac{L_{\text {Large }}}{k_{\text {Large }}}\right]^{2 / D}
$$

Assuming for the moment that the large and small watersheds have the same fractal dimension, D, the length of stream network in the small watershed can be stated as:

$$
\mathrm{L}_{\text {Small }}=\mathrm{k}_{\text {Small }}\left[\chi A_{\text {Large }}\right]^{D / 2}
$$


Substituting Eq.L.5 into Eq.L.6, the relationship of the length of stream network in the small watershed to that of the large watershed can be stated as:

$$
\mathrm{L}_{\text {Small }}=\mathrm{L}_{\text {Large }}\left[\frac{k_{\text {Small }}}{k_{\text {Large }}} \chi^{D / 2}\right]
$$

where:

$\mathrm{L}$ is the length of streams in a network (Small and Large watersheds);

$\mathrm{D}$ is the fractal dimension of the river network;

$\chi$ is the ratio of small watershed area to the larger watershed area

$\mathrm{k}$ is a constant (for Small and Large watersheds).

Thus, smaller watersheds in a network with the same fractal dimension have proportionately more stream length than larger watersheds. If the watershed dimension, $\mathrm{D}$, is assumed to be 1.54 (i.e. the average identified by Schuller et al. (2001)), two smaller watersheds that are $5 \%$ and $50 \%$ the size of a larger watershed would have relative stream network lengths proportionately about $10 \%$ and $60 \%$ longer $\left(0.1\left(\frac{k_{\text {Small }}}{k_{\text {Large }}}\right) \mathrm{L}_{\text {Large }}\right.$; and, $\left.0.59\left(\frac{k_{\text {Small }}}{k_{\text {Large }}}\right) \mathrm{L}_{\text {Large }}\right)$, subject to the ratio of the constants.

This theoretical relationship supports the finding by Schuller et al. (2001) that drainage density increases with decreasing area. However, if drainage density is higher in smaller watersheds, the fractal dimension, $\mathrm{D}$, of the smaller watershed would be larger (i.e. the lacunarity dimension is higher for denser networks). Stating the relationship of fractal dimension for the larger watershed as a fraction, $p$, of the smaller watershed,

$$
\mathrm{D}_{\text {large }}=p \mathrm{D}_{\text {small }}
$$


Substituting Eq.L.8 into Eq.L.7, the denominator increases in the ratio of the constants, offsetting the exponential relationship with the length of the large watershed network:

$$
\mathrm{L}_{\text {Small }}=\mathrm{L}_{\text {Large }} \mathrm{1}^{1 / \mathrm{p}} \quad\left[\frac{k_{\text {Small }}}{k_{\text {Large }}{ }^{1 / p}} \chi^{D S / 2}\right]
$$

where:

$\mathrm{L}$ is the length of streams in a network (Small and Large watersheds);

Ds is the fractal dimension of the small river network;

$\chi$ is the ratio of small watershed area to the larger watershed area

$p$ is the ratio of the large watershed fractal dimension to small dimension, Ds

$\mathrm{k}$ is a constant (for Small and Large watersheds).

Watersheds do not necessarily conform perfectly to fractal math because they are not always self-similar. Recalling that many watersheds are self-affine, which means they require two scaling dimensions. They have a longitudinal dimension due to higher drainage density in headwaters than along the mainstem near a confluence (e.g. see Nikora and Sapozhnikov (1993) discussion of self-affine networks).

The literature points out the inherent difficulty in measuring fractal dimensions in the field and in desktop estimations. It is not the purpose of this chapter to attempt to estimate the fractal dimensions of study watersheds or even to fully explore fractal relationships. Rather, the objective is to highlight the very simple outcome of urbanizing higher density regions within headwaters and smaller watersheds. That simple outcome, 
as illustrated in Eq. L.7 and Eq.L.9, is that more stream length is replaced and simplified by engineered infrastructure in smaller watersheds (and denser drainage networks) than for the same percent urban land use conversion in larger (or less dense) watersheds. For example, if the same new subdivision design is implemented over $\mathrm{x} \mathrm{km}^{2}$ in a large and a small watershed, the engineered drainage system in the small watershed would replace more natural stream length than in the larger watershed.

Given that length of stream per area varies with watershed size, in addition to the empirical relationship developed for total runoff (Chapter 5), an interaction of urban area with watershed scale should also be expected for event-scale hydrologic characteristics.

\section{Discussion of the Fractal Effect}

As watersheds urbanize, the complex natural stream paths are replaced with storm sewers. By design, surfaces of engineered infrastructure are smoother, straighter and have more constant slopes than natural channels and hillslopes. Instead of acting to dissipate the energy of rainfall, urban drainage infrastructure preserves or even increases it. With simplified landscapes, the energy of rainfall is not dissipated by vegetation and groundwater infiltration but, instead, the energy is transmitted more directly to stream systems during storm runoff. In some highly urbanized regions, segments of urban streams have concrete-lined channels or meander prevention measures (e.g. gabion baskets) (TRCA, 1999), which further limit streams' capacity to dissipate energy through geomorphological processes. Natural channels that receive discharges from engineered networks must accommodate increased flow volumes and flow energy. Flow acceleration 
is a mechanism for energy dissipation.

Unlike meandering watercourses with a fractal dimension, engineered sewer lengths can be calculated by simply adding the lengths of individual sewer segments. Even the natural portion of many urban watercourses has been straightened and channelized, serving to 'defractal' the system. Thus the length of engineered drainage is simpler and, ultimately, shorter than the natural system it replaces.

Tracking the evolution of the stream network length as a watershed is converted from natural to engineered drainage would be fraught with measurement difficulties. However, for empirical analyses, it may be feasible to estimate a watershed's stream network length prior to development (recognizing the measurement limitations) for comparison with post development at milestones for urban land use (e.g. at 4\% UP, $10 \%$ UP, and higher). With this information, the rate of flows through the engineered system could be estimated from engineering principles or with gauges at storm sewer outfalls and compared to empirical measurements of the pre-urban system.

\section{Conclusions and Implications}

The simplification of smaller watershed stream networks by conversion to engineered drainage is more dramatic in smaller watersheds than larger ones because more length of stream network is simplified for the same area of urban land use. The important implication of this relationship is that engineered urban drainage will disproportionately affect headwaters and watersheds with higher drainage densities thus small watersheds 
can be expected to exhibit a disproportionate hydrologic responses to urban land use. If urbanization does compromise water balance, headwater watersheds (or watersheds with relatively high drainage density) can be expected to 'dry out' sooner than larger or less dense networks if conventional storm sewers are installed. 


\section{Appendix M Fish Species in Long-term and Recent databases}

Species codes in each of the three databases analysed are summarized in Table M.1. For species names, refer to the OMNR Manual of Instructions: Nearshore Community Index Netting (NSCIN) Report (Sterling, 1999); Appendix A: Master List Of Species Codes And Common Names Of Ontario Fish. Available at URL:

https://dr6j45jk9xcmk.cloudfront.net/documents/2664/226869.pdf.

Table M.1 Species Codes in each of three study databases.

\begin{tabular}{|c|c|c|c|c|c|}
\hline $\begin{array}{c}\text { All Species } \\
\text { Database } \\
\text { Codes }\end{array}$ & $\begin{array}{l}\text { Species } \\
\text { Count }\end{array}$ & $\begin{array}{c}\text { Long-Term } \\
\text { Database Codes }\end{array}$ & $\begin{array}{l}\text { Species } \\
\text { Count }\end{array}$ & $\begin{array}{c}\text { Recent } \\
\text { Database } \\
\text { Codes }\end{array}$ & $\begin{array}{l}\text { Species } \\
\text { Count }\end{array}$ \\
\hline S10 & 1 & & & $\mathrm{~S} 10$ & 1 \\
\hline S11 & 2 & S11 & 1 & S11 & 2 \\
\hline S12 & 3 & & & S12 & 3 \\
\hline S13 & 4 & & & & \\
\hline S14 & 5 & S14 & 2 & S14 & 4 \\
\hline S15 & 6 & S15 & 3 & S15 & 5 \\
\hline S61 & 10 & S61 & 4 & S61 & 6 \\
\hline S63 & 11 & & & S63 & 7 \\
\hline S70 & 12 & & & S70 & 8 \\
\hline S73 & 13 & & & S73 & 9 \\
\hline S75 & 14 & & & S75 & 10 \\
\hline S76 & 15 & S76 & 5 & S76 & 11 \\
\hline S77 & 16 & S77 & 6 & S77 & 12 \\
\hline S78 & 17 & S78 & 7 & S78 & 13 \\
\hline S80 & 18 & S80 & 8 & S80 & 14 \\
\hline S103 & 21 & & & S103 & 15 \\
\hline S131 & 23 & S131 & 9 & S131 & 16 \\
\hline S141 & 24 & S141 & 10 & S141 & 17 \\
\hline S160 & 25 & & & S160 & 18 \\
\hline S163 & 27 & S163 & 11 & S163 & 19 \\
\hline S165 & 28 & S165 & 12 & S165 & 20 \\
\hline S168 & 29 & & & & \\
\hline S171 & 30 & & & S171 & 21 \\
\hline S172 & 31 & & & S172 & 22 \\
\hline S176 & 32 & & & S176 & 23 \\
\hline
\end{tabular}




\begin{tabular}{|c|c|c|c|c|c|}
\hline $\begin{array}{c}\text { All Species } \\
\text { Database } \\
\text { Codes }\end{array}$ & $\begin{array}{l}\text { Species } \\
\text { Count }\end{array}$ & $\begin{array}{c}\text { Long-Term } \\
\text { Database Codes }\end{array}$ & $\begin{array}{l}\text { Species } \\
\text { Count }\end{array}$ & $\begin{array}{c}\text { Recent } \\
\text { Database } \\
\text { Codes }\end{array}$ & $\begin{array}{l}\text { Species } \\
\text { Count }\end{array}$ \\
\hline S177 & 33 & S177 & 13 & & \\
\hline S180 & 34 & & & S180 & 24 \\
\hline S181 & 35 & & & S181 & 25 \\
\hline S182 & 36 & S182 & 14 & S182 & 26 \\
\hline S183 & 37 & S183 & 15 & S183 & 27 \\
\hline S184 & 38 & S184 & 16 & S184 & 28 \\
\hline S185 & 39 & S185 & 17 & S185 & 29 \\
\hline S186 & 40 & S186 & 18 & S186 & 30 \\
\hline S189 & 41 & & & S189 & 31 \\
\hline S190 & 42 & S190 & 19 & & \\
\hline S192 & 44 & S192 & 20 & S192 & 32 \\
\hline S193 & 45 & S193 & 21 & S193 & 33 \\
\hline S194 & 46 & S194 & 22 & S194 & 34 \\
\hline S195 & 47 & & & & \\
\hline S196 & 48 & S196 & 23 & S196 & 35 \\
\hline S197 & 49 & & & S197 & 36 \\
\hline S198 & 50 & S198 & 24 & S198 & 37 \\
\hline S199 & 51 & & & & \\
\hline S200 & 52 & S200 & 25 & S200 & 38 \\
\hline S201 & 53 & S201 & 26 & S201 & 39 \\
\hline S202 & 54 & S202 & 27 & S202 & 40 \\
\hline S203 & 55 & S203 & 28 & S203 & 41 \\
\hline S204 & 56 & & & S204 & 42 \\
\hline S206 & 57 & S206 & 29 & S206 & 43 \\
\hline S208 & 58 & S208 & 30 & S208 & 44 \\
\hline S209 & 59 & S209 & 31 & S209 & 45 \\
\hline S210 & 60 & S210 & 32 & S210 & 46 \\
\hline $\mathrm{S} 211$ & 61 & S211 & 33 & S211 & 47 \\
\hline S212 & 62 & S212 & 34 & S212 & 48 \\
\hline S213 & 63 & & & S213 & 49 \\
\hline S214 & 64 & S214 & 35 & S214 & 50 \\
\hline S216 & 65 & & & S216 & 51 \\
\hline S217 & 66 & & & S217 & 52 \\
\hline S219 & 67 & & & S219 & 53 \\
\hline S220 & 68 & & & S220 & 54 \\
\hline S223 & 70 & & & S223 & 55 \\
\hline S224 & 71 & & & S224 & 56 \\
\hline
\end{tabular}




\begin{tabular}{|c|c|c|c|c|c|}
\hline $\begin{array}{c}\text { All Species } \\
\text { Database } \\
\text { Codes }\end{array}$ & $\begin{array}{l}\text { Species } \\
\text { Count }\end{array}$ & $\begin{array}{c}\text { Long-Term } \\
\text { Database Codes }\end{array}$ & $\begin{array}{l}\text { Species } \\
\text { Count }\end{array}$ & $\begin{array}{c}\text { Recent } \\
\text { Database } \\
\text { Codes }\end{array}$ & $\begin{array}{l}\text { Species } \\
\text { Count }\end{array}$ \\
\hline S225 & 72 & & & S225 & 57 \\
\hline S226 & 73 & & & S226 & 58 \\
\hline S230 & 74 & & & S230 & 59 \\
\hline S231 & 75 & & & S231 & 60 \\
\hline S232 & 76 & & & S232 & 61 \\
\hline $\mathrm{S} 233$ & 77 & S233 & 36 & S233 & 62 \\
\hline S234 & 78 & $\mathrm{~S} 234$ & 37 & & \\
\hline S235 & 79 & S235 & 38 & S235 & 63 \\
\hline S236 & 80 & S236 & 39 & & \\
\hline S239 & 81 & & & S239 & 64 \\
\hline S241 & 82 & & & & \\
\hline S242 & 83 & S242 & 40 & & \\
\hline S251 & 84 & & & S251 & 65 \\
\hline S261 & 85 & S261 & 41 & & \\
\hline S271 & 86 & & & & \\
\hline S280 & 87 & & & S280 & 66 \\
\hline S281 & 88 & S281 & 42 & S281 & 67 \\
\hline S282 & 89 & S282 & 43 & S282 & 68 \\
\hline S291 & 90 & S291 & 44 & S291 & 69 \\
\hline S301 & 91 & & & & \\
\hline S302 & 92 & & & S302 & 70 \\
\hline S310 & 93 & & & S310 & 71 \\
\hline S311 & 94 & S311 & 45 & S311 & 72 \\
\hline S312 & 95 & & & S312 & 73 \\
\hline S313 & 96 & S313 & 46 & S313 & 74 \\
\hline S314 & 97 & & & S314 & 75 \\
\hline S316 & 98 & S316 & 47 & S316 & 76 \\
\hline S317 & 99 & S317 & 48 & S317 & 77 \\
\hline S319 & 100 & & & S319 & 78 \\
\hline S320 & 101 & & & S320 & 79 \\
\hline S330 & 102 & & & S330 & 80 \\
\hline S331 & 103 & S331 & 49 & S331 & 81 \\
\hline S334 & 104 & & & & \\
\hline S337 & 105 & S337 & 50 & S337 & 82 \\
\hline S338 & 106 & S338 & 51 & S338 & 83 \\
\hline S339 & 107 & S339 & 52 & S339 & 84 \\
\hline S340 & 108 & & & & \\
\hline
\end{tabular}




\begin{tabular}{|c|c|c|c|c|c|}
\hline $\begin{array}{c}\text { All Species } \\
\text { Database } \\
\text { Codes }\end{array}$ & $\begin{array}{c}\text { Species } \\
\text { Count }\end{array}$ & $\begin{array}{c}\text { Long-Term } \\
\text { Database Codes }\end{array}$ & $\begin{array}{c}\text { Species } \\
\text { Count }\end{array}$ & $\begin{array}{c}\text { Recent } \\
\text { Database } \\
\text { Codes }\end{array}$ & $\begin{array}{c}\text { Species } \\
\text { Count }\end{array}$ \\
\hline S341 & 109 & S341 & 53 & S341 & 85 \\
\hline S342 & 110 & & & S342 & 86 \\
\hline S344 & 111 & & & S344 & 87 \\
\hline S345 & 112 & & & S346 & 88 \\
\hline S346 & 113 & & & S348 & 89 \\
\hline S348 & 114 & & & S351 & 90 \\
\hline S351 & 115 & & & S366 & 91 \\
\hline S366 & 116 & & & S371 & 92 \\
\hline S371 & 117 & & 54 & S380 & 93 \\
\hline S380 & 118 & & 55 & S382 & 94 \\
\hline S381 & 119 & S381 & & S600 & 96 \\
\hline S382 & 120 & S382 & & S612 & 97 \\
\hline S600 & 123 & & & S703 & 98 \\
\hline S612 & 124 & & & S921 & 99 \\
\hline S703 & 127 & & & & \\
\hline S921 & 129 & & & & \\
\hline
\end{tabular}




\section{Appendix N Principal Component Analyses Results}

\section{N.1 Long-Term Database Independent Variables}

Charts N.1a and N.1b summarize results for the first four Principal Components for independent variables of the Long-term database.

N.1a Importance of components

$\begin{array}{lrrrr} & \text { PC1 } & \text { PC2 } & \text { PC3 } & \text { PC4 } \\ \text { Eigenvalue } & 5.2096 & 3.1300 & 2.1933 & 1.11224 \\ \text { Proportion Explained } & 0.3721 & 0.2236 & 0.1567 & 0.07945 \\ \text { Cumulative Proportion } & 0.3721 & 0.5957 & 0.7523 & 0.83179\end{array}$

N.1b Independent Variable Loadings

$\begin{array}{lrrrr} & \text { PC1 } & \text { PC2 } & \text { PC3 } & \text { PC4 } \\ \text { DistanceFromMouth } & -0.83354 & -0.602900 & 0.32991 & 0.122721 \\ \text { Channelslopempm } & -0.44623 & -0.777073 & -0.26883 & -0.305570 \\ \text { Basinslopempm } & -0.49198 & -1.071636 & -0.38100 & -0.032398 \\ \text { DraingeArea_km2 } & -0.37924 & 0.003073 & -1.28464 & 0.038037 \\ \text { Total_Length } & -0.74763 & 0.038003 & -1.09523 & 0.019376 \\ \text { urbanPercent } & 1.07206 & -0.294298 & -0.30406 & 0.412301 \\ \text { tenthEventPOWERm } & 0.62880 & -1.134142 & 0.12464 & -0.184354 \\ \text { nintEventPOWERm } & 1.15918 & -0.440121 & 0.16967 & -0.255645 \\ \text { meanflowm } & 1.10889 & -0.703730 & -0.06391 & -0.007943 \\ \text { skew runoff } & 0.88973 & 0.578596 & 0.19623 & -0.107054 \\ \text { skew Acce1 } & -0.48549 & -0.131755 & 0.32346 & 1.154950 \\ \text { BFI } & -0.05291 & -1.105505 & 0.18838 & 0.246856 \\ \text { Max ACce1 } & 1.11132 & 0.146520 & -0.47870 & 0.520389 \\ \text { Mean Acce1 } & 1.19351 & 0.144253 & -0.58000 & 0.040783\end{array}$




\section{N.2 Recent Database Independent Variables}

Charts N.2a and N.2b summarize results for the first four Principal Components for independent variables of the Recent database.

N.2a Importance of components

$$
\text { PC1 PC2 PC3 PC4 }
$$

$\begin{array}{lllll}\text { Eigenvalue } \quad 7.3770 & 2.8224 & 1.23404 & 0.87667\end{array}$

Proportion Explained $0.52690 .2016 \quad 0.088150 .06262$

Cumulative Proportion $0.52690 .72850 .81668 \quad 0.87930$

\section{N.2b Independent Variable Loadings}

$\begin{array}{lrrrr} & \text { PC1 } & \text { PC2 } & \text { PC3 } & \text { PC4 } \\ \text { DistanceFromMouth } & -0.8695 & 0.3345 & 0.09618 & -0.13685 \\ \text { Channe1slopempm } & -0.7188 & 0.3576 & 0.12040 & 0.31772 \\ \text { Basinslopempm } & -0.9105 & 0.1250 & 0.29775 & -0.08721 \\ \text { DraingeArea } & -0.3298 & -0.8981 & 0.29091 & -0.13052 \\ \text { Tota1_Length } & -0.4650 & -0.8557 & 0.25943 & -0.16738 \\ \text { UrbanPercent } & 0.9591 & 0.3112 & -0.13533 & -0.06031 \\ \text { skew runoff } & 0.8604 & 0.2305 & 0.05523 & -0.34727 \\ \text { Max Acce1 } & 0.9150 & -0.1957 & 0.15197 & -0.34768 \\ \text { skewAcce1 } & -0.4435 & 0.3112 & -0.59396 & -0.54299 \\ \text { Mean Acce1 } & 0.9317 & -0.2632 & 0.30510 & -0.13215 \\ \text { BFI } & -0.7828 & 0.3025 & 0.26389 & -0.27391 \\ \text { tenthEventPOWERm } & -0.3812 & 0.6984 & 0.51181 & -0.15343 \\ \text { nintEventPOWERm } & 0.6512 & 0.4595 & 0.43947 & -0.10808 \\ \text { meanflowm } & 0.8458 & 0.2799 & 0.19964 & 0.31175\end{array}$




\section{Appendix O Fish Richness Independent Variable Correlations}

The independent variables in the Long-term database have multiple significant Spearman correlations (Illustration O.1) (Graphics per Peter and Peterson, 2013).

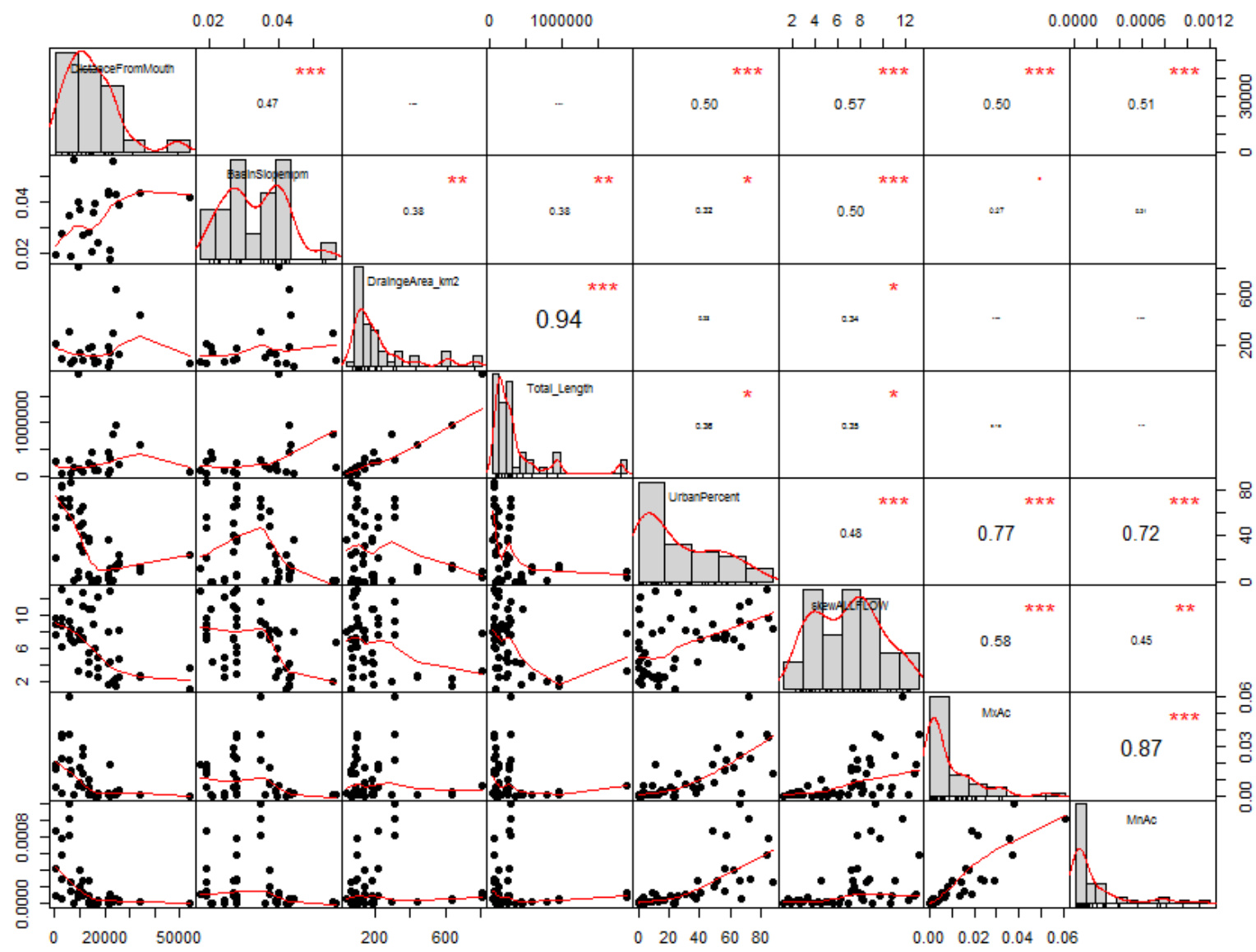

Illustration O.1. Correlations of independent variables. Independent variables with the highest correlations are indicated with three stars; text size for Spearman correlation coefficient is larger for higher correlations; red lines indicate lowess trace. 


\section{Appendix P Negative Binomial Model}

The GLMM model for the Long-term database had over-dispersion in the residuals (see Table 4 text). For comparison, a negative binomial model was fit for fixed effects only (Table P.1, Illustration P.1)

\section{Table P.1. Negative Binomial model to predict fish richness with 2 independent} variables: skew in runoff and total length. Coefficients for a negative binomial model to predict fish richness with Skew in runoff and Total length.

\begin{tabular}{|c|c|c|c|c|c|c|}
\hline $\begin{array}{l}\text { Independent } \\
\text { variable }\end{array}$ & $\begin{array}{l}\text { Est. } \\
\text { coef. }\end{array}$ & $\begin{array}{l}\text { Coef. } \\
\text { Std. } \\
\text { Error }\end{array}$ & $\begin{array}{l}\text { Coef. } \\
\text { p-value }\end{array}$ & $\begin{array}{l}\text { Model } \\
\text { residual } \\
\text { deviance }\end{array}$ & Theta & $\begin{array}{l}\text { AIC/ } \\
\text { 2xlog- } \\
\text { like. }\end{array}$ \\
\hline $\begin{array}{l}\log _{10} \text { Total } \\
\text { length }\end{array}$ & 0.492 & 0.184 & 0.0076 & \multirow{3}{*}{$\begin{array}{c}58.17 \text { on } \\
46 \mathrm{df} \\
\text { (Null } \\
\text { deviance } \\
85.23 \text { on } \\
48 \mathrm{df} \text { ) }\end{array}$} & \multirow{3}{*}{$\begin{array}{c}11.7 \\
(\mathrm{SE} \\
7.38)\end{array}$} & \multirow{3}{*}{$\begin{array}{c}263.32 \\
/- \\
255.32\end{array}$} \\
\hline $\begin{array}{l}\log _{10} \text { Skew in } \\
\text { runoff }\end{array}$ & -0.785 & 0.275 & 0.0043 & & & \\
\hline Intercept & -0.127 & 1.093 & 0.907 & & & \\
\hline
\end{tabular}




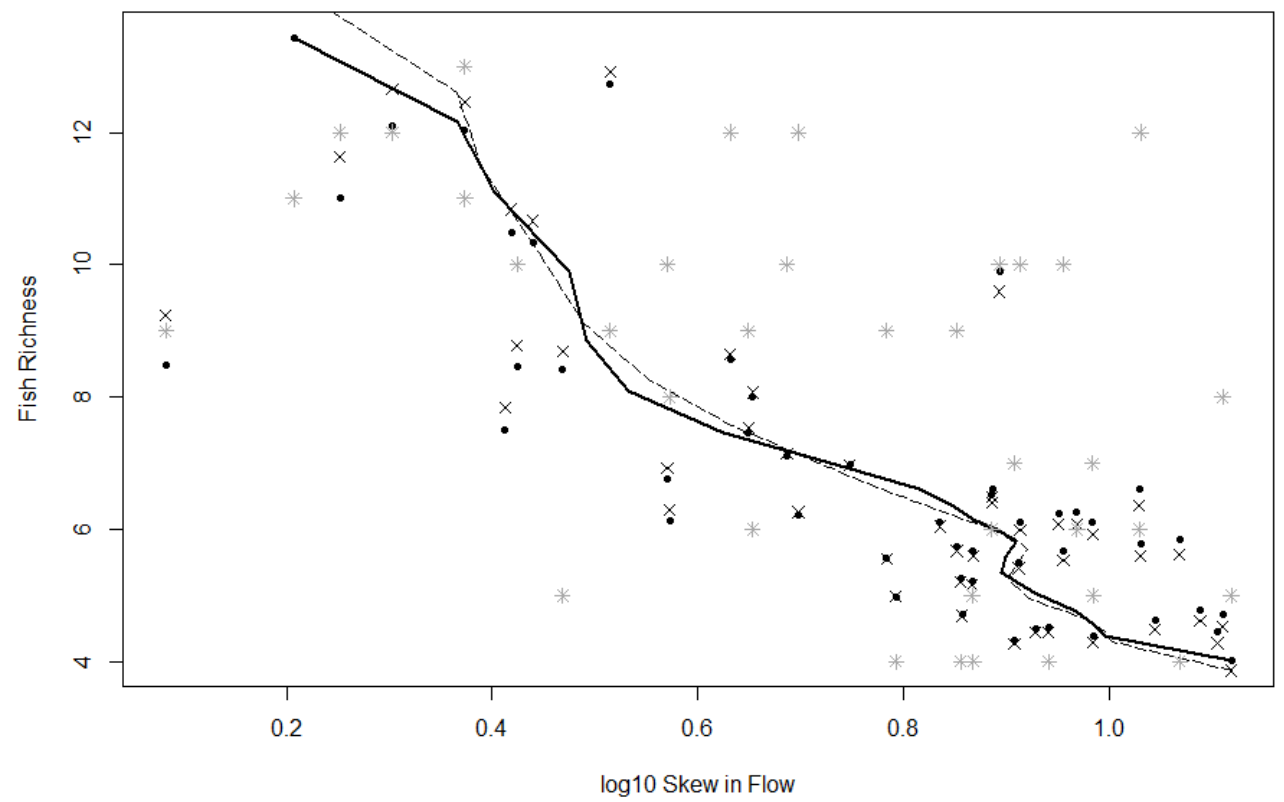

Illustration P.1. Model Comparisons for Long-term database. Comparison of results (predicted mean fish richness) for the fixed effects of the GLMM with over-dispersion in residuals (independent variables $\log _{10}$ Skew in runoff and $\log _{10}$ Total length) versus $\log _{10}$ Skew in runoff (solid dots and solid line) and a negative binomial model with the same independent variables ( $\mathrm{x}$ dots and dotted line). Actual data (fish richness versus $\log _{10}$ Skew in runoff, with no adjustment for Total length) are plotted in grey stars. Smoothers plotted with Bezier splines (R Code by nico at http://stackoverflow.com/questions/3480388/how-to-fit-a-smooth-curve-to-my-data-in-r). 


\section{Appendix Q Comparison of independent variable ranges in the Long-term and Recent databases}

Table E.1. Range of hydrologic variables in two databases: Long-term database and Recent database. Comparison of the span of select variables in the Long-term database versus the Recent database for maximum record, minimum record and span.

\begin{tabular}{|c|c|c|c|c|c|c|}
\hline Dataset & Long-term & sh database & records) & Recent rec & ds database & 7 records) \\
\hline Variable & Minimum & Maximum & $\begin{array}{l}\text { Comparison with Recent } \\
\text { Database }\end{array}$ & Minimum & Maximum & Comment \\
\hline Year & 1959 & 2010 & & 2000 & 2010 & \\
\hline $\begin{array}{l}\text { Total Fish } \\
\text { Species }\end{array}$ & 0 & 18 & & 2 & 18 & \\
\hline Urban Percent & 0.06 & 87.6 & $\begin{array}{l}\text { Very low minimum urban } \\
\text { cover }\end{array}$ & 9.2 & 87.6 & $\begin{array}{l}\text { Minimum in recent database } \\
150 \text { times higher than min in } \\
\text { Long-term database }\end{array}$ \\
\hline MF.m2 & $2.16 \mathrm{e}-10$ & $1.55 \mathrm{e}-08$ & $\begin{array}{l}\text { Ratio max: minimum } \sim 70 \\
\text { versus } \sim 5 \text { for Recent database }\end{array}$ & $3.38 \mathrm{e}-09$ & $15.53 \mathrm{e}-09$ & $\begin{array}{l}\text { Minimum in recent database } \\
1.6 \text { times higher than } \\
\text { minimum in Long-term } \\
\text { database }\end{array}$ \\
\hline Skew in runoff & 1.21 & 13.13 & $\begin{array}{l}\text { Ratio max: minimum } 10.8 \\
\text { versus } 9.7 \text { for Recent database }\end{array}$ & 1.21 & 11.70 & Same minimum skew \\
\hline $\begin{array}{l}\text { Maximum } \\
\text { Acceleration }\end{array}$ & $6.78 \mathrm{e}-05$ & 0.0603 & $\begin{array}{l}\text { Ratio max: minimum } \sim 900 \\
\text { versus } \sim 400 \text { for Recent } \\
\text { database }\end{array}$ & 0.00015 & 0.0603 & $\begin{array}{l}\text { Minimum in recent database } 2 \\
\text { times higher than minimum in } \\
\text { Long-term database }\end{array}$ \\
\hline $\begin{array}{l}\text { Skew } \\
\text { Acceleration }\end{array}$ & 3.24 & 35.53 & $\begin{array}{l}\text { Ratio max: minimum } \sim 10 \\
\text { versus } \sim 4 \text { for Recent database }\end{array}$ & 4.53 & 17.48 & \\
\hline $\begin{array}{l}90^{\text {th }} \text { Percentile } \\
\text { Power per } \\
\text { length channel } \\
\text { per square } \\
\text { meter drainage } \\
\text { area }\end{array}$ & $0.26 \mathrm{e}-07$ & $23.53 \mathrm{e}-07$ & $\begin{array}{l}\text { Ratio max: minimum } \sim 89 \\
\text { versus } \sim 14 \text { for Recent database }\end{array}$ & $1.68 \mathrm{e}-07$ & $23.53 e-07$ & $\begin{array}{l}\text { Minimum in recent database } 6 \\
\text { times higher than minimum in } \\
\text { Long-term database }\end{array}$ \\
\hline
\end{tabular}




\section{Appendix R Potential Confounding Factors Contributing to Fish Richness Decline in Urban Areas}

As a supplement to the discussion of urban stream syndrome in Chapter 6, potential sources of confounding factors in models for biodiversity within urban areas include:

- Dams, perched culverts

- Thermal regime change

- Water quality change

- Historic degradation (sediment quality, prior land uses, channelization, dredging)

- Historic land uses and on-going influences (e.g. past industrial sites and wastewater effluents)

- Spatial and temporal patterns of land development (Konrad and Booth, 2005)

- Resource extraction pressures (e.g. fishing)

- Invasive species (e.g. zebra mussels, invasive plants)

- Climate change (temperature-related changes, algae blooms, spring freshet, winter freeze thaw timing, snow pack, thermal regime, groundwater patterns).

Data collection and interpretation of these potential factors was outside the scope of the present research, but may be worth considering in follow-up research to explain additional variation in fish richness. 